OLAVO VIANA CABRAL NETTO

\title{
UMA VISÃO HOLÍSTICA DA INTELIGÊNCIA COMPETITIVA PARA A CONSTRUÇÃO DE UMA TEORIA
}

Dissertação apresentada à Escola

Politécnica da Universidade de São Paulo para obtenção do título de Mestre em Engenheiro de Produção 


\section{UMA VISÃO HOLÍSTICA DA INTELIGÊNCIA COMPETITIVA PARA A CONSTRUÇÃO DE UMA TEORIA}

Dissertação apresentada à Escola Politécnica da Universidade de São Paulo para obtenção do título de Mestre em

Engenheiro de Produção

Área de Concentração:

Engenharia de Produção Mecânica

Orientador:

Prof. Doutor

Fernando José Barbin Laurindo 


\section{FICHA CATALOGRÁFICA}

\section{Cabral Netto, Olavo Viana}

Uma visão holística da inteligência competitiva para a construção de uma teoria / O.V. Cabral Netto. -- São Paulo, 2011. $164 \mathrm{p}$.

Dissertação (Mestrado) - Escola Politécnica da Universidade de São Paulo. Departamento de Engenharia de Produção.

1. Inteligência competitiva 2. Monitoramento ambiental 3. Gestão do conhecimento 4. Estratégia organizacional I. Universidade de São Paulo. Escola Politécnica. Departamento de Engenharia de Produção II. t. 


\section{AGRADECIMENTOS}

Agradeço a Deus por tudo o que tem me proporcionado ao longo da vida e pela fonte de inspiração e motivação em todos os momentos.

Agradeço a meus pais, Olavo Viana Cabral Junior e Sylma Verardi Viana Cabral, que sempre apoiaram minhas iniciativas e decisões bem como estiveram presente em todos os momentos da minha vida.

Agradeço ao meu orientador Prof. Dr. Fernando José Barbin Laurindo que tem acompanhado o desenvolvimento do meu trabalho assim como conduzido minha evolução pelos caminhos acadêmicos desde os tempos da graduação.

Agradeço à minha amiga e companheira Karine Lima de Carvalho pelo incentivo e orientação em todos os momentos da construção do meu trabalho, desde a concepção criativa até a execução, e especialmente por sua compreensão.

Agradeço enfim a todos meus colegas que, direta ou indiretamente, contribuíram com a execução deste trabalho. 


\section{RESUMO}

É de conhecimento geral que as mudanças ocorridas no contexto global provocaram mudanças profundas na sociedade $\mathrm{e}$, sobretudo, na competitividade das organizações. Hoje, obtém-se vantagem competitiva através da gestão ótima dos conhecimentos organizacionais, representada pela transformação da informação em inteligência. Este movimento tem se fortalecido no ambinte corporativo em função da crescente necessidade dos gestores tomarem decisões mais assertivas em meio à grande quantidade de dados e informações disponíveis. Diante deste cenário, o processo pelo qual as organizações convertem informação em inteligência tem sido tratado como inteligência competitiva (IC). No Brasil, encontram-se diferentes termos que descrevem este processo, como inteligência de mercado e inteligência de negócios. $O$ fato é que, independente da taxonomia utilizada, as iniciativas práticas em termos da implantação de ações organizacionais e pesquisas científicas têm se intensificado ano após ano. Entretanto, ainda se sente a necessidade de um modelo integrado da IC com as demais estruturas teóricas e práticas que seja capaz de facilitar a compreensão deste fenômeno em sua totalidade. Por isso, o presente trabalho desenvolve uma visão holística sobre a IC e, para isso, é utilizado o método de teoria fundamentada (grounded theory) baseado na triangulação de métodos de pesquisa quanti-quali. De um lado, a pesquisa teórica permitiu compreender a relação entre os diversos aspectos conceituais do tema, destacando a análise quantitativa das publicações em IC que identificou os campos de pesquisa e as referências bibliográficas mais relevantes, utilizada para identificar os principais constructos do modelo holístico. De outro lado, os estudos de caso permitiram confirmar a validade de algumas proposições identificadas no referencial teórico para a construção do modelo. Assim, o trabalho oferece a construção de uma visão holística de IC que emerge dos resultados obtidos ao longo do trabalho, constituído sobre métodos científicos.

PALAVRAS-CHAVE: inteligência competitiva; monitoramento ambiental; gestão do conhecimento; estratégia organizacional 


\begin{abstract}
Transformations in the global context have caused some deep changes in society, specially in organizations competitiveness. Nowadays, it is possible to achieve competitive advantage through an optimal management of organizational knowledge, represented by the transformation of information into intelligence. This tendency has gained strength in the corporate world because of the growing need of managers to make more assertive decisions due to a great quantity of data and information available. Inside this scenario, the process by which organizations convert information into intelligence has been treated as competitive intelligence (CI). In Brazil, the practical initiatives on the implementation of organizational actions and scientific research have intensified year after year. However, an integrated $\mathrm{Cl}$ model with all the structures, both practical and theoretical is still necessaryto facilitate the understanding of this phenomenon in its totality - therefore, this project develops a holistic view of $\mathrm{Cl}$. It is based on the grounded theory method, composed of quantitative and qualitative researches. On the one hand, the theoretical research allowed understanding the relationship between the conceptual aspects of the theme, highlighting the quantitative analysis of $\mathrm{Cl}$ publications that identified fields of research and relevant references, used to identify the key constructs of the holistic model. On the other hand, the case studies have allowed confirming the validity of some propositions identified in the theoretical framework. Thus, this project offers the construction of the holistic view of $\mathrm{Cl}$ that emerges from the results obtained during the work, constituted of scientific methods.
\end{abstract}

KEYWORDS: competitive intelligence; environmental scanning; knowledge management; organizational strategy 


\section{LISTA DE ILUSTRAÇÕES}

Figura 1.1 - Distribuição das ações de inteligência .................................................... 13

Figura 1.2 - Evolução anual das publicações em IC ................................................. 14

Figura 1.3 - Distribuição em disciplinas das publicações sobre IC ........................... 15

Figura 1.4 - Evolução anual das citações recebidas pelos artigos em IC .................. 16

Figura 1.5 - Estrutura da pesquisa ........................................................................ 19

Figura 2.1 - Distribuição dos relacionamentos …………………………………........ 34

Figura 2.2 - Distribuição de relacionamentos de competitive intelligence................... 36

Figura 2.3 - Mapa de co-palavras de competitive intelligence ................................... 37

Figura 2.4 - Modelo de IC em primeira versão .......................................................... 38

Figura 2.5 - Distribuição de relacionamentos dos campos de pesquisa..................... 39

Figura 2.6 - Mapa de co-palavras ............................................................................... 41

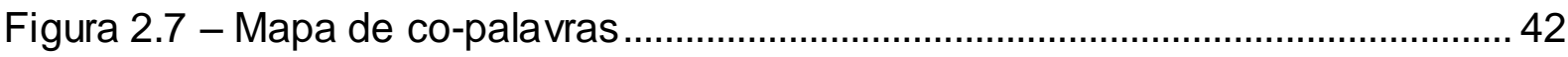

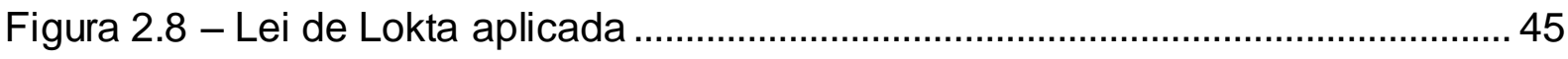

Figura 2.9 - Modelo de IC em segunda versão ...................................................... 48

Figura 3.1 - Hipóteses sobre o ambiente ………………...................................... 56

Figura 3.2 - Comparação entre as posturas da organização ......................................56

Figura 3.3 - Modelos de monitoramento ambiental ....................................................5 57

Figura 3.4 - Continuum dos modelos de monitoramento .............................................58

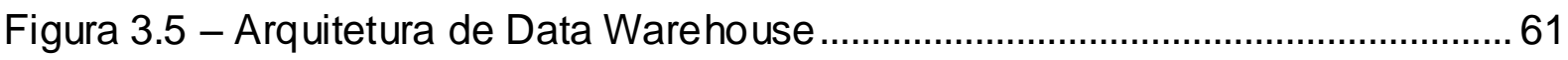

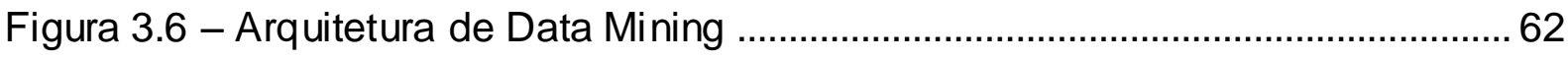

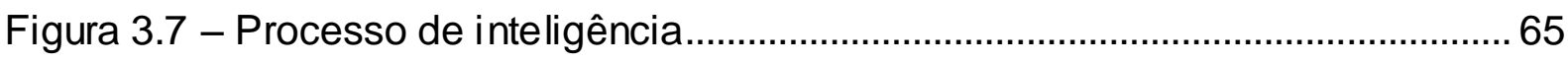

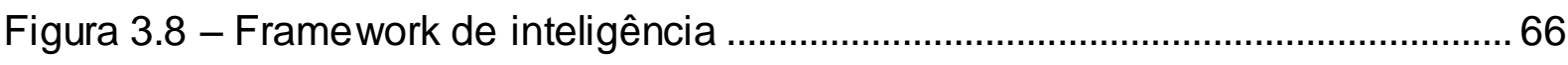

Figura 4.1 - Evolução do mercado de crédito para pessoa física ................................. 71

Figura 4.2 - Distribuição da carteira de crédito PF em dez/2009 ………………....... 72

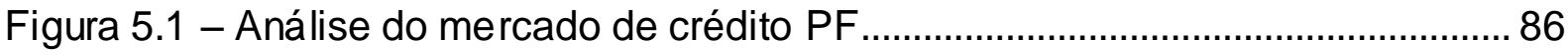

Figura 5.2 - Evolução do mercado de empréstimo pessoal....................................... 87

Figura 5.3 - Evolução do mercado de financiamento de veículos .............................. 88

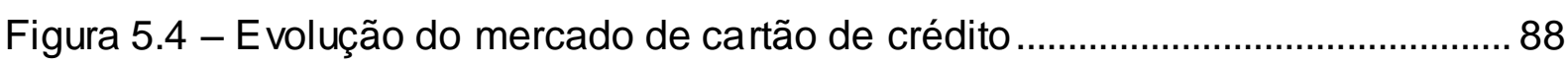

Figura 5.5 - Evolução do mercado de crédito direto ao consumidor ............................. 89

Figura 5.6 - Sistema de valor do caso A ............................................................. 90

Figura 5.7 - Sistema de valor do caso B ............................................................. 97 


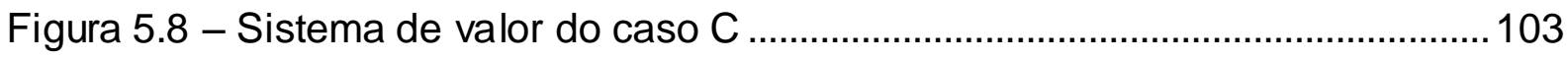

Figura 5.9 - Sistema de valor do caso D ..................................................................

Figura 6.1 - Interação da organização com o ambiente competitivo ..........................120

Figura 6.2 - Papel da IC no processo de decisão estratégica .................................. 122

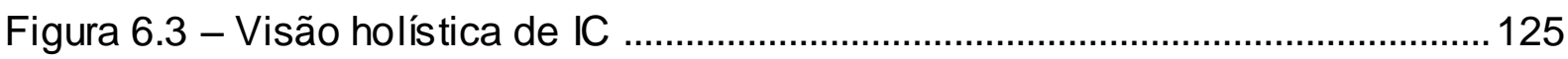

Figura I.1 - Análise estrutural da indús tria ............................................................. 163 


\section{LISTA DE TABELAS}

Tabela 2.1 - Comparação entre métodos quantitativos de avaliação ………………. 23

Tabela 2.2 - Métodos de análise da intensidade de relacionamento .......................... 24

Tabela 2.3 - Critérios de construção da base de artigos ............................................. 30

Tabela 2.4 - Exemplo de matriz de co-palavras.......................................................... 31

Tabela 2.5 - Critério de classificação da intensidade de relacionamento ..................... 32

Tabela 2.6 - Lista de palavras-chave padronizadas ..................................................... 35

Tabela 2.7 - Palavras-chaves relacionadas ao termo competitive intelligence ......... 37

Tabela 2.8 - Relacionamentos por campo de pesquisa ........................................... 40

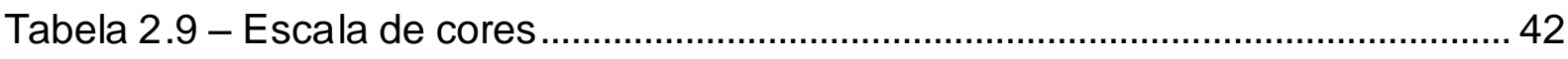

Tabela 2.10 - Catalogação dos artigos selecionados ................................................. 43

Tabela 2.11 - Catalogação das referências bibliográficas selecionadas .................... 46

Tabela 3.1 - Atividades da Inteligência Competitiva .................................................. 52

Tabela 3.2 - Modelos de ambiente de negócio ………………………………….... 55

Tabela 3.3 - Ferramentas de BI relacionadas a coleta ..............................................6 60

Tabela 3.4 - Ferramentas de BI relacionadas a análise ............................................... 61

Tabela 3.5 - Atividades da Gestão do Conhecimento .................................................. 63

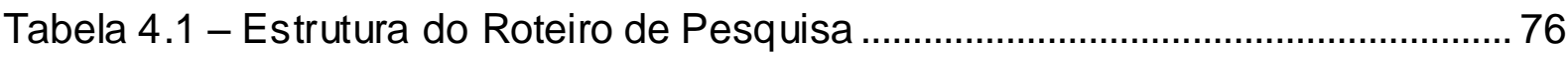

Tabela 4.2 - Diagnóstico referente à gestão do conhecimento …………………….... 81

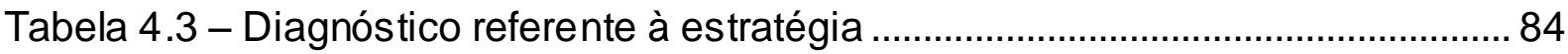

Tabela 5.1 - Dados do caso A: monitoramento ambiental ............................................ 91

Tabela 5.2 - Análise do caso A: monitoramento ambiental ......................................... 92

Tabela 5.3 - Dados do caso A: business intelligence e gestão do conhecimento ....92

Tabela 5.4 - Dados do caso A: estratégia ................................................................ 94

Tabela 5.5 - Intensidade das forças competitivas do caso A ..................................... 95

Tabela 5.6 - Análise sobre alinhamento estratégico do caso A ...................................96

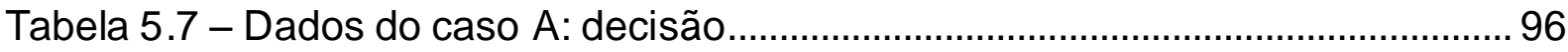

Tabela 5.8 - Dados do caso B: monitoramento ambiental .........................................98

Tabela 5.9 - Análise sobre o monitoramento ambiental do caso B ............................ 99

Tabela 5.10 - Dados do caso B: business intelligence e gestão do conhecimento .. 99

Tabela 5.11 - Dados do caso B: estratégia...........................................................100

Tabela 5.12 - Intensidade das forças competitivas do caso B ................................. 102 
Tabela 5.13 - Análise sobre alinhamento estratégico do caso B .............................102

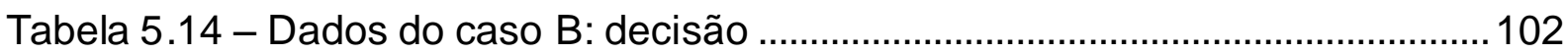

Tabela 5.15 - Dados do caso C: monitoramento ambiental.......................................105

Tabela 5.16 - Análise sobre o monitoramento ambiental do caso C ........................105

Tabela 5.17 - Dados do caso C: business intelligence e gestão do conhecimento 106

Tabela 5.18 - Dados do caso C: estratégia ................................................................. 107

Tabela 5.19 - Intensidade das forças competitivas do caso C ................................... 108

Tabela 5.20 - Análise sobre alinhamento estratégico do caso C .............................109

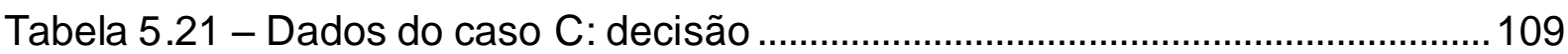

Tabela 5.22 - Dados do caso D: monitoramento ambiental.......................................111

Tabela 5.23 - Análise sobre o monitoramento ambiental do caso D ........................111

Tabela 5.24 - Dados do caso D: business intelligence e gestão do conhecimento 112

Tabela 5.25 - Dados do caso D: estratégia ...............................................................113

Tabela 5.26 - Intensidade das forças competitivas do caso D ...................................114

Tabela 5.27 - Análise sobre alinhamento estratégico do caso D .............................115

Tabela 5.28 - Dados do caso D: decisão ..................................................................115

Tabela 6.1 - Análise sobre o monitoramento ambiental ............................................117

Tabela I.1 - Decomposição das forças competitivas ................................................. 164 


\section{SUMÁRIO}

1 INTRODUÇÃO _ 12

1.1 Contexto_ 12

1.2 Justificativa 13

1.3 Objetivos 17

1.4 Estrutura 18

2 ANÁLISE QUANTITATIVA DA LITERATURA 21

2.1 Definição do Método Quantitativo__ 23

2.2 Critérios de Análise _ 30

2.3 Delimitação da Literatura__ 34

2.4 Considerações Iniciais___ 47

3 REVISÃO DA LITERATURA__ 49

3.1 Inteligência Competitiva 50

3.2 Monitoramento Ambiental _ 54

3.3 Business Intelligence___ 58

3.4 Gestão do Conhecimento __ 62

3.5 Estratégia_ 64

3.6 Decisão 65

4 METODOLOGIA _ 67

4.1 Modelo de Estudo de Caso__ 68

4.2 Critérios de Seleção dos Casos __ 70

4.3 Roteiro de Pesquisa _ 72

4.4 Critérios de Coleta e Análise dos Dados _ 76

5 RESULTADOS 86

5.1 Caso A - Empréstimo Pessoal ___ 89

5.2 Caso B - Financiamento de Veículos _ 97

5.3 Caso C - Cartão de Crédito ___ 103

5.4 Caso D - Crédito Direto ao Consumidor___ 109

5.5 Considerações Finais __ 115

6 DISCUSSÃO__ 117

6.1 A Interação da Organização com o Ambiente Competitivo __ 117

6.2 A Visão Holística de IC 120

7 CONCLUSÃO _ 126

8 BIBLIOGRAFIA_ 129

8.1 Referências Bibliográficas__ 129

8.2 Bibliografia Consultada __ 145

APÊNDICE I - ANÁLISE ESTRUTURAL DA INDÚSTRIA __ 163 


\section{INTRODUÇÃO}

\subsection{Contexto}

Seria simplificação admitir que a transição da sociedade para a Era do Conhecimento é reflexo da terceirização da economia; esta, por sua vez, não deve ser compreendida como o simples deslocamento das atividades industriais para os serviços. Enquanto o mundo dos serviços se industrializa cada vez mais com objetos técnicos, softwares, sistemas especialistas e outros, o mundo dos industriais concebe sua atividade cada vez mais como um serviço (LÉVY, 1994).

Nesse sentido, as organizações romperam paradigmas que se encerram em diferentes evidências: o desenvolvimento de novas tecnologias, o surgimento de novos ambientes competitivos, o advento de novas empresas e a organização de uma nova ordem geopolítica. Tais evidências suportam o aparecimento de uma nova estrutura social, denominada Sociedade da Informação (TARAPANOFF; GREGOLIN, 2001).

No ambiente corporativo, entretanto, possuir a informação correta não representa o fim, mas o início de um processo de decisão mais assertivo. Os concorrentes estão mais agressivos, os clientes são mais exigentes, as tecnologias se desenvolvem mais rapidamente e qualquer movimento estratégico equivocado pode destruir uma organização (KAHANER, 1996).

Assim, admiti-se que a prosperidade das organizações depende da sua capacidade de navegar no espaço do saber: sua competitividade é atribuída à gestão ótima de seus conhecimentos de qualquer natureza. Desta forma, quanto melhor as organizações conseguem se constituir em coletivos inteligentes, entendido como grupos humanos compostos por sujeitos cognitivos, abertos, capazes de iniciativa, de imaginação e de reação rápidas, melhor asseguram seu sucesso no ambiente altamente competitivo (LÉVY, 1994).

Para responder às novas condições da vida econômica, as empresas tendem a se organizar de forma a serem percorridas por redes de inovação, as quais se estabelecem através de relações transversais e, especialmente, trans-empresariais. O crescente desenvolvimento de parcerias e alianças estratégicas é um exemplo da importância de importar e produzir novas competências. Assim, as organizações devem se abrir a uma circulação contínua e constantemente renovada de 
especialidades científicas, técnicas, sociais ou mesmo estéticas, pois o skill flow condiciona o cash flow. Em suma, o saber tornou-se a nova infra-estrutura (LÉVY, 1994).

Neste contexto, a gestão pró-ativa destes conhecimentos assume caráter central no ambiente econômico, através da transformação de informação em inteligência (TERRA, 2001). De acordo com Kahaner (1996), o processo pelo qual as organizações transformam informação em inteligência é chamado inteligência competitiva (IC).

\subsection{Justificativa}

Dados de uma pesquisa realizada pelo Instituto Brasileiro de Inteligência de Mercado (IBRAMERC) com mais de 130 empresas de grande expressão para o mercado brasileiro apontam para o crescimento da inteligência competitiva nas organizações. Em 2008, 83,6\% das empresas pesquisadas afirmaram a existência de ações de inteligência, o que representa o crescimento de $16,1 \%$ sobre os $72,0 \%$ obtidos no ano anterior. Além disso, tais ações possuem diferentes focos, com destaque para as ações sobre clientes, tendências de mercado e concorrentes, conforme a Figura 1.1 (IBRAMERC, 2009).

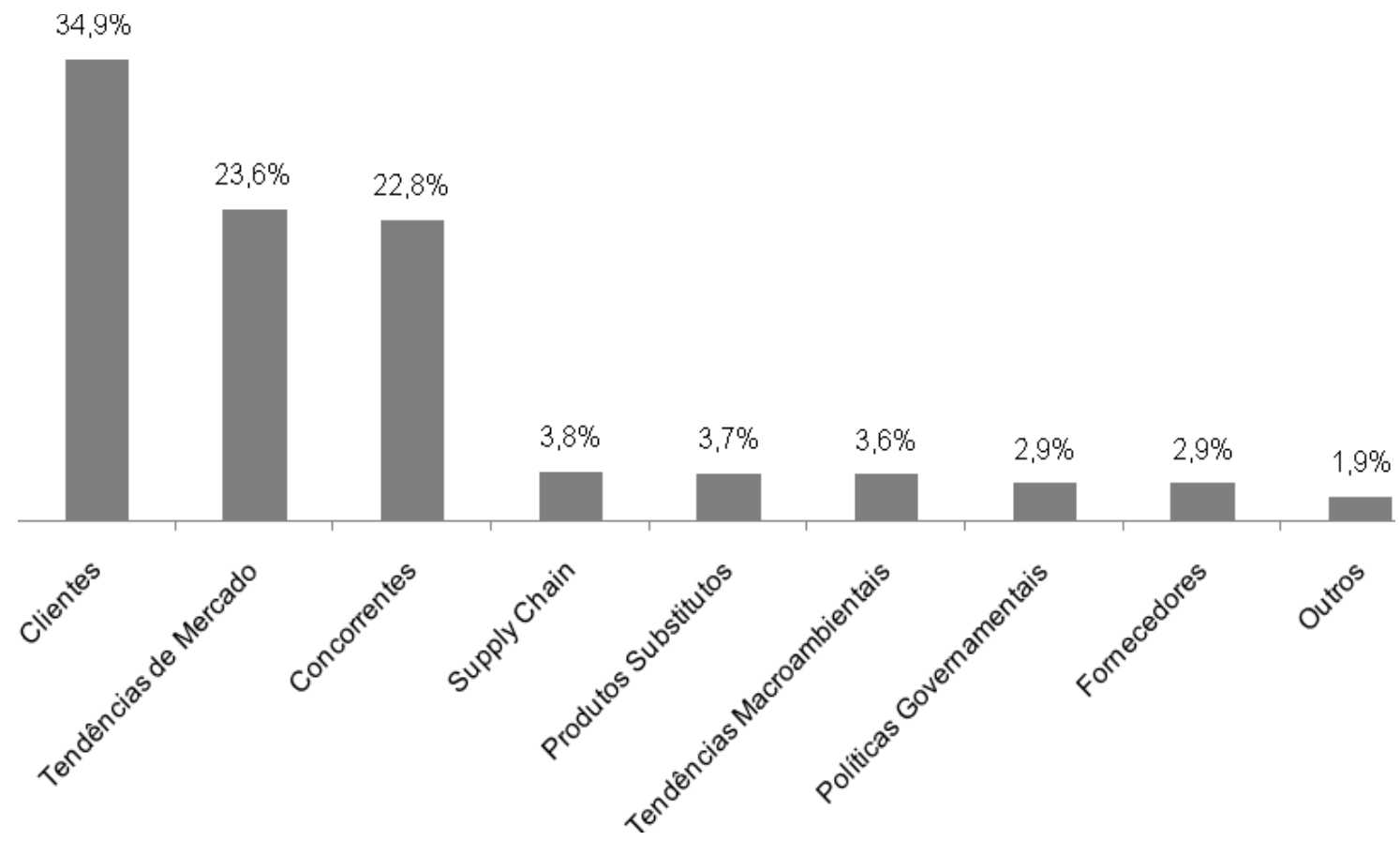

Figura 1.1 - Distribuição das ações de inteligência

Fonte: IBRAMERC (2009) 
Entretanto, mesmo com o avanço do tema no mundo corporativo, a inteligência competitiva ainda encontra dificuldades para o desenvolvimento de uma teoria consistente do ponto de vista acadêmico. Saayman et al. (2008) afirma que ainda é necessário o desenvolvimento de uma visão holística sobre a IC e, nesse sentido, a análise bibliométrica desenvolvida por Jourdan; Reiner e Marshall (2008) figura como uma das principais iniciativas.

A análise cienciométrica ${ }^{1}$ construída ao longo deste trabalho indicou que a IC ainda é uma literatura recente e emergente. A Figura 1.2 apresenta a evolução do volume de publicações com foco em IC, o que demonstra o caráter recente. De acordo com os resultados, as publicações dos últimos 5 anos (2004-2009) representam mais de $57 \%$ das publicações totais sobre o tema e, se forem considerados os últimos 10 anos (1999-2009), este percentual se eleva a aproximadamente $80 \%$. Além disso, a intensidade das publicações mostra o crescimento de $330 \%$ no período, comparando os anos de 2008 e 1999.

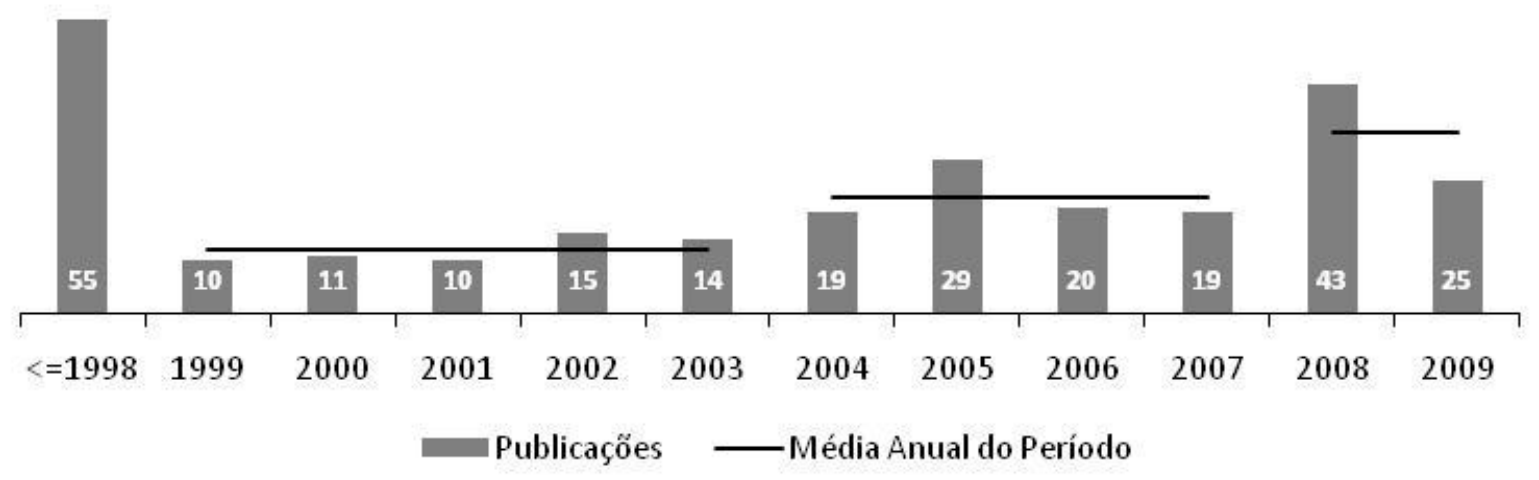

Figura 1.2 - Evolução anual das publicações em $I^{2}$

Fonte: elaborado pelo autor

A análise dos dados aponta que a quantidade média de publicações anuais aumentou de 12 para 22, o que representa um crescimento de mais de $80 \%$. Além disso, os últimos dois anos (2008 e 2009) já indicam uma média de publicações superior. Esse crescente número de publicações indica que a inteligência competitiva, enquanto objeto de pesquisa acadêmica, tem obtido maior destaque nos periódicos relevantes.

\footnotetext{
${ }^{1}$ A definição e os critérios de realização da análise quantitativa, bibliométrica e cienciométrica, são apresentados na seção 2.2.

${ }^{2}$ O gráfico reflete os dados obtidos até o junho de 2009.
} 
Por outro lado, a análise complementar sobre a mesma pesquisa constata que a IC tem caráter multidisciplinar. A Figura 1.3 indica a distribuição destas publicações em diferentes disciplinas, dos quais se destacam a ciência da computação e a administração de negócios, ambas com mais de $50 \%$ das publicações.

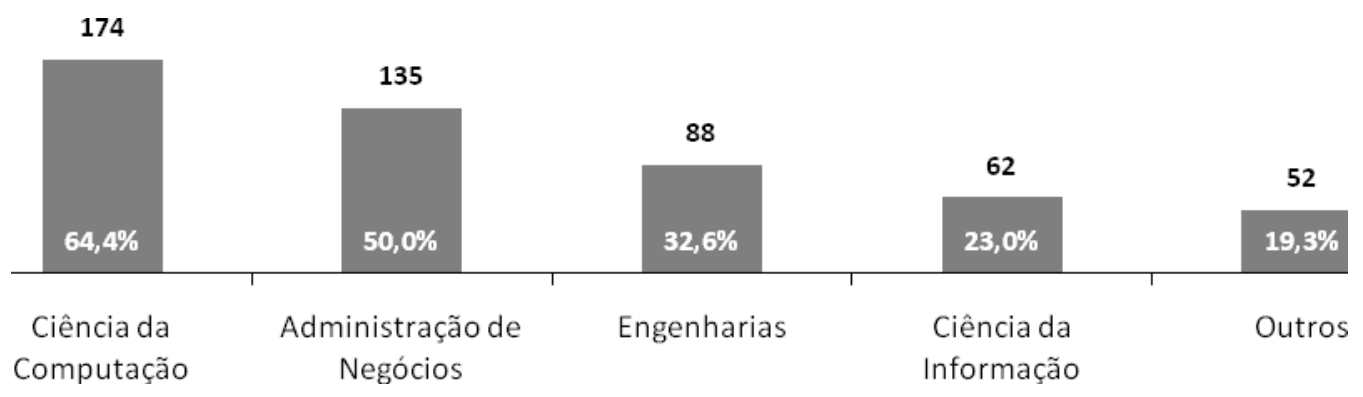

Figura 1.3 - Distribuição em disciplinas das publicações sobre IC

Fonte: elaborado pelo autor

Esta multidisciplinaridade indica que a IC é um campo de estudo que envolve o conhecimento de diferentes áreas de pesquisa com foco sobre a utilização de tecnologias computacionais aplicadas a administração de negócios. Esta característica sugere que os profissionais e pesquisadores que exploram o tema necessitam de um amplo conhecimento para poder elaborar e desenvolver uma teoria consistente sobre a inteligência. Neste sentido, a multidisciplinaridade pode ser interpretada como uma ameaça ao desenvolvimento desta teoria.

Além disso, uma análise bibliométrica sobre a mesma pesquisa, elaborada para avaliar a evolução das citações recebidas pelos artigos selecionados na pesquisa, ressalta esta dificuldade. Conforme aponta a Figura 1.4, mesmo com o número de publicações em ascensão, a quantidade de citações recebidas, representada pela média móvel dos últimos quatro períodos, tem decaído consideravelmente. Desta forma, constata-se que o aumento do número de publicações tem ocorrido de modo disperso, o que dificulta o desenvolvimento de uma teoria sólida para aumentar a aplicabilidade destes conceitos.

Estes resultados reforçam que a literatura científica em IC ainda está em desenvolvimento e de modo disperso. Com isso, evidencia-se a necessidade de definir melhor os campos de pesquisa em IC para a exploração e o desenvolvimento dos conceitos relacionados. 


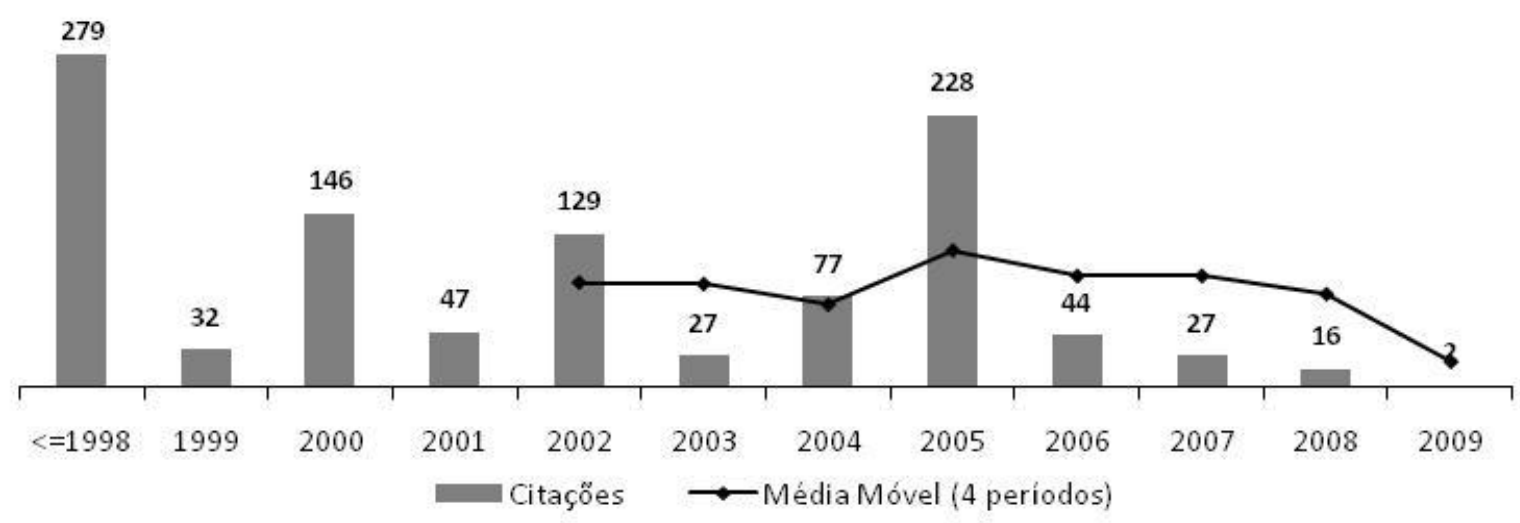

Figura 1.4 - Evolução anual das citações recebidas pelos artigos em $\mathrm{IC}^{3}$

Fonte: elaborado pelo autor

Além disto, a análise qualitativa das publicações também indica dificuldades ao desenvolvimento da teoria. A IC tem sido abordada pela literatura acadêmica como o processo de utilização do conhecimento sobre determinado ambiente competitivo nos processos de decisão organizacional, em níveis estratégicos e táticos. Embora exista um volume crescente de publicações, a revisão da literatura especializada sobre o tema assinala distorções conceituais e taxonômicas para a construção de uma abordagem cientificamente aplicável (CABRAL NETTO, 2007).

Um ensaio introdutório sobre o conceito de IC fornece indícios da dificuldade de construção de um arcabouço conceitual sólido e sustentável para o desenvolvimento de uma literatura científica qualificada. Tarapanoff e Gregolin (2001, p. 46) argumentam que inteligência competitiva "é o processo de estudar qualquer coisa que possa tornar a organização mais competitiva e posicioná-la melhor no mercado". Esta construção, com destaque para a expressão "estudar qualquer coisa", indica a amplitude de conhecimentos necessários ao desenvolvimento da literatura.

Neste sentido, Tyson (1998) e Kahener (1996) apresentam-na como um programa institucional, sistemático e analítico que envolve garimpar e analisar informações de todas as organizações e eventos externos que provocam impactos de qualquer caráter na organização. Apesar do detalhamento da definição contribuir para o delineamento de conceitos centrais em inteligência competitiva, ainda se carregam expressões abstratas, como "analisar informações de todas as organizações e eventos externos" e "provocam impactos de qualquer natureza". Tais expressões

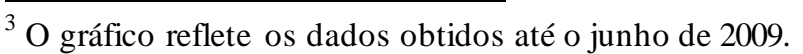


remetem a definição para níveis de generalização muito elevados quando o ovjetivo é o tratamento científico adequado.

No sentido de especificar as definições anteriores e figurando como uma iniciativa no delineamento do escopo do tema IC, Valentim et al. (2003) apresenta o conceito de modo pragmático:

\footnotetext{
"A inteligência competitiva é o processo que investiga o ambiente onde a empresa está inserida, com o propósito de descobrir oportunidades e reduzir os riscos, bem como diagnostica o ambiente interno organizacional, visando o estabelecimento de estratégias de ação a curto, médio e longo prazo." (VALENTIM, 2003, p. 2)
}

Se por um lado a amplitude conceitual dificulta a conceituação da IC, por outro lado a multidisciplinaridade aponta à lacuna acadêmica a explorar. Em geral, as referências para a construção do conhecimento científico em IC são obras clássicas em outras áreas da ciência, isto é, obras com vida média longa. Através de uma análise de co-citações ${ }^{4}$ é possível identificar as referências mais comuns dos artigos com foco em IC, das quais se destacam obras como Porter (1985), Aguilar (1967), Ghoshal (1991), Daft; Sormunen, e Parks (1988), Prescott (1989) e Lenz e Engledow (1986). Assim, além de confirmar a multidisciplinaridade, esta análise aponta para a terceira dificuldade: parece paradoxal que uma literatura acadêmica com foco em IC que se mostra tão recente e emergente utilize referências tão clássicas.

Diante dos resultados identificados, torna-se evidente a necessidade de se organizar o conhecimento já desenvolvido em IC. No atual momento da literatura acadêmica, o mapeamento analítico das obras aparece como uma das atividades de pesquisa mais necessárias ao desenvolvimento de uma teoria consistente e, portanto, foco da pesquisa.

\subsection{Objetivos}

Este trabalho tem por objetivo desenvolver uma visão holística da IC através da investigação da literatura produzida em IC. O conceito de "holística" remete à origem do termo cuja referência em grego é "holos" e siginifica "igual ao todo" e, por isso, o termo indica a tendência ao ver o todo além das partes. Assim, o desenvolvimento de uma visão holística pode contribuir com a proposta de organização da teoria, através do desenvolvimento de um modelo teórico-conceitual que identifique e

\footnotetext{
${ }^{4}$ Os critérios de realização da análise são apresentados na seção 2.2 .
} 
diferencie os campos de pesquisa relacionados a IC. Para isso, é necessário cumprir com os seguintes objetivos específicos:

- Identificar os campos de pesquisa em IC;

- Identificar as principais referências bibliográficas em cada campo de pesquisa relacionado à $\mathrm{IC}$;

- Identificar conceitos centrais em cada campo de pesquisa, confrontando os diferentes argumentos dos principais autores;

- Confirmar como as iniciativas práticas em IC utilizam os conceitos identificados em cada um dos campos de pesquisa identificados através de estudos de caso; e

- Apresentar uma proposta de modelo de IC que relacione os campos de pesquisa, baseado nos resultados verificados no estudo das organizações.

\subsection{Estrutura}

Do mesmo modo que ocorre em âmbito mundial, a pesquisa em estratégia no Brasil tem experimentado a utilização de métodos de pesquisa alternativos ao paradigma tradicional de bases positivistas. Sejam de cunho fenomenológico, interpretativo ou dialético, esses métodos são, na maioria das vezes, denominados de métodos qualitativos de pesquisa. Paralelo a disseminação dos métodos qualitativos de pesquisa em estratégia, pode-se notar o aumento do ceticismo por parte da comunidade acadêmica, principalmente no que se refere à falta de clareza com relação aos procedimentos de análise utilizados, a arbitrariedade do pesquisador no processo de pesquisa e a consequente impossibilidade de escrutínio público.

$\mathrm{Na}$ realidade, a distância epistemológica que separam os métodos objetivos e subjetivos (MORGAN; SMIRCICH, 1980) impede comparações que utilizam os mesmos critérios de rigor científico. Por exemplo, o método fenomenológico, a etnografia e a experiência vivida são métodos que não se preocupam com a possibilidade de refutação ou a objetividade de seus achados, mas intencionam apresentar a narração da versão dos envolvidos ou deixar que os "dados falem por si”. Ou ainda, em um nível mais abstrato, reduzir os dados a conceitos que signifiquem a interpretação dos envolvidos sobre o fenômeno ao qual se deparam. Porém, esse argumento não exclui, qualquer que seja o método, a explicitação dos 
critérios pelos quais o leitor deve avaliar os resultados da pesquisa e nem de como 0 pesquisador perseguiu esses critérios ao longo do desenvolvimento do projeto.

Em consonância com seus objetivos, este trabalho foi desenvolvido através de teoria fundamentada. A teoria fundamentada é um dos métodos de pesquisa interpretativos cujo objetivo é formar um grupo de conceitos explanatórios que seja fiel e esclareça a área que está sendo investigada, visando atingir prescrições e recomendações sobre planos de ação com a teoria. Ela que se apresenta como uma forma viável de conduzir pesquisas cuja intenção é gerar teoria substantiva ou apenas de proceder a uma ordenação conceitual (COLLINS; HUSSEY, 2005).

Para isso, diversos métodos de pesquisas são triangulados: cienciometria, bibliometria, revisão de literatura, estudos de caso e desenvolvimento teóricoconceitual. No entanto, tal como ocorre com outros métodos de análise qualitativa dos dados, é necessário definir critérios de avaliação da qualidade da pesquisa e como persegui-los na prática. Por este motivo, o trabalho está estruturado em seções com objetivos diferentes e complemetares, conforme a Figura 1.5:

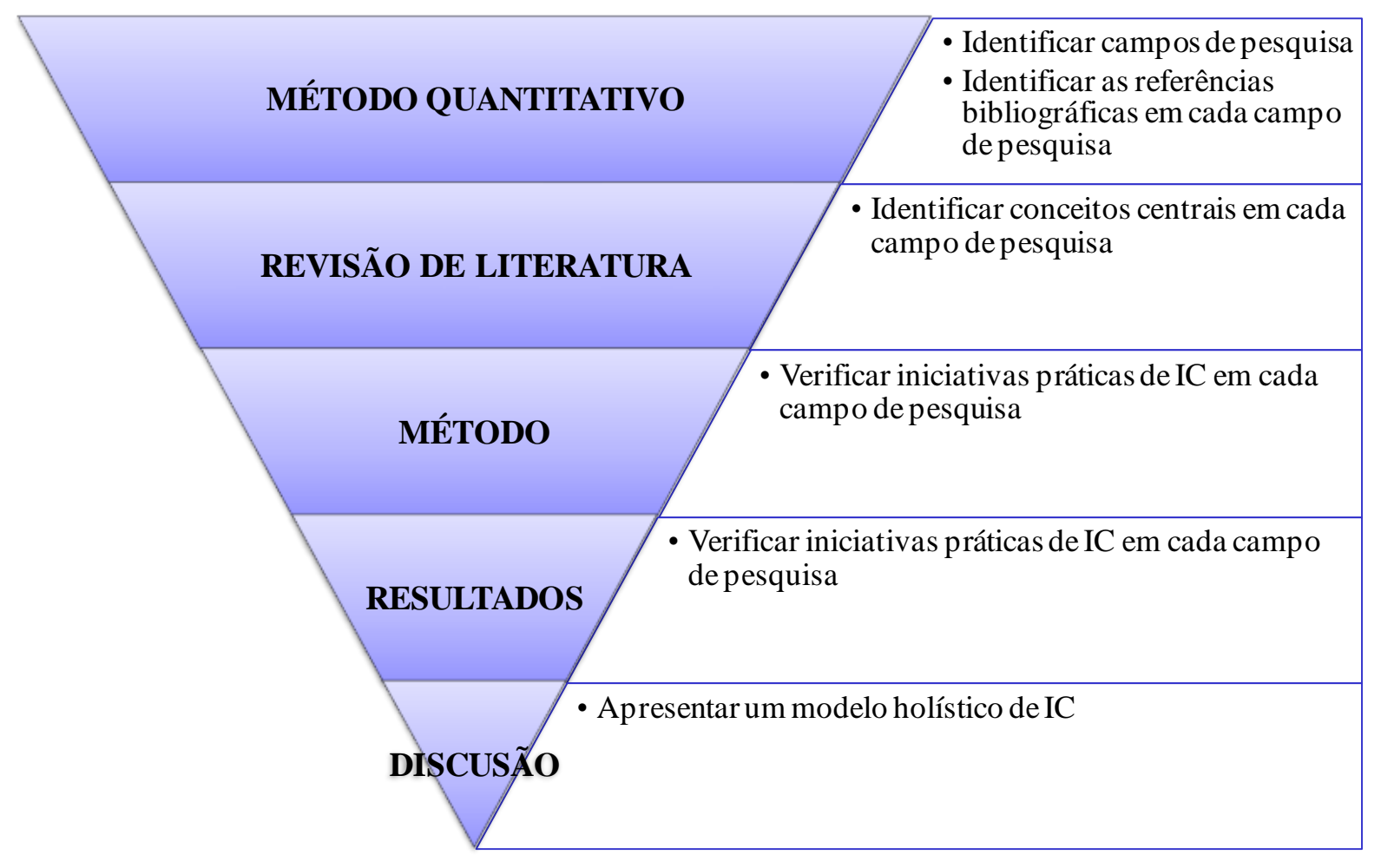

Figura 1.5 - Estrutura da pesquisa

Fonte: elaborado pelo autor 
A estrutura em funil da Figura 1.5 reflete a lógica de organização da teoria fundamentada, com objetivo de compreender um fenômeno complexo e promover sua tradução em um modelo simples de interpretação da realizadade. Para isso, cada seção possui um objetivo claro, conforme descrito a seguir:

- Análise Quantitativa é a seção que descreve e promove a análise quantitativa das publicações em IC com o objetivo de identificar os campos de pesquisa em IC (cienciometria) bem como as principais referencias bibliográficas (bibliometria) em cada campo de pesquisa;

- Revisão de Literatura é a seção que se destina à identificação de um conjunto de proposições sobre a teoria de IC, baseados nas publicações identificadas na Análise Quantitativa;

- Metodologia é a seção que descreve o roteiro de pesquisa utilizado na realização dos estudos de caso confirmatórios, cujo objetivo é validar as proposições identficadas na Revisão de Literatura;

- Resultados é a seção orientada à apresentação das informações obtidas com os estudos de caso realizados bem como promove uma análise preliminar consolidando os principais resultados obtidos;

- Discussão é a seção que se propõe ao desenvolvimento teórico-conceitual de um modelo de IC que relacione os diversos constructos identificados, permitindo a construção da visão holística sobre o tema; e

- Conclusão é a seção que oferece o desfecho do texto, sintetizando as principais contribuições e limitações desta pesquisa assim como destaca oportunidades de pesquisa decorrentes deste trabalho. 


\section{ANÁLISE QUANTITATIVA DA LITERATURA}

$\mathrm{Na}$ engenharia de produção é comum a utilização de métodos racionalistas de pesquisas, destacando-se as análises estatísticas para a compreensão de situações (VOSS; TSIKTIKTSIS; FROHLICH, 2002). A principal característica dessa espécie de pesquisa é a existência independente do fenômeno e do contexto em que está inserido, o que se contrapõe ao fato da engenharia de produção, e a estratégia, serem reconhecidas como uma ciência aplicada em um cenário inconstante. Por este motivo, algumas abordagens alternativas têm sido muito exploradas nas organizações, tanto industriais quanto de serviços (FILIPPINI, 1997).

Dentre as abordagens de pesquisa, destaca-se a pesquisa bibliográfica ou revisão de literatura. Esta tem papel fundamental na transferência de informações entre pesquisadores (SAYERS; JOICE; BAWDEN, 1990; BUTKOVICH, 1996) e permite identificar, conhecer e acompanhar o desenvolvimento de pesquisas e suas novas perspectivas (NORONHA; FERREIRA, 2000). Além dessa, destaca-se o desenvolvimento teórico-conceitual: quanto ao escopo, essa estratégia de pesquisa está vinculada a modelagens conceituais que culminam em novas teorias, mas podem suceder de discussões conceituais da literatura (BERTO; NAKANO, 2000). Os procedimentos necessários para uma contribuição teórica são discutidos por alguns autores em relação à métrica das teorias (WACKER, 2004), como se constituem (WACKER, 1998; WHETTEN, 1989) ou até relacionando-a ao nível empírico (LEWIS, 1998; EISENHARDT, 1989).

O processo de avaliação da ciência não é recente no meio acadêmico. Os periódicos compõem um dos canais mais utilizados para a comunicação de resultados de pesquisa, através dos quais, o pesquisador publica seus artigos para expor idéias, garantir a propriedade científica e se submeter à avaliação dos pares (TARGINO; GARCIA, 2000). As premissas para o uso de periódicos como veículo de progresso científico são (ROSSEAU, 1998):

- O progresso é alcançado mediante o trabalho de cientistas, que o constrõem sobre as obras de precursores de sua área;

- Os resultados desses trabalhos são publicados e submetidos à apreciação de pares; 
- Em suas publicações, os cientistas mostram como construíram seus trabalhos a partir de obras anteriores mencionando-as em seus textos em uma lista de referências;

- As revistas científicas desempenham papel essencial na comunicação entre pesquisadores correlacionados;

- O número de publicações de um grupo de pesquisa pode ser considerado como um indicador da sua produção científica;

- O número de vezes que as obras de um grupo são citadas por outras publicações é a medida do impacto ou da visibilidade internacional dessas obras; e

- No sistema global de revistas, é possível distinguir entre as revistas internacionais centrais e periféricas;

Nesse sentido, a atividade de publicação produz um fluxo informacional que propicia a transformação da informação em conhecimento e, em conseqüência, os resultados das investigações científicas contribuem para o avanço da ciência (MEADOWS, 1999; GARVEY, 1979). Além disso, as citações:

"(...) contribuem para o desenvolvimento da ciência, proveem o necessário
reconhecimento de um cientista por seus colegas, estabelecem os direitos
de propriedade e prioridade da contribuição científica de um autor,
constituem importantes fontes de informação, ajudam a julgar os hábitos de
uso da informação e mostram a literatura que é indispensável para o
trabalho dos cientistas." (FORESTI, 1989, p. 2)

Por este motivo, a necessidade de avaliar o avanço científico e o desenvolvimento das áreas de conhecimento através da revisão das citações tornou-se evidente nas últimas décadas. Em geral, essas revisões para o conhecimento da literatura são realizadas através de métodos quantitativos (CARDOSO et al., 2005). Segundo Van Raan (1997), os métodos quantitativos para a compreensão do progresso científico se destacam para:

- Desenvolvimento de métodos e técnicas para construção e aplicação de indicadores quantitativos em importantes aspectos da ciência;

- Desenvolvimento de sistemas de informação em ciência e tecnologia;

- Estudo das interações entre ciência e tecnologia; e 
- Estudo das estruturas cognitivas e sócio-organizacionais dos campos da ciência.

Entretanto, deve-se salientar que tais métodos não objetivam substituir os métodos tradicionais de pesquisa, mas sim facilitar o alcance das informações e tornar as pesquisas visíveis e analisáveis para que, desta forma, a construção e a formulação de opiniões sejam melhor fundamentadas (ABELSON, 1990; WALLMARK; SEDIG, 1986). Deste modo, como parte importante do processo de compreensão da ciência, a análise bibliométrica deve ser acompanhada de outros métodos para que os seus resultados possam ser interpretados em sua abrangência (CARDOSO et al., 2005).

De acordo com o objeto de estudo, os métodos quantitativos podem ser segmentados em diferentes campos de estudo (VAN RAAL, 1997). Cada campo de estudo possui variáveis específicas e métodos próprios para atingir um determinado objetivo, conforme a Tabela 2.1 (VANTI, 2002).

Tabela 2.1 - Comparação entre métodos quantitativos de avaliação

\begin{tabular}{|c|c|c|}
\hline Tipologia & Bibliometria & Cienciometria \\
\hline Objeto & $\begin{array}{l}\text { Livros, documentos, revistas, artigos, } \\
\text { autores e usuários }\end{array}$ & $\begin{array}{l}\text { Disciplinas, assuntos, áreas e campos } \\
\text { científicos e tecnológicos }\end{array}$ \\
\hline Variáveis & $\begin{array}{l}\text { Número de empréstimos e de citações, } \\
\text { freqüência e extensão das frases }\end{array}$ & Fatores que diferenciam as disciplinas \\
\hline Métodos & Ranking, freqüência e distribuição & $\begin{array}{l}\text { Co-ocorrência de termos, expressões e } \\
\text { palavras-chave }\end{array}$ \\
\hline Objetivos & Otimizar alocação de recursos & Identificar domínios de interesse \\
\hline
\end{tabular}

Fonte: Adaptado de Vanti (2002)

\subsection{Definição do Método Quantitativo}

\subsubsection{Análise Cienciométrica}

A análise cienciométrica é multidimensional e requer a análise combinada de diferentes indicadores (VINKLER, 2006). Os temas que interessam a cienciometria estão relacionados ao crescimento e desenvolvimento das áreas e campos científicos. Neste sentido, a cienciometria pode ser desenvolvida com os seguintes objetivos (VANTI, 2002):

- Identificar as tendências e o crescimento do conhecimento em uma área;

- Determinar o desempenho dos sistemas de recuperação da informação;

- Avaliar os aspectos estatísticos da linguagem, das palavras e das frases;

- Medir o crescimento de determinadas áreas e o surgimento de novos temas. 
Para o desenvolvimento de uma análise cienciométrica, é necessário verificar a ocorrência simultânea de diferentes palavras selecionadas em um grupo específico de publicações. O método permite o estudo quantitativo da estrutura e do conteúdo destas publicações à medida que relaciona pares de palavras. Esta análise é denominada análise de co-palavras e representa o principal método cienciométrico para a identificação de áreas de pesquisa emergentes, tanto entre diversos campos científicos quanto em um único campo de estudo (BHATTACHARYA; BASU, 1998).

O ponto central para a análise de co-palavras é a utilização de palavras-chave. Inicialmente, os artigos são codificados em vetores de palavras-chave que sintetizem suas estruturas cognitivas e são armazenados em um banco de dados a partir do qual as ocorrências da palavra-chave i são contabilizadas $\left(\mathrm{c}_{\mathrm{i}}\right)$ assim como as ocorrências simultâneas das palavras-chave i e j $\left(\mathrm{c}_{\mathrm{ij}}\right)$. Com estes valores, pode-se construir a matriz de co-palavras que dará origem às análises de intensidade.

A análise de intensidade pode ser realizada por métodos distintos, conforme a Tabela 2.2.

Tabela 2.2 - Métodos de análise da intensidade de relacionamento

\begin{tabular}{ccc}
\hline Jaccard & Estatístico & Inclusão \\
\hline$J_{i j}=\frac{c_{i j}}{c_{i}+c_{j}-c_{i j}} \quad S_{i j}=\frac{1}{\sigma} \cdot\left(c_{i j}-\frac{c_{i} \cdot c_{j}}{N}\right)$ & $I_{i j}=\frac{c_{i j}}{\min \left(c_{i} ; c_{j}\right)}$ & $P_{i j}=\frac{N \cdot c_{i j}}{c_{i} \cdot c_{j}}$
\end{tabular}

Fonte: Rip e Courtial (1984)

A construção desta análise deve considerar que (RIP; COURTIAL, 1984):

- Os índices de intensidade avaliam que quanto menor o valor do índice, menor a intensidade;

- O método estatístico pode ser utilizado se a base de artigos for limitada e conhecida a priori; e

- O método de inclusão pode ser utilizado se a base de artigos não for limitada ou conhecida a posteriori.

\subsubsection{Análise Bibliométrica}

Dentre os métodos quantitativos de avaliação da literatura, destaca-se a bibliometria: a análise quantitativa da literatura tecno-científica (SPINAK, 1998; VAN RAAL, 1997). A bibliometria consiste na aplicação de técnicas estatísticas e matemáticas 
para descrever aspectos da literatura e de outros meios de comunicação. Este método, é comumente associado à medida quantitativa de documentos e representa uma técnica quantitativa e estatística de medição dos índices de produção e disseminação do conhecimento científico que possibilita avaliação e reflexão de trabalhos por meio de revisões sistemáticas (ARAÚJO, 2006). Classicamente, a análise bibliométrica é:

"(...) o estudo dos aspectos quantitativos da produção, disseminação e uso da informação registrada. A bibliometria desenvolve padrões e modelos matemáticos para medir esses processos, usando seus resultados para elaborar previsões e apoiar tomadas de decisões". (MACIAS-CHAPULA, 1998, p. 134)

A análise bibliométrica é multidimensional, o que inviabiliza a utilização de indicadores isolados na análise (MARTIN, 1996). Desta forma, são desenvolvidos diversos índices para avaliação da performance de diferentes atividades e aspectos, sendo necessária a análise combinada (VINKLER, 2006). Ela pode ser desenvolvida com diferentes objetivos (VANTI, 2002):

- Identificar as revistas do núcleo de uma disciplina;

- Mensurar a cobertura das revistas secundárias;

- Identificar os usuários de uma disciplina;

- Prever tendências de publicação;

- Estudar a dispersão e a obsolescência da literatura científica;

- Prever a produtividade de autores individuais, organizações e países;

- Medir o grau e padrões de colaboração entre autores;

- Analisar o grau e padrões de colaboração entre autores;

- Analisar os processos de citação e co-citação; e

- Avaliar a circulação e uso de documentos em um centro de documentação.

De modo geral, os índices bibliométricos podem ser utilizados para avaliar a produtividade e a qualidade da pesquisa científica através da medição do número de publicações e citações (VANTI, 2002). Classicamente,

“(..) a bibliometria examina, primeiramente, as relações entre diferentes variáveis: recursos humanos-documentos, artigos-periódicos, produçãoconsumo, etc., que apresentam diversas regularidades de distribuição. $O$ número de artigos que originam $\mathrm{n}$ citações, o número de instituições 
produzindo anualmente $\mathrm{n}$ doutorados, o número de autores com $\mathrm{n}$ artigos, o número de revistas contendo $\mathrm{n}$ artigos constituem exemplos do mesmo tipo de distribuição". (BRAGA, 1972, p. 162)

A regularidade das distribuições incentivou os teóricos da bibliometria a desenvolverem leis empíricas para a análise da produção científica (CARDOSO et al., 2005). Dentre as leis, destacam-se: Lei de Bradford, Lei de Lokta e Lei de Zipf (VANTI, 2002; ROUSSEAU, 1998; CHEN; CHONG; TONG, 1994).

A Lei de Bradford (ou Lei da Dispersão) permite estabelecer o núcleo e as áreas de dispersão sobre um determinado assunto em um mesmo conjunto de publicações, mediante sua medição de produtividade. A dispersão é verificada a partir da identificação do núcleo de periódicos dedicados a determinado assunto, que é formado por poucos títulos produtores de grande número de artigos de interesse (ARAÚJO, 2006).

Se os periódicos científicos forem ordenados em ordem de produtividade decrescente de artigos sobre determinado assunto, poderão ser distribuídos em um núcleo de periódicos mais particularmente dedicados a esse assunto e em diversos grupos ou zonas contendo o mesmo número de artigos que o núcleo, sempre que o número de periódicos do núcleo e das zonas sucessivas for igual a $1: n: n^{2} \ldots$ (BRADFORD, 1961 apud COUTINHO, 1988).

A Lei de Lokta (ou Lei dos Quadrados Inversos) refere-se à medição da produtividade de autores mediante um modelo de distribuição de tamanhofrequência em um conjunto de documentos. A partir desta, admite-se que poucos autores são responsáveis pela produção de grande parte do conhecimento científico e, portanto, os demais autores participam com uma pequena contribuição à teoria. $A$ formulação original da lei permite estimar a frequência $y_{x}$ de autores publicando número ${ }^{x}$ de trabalhos, onde $a$ é um valor constante para cada campo científico, sendo expressa pela Equação 2.1 (ARAÚJO, 2006).

Equação 2.1 - Lei de Lokta

$$
y_{x}=\frac{6}{p^{2} \cdot x^{a}}
$$

Fonte: Araújo (2006) 
Outra abordagem de formulação para esta lei, como mostra a Equação 2ª , indica que o número a de autores que publicam $\mathrm{n}$ artigos, onde o coeficiente $\mathrm{c}$ pode variar conforme a amostra e pode ser estimado através do modelo de regressão linear da Equação 2.2 (CARDOSO et al., 2005; LEAL; OLIVEIRA; SOLURI, 2003; CHUNG, COX; PAK, 1992)

Equação 2.2 - Lei de Lokta modificada

$$
\alpha_{n}=\alpha_{1} \cdot \frac{1}{n^{c}} \quad \ln \left(\frac{\alpha_{n}}{\alpha_{1}}\right)=-c \cdot \ln (n)
$$

Fonte: Araújo (2006)

A Lei de Zipf (ou Lei do Mínimo Esforço) consiste em medir a frequência do aparecimento de expressões em diferentes textos com o objetivo de gerar uma lista ordenada de termos de uma determinada disciplina ou assunto. A partir desta lei, admite-se correlação entre o número de palavras diferentes e a frequência de seu uso e concluiu que existe uma regularidade fundamental na seleção e uso das palavras e que um pequeno número de palavras é usado continuamente (CARDOSO et al., 2005).

Existe uma economia do uso de palavras, e se a tendência é usar o mínimo significa que elas não vão se dispersar, pelo contrário, uma mesma palavra vai ser usada muitas vezes; as palavras mais usadas indicam o assunto do documento. Assim, se listarmos as palavras que ocorrem num texto em ordem decrescente de frequência, a posição $r$ de uma palavra na lista multiplicada por sua frequência f é igual a uma constante k (aproximadamente 26500), conforme a Equação 2.3 (ARAÚJO, 2006).

$$
\begin{gathered}
\text { Equação } 2.3 \text { - Lei de Zipf } \\
r \cdot f=k \\
\text { Fonte: Araújo (2006) }
\end{gathered}
$$

Entretanto, o caráter empírico das leis bibliométricas dificulta sua aplicabilidade prática. Devido a estas dificuldades, o campo de estudo mais relevante da bibliometria é a análise de citações. Citação é uma referência a outro elemento de texto sob a perspectiva do artigo que os cita e engloba um conjunto de referências bibliográficas incluídas em uma publicação. Nesse sentido, a citação dá suporte à comunicação entre especialistas para o desenvolvimento de conhecimento científico, permitindo que autores e pesquisadores selecionem artigos relevantes em diferentes 
contextos ao mesmo tempo. Portanto, as citações evidenciam os relacionamentos entre as publicações, facilitando a identificação de uma publicação com outra (LEYDESDORFF, 1998).

A teoria sobre citações presume-as como auto-explicativas e, por isso, elas podem ser utilizadas de duas formas: explanans, que representa o uso de citações para a explicação de algo, ou explanandum, que representa o uso de citações para a identificação da origem de algo. Essas relações são recursivas, ou seja, rede de citações é ampliada a cada momento e reproduzida ao longo do tempo. Assim, as citações ocupam uma determinada posição em um espaço multidimensional (LEYDESDORFF, 1998). Nesse sentido, a análise de citação é “(...) a parte da bibliometria que investiga as relações entre os documentos citantes e os documentos citados considerados como uma unidade de análise, no todo ou em suas diversas partes" (FORESTI, 1989, p. 3), isto é, a análise de citações rastreia a distribuição dessas relações em um sistema de rede (LEYDESDORFF, 1998).

A análise de citações pode ser feita através de técnicas de co-ocorrência de citações relacionando inúmeras publicações a uma quantidade finita e restrita de citações comuns, através de referências bibliográficas (VAN RAAN, 1997). Dentre as técnicas biblioméricas utilizadas para a análise de citações destaca-se o ranking de classificação dos objetivos de estudo em função de fatores de impacto (VINKLER, 1997). Os fatores de impacto, indicadores comparativos da influência das publicações científicas, foram introduzidos por Raisig (1960) e largamente utilizados por Garfield (1979). Não existe consenso internacional sobre a metodologia destes indicadores que relacionam o número de publicações e citações para avaliar, dentre outras variáveis, a produtividade e a relevância em vários níveis: autores, publicações, periódicos, instituições e outros (SPINAK, 1998). Vinkler (1997) discute três diferentes indicadores bibliométricos que, apesar de serem formulados para mensurar o fator de impacto de um determinado nível, pode ser igualmente generalizado para outros níveis:

Relative Publication Strategy (RPS): fator de impacto de um periódico, determinado como soma dos fatores de impacto dos j periódicos $\left(h_{\mathrm{j}}\right)$ ponderado pela quantidade (N) de artigos publicados pelo periódico $\left(n_{\mathrm{j}}\right)$ e dividido pelo fator de impacto médio ponderado dos periódicos dedicados ao tema $\left(h_{S}\right)$, sendo conforme a Equação 2.4. 
Equação 2.4 - Método de cálculo do indicador RPs

$$
R P_{S}=\frac{\left(\sum_{j=1}^{J} n_{j} \cdot h_{j}\right) / N}{h_{s}}
$$

Fonte: Vinkler (1997)

Relative Citation Rate (RCR): fator de impacto que relaciona as citações (C) recebidas por um autor com o total de suas publicações $(\mathrm{N})$ dividido pelo fator de impacto $\left(h_{\mathrm{j}}\right)$ ponderado pelo número de publicações $\left(n_{j}\right)$ dos periódicos em que foram publicados, conforme a Equação 2.5.

Equação 2.5 - Método de cálculo do indicador RCR

$$
R C R=\frac{C / N}{\left(\sum_{j=1}^{J} n_{j} \cdot h_{j}\right) / N}
$$

Fonte: Vinkler (1997)

Relative Subfield Citedness $\left(\mathrm{R}_{\mathrm{W}}\right)$ : fator de impacto que relaciona as citações $(\mathrm{C})$ com as publicações $(\mathrm{N})$ de um determinado periódico e que apresenta relação com os indicadores anteriores, conforme a Equação 2.6.

Equação 2.6 - Método de cálculo do indicador Rw

$$
R_{W}=R P_{S} \cdot R C R=\frac{C}{N}
$$

Fonte: Vinkler (1997)

Além destes indicadores, Hirsch (2005) introduz o conceito de $h$-index. Para a construção deste indicador, são considerados quatro tipos de pesquisadores (VINKLER, 2006):

- Pesquisadores que publicam muitos artigos e obtém muitas citações;

- Pesquisadores que publicam muitos artigos e obtém poucas citações;

- Pesquisadores que publicam poucos artigos e obtém muitas citações;

- Pesquisadores que publicam poucos artigos e obtém poucas citações;

Assim, o $h$-index considera que um pesquisador que tem índice $\mathrm{h}$ possua $\left(\mathrm{N}_{\mathrm{P}}\right)$ publicações com pelo menos $h$ citações cada e outros $\left(N_{P}-h\right)$ publicações com menos de h citações. Desta forma, pode-se selecionar o grupo de elite (autores, 
instituições, países e outros grupos) de um determinado campo de pesquisa (VINKLER, 2006). Em suma, a análise bibliométrica representa um valioso método para a identificação e avaliação dos pontos fortes e fracos da literatura acadêmica (VAN RAAN, 1997).

\subsection{Critérios de Análise}

O método de realização desta pesquisa é baseado nas técnicas apresentadas anteriormente. Nesta seção inicial da pesquisa, serão selecionados os artigos acadêmicos relevantes ao tema para posterior análise de co-palavras e análise de citações. Com isso, espera-se identificar os campos de pesquisa em IC bem como as principais referências bibliográficas em cada um destes campos para a construção do referencial teórico.

\subsubsection{Seleção de artigos}

A primeira etapa da pesquisa foi selecionar a literatura científica publicada para a realização da análise bibliométrica e, portanto, tem objetivo de construir uma base de artigos. Nesse sentido, foram definidos critérios conforme a Tabela 2.3.

Tabela 2.3 - Critérios de construção da base de artigos

\begin{tabular}{ll}
\hline Critério & Definição \\
\hline Base de dados & ISI Web of Science \\
Tipo de documento & Artigos \\
Palavras-chave & "competitive intelligence" OU "business intelligence" \\
Áreas de estudo & Sem restrições \\
Período de publicação & Sem restrições \\
Instituição de pesquisa & Sem restrições \\
Língua de publicação & Sem restrições \\
\hline & Fonte: elaborado pelo autor
\end{tabular}

Para sua realização, foi utilizada a base de dados online ISI Web of Science. A decisão pelo uso desta base de dados esta sustentada na amplitude da cobertura do Institute for Scientific Information (ISI), que reúne a maioria das revistas internacionais importantes nas áreas de ciências puras, sociais, aplicadas e médicas (ROUSSEAU, 1998). Além disso, destaca-se que a pesquisa foi restrita aos artigos publicados em periódicos cadastrados nesta base de dados. A decisão pelo uso apenas dos artigos esta baseada nas premissas para o uso de periódicos no progresso científico (VANTI, 2002).

Em relação à decisão sobre as palavras-chaves, foi considerada a pesquisa de Matheus e Parreiras (2004) na qual se avalia os termos inteligência competitiva e 
inteligência de negócios, assim como suas respectivas traduções "competitive intelligence" e "business intelligence". Nota-se que a distinção dos termos na literatura internacional é maior quando comparada à nacional: "competitive intelligence" está associado à literatura de negócios e "business intelligence" à literatura de tecnologia de informação (CABRAL NETTO, 2007). Entretanto, a dificuldade no isolamento conceitual inviabiliza a restrição da pesquisa a um único termo. Por este motivo, a análise de co-palavras requer uma análise prévia sobre as delimitações de cada um destes campos de estudo.

Em relação às áreas de estudo, o caráter multidisciplinar da IC requer a seleção de todas as áreas de estudo. Analogamente, não foram consideradas restrições sobre as instituições de pesquisa. Já a característica exploratória desta pesquisa inviabiliza a restrição de período ou língua de publicação. Os dados referentes a estes artigos extraídos da base ISI foram exportados ao software STKIS para a realização das análises que seguem (SCHILDT, 2002).

\subsubsection{Análise de Co-Palavras}

$\mathrm{Na}$ segunda etapa foi realizada a análise de co-palavras com objetivo de identificar os campos de pesquisa em IC. Neste sentido, são desenvolvidas três atividades:

- Elaboração da matriz de co-palavras: com o objetivo de estabelecer a coocorrência das palavras-chaves selecionadas nos diferentes artigos, foi elaborada a matriz de co-palavras; assim, conforme o exemplo da Tabela 2.4, $\mathrm{C}_{\mathrm{AB}}$ representa a quantidade de co-ocorrências das palavras-chave $\mathrm{A}$ e $\mathrm{B}$ na base de artigos selecionados.

Tabela 2.4 - Exemplo de matriz de co-palavras

\begin{tabular}{ccccccccc}
\hline Palava-chave & $\mathrm{A}$ & $\mathrm{B}$ & $\mathrm{C}$ & $\mathrm{D}$ & $\mathrm{E}$ & $\mathrm{F}$ & $\mathrm{G}$ & $\mathrm{H}$ \\
\hline $\mathrm{A}$ & $\mathrm{C}_{\mathrm{A}}$ & $\mathrm{C}_{\mathrm{AB}}$ & $\mathrm{C}_{\mathrm{AC}}$ & $\mathrm{C}_{\mathrm{AD}}$ & $\mathrm{C}_{\mathrm{AE}}$ & $\mathrm{C}_{\mathrm{AF}}$ & $\mathrm{C}_{\mathrm{AG}}$ & $\mathrm{C}_{\mathrm{AH}}$ \\
$\mathrm{B}$ & & $\mathrm{C}_{\mathrm{B}}$ & $\mathrm{C}_{\mathrm{BC}}$ & $\mathrm{C}_{\mathrm{BD}}$ & $\mathrm{C}_{\mathrm{BE}}$ & $\mathrm{C}_{\mathrm{BF}}$ & $\mathrm{C}_{\mathrm{BG}}$ & $\mathrm{C}_{\mathrm{BH}}$ \\
$\mathrm{C}$ & & & $\mathrm{C}_{\mathrm{C}}$ & $\mathrm{C}_{\mathrm{CD}}$ & $\mathrm{C}_{\mathrm{CE}}$ & $\mathrm{C}_{\mathrm{CF}}$ & $\mathrm{C}_{\mathrm{CG}}$ & $\mathrm{C}_{\mathrm{CH}}$ \\
$\mathrm{D}$ & & & & $\mathrm{C}_{\mathrm{D}}$ & $\mathrm{C}_{\mathrm{DE}}$ & $\mathrm{C}_{\mathrm{DF}}$ & $\mathrm{C}_{\mathrm{DG}}$ & $\mathrm{C}_{\mathrm{DH}}$ \\
$\mathrm{E}$ & & & & & $\mathrm{C}_{\mathrm{E}}$ & $\mathrm{C}_{\mathrm{EF}}$ & $\mathrm{C}_{\mathrm{EG}}$ & $\mathrm{C}_{\mathrm{EH}}$ \\
$\mathrm{F}$ & & & & & & $\mathrm{C}_{\mathrm{F}}$ & $\mathrm{C}_{\mathrm{FH}}$ & $\mathrm{C}_{\mathrm{FH}}$ \\
$\mathrm{G}$ & & & & & & $\mathrm{C}_{\mathrm{G}}$ & $\mathrm{C}_{\mathrm{GH}}$ \\
$\mathrm{H}$ & & & & & & $\mathrm{C}_{\mathrm{H}}$ \\
\hline \multicolumn{7}{c}{ Fonte: elaborado pelo autor }
\end{tabular}

- Classificação do relacionamento das palavras-chave: visando identificar as co-ocorrências relevantes, foi calculado o indicador de intensidade pelo 
método de inclusão, conforme a Tabela 2.2; assim, a intensidade do relacionamento entre as palavras-chave é classificada conforme a Tabela 2.5.

Tabela 2.5 - Critério de classificação da intensidade de relacionamento

\begin{tabular}{ll}
\hline Faixa de Intensidade & Classificação \\
\hline Igual a $00 \%$ & Nula \\
Maior que $00 \%$ e menor ou igual a $33 \%$ & Fraca \\
Maior que $33 \%$ e menor ou igual a $66 \%$ & Média \\
Maior que $66 \%$ e menor ou igual a $100 \%$ & Forte \\
lgual a $100 \%$ & Absoluto \\
\hline \multicolumn{2}{c}{ Fonte: elaborado pelo autor }
\end{tabular}

- Construção do mapa de co-palavras: as intensidades das co-ocorrências foram graficamente apresentadas através de mapas de co-palavras construídos a partir de duas abordagens distintas e complementares:

- A primeira abordagem se refere à identificação das palavras-chave cuja classificação do relacionamento seja superior a $66 \%$, ou seja, aqueles relacionamentos considerados de intensidade FORTE ou ABSOLUTO.

- Esta abordagem permite identificar a proximidade conceitual dos diferentes termos, facilitando a identificação dos sub-campos do modelo conceitual.

- A segunda abordagem se refere à identificação das palavras-chave cuja classificação do relacionamento não seja NULA, mas inferior a $33 \%$, ou seja, aqueles relacionamentos de intensidade FRACA.

- Esta abordagem permite identificar a proximidade conceitual entre os diferentes campos de pesquisa, facilitando a identificação das interfaces do modelo conceitual.

É importante observar que para a construção da análise de co-palavras é necessária a definição de critérios de seleção das palavras-chaves. Assim, para que uma palavra-chave seja elegível às categorias de interface ou sub-campo, foram estipulados os seguintes critérios qualificadores:

- A palavra-chave não deve ser relacionada a uma aplicação de tecnologia, como ERP, por exemplo; nestes casos, as palavras-chave foram eliminadas da análise; 
- A palavra-chave não deve representar um país ou região, como SOUTH $A F R I C A$, por exemplo; nestes casos, as palavras-chave foram eliminadas da análise;

- A palavra-chave não deve representar um método de pesquisa, como EXPERIMENTAL RESEARCH, por exemplo; nestes casos, as palavraschaves foram eliminadas da análise; $\mathrm{e}$

- A palavra-chave não deve representar qualificações abstratas ou genéricas, como EFICIENCY e ORGANIZATION, por exemplo; nestes casos, as palavras-chaves foram eliminadas da análise.

\subsubsection{Análise de Citações}

Por fim, foi desenvolvida a análise de citações com o objetivo de identificar as principais referências bibliográficas em cada um dos campos de pesquisa identificados pelo método anterior. Para isso, foram desenvolvidas três atividades:

- Catalogação dos artigos nos campo de pesquisa: através das palavraschaves relacionadas a cada artigo, as publicações foram catalogados nos campos de pesquisa identificados;

- Classificação dos artigos nos campo de pesquisa: para cada campo de pesquisa, foi construído um ranking de relevância das publicações através das citações médias recebidas por cada uma, conforme Equação 2.7:

- $O$ indicador relaciona o total das citações $\left(C_{i}\right)$ recebidas por um artigo (i) com seu período (ti) de publicação;

Equação 2.7 - Método de classificação dos artigos

$$
R_{i}=\frac{C_{i}}{t_{i}}
$$

Fonte: Vinkler (1997)

- Identificação das referências bibliográficas relevantes: para cada campo de pesquisa, foi construído um ranking de relevância através do indicador bibliométrico $R_{W}$, conforme Equação 2.8:

- O indicador relaciona o total das citações $\left(C_{i}\right)$ recebidas por um autor (i) com o total de publicações $\left(\mathrm{N}_{\mathrm{i}}\right)$ do campo de pesquisa; 
Equação 2.8 - Método de classificação das referências

$$
R w_{i}=\frac{C_{i}}{N_{i}}
$$

Fonte: Vinkler (1997)

\subsection{Delimitação da Literatura}

Conforme introduzido na seção anterior, a análise quantitativa das publicações em IC é o ponto inicial da avaliação da teoria. A construção da base de artigos, segundo os parâmetros definidos naquela seção, resultou em 270 publicações, cujo perfil foi apresentado na seção de introdução deste trabalho. Recuperada esta visão inicial, esta fase do trabalho foca a análise de co-palavras e citações.

Iniciando pela análise de co-palavras, entre os artigos selecionados foram identificados 776 palavras-chave. Entretanto, existe certa variação no modo como elas foram escritas que as tornam redundantes. Para evitar este problema, algumas palavras-chave foram padronizadas, conforme a Tabela 2.6, o que reduziu a quantidade de palavras-chave para 747. Após esta normalização, foram identificados 556.516 relacionamentos entre as palavras-chave. Sendo assim, a matriz de co-palavras foi construída e utilizada para a identificação da intensidade de relacionamento, cuja distribuição está apresentada na Figura 2.1.

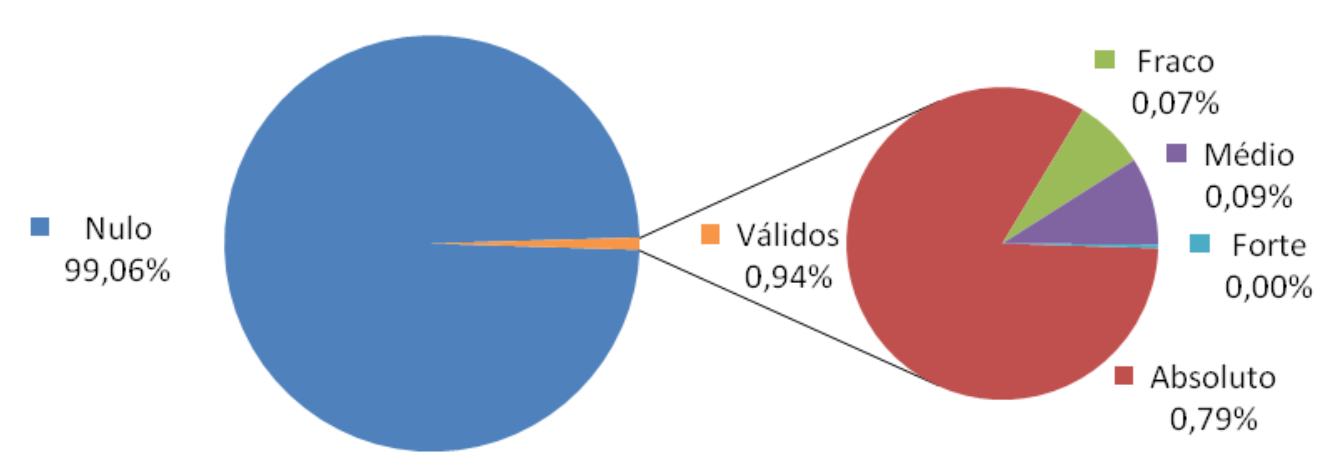

Figura 2.1 - Distribuição dos relacionamentos

Fonte: elaborado pelo autor 
Tabela 2.6 - Lista de palavras-chave padronizadas

\begin{tabular}{|c|c|}
\hline PADRONIZAÇÃO & PALAVRA-CHAVEORIGINAL \\
\hline ALGORTHMS & ALGORITHM; ALGORTHMS \\
\hline ARTIFICIAL NEURAL NETWORKS & ARTIFICIAL NEURAL NETWORK; ARTIFICIAL NEURAL NETWORKS \\
\hline BUSINESS INTELLIGENCE & $\begin{array}{l}\text { BUSINESS INTELLIGENCE; BUSINESS INTELLIGENCE (BI); BUSINESS- } \\
\text { INTELLIGENCE (BI) }\end{array}$ \\
\hline COMPETITIVE INTELLIGENCE & COMPETITIVE INTELLIGENCE; COMPETITIVE INTELLIGENCE (Cl) \\
\hline DATA MINING & DATA MINING; DATA-MINING (DM) \\
\hline DATA WAREHOUSES & DATA WAREHOUSE; DATA WAREHOUSES \\
\hline DATA WAREHOUSING & DATA WAREHOUSING; DATA WAREHOUSING (DW) \\
\hline DECISION & DECISION; DECISIONS \\
\hline DECISION MAKING & DECISION MAKING; DECISION-MAKING \\
\hline DECISION SUPPORT & DECISION SUPPORT; DECISION-SUPPORT \\
\hline DECISION SUPPORT SYSTEMS & $\begin{array}{l}\text { DECISION SUPPORT SYSTEMS; DECISION-SUPPORT SYSTEMS; } \\
\text { DECISION-SUPPORT-SYSTEMS }\end{array}$ \\
\hline E-COMMERCE & E-COMMERCE; ECOMMERCE \\
\hline ENVIRONMENTS & ENVIRONMENT; ENVIRONMENTS \\
\hline FIRMS & FIRM; FIRMS \\
\hline INFORMATION SOURCES & INFORMATION SOURCES; INFORMATION-SOURCES \\
\hline INFORMATION SYSTEMS & INFORMATION SYSTEMS; INFORMATION-SYSTEMS \\
\hline INTELLIGENCE PROCESSES & INTELLIGENCE PROCESS; INTELLIGENCE PROCESSES \\
\hline INTELLIGENT AGENTS & INTELLIGENT AGENT; INTELLIGENT AGENTS \\
\hline KNOWLEDGE BASED SYSTEMS & KNOWLEDGE BASED SYSTEM;KNOWLEDGE BASED SYSTEMS \\
\hline KNOWLEDGE MANAGEMENT & KNOWLEDGE MANAGEMENT; KNOWLEDGE MANAGEMENT (KM) \\
\hline MODELS & MODEL; MODELS \\
\hline MULTIAGENT SYSTEM & MULTI-AGENT SYSTEM; MULTIAGENT SYSTEM \\
\hline SERVICES & SERVICE; SERVICES \\
\hline SMES & SME; SMES \\
\hline STRATEGIC INFORMATION SYSTEMS & STRATEGIC INFORMATION SYSTEM; STRATEGIC INFORMATION SYSTEMS \\
\hline STRATEGY & STRATEGIES; STRATEGY \\
\hline SYSTEMS & SYSTEM; SYSTEMS \\
\hline
\end{tabular}

Nota-se que grande parte dos relacionamentos existentes é nula, isto é, $99,06 \%$ dos relacionamentos não apresentam qualquer relevância para esta análise. Com isso, restam 5.256 relacionamentos válidos, cuja distribuição foi apresentada. Desta forma, mesmo que existam muitas palavras-chaves, a Lei de Zipf reforça a validade da análise para aquelas mais frequentes e, por isso, a análise será realizada neste momento com os relacionamentos válidos, que representam $0,94 \%$ do total.

\subsubsection{Definição dos Campos de pesquisa}

A investigação sobre os campos de pesquisa em inteligência competitiva começa com a análise da palavra-chave COMPETITIVE INTELLIGENCE. O exame inicial deste termo na base selecionada indica sua manifestação em 26 publicações, aproximadamente $10,0 \%$ da seleção total, com 151 relacionamentos válidos para esta análise, distribuídos conforme a Figura 2.2. 


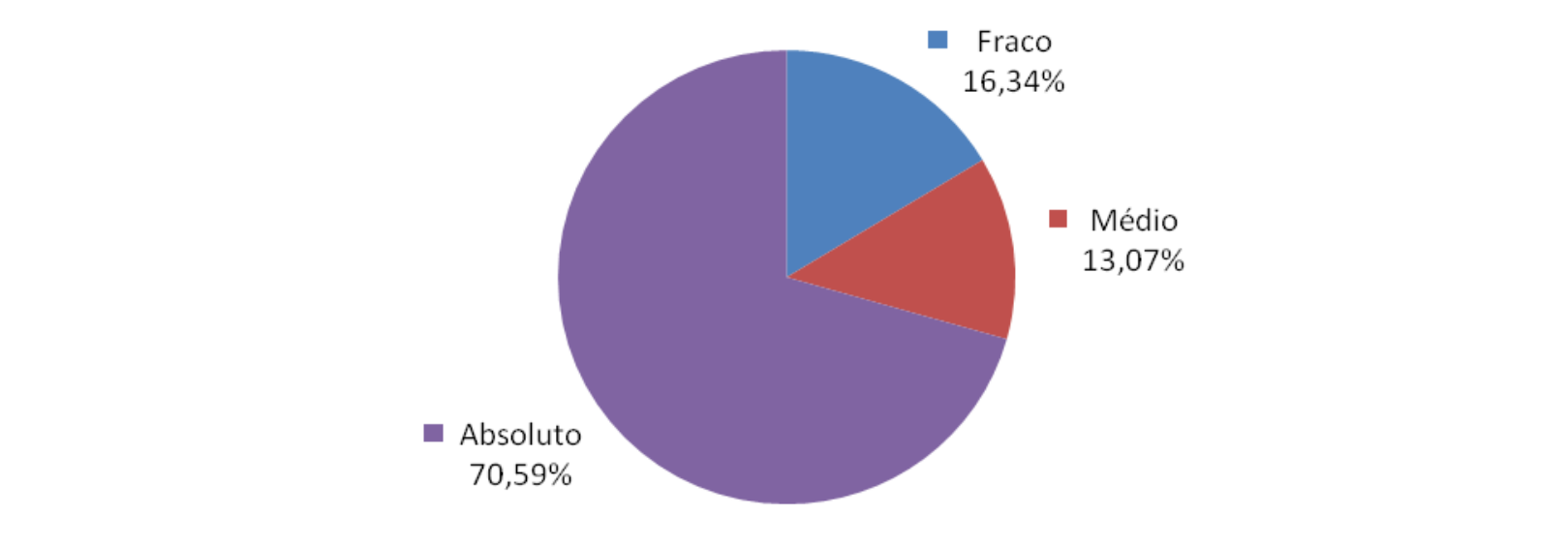

Figura 2.2 - Distribuição de relacionamentos de competitive intelligence

Fonte: elaborado pelo autor

Por um lado, o gráfico indica que mais de $70 \%$ das palavras-chave relacionadas à COMPETITIVE INTELLIGENCE estão totalmente relacionados a ela. Este resultado pode ser interpretado de duas formas:

- Algumas palavras-chave estão totalmente relacionadas ao termo, pois foram publicadas uma única vez e, portanto, esta massa de palavras-chaves pode ser desconsiderada da análise, conforme a Lei de Zipf; ou

- Algumas palavras-chave se referem única e exclusivamente ao termo, com equivalência conceitual e, assim, podem ser desconsideradas da análise.

Em suma, qualquer que seja a interpretação destes resultados, os relacionamentos absolutos pouco agregam à análise de identificação dos campos de pesquisa para construção do modelo conceitual. Sendo assim, eles são preteridos da análise.

Por outro lado, os resultados mostram que outros 30\% das palavras-chave, descritos na Tabela 2.7, possuem relacionamentos não-nulos e não-absolutos, distribuídos nas faixas intensidade fraca e média. Constata-se a ausência de relacionamentos de intensidade forte, o que pode ser justificado por se tratar de uma literatura recente e em desenvolvimento. Após a aplicação dos critérios qualificadores descritos na seção reservada ao método, a análise de co-palavras para a identificação de campos de pesquisa em inteligência competitiva fica restrita a 17 candidatas. Considerando o contexto deste trabalho, no qual se remete a uma literatura recente e emergente, a existência de tantos campos de pesquisa destoa das expectativas. 
Sendo assim, novos métodos para refinamento destas candidatas são desenvolvidos, com base em análises gráficas da co-ocorrência destas.

Tabela 2.7 - Palavras-chaves relacionadas ao termo competitive intelligence

\begin{tabular}{|c|c|c|c|c|}
\hline PALAVRA-CHAVE & PUBLICAÇOES & CO-OCORRENCTAS & TNIENSIDADE & STATUS \\
\hline DECISION MAKING & 3 & 2 & $66 \%$ & Sub-campo \\
\hline ENVIRONMENTAL-ANALYSIS & 2 & 1 & $50 \%$ & Sub-campo \\
\hline NEURAL NETWORKS & 2 & 1 & $50 \%$ & Sub-campo \\
\hline TECHNICAL INTELLIGENCE & 2 & 1 & $50 \%$ & Sub-campo \\
\hline INTELLIGENCE PROCESSES & 2 & 1 & $50 \%$ & Sub-campo \\
\hline STRATEGY & 5 & 2 & $40 \%$ & Sub-campo \\
\hline TECHNOLOGY INTELLIGENCE & 3 & 1 & $33 \%$ & Interface \\
\hline KNOWLEDGE MANAGEMENT & 15 & 4 & $26 \%$ & Interface \\
\hline DATA ANALYSIS & 4 & 1 & $25 \%$ & Interface \\
\hline STRATEGIC MANAGEMENT & 4 & 1 & $25 \%$ & Interface \\
\hline INFORMATION-RETRIEVAL & 5 & 1 & $20 \%$ & Interface \\
\hline CLASSIFICATION & 6 & 1 & $16 \%$ & Interface \\
\hline DECISION SUPPORT SYSTEMS & 6 & 1 & $16 \%$ & Interface \\
\hline DATA WAREHOUSING & 12 & 1 & $8 \%$ & Interface \\
\hline BUSINESS INTELLIGENCE & 47 & 2 & $7 \%$ & Interface \\
\hline DATA MINING & 19 & 1 & $5 \%$ & Interface \\
\hline
\end{tabular}

Fonte: elaborado pelo autor

Buscando o refinamento desta seleção, foi construído um mapa de co-palavras com todas as candidatas, conforme a Figura 2.3.

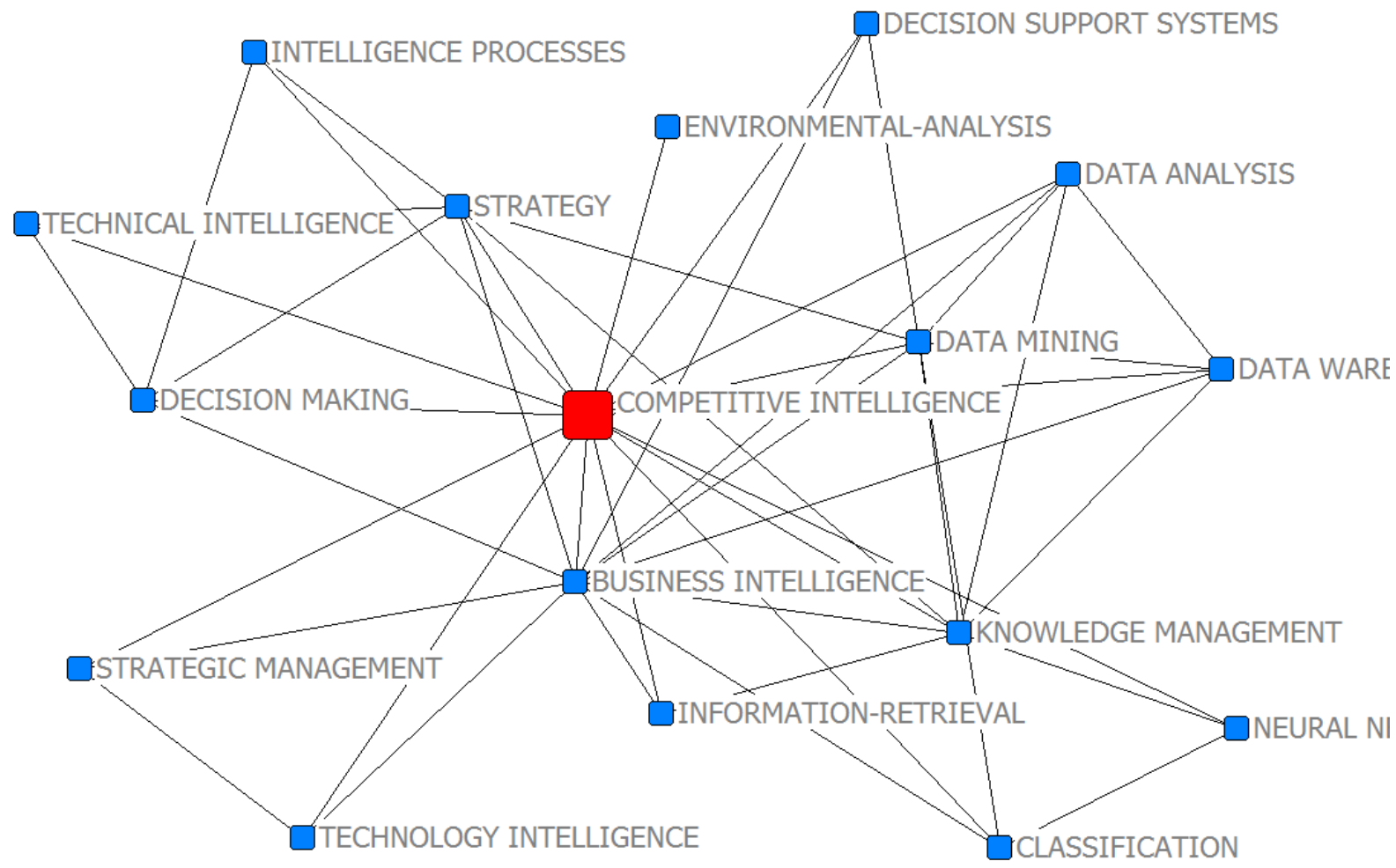

Figura 2.3 - Mapa de co-palavas de competitive intelligence

Fonte: elaborado pelo autor 
Entretanto, este mapa mostra não apenas o relacionamento destas com o termo COMPETITIVE INTELLIGENCE, mas também destas entre si. Através da análise do mapa, é possível perceber algumas palavras-chaves que centralizam muitos relacionamentos, como BUSINESS INTELLIGENCE, STRATEGY e KNOWLEDGE MANAGEMENT. Por esta razão, estas palavras-chave permanecem como candidatas a compor o modelo conceitual. Além disso, nota-se a existência de apenas uma candidata que se relaciona única e exclusivamente a COMPETITIVE INTELLIGENCE: ENVIRONMENTAL ANALYSIS, que também permanece no processo.

Para finalizar o refinamento desta seleção, deve-se observar que existem coligações entre algumas palavras-chave. Observando as palavras-chaves INTELLIGENCE PROCESS, TECHNICAL INTELLIGENCE, DECISION MAKING, STRATEGY e COMPETITIVE INTELLIGENCE assinala-se que estão relacionadas entre si. Como as duas últimas já estão selecionadas como campos de pesquisa, as três primeiras formam um novo campo. Considerando ser um termo com mais publicações, seleciona-se a palavra-chave DECISION MAKING como representante.

Desta forma, esta análise resulta nos campos de pesquisa para a construção do modelo conceitual, cuja primeira versão é apresentada na Figura 2.4.

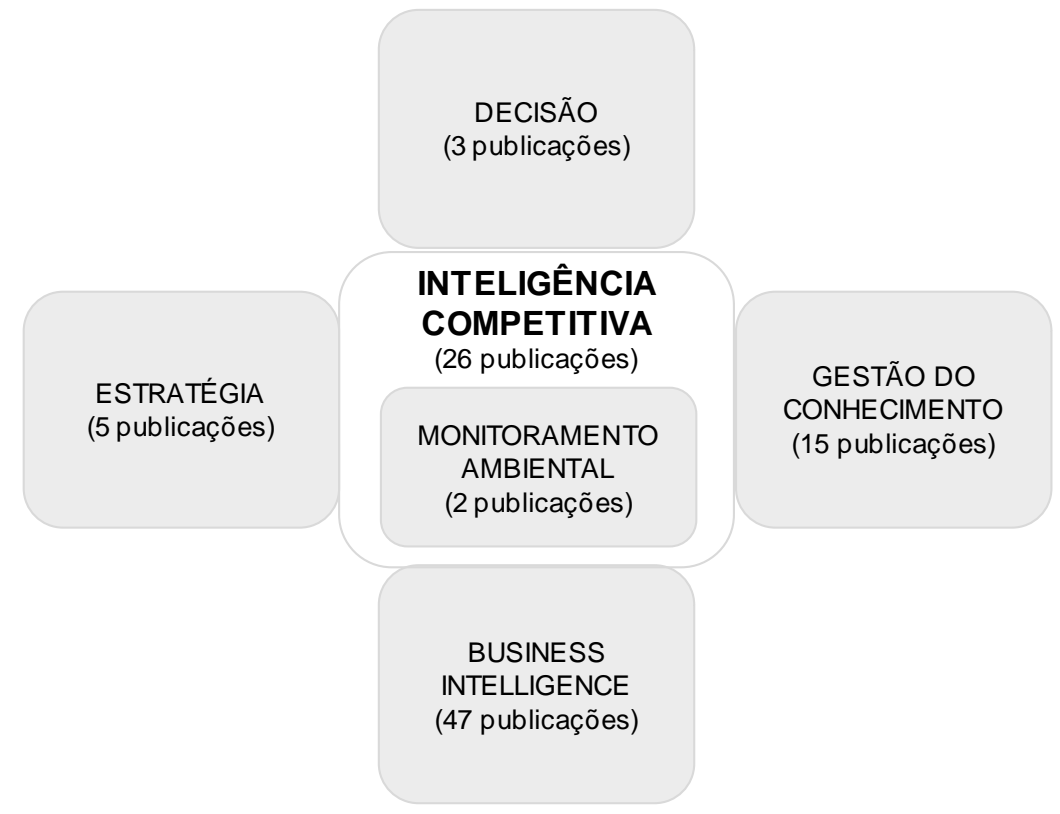

Figura 2.4 - Modelo de IC em primeira versão

Fonte: elaborado pelo autor 
Nesta primeira versão, identificam-se apenas cinco campos de pesquisa, cujas intersecções são desconhecidas e, por isso, precisam ser melhor analisadas. Para tanto, foram desenvolvidas análises de co-palavras para cada campo, considerando as intensidades de relacionamentos apresentadas na Figura 2.5.

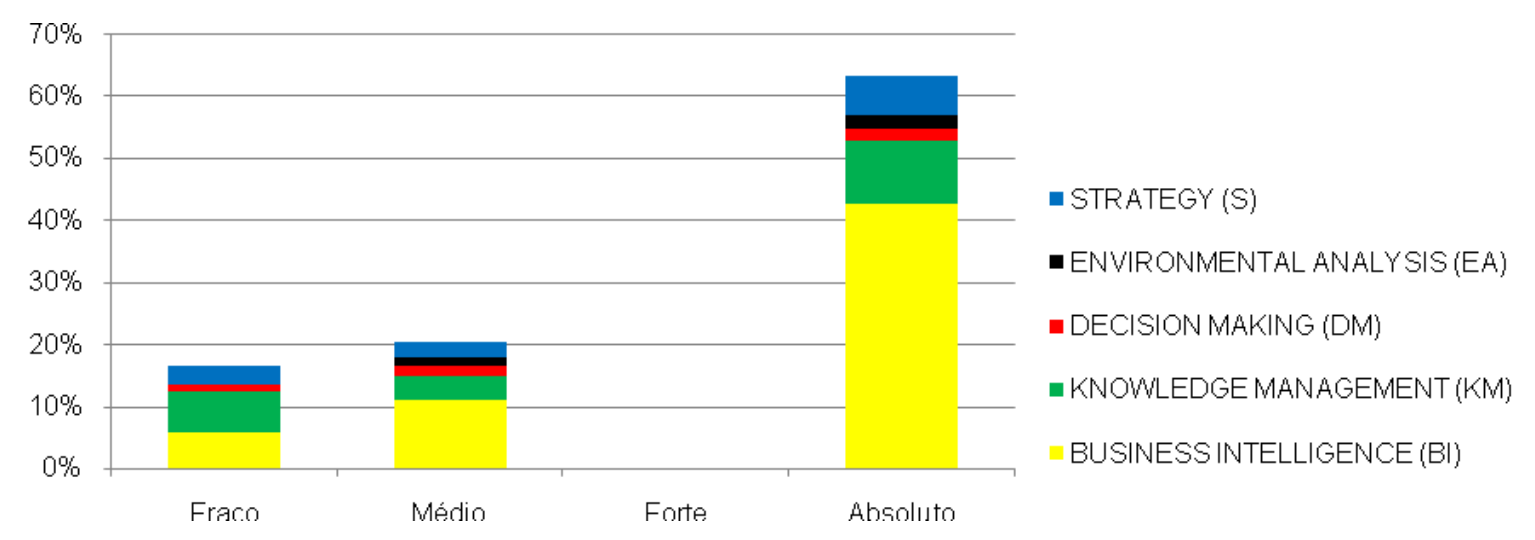

Figura 2.5 - Distribuição de relacionamentos dos campos de pesquisa

Fonte: elaborado pelo autor

Observa-se que os relacionamentos classificados como absoluto representam mais de $60 \%$ dos relacionamentos válidos para análise. Entretanto, pelo mesmo raciocínio construído anteriormente, estes relacionamentos não carregam informações relevantes à construção do modelo. Deste modo, a análise fica restrita aos relacionamentos fracos e médios, apresentados na Tabela 2.8. 
Tabela 2.8 - Relacionamentos por campo de pesquisa

\begin{tabular}{|c|c|c|c|c|c|c|}
\hline PUBLICAÇOES & PALAVRAS-CHAVE & $\mathrm{BI}$ & $\mathrm{KM}$ & DM & EA & $\mathrm{S}$ \\
\hline 47 & BUSINESS INTELLIGENCE & & $40 \%$ & $33 \%$ & & $40 \%$ \\
\hline 26 & COMPETITIVE INTELLIGENCE & $7 \%$ & $26 \%$ & $66 \%$ & $50 \%$ & $40 \%$ \\
\hline 19 & DATA MINING & $57 \%$ & $13 \%$ & & & $20 \%$ \\
\hline 15 & KNOWLEDGE MANAGEMENT & $40 \%$ & & & & $20 \%$ \\
\hline 12 & DATA WAREHOUSING & $66 \%$ & $8 \%$ & & & \\
\hline 10 & COMPETIIVE STRATEGY & $20 \%$ & & & & $20 \%$ \\
\hline 9 & OLAP & $44 \%$ & $11 \%$ & & & \\
\hline 7 & DATA WAREHOUSES & $42 \%$ & & & & \\
\hline 6 & CLASSIFICATION & $16 \%$ & & & & \\
\hline 6 & MARKETING INTELLIGENCE & $16 \%$ & & & & \\
\hline 6 & VISUALIZATION & $66 \%$ & & & & \\
\hline 5 & CATEGORIZATION & $60 \%$ & $20 \%$ & & & \\
\hline 5 & COMPETITIVE ADVANTAGE & $40 \%$ & $20 \%$ & & & \\
\hline 5 & INFORMATION-RETRIEVAL & $40 \%$ & $20 \%$ & & & \\
\hline 5 & RETRIEVAL & $40 \%$ & $20 \%$ & & & \\
\hline 5 & STRATEGY & $40 \%$ & $20 \%$ & $33 \%$ & & \\
\hline 4 & DATA ANALYSIS & $25 \%$ & $25 \%$ & & & \\
\hline 4 & INFORMATION SYSTEMS & $25 \%$ & & & & $25 \%$ \\
\hline 4 & INFORMATION TECHNOLOGY & $25 \%$ & & & & \\
\hline 4 & STRATEGIC MANAGEMENT & $25 \%$ & & & & \\
\hline 3 & DECISION & $66 \%$ & & & & \\
\hline 3 & DECISION MAKING & $33 \%$ & & & & $33 \%$ \\
\hline 3 & MACHINE LEARNING & $66 \%$ & & & & \\
\hline 3 & ORGANIZATIONAL PERFORMANCE & & & $33 \%$ & & \\
\hline 3 & TECHNOLOGY INTELLIGENCE & $66 \%$ & & & & \\
\hline 2 & ACTIVE LEARNING & $50 \%$ & & & & \\
\hline 2 & BROWSING & & $50 \%$ & & & \\
\hline 2 & COMPETITOR INTELLIGENCE & & & & & $50 \%$ \\
\hline 2 & DOCUMENT WAREHOUSING & & $50 \%$ & & & \\
\hline 2 & INFORMATION SOURCES & $50 \%$ & & & & \\
\hline 2 & INTELLIGENCE PROCESSES & & & $50 \%$ & & $50 \%$ \\
\hline 2 & LEARNING ORGANIZATION & & & & & $50 \%$ \\
\hline 2 & MARKET INTELLIGENCE & & $50 \%$ & $50 \%$ & & $50 \%$ \\
\hline 2 & NEURAL NETWORKS & & $50 \%$ & & & \\
\hline 2 & SPATIAL OLAP & $50 \%$ & & & & \\
\hline 2 & STRATEGIC INFORMATION SYSTEMS & $50 \%$ & & $50 \%$ & & \\
\hline 2 & STRATEGIC MARKETING & $50 \%$ & & & & \\
\hline 2 & SUMMARIZATION & $50 \%$ & & & & \\
\hline 2 & TECHNICAL INTELLIGENCE & & & $50 \%$ & & $50 \%$ \\
\hline 2 & TECHNOLOGY SCANNING & $50 \%$ & & $50 \%$ & & $50 \%$ \\
\hline 2 & WEB USAGE MINING & $50 \%$ & & & & \\
\hline
\end{tabular}

A partir destes relacionamentos, foi elaborado o mapa de co-palavras geral, conforme a Figura 2.7, na qual se observa todos os relacionamentos entre todas as palavras-chave listadas na tabela. 


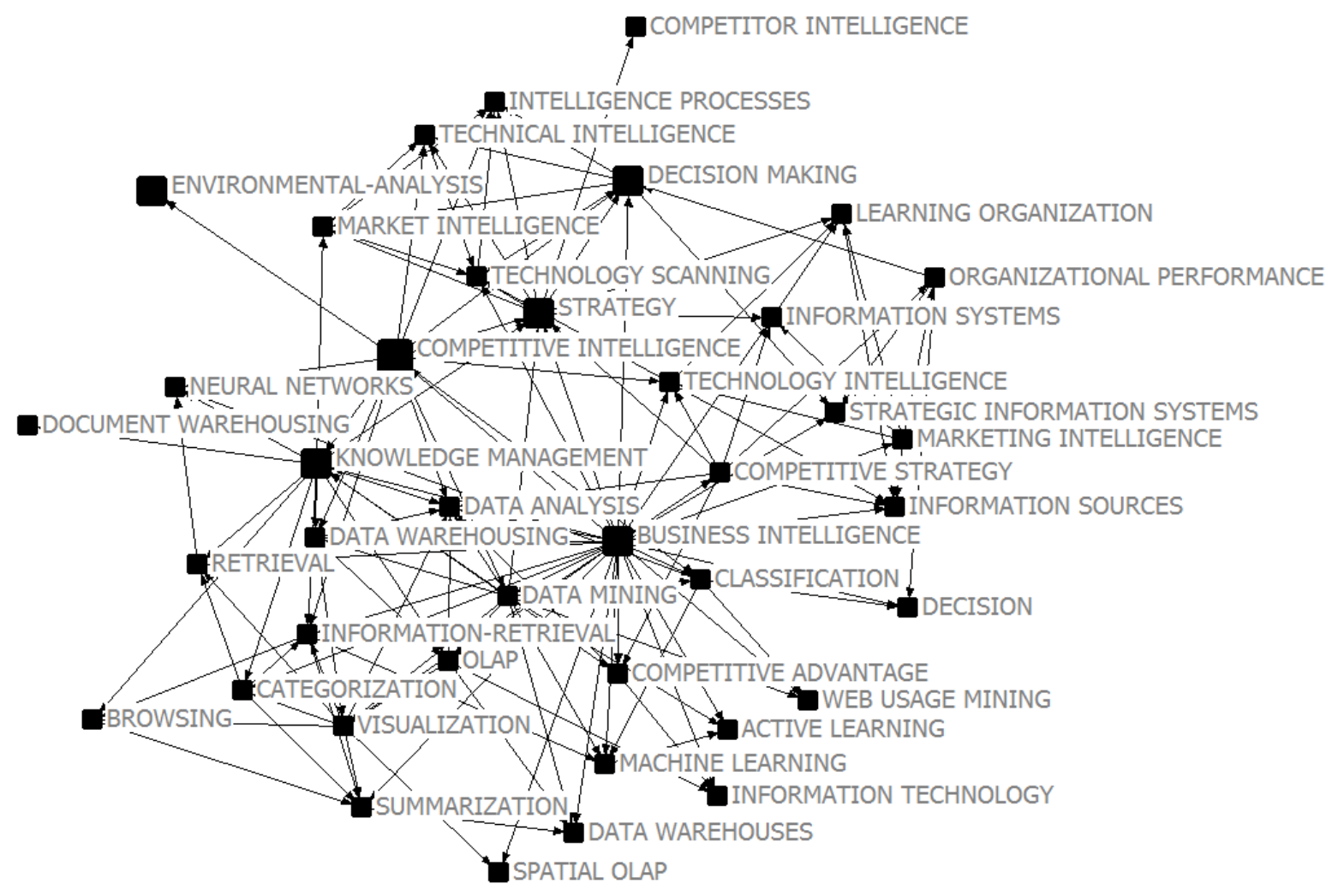

Figura 2.6 - Mapa de co-palavras

Fonte: elaborado pelo autor

A análise do mapa fornece alguns indícios sobre o relacionamento dos campos de pesquisa. Em primeiro lugar, destaca-se ENVIRONMENTAL-ANALYSIS como uma palavra-chave relacionada unicamente ao campo COMPETITIVE INTELLIGENCE, o que reforça sua classificação como sub-campo de pesquisa. Entretanto, os diversos relacionamentos que o campo de pesquisa DECISION MAKING possui apontam não para um sub-campo, mas uma interface. Por fim, a quantidade de relacionamentos dos demais campos de pesquisa reforça suas classificações como interface. Entretanto, a disposição do mapa não mostra claramente as interações entre os campos de pesquisa. Para facilitar a identificação destas interações na figura, foi utilizado o sistema de cores RGB, conforme a Tabela 2.9. É importante destacar que a quantidade de campos de pesquisa identificados não é compatível com a aplicação pura desta escala e, por possuir apenas três dimensões de cores, foi necessário incluir uma variável relacionada ao formato dos campos. 
Tabela 2.9 - Escala de cores

\begin{tabular}{|c|c|c|c|c|c|c|c|c|}
\hline \multicolumn{5}{|c|}{ Campos de Pesquisa } & \multicolumn{4}{|c|}{ Especificação de Cor e Forma } \\
\hline $\mathrm{Cl}$ & BI & KM & DM & $\mathbf{S}$ & Formato & Vermelho & Verde & Azul \\
\hline \multirow[t]{10}{*}{$\checkmark$} & $x$ & & & & [ & 0 & 0 & 0 \\
\hline & $\checkmark$ & & & & - & 0 & 0 & 0 \\
\hline & & $\checkmark$ & $x$ & $x$ & च & 0 & 255 & 0 \\
\hline & & $x$ & $\checkmark$ & $x$ & घ & 255 & 0 & 0 \\
\hline & & $x$ & $x$ & $x$ & घ & 0 & 0 & 0 \\
\hline & & $x$ & $x$ & $\checkmark$ & घ & 0 & 0 & 255 \\
\hline & & $\checkmark$ & $\checkmark$ & $x$ & $\square$ & 255 & 255 & 0 \\
\hline & & $\checkmark$ & $x$ & $\checkmark$ & [ & 255 & 0 & 255 \\
\hline & & $x$ & $\checkmark$ & $\checkmark$ & घ & 0 & 255 & 255 \\
\hline & & $\checkmark$ & $\checkmark$ & $\checkmark$ & & 255 & 255 & 255 \\
\hline
\end{tabular}

Fonte: elaborado pelo autor

Neste sentido, as palavras-chaves que se relacionam apenas com um campo de pesquisa foram identificadas pelo mesmo tom e aquelas que possuírem mais de um relacionamento com os campos de pesquisa serão coloridas por tons hỉbridos.

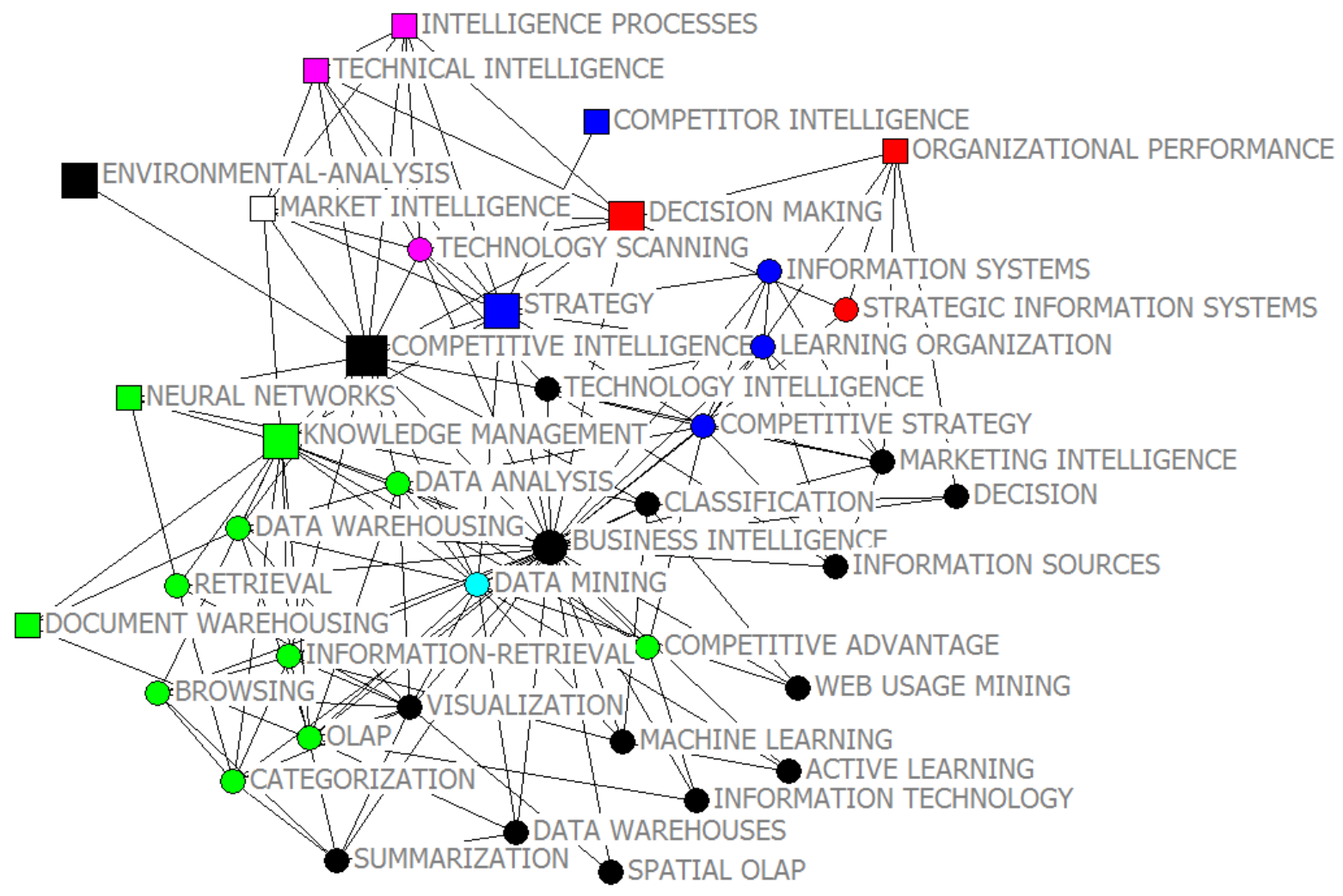

Figura 2.7 - Mapa de co-palavras

Fonte: elaborado pelo autor 


\subsubsection{Definição das Referências Bibliográficas}

Uma vez que os campos de pesquisa foram definidos, torna-se necessário conhecer suas principais publicações e referências bibliográficas. Para isso, os artigos foram catalogados e distribuídos nos campos de pesquisa identificados, conforme mostra a Tabela 2.10. Nesse sentido, cada campo de pesquisa apresenta dois conjuntos de publicações que compõem seu quadro de principais referências.

Por um lado, é importante conhecer as obras clássicas de cada tema, o que se pretende alcançar com a análise das referências bibliográficas mais citadas nos artigos que compõe um campo de pesquisa. Por outro lado, é importante conhecer os trabalhos que acrescentaram maiores contribuições ao desenvolvimento da teoria. Por este motivo, esta análise visa construir dois rankings de frequência de citações para cada campo de pesquisa, culminando com a elaboração do seu mapa de citações.

Tabela 2.10 - Catalogação dos artigos selecionados

\begin{tabular}{lccccccccc}
\hline Autores & Ano & Citações & Ri & Cl & BI & S & DM & EA KM \\
\hline Schultze e Boland & 2000 & 44 & 4,4 & 1 & 0 & 0 & 0 & 0 & 0 \\
Butterfield; Trevino e Weaver & 2000 & 42 & 4,2 & 1 & 0 & 0 & 0 & 0 & 0 \\
Chung; Chen e Nunamaker Junior & 2005 & 20 & 4,0 & 0 & 1 & 0 & 0 & 0 & 0 \\
Ong et al. & 2005 & 19 & 3,8 & 0 & 0 & 0 & 0 & 0 & 1 \\
Chen; Chau e Zeng & 2002 & 25 & 3,1 & 1 & 0 & 0 & 0 & 0 & 0 \\
Teoe Choo & 2001 & 23 & 2,6 & 1 & 0 & 0 & 0 & 0 & 0 \\
Kohavi, et al. & 2004 & 14 & 2,3 & 0 & 1 & 0 & 0 & 0 & 0 \\
March e Hevner & 2007 & 6 & 2,0 & 0 & 1 & 0 & 0 & 0 & 0 \\
Lee, et al. & 2001 & 17 & 1,9 & 0 & 1 & 0 & 0 & 0 & 0 \\
Fan; Gordon e Pathak & 2005 & 8 & 1,6 & 0 & 1 & 0 & 0 & 0 & 0 \\
Heinrichs e Lim & 2003 & 11 & 1,6 & 0 & 1 & 0 & 0 & 0 & 1 \\
Prinzie e Van den Poel & 2006 & 6 & 1,5 & 0 & 1 & 0 & 0 & 0 & 0 \\
Du Toit & 2003 & 1 & 1,5 & 1 & 0 & 0 & 0 & 0 & 0 \\
Lichtenthaler & 2005 & 7 & 1,4 & 1 & 1 & 0 & 0 & 0 & 0 \\
Berler; Pavlopoulos e Koutsouris & 2005 & 7 & 1,4 & 0 & 1 & 0 & 0 & 0 & 0 \\
Van den Poel e Buckinx & 2005 & 7 & 1,4 & 0 & 1 & 0 & 0 & 0 & 0 \\
Xu e Wang & 2002 & 11 & 1,4 & 0 & 1 & 0 & 0 & 0 & 0 \\
Mortara, et al. & 2009 & 1 & 1,0 & 1 & 0 & 1 & 1 & 0 & 0 \\
Shi, et al. & 2007 & 3 & 1,0 & 0 & 1 & 0 & 0 & 0 & 0 \\
Gregg e Walczak & 2007 & 3 & 1,0 & 0 & 1 & 0 & 0 & 0 & 0 \\
Araya; Silva e Weber & 2004 & 6 & 1,0 & 0 & 1 & 0 & 0 & 0 & 0 \\
Raol, et al. & 2002 & 7 & 0,9 & 0 & 0 & 0 & 0 & 0 & 1 \\
Chung, et al. & 2006 & 3 & 0,8 & 0 & 1 & 0 & 0 & 0 & 0 \\
Rouibah e Ould-ali & 2002 & 6 & 0,8 & 0 & 1 & 0 & 0 & 0 & 0 \\
Powell e Bradford & 2000 & 6 & 0,6 & 0 & 0 & 1 & 0 & 0 & 0 \\
Dishman e Calof & 2008 & 1 & 0,5 & 0 & 1 & 0 & 1 & 0 & 0 \\
Wang e Wang & 2008 & 1 & 0,5 & 0 & 1 & 0 & 0 & 0 & 1 \\
Li; Shue e Lee & 2008 & 1 & 0,5 & 0 & 1 & 0 & 0 & 0 & 0 \\
Jourclan; Rainer, RK e Marshall & 2008 & 1 & 0,5 & 1 & 1 & 0 & 0 & 0 & 0 \\
Baars e Kemper & 2008 & 1 & 0,5 & 0 & 1 & 0 & 0 & 0 & 0 \\
Chung, et al. & 2008 & 1 & 0,5 & 0 & 1 & 0 & 0 & 0 & 1 \\
Hart e Porter & 2004 & 3 & 0,5 & 0 & 1 & 0 & 0 & 0 & 0
\end{tabular}


Tabela 2.10 - Catalogação dos artigos selecionados (continuação)

\begin{tabular}{|c|c|c|c|c|c|c|c|c|c|}
\hline Autores & Ano & Citações & $\mathbf{R i}$ & $\mathrm{Cl}$ & $\mathbf{B I}$ & $\mathrm{S}$ & DM & $\overline{E A}$ & $\mathrm{KM}$ \\
\hline Marin e Poulter & 2004 & 3 & 0,5 & 1 & 0 & 0 & 0 & 0 & 1 \\
\hline Pawar e Sharda & 1997 & 7 & 0,5 & 1 & 0 & 0 & 0 & 0 & 0 \\
\hline$X u$, et al. & 2005 & 2 & 0,4 & 0 & 1 & 0 & 0 & 0 & 0 \\
\hline Gibbons e Prescott & 1996 & 6 & 0,4 & 1 & 0 & 0 & 0 & 0 & 0 \\
\hline Yeung, et al. & 2007 & 1 & 0,3 & 0 & 1 & 0 & 0 & 0 & \\
\hline Tseng e Chou & 2006 & 1 & 0,3 & 0 & 0 & 0 & 0 & 0 & 1 \\
\hline Du Plessis e Du Toit & 2006 & 1 & 0,3 & 0 & 0 & 0 & 0 & 0 & 1 \\
\hline Chamoni e Gluchowski & 2004 & 2 & 0,3 & 0 & 1 & 0 & 0 & 0 & 0 \\
\hline Dishman e Pearson & 2003 & 2 & 0,3 & 1 & 0 & 0 & 0 & 0 & 1 \\
\hline Canongia; Antunes e Pereira & 2004 & 1 & 0,2 & 1 & 0 & 0 & 0 & 0 & 0 \\
\hline Yuan e Huang & 2001 & 2 & 0,2 & 1 & 0 & 0 & 0 & 0 & 0 \\
\hline McHugh; Roche e Bedard & 2009 & 0 & 0,0 & 0 & 1 & 0 & 0 & 0 & 0 \\
\hline Salmeron & 2009 & 0 & 0,0 & 0 & 1 & 0 & 0 & 0 & 0 \\
\hline Liu e Wang & 2009 & 0 & 0,0 & 0 & 0 & 0 & 0 & 0 & 1 \\
\hline Saar-Tsechansky; Melville e Provost & 2009 & 0 & 0,0 & 0 & 1 & 0 & 0 & 0 & 0 \\
\hline Erickson e Rothberg & 2009 & 0 & 0,0 & 1 & 0 & 1 & 0 & 0 & 1 \\
\hline Zangoueinezhad e Moshabaki & 2009 & 0 & 0,0 & 0 & 1 & 0 & 0 & 0 & 0 \\
\hline Ratiu-Suciu & 2009 & 0 & 0,0 & 0 & 1 & 0 & 0 & 0 & 0 \\
\hline $\mathrm{Nie}$, et al. & 2009 & 0 & 0,0 & 0 & 1 & 0 & 0 & 0 & 0 \\
\hline Winter; Gericke e Bucher & 2008 & 0 & 0,0 & 0 & 1 & 0 & 0 & 0 & 0 \\
\hline Chung; Chen e Reid & 2009 & 0 & 0,0 & 1 & 0 & 0 & 0 & 0 & 0 \\
\hline Cheng; Lu e Sheu & 2009 & 0 & 0,0 & 0 & 1 & 0 & 0 & 0 & 1 \\
\hline Lin, et al. & 2009 & 0 & 0,0 & 0 & 1 & 0 & 0 & 0 & \\
\hline Lesca e Caron-Fasan & 2008 & 0 & 0,0 & 1 & 0 & 0 & 0 & 1 & 0 \\
\hline Saayman, et al. & 2008 & 0 & 0,0 & 0 & 1 & 1 & 0 & 0 & 0 \\
\hline Bhatti; Gao e Li & 2008 & 0 & 0,0 & 0 & 1 & 0 & 0 & 0 & 0 \\
\hline Lungu, et al. & 2008 & 0 & 0,0 & 0 & 1 & 0 & 0 & 0 & 0 \\
\hline Muresan & 2008 & 0 & 0,0 & 0 & 1 & 0 & 0 & 0 & 1 \\
\hline Wixom, et al. & 2008 & 0 & 0,0 & 0 & 1 & 0 & 0 & 0 & 0 \\
\hline Nagy, et al. & 2008 & 0 & 0,0 & 0 & 1 & 0 & 0 & 0 & 0 \\
\hline Roussinov e Chau & 2008 & 0 & 0,0 & 0 & 1 & 0 & 0 & 0 & 0 \\
\hline Comai; Tena e Vergara & 2006 & 0 & 0,0 & 1 & 0 & 0 & 0 & 0 & 0 \\
\hline Smith & 2006 & 0 & 0,0 & 1 & 0 & 0 & 0 & 0 & 0 \\
\hline Wintere Gericke & 2006 & 0 & 0,0 & 0 & 1 & 0 & 0 & 0 & 0 \\
\hline Junqua, et al. & 2006 & 0 & 0,0 & 1 & 0 & 0 & 0 & 0 & 0 \\
\hline Benczur & 2005 & 0 & 0,0 & 0 & 1 & 0 & 0 & 0 & 0 \\
\hline Ifan, et al. & 2004 & 0 & 0,0 & 1 & 0 & 0 & 0 & 0 & 0 \\
\hline Abbott & 2004 & 0 & 0,0 & 1 & 0 & 0 & 0 & 0 & 1 \\
\hline Persidis & 1999 & 0 & 0,0 & 1 & 0 & 0 & 0 & 0 & 0 \\
\hline Günter & 1999 & 0 & 0,0 & 1 & 0 & 0 & 0 & 0 & 0 \\
\hline Christensen e Bailey & 1998 & 0 & 0,0 & 0 & 0 & 0 & 1 & 0 & 0 \\
\hline Hannon & 1997 & 0 & 0,0 & 0 & 0 & 0 & 0 & 1 & 0 \\
\hline TOTAL & & & & 24 & 44 & 4 & 3 & 2 & $\overline{14}$ \\
\hline
\end{tabular}

Fonte: elaborado pelo autor

A tabela de catalogação dos artigos apresenta também sua classificação em relação ao indicador $\mathrm{R}$, uma forma de avaliar o grau de relevância de cada publicação. Atente-se que existem alguns artigos com indicador elevado, como Schultze e Boland, (2000), com 4,4, por exemplo. Isto significa que este artigo foi citado, em média, mais de 4 vezes por ano, ou seja, possui um grau de relevância alto. 
Além disso, a tabela avalia o relacionamento de cada artigo com os campos de pesquisa, através de variáveis binárias. Utilizando o mesmo exemplo, Schultze e Boland, (2000) possui 1 para o campo de pesquisa COMPETITIVE INTELLIGENCE e 0 para os demais campos. Isso significa que este artigo está relacionado somente a este campo de pesquisa. Através deste método, os artigos selecionados foram distribuídos e relacionados aos campos de pesquisa do modelo.

É importante destacar que todas estas publicações se referem de algum modo ao conceito de inteligência competitiva, pois atendem aos critérios de seleção prédefinidos. Nesta perspectiva, a maior frequência de publicações relacionadas a business intelligence e gestão do conhecimento indica que estes campos já possuem algum desenvolvimento conceitual que os relacionem à inteligência competitiva. Entretanto, a pouca incidência de artigos relacionados à estratégia, decisão e monitoramento ambiental demonstram uma lacuna conceitual.

Além disso, a partir desta distribuição foram identificadas as referências relevantes para a pesquisa. As referências foram classificadas em função da quantidade de citações recebidas pelo conjunto das publicações selecionadas na Tabela 2.10, resultando na identificação de 2568 obras. Entretanto, considerando a Lei de Lokta e as premissas identificadas por Rosseau (1998), pode-se reduzir o número de referências relevantes assumindo que poucos autores são responsáveis por grande parte do conhecimento produzido e que as citações recebidas pelas publicações representam seu impacto. Assim, para fundamentar a seleção das referências a serem utilizadas na análise qualitativa, é apresentada a Figura 2.8 na qual se verifica a frequência de citações recebidas por uma referência.

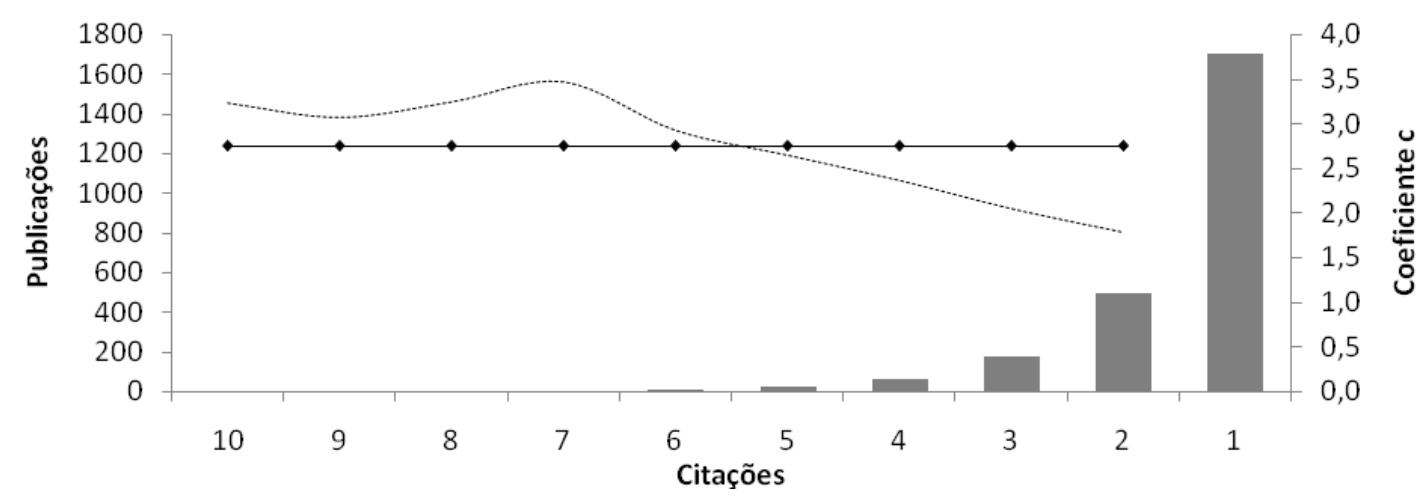

Figura 2.8 - Lei de Lokta aplicada

Fonte: elaborado pelo autor 
Nesta figura, observa-se primeiramente que as citações se aproximam de um padrão exponencial, conforme constatações empíricas da Lei de Lokta. A linha tracejada calcula o parâmetro $c$ da Equação 2.2 para cada quantidade de citações e, para valores superiores a 4, demonstra a proximidade da Lei de Lokta, adotando o coeficiente c de 2,7 (linha contínua). Desta forma, admite-se que grande parte do conhecimento desenvolvido é encontrado nas publicações que receberão 5 ou mais citações nesta amostra, o que representa $1,6 \%$ do total de referências identificadas. Portanto, as referências apresentadas na Tabela 2.11 foram selecionadas para a análise qualitativa e construção do referencial teórico do modelo conceitual.

Tabela 2.11 - Catalogação das referências bibliográficas selecionadas

\begin{tabular}{|c|c|c|c|c|c|c|c|c|}
\hline CITAÇOES & AUTORES & ANO & CI & BI & KM & DM & S & EA \\
\hline 10 & AGUILAR FJ & 1967 & $16,0 \%$ & $8,9 \%$ & $0,0 \%$ & $33,3 \%$ & $0,0 \%$ & $50,0 \%$ \\
\hline 9 & KAHANER L & 1996 & $8,0 \%$ & $4,4 \%$ & $0,0 \%$ & $66,7 \%$ & $50,0 \%$ & $50,0 \%$ \\
\hline 9 & DAFT RL & 1988 & $16,0 \%$ & $8,9 \%$ & $0,0 \%$ & $33,3 \%$ & $0,0 \%$ & $0,0 \%$ \\
\hline 8 & PORTER ME & 1980 & $12,0 \%$ & $6,7 \%$ & $0,0 \%$ & $33,3 \%$ & $25,0 \%$ & $0,0 \%$ \\
\hline 8 & BROCKHOFF K & 1991 & $8,0 \%$ & $6,7 \%$ & $0,0 \%$ & $66,7 \%$ & $25,0 \%$ & $0,0 \%$ \\
\hline 7 & SINKULA JM & 1994 & $4,0 \%$ & $4,4 \%$ & $7,1 \%$ & $33,3 \%$ & $50,0 \%$ & $0,0 \%$ \\
\hline 7 & GHOSHAL S & 1986 & $4,0 \%$ & $4,4 \%$ & $0,0 \%$ & $33,3 \%$ & $25,0 \%$ & $100,0 \%$ \\
\hline 6 & MONTGOMERY DB & 1979 & $4,0 \%$ & $4,4 \%$ & $0,0 \%$ & $33,3 \%$ & $25,0 \%$ & $50,0 \%$ \\
\hline 6 & LENZ RT & 1986 & $4,0 \%$ & $4,4 \%$ & $0,0 \%$ & $33,3 \%$ & $25,0 \%$ & $50,0 \%$ \\
\hline 6 & GHOSHAL S & 1991 & $12,0 \%$ & $2,2 \%$ & $0,0 \%$ & $0,0 \%$ & $0,0 \%$ & $100,0 \%$ \\
\hline 6 & BONTIS N & 1999 & $8,0 \%$ & $0,0 \%$ & $7,1 \%$ & $33,3 \%$ & $50,0 \%$ & $0,0 \%$ \\
\hline 6 & GRABOWSKI D & 1987 & $4.0 \%$ & $4.4 \%$ & $7.1 \%$ & $33,3 \%$ & $25.0 \%$ & $0.0 \%$ \\
\hline 6 & EISENHARDT KM & 1989 & $12,0 \%$ & $2,2 \%$ & $0,0 \%$ & $33,3 \%$ & $25,0 \%$ & $0,0 \%$ \\
\hline 6 & NONAKA I & 1995 & $4,0 \%$ & $2,2 \%$ & $21,4 \%$ & $0,0 \%$ & $25,0 \%$ & $0,0 \%$ \\
\hline 6 & KIMBALL R & 1996 & $0,0 \%$ & $11,1 \%$ & $7,1 \%$ & $0,0 \%$ & $0,0 \%$ & $0,0 \%$ \\
\hline 6 & SLATER SF & 1994 & $4,0 \%$ & $4,4 \%$ & $7,1 \%$ & $33,3 \%$ & $0,0 \%$ & $0,0 \%$ \\
\hline 5 & PRESCOTT JE & 1987 & $8,0 \%$ & $2,2 \%$ & $0,0 \%$ & $33,3 \%$ & $0,0 \%$ & $50,0 \%$ \\
\hline 5 & HAMBRICK DC & 1982 & $8,0 \%$ & $2,2 \%$ & $0,0 \%$ & $33,3 \%$ & $0,0 \%$ & $50,0 \%$ \\
\hline 5 & HUBER GP & 1990 & $4,0 \%$ & $4,4 \%$ & $0,0 \%$ & $66,7 \%$ & $0,0 \%$ & $0,0 \%$ \\
\hline 5 & REGER G & 2001 & $8,0 \%$ & $2,2 \%$ & $0,0 \%$ & $33,3 \%$ & $25,0 \%$ & $0,0 \%$ \\
\hline 5 & ASHTON WB & 1991 & $8,0 \%$ & $2,2 \%$ & $0,0 \%$ & $33,3 \%$ & $25,0 \%$ & $0,0 \%$ \\
\hline 5 & LICHTENTHALER E & 2003 & $8,0 \%$ & $2,2 \%$ & $0,0 \%$ & $33,3 \%$ & $25,0 \%$ & $0,0 \%$ \\
\hline 5 & LICHTENTHALER E & 2004 & $8,0 \%$ & $2,2 \%$ & $0,0 \%$ & $33,3 \%$ & $25,0 \%$ & $0,0 \%$ \\
\hline 5 & FULD LM & 1995 & $8,0 \%$ & $2,2 \%$ & $0,0 \%$ & $33,3 \%$ & $25,0 \%$ & $0,0 \%$ \\
\hline 5 & CLELAND DI & 1975 & $4,0 \%$ & $4,4 \%$ & $0,0 \%$ & $33,3 \%$ & $25,0 \%$ & $0,0 \%$ \\
\hline 5 & GILAD T & 1986 & $0,0 \%$ & $6,7 \%$ & $0,0 \%$ & $33,3 \%$ & $25,0 \%$ & $0,0 \%$ \\
\hline 5 & ANSOFF HI & 1975 & $8,0 \%$ & $4,4 \%$ & $0,0 \%$ & $0,0 \%$ & $0,0 \%$ & $50,0 \%$ \\
\hline 5 & GRAHAM C & 2005 & $4,0 \%$ & $6,7 \%$ & $0,0 \%$ & $0,0 \%$ & $0,0 \%$ & $50,0 \%$ \\
\hline 5 & WALLE AH & 1999 & $8,0 \%$ & $2,2 \%$ & $7,1 \%$ & $33,3 \%$ & $0,0 \%$ & $0,0 \%$ \\
\hline 5 & PEDHAZUR EJ & 1991 & $4,0 \%$ & $2,2 \%$ & $14,3 \%$ & $0,0 \%$ & $25,0 \%$ & $0,0 \%$ \\
\hline 5 & DEGEUS AP & 1988 & $8,0 \%$ & $2,2 \%$ & $7,1 \%$ & $0,0 \%$ & $25,0 \%$ & $0,0 \%$ \\
\hline 5 & CHUNGW & 2005 & $4,0 \%$ & $6,7 \%$ & $7,1 \%$ & $0,0 \%$ & $0,0 \%$ & $0,0 \%$ \\
\hline 5 & GARVIN DA & 1993 & $0,0 \%$ & $4,4 \%$ & $0,0 \%$ & $33,3 \%$ & $25,0 \%$ & $50,0 \%$ \\
\hline 5 & GILAD B & 1989 & $4,0 \%$ & $4,4 \%$ & $0,0 \%$ & $33,3 \%$ & $25,0 \%$ & $0,0 \%$ \\
\hline 5 & SAWKA KA & 1995 & $0,0 \%$ & $6,7 \%$ & $0,0 \%$ & $33,3 \%$ & $25,0 \%$ & $0,0 \%$ \\
\hline 5 & FAYYAD U & 1996 & $4,0 \%$ & $4,4 \%$ & $14,3 \%$ & $0,0 \%$ & $0,0 \%$ & $0,0 \%$ \\
\hline 5 & $\mathrm{CHOO} \mathrm{CW}$ & 1997 & $8,0 \%$ & $0,0 \%$ & $0,0 \%$ & $33,3 \%$ & $0,0 \%$ & $50,0 \%$ \\
\hline 5 & PORTER ME & 1985 & $4,0 \%$ & $6,7 \%$ & $0,0 \%$ & $33,3 \%$ & $0,0 \%$ & $0,0 \%$ \\
\hline 5 & YIN RK & 1989 & $8,0 \%$ & $2,2 \%$ & $0,0 \%$ & $33,3 \%$ & $0,0 \%$ & $0,0 \%$ \\
\hline 5 & CHEN HC & 1997 & $4,0 \%$ & $6,7 \%$ & $7,1 \%$ & $0,0 \%$ & $0,0 \%$ & $0,0 \%$ \\
\hline
\end{tabular}

Fonte: elaborado pelo autor 


\subsection{Considerações Iniciais}

Em relação ao desenvolvimento de um modelo conceitual sobre IC, é importante destacar que teoria pode ser definida por "um conjunto de constructos (variáveis) inter-relacionados, definições e proposições que apresentam uma visão sistemática de fenômenos especificando relações entre variáveis com o propósito de explicar fenômenos naturais" (KERLINGER, 1974, p. 64), ou seja, são "explicações de como as coisas funcionam ou por que os eventos acontecem" (BLACK, 1993, p. 25). Sendo assim, a partir da nova composição da figura, aponta-se a existência de aglomerações de palavras-chave em função das cores. Portanto, considerando estes grupos e os conceitos a eles relacionados, pode ser construído um conjunto preliminar de proposições para a construção de uma teoria sobre inteligência competitiva.

Primeiramente, observando as palavras-chave relacionadas ao campo de pesquisa KNOWLEDGE MANAGEMENT, destaca-se sua forte interação com o campo BUSINESS INTELLIGENCE, em mais de $70 \%$ das palavras-chave. Além disso, notase que muitos dos seus sub-campos de pesquisa remetem aos objetivos identificados para a utilização das aplicações de $\mathrm{Tl}$, o que permite construir a proposição: a gestão do conhecimento representa o campo de pesquisa que se preocupa com a gestão da inteligência obtida ao longo dos processos de inteligência competitiva.

Além disso, a análise do campo de pesquisa DECISION MAKING indica a existência de duas frentes. A primeira, relacionada ao campo STRATEGY, preocupa-se com os processos de decisão estratégica enquanto a segunda se pauta no desempenho organizacional. Desta forma, é possível construir a proposição: a inteligência competitiva tem foco na melhoria dos processos de decisão estratégica.

Entretanto, no âmbito do campo de pesquisa STRATEGY, observam-se dois subcampos. Por um lado, a palavra-chave COMPETITOR INTELLIGENCE remete à necessidade de compreensão da competição dos mercados. Por outro lado, LEARNING ORGANIZATION associado à COMPETITIVE STRATEGY, remonta às organizações que aprendem com o desenvolvimento de estratégias competitivas e, portanto, permite construir a proposição: a inteligência competitiva desenvolve estratégias competitivas através do processo de aprendizagem organizacional. 
Adicionalmente, o mapa de co-palavras não destaca nenhum relacionamento para ENVIRONMENTAL ANALYSIS. Desta forma, pode-se construir a proposição: 0 monitoramento ambiental é um processo da inteligência competitiva.

Por fim, percebe-se que todos os campos de pesquisa possuem relacionamentos com o campo BUSINESS INTELLIGENCE através de palavras-chave que remetem ao uso de tecnologias de suporte aos processos de gestão de dados, do qual se extrai a seguinte proposição: business intelligence representa o campo de pesquisa que promove soluções de $\mathrm{TI}$ aos processos de inteligência competitiva. Nesse sentido, pode-se inferir que alguns dos objetivos da utilização de tecnologias de $\mathrm{BI}$ em relação à gestão de dados são: classificação (CLASSIFICATION), categorização (CATEGORIZATION), armazenamento (DATA WAREHOUSE), recuperação (RETRIEVAL), processamento (OLAP), exploração (BROWSING), mineração (DATA MINING), análise (DATA ANALYSIS), sumarização (SUMMARIZATION), visualização (VISUALIZATION) e aprendizagem (ACTIVE LEARNING).

Em suma, o conjunto de proposições construído pode ser utilizado para refinar o modelo inicialmente apresentado, conforme a Figura 2.4.

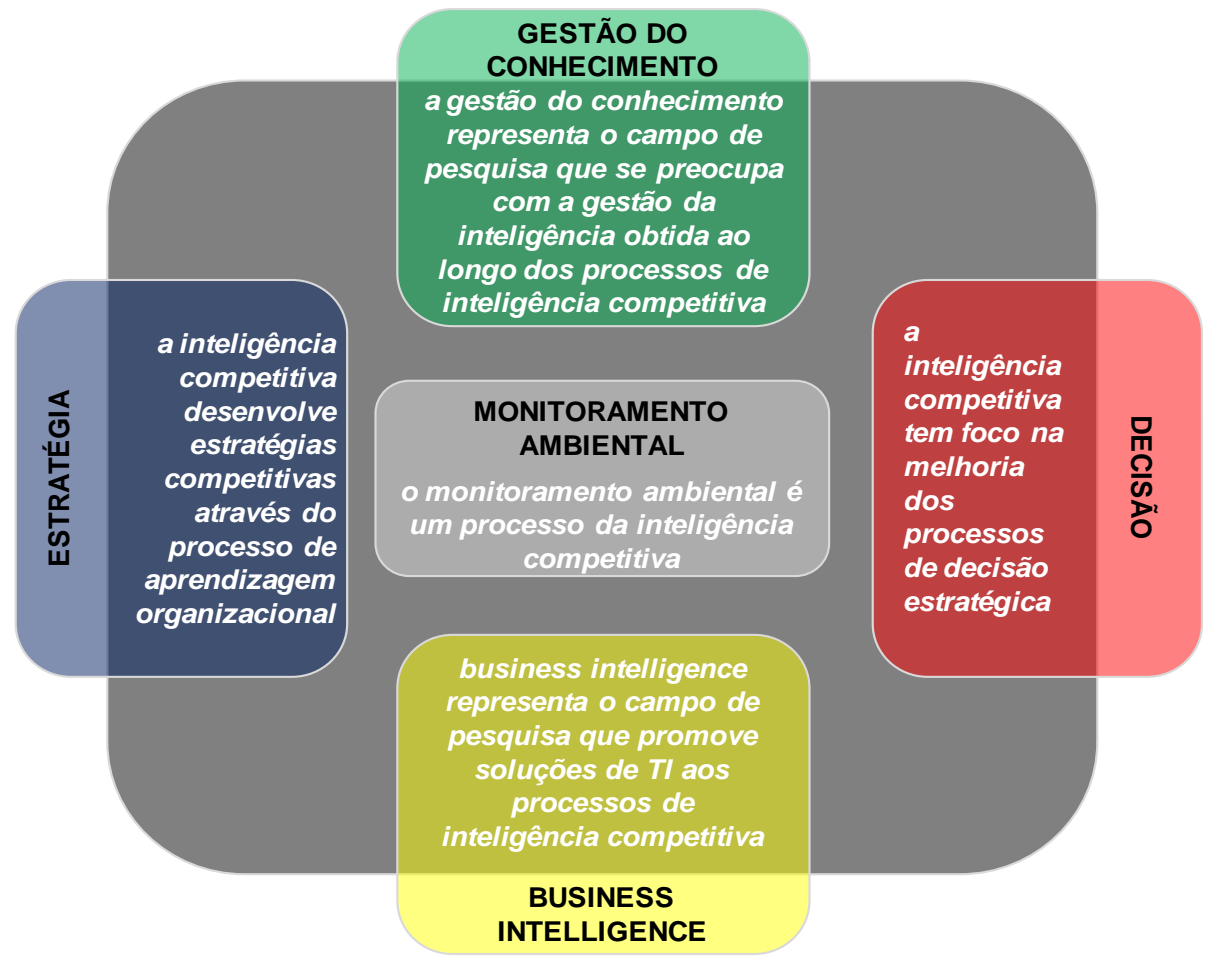

Figura 2.9 - Modelo de IC em segunda versão

Fonte: elaborado pelo autor 


\section{REVISÃO DA LITERATURA}

As recentes mudanças do contexto tecnológico provocaram o aumento da competição global, através da participação de novos e mais agressivos competidores em escala mundial (ZANGOUEINEZHAD; MOSHABAKI, 2009). Como efeito do aumento da competição e do dinamismo dos mercados, pode-se considerar que a necessidade de inovar continuamente é um dos grandes objetivos das organizações (LIU; WANG, 2009).

O aumento da disponibilidade de informações, simbolizado pela proliferação das bases de dados comerciais acessíveis pela internet, permitiu o refinamento dos modelos de decisão (ZANGOUEINEZHAD; MOSHABAKI, 2009). Consequentemente, o conhecimento passou a ser seu recurso mais relevante e a aprendizagem organizacional o processo fundamental das organizações (LIU; WANG, 2009). Nesse sentido, Erickson e Rothberg (2009) discutem a importância de uma gestão ótima dos conhecimentos organizacionais, ou ativos do conhecimento, baseado em:

- As melhores práticas de identificação e utilização dos ativos de conhecimento permitem a criação de vantagens competitivas à organização;

- A gestão ótima de ativos do conhecimento pode ser aplicada de modo semelhante para todos os tipos de organizações em qualquer situação; e

As indústrias com melhor gestão dos seus ativos de conhecimento são melhores. Desta forma, somente ter a informação certa deixou de ser suficiente para uma boa decisão estratégica; é necessário transformá-las em conhecimento aplicável a estratégia organizacional (KAHANER, 1996). Nesse sentido, o autor afirma que uma organização pode optar por quatro modos de obter informações para a tomada de decisão:

- By-product technique: os executivos recebem relatórios de diferentes departamentos, entretanto é produzida informação em excesso;

- Null approach: os executivos avaliam as opiniões relacionadas a um assunto determinado, mas demanda muito tempo para a decisão; 
- Key indicator system: os executivos recebem relatórios com o desempenho de alguns indicadores fundamentais para a sobrevivência da organização, contudo a superficialidade dos dados inviabiliza a tomada de decisão; ou

- Total study process: os executivos solicitam informações que necessitam para a tomada de decisão, no entanto estas demandas podem se alterar ao longo do tempo.

Focadas em competitividade, as organizações coletam informações sobre seu ambiente, visando antecipar oportunidades e ameaças. Na prática, frequentemente se descobre que uma oportunidade foi perdida ou uma ameaça poderia ter sido evitada. De qualquer forma, as duas situações são consideradas surpresas estratégicas (ANSOFF, 1975).

Por este motivo, ao longo das últimas décadas, a IC deixou de ser considerada apenas uma área de interesse para se transformar em uma disciplina internacionalmente reconhecida (TEO; $\mathrm{CHOO}, 2001$ ). O estudo de Jourdan; Rainer e Marshall (2008) indicam que a IC tem se tornado mais importante tanto para seus pesquisadores como para seus praticantes.

\subsection{Inteligência Competitiva}

A literatura em IC (competitive intelligence) indica que ainda hoje existem diferentes percepções sobre o seu conceito, pois a inteligência tem dupla conotação: posse e criação de conhecimento. Se, por um lado, a criação de conhecimento é um processo no qual se trabalha um conjunto de dados e informações brutos para que se possa agregar valor, ou conhecimento, por outro lado, a posse de conhecimento representa uma função cognitiva da organização na qual é possível acessar o conhecimento com diferentes finalidades (JOURDAN; REINER; MARSHALL, 2008).

Decorrem desta ambiguidade as diferentes percepções sobre o conceito de IC, pois ela pode ser entendida como um processo organizacional que coleta sinais de mercado no ambiente competitivo para que entregue o conhecimento a determinado grupo de decisão (LESCA; CARON-FASAN, 2008) ou uma função organizacional na qual se é possível acessar o conhecimento organizacional (DU TOT, 2003). Seja uma função organizacional ou um processo, qualquer programa de IC está relacionado ao desenvolvimento das capacidades organizacionais específicas de 
captura e análise de dados ou informações e disseminação de conhecimento aplicável ao negócio (ERICKSON; ROTHBERG, 2009).

De modo amplo, essas capacidades organizacionais necessárias ao desenvolvimento dos programas de IC estão relacionadas ao ciclo de inteligência. Apesar de existirem variações na literatura, as atividades relacionadas a este ciclo são: planejamento do ciclo, coleta de dados e informações relevantes, análise do material coletado e disseminação da inteligência adquirida (KAHANER, 1996). O trabalho de Schultze e Boland Junior (2000) na avaliação das atividades dos profissionais de IC mostra que, na prática, este ciclo de quatro etapas representa suas atividades. Contudo, na literatura, é possível destacar as seguintes variações:

- Mortara et al. (2008) apresentam o ciclo como um processo iterativo composto pelas atividades de coordenação, pesquisa, filtragem, análise, documentação e disseminação da informação;

- Erickson e Rothberg (2009) discutem que o ciclo deve conter as atividades de coleta, armazenamento e distribuição de conhecimento codificado;

- Du Toit (2003) argumenta que o ciclo como um processo combinado de IC e gestão do conhecimento. Enquanto este representa a captura, arquivamento e categorização das informações, aquele é composto por análise e utilização destas informações;

- Yuan e Huang (2001), admitindo que os dados brutos estejam disponíveis, mostram o ciclo, no que se refere à análise, como mineração dos dados, ou seja, pré-processamento, segmentação e extração de significado;

- Chen; Chau e Zeng (2002) oferecem a sequência do ciclo formada por identificação das variáveis a serem monitoradas, identificação de fontes de informação, validação da confiabilidade e aplicabilidade, recolhimento das informações, interpretação, análise, criação de sentido, recomendação e disseminação; e

- Chung; Chen e Reid (2009) debatem que o ciclo requer aquisição, coleta, classificação, catalogação, análise, interpretação e exploração das informações. 
Considerando as etapas do ciclo de inteligência, a Tabela 3.1 consolida todas as atividades propostas na literatura para o processo de IC.

Tabela 3.1 - Atividades da Inteligência Competitiva

\begin{tabular}{|c|c|c|c|}
\hline PLANEJAMENTO & COLETA & ANÁLISE & DISSEMINAÇĀO \\
\hline $\begin{array}{l}\text { Identificação de } \\
\text { variáveis } \\
\text { Identificação de fontes } \\
\text { de informação }\end{array}$ & $\begin{array}{l}\text { Captura } \\
\text { Validação } \\
\text { Catalogação } \\
\text { Classificação } \\
\text { Armazenamento }\end{array}$ & $\begin{array}{l}\text { Processamento } \\
\text { Mineração } \\
\text { Interpretação }\end{array}$ & $\begin{array}{l}\text { Seleção de } \\
\text { destinatários } \\
\text { Distribuição }\end{array}$ \\
\hline
\end{tabular}

Fonte: elaborado pelo autor

Além dos conceitos de atividade de IC, Choo (2001) inicia a discussão sobre o valor adicionado por produtos e serviços de informação que, em última instância, podem ser relacionados a estes programas. Nesse sentido, são identificadas mais de vinte possíveis atividades que podem adicionar valor às informações trabalhadas, as quais são divididas em seis categorias (TAYLOR, 1986 apud CHOO, 2001).

- Facilidade de uso: redução da dificuldade na utilização de produtos e serviços de informação e se refere às capacidades de:

- Bronsing: permitir que os usuários realizem suas próprias navegações;

- Formatação: organizar e apresentar dados aos usuários para facilitar a navegação e seleção;

- Interface: auxiliar os usuários na obtenção de respostas e no acúmulo de experiência com o novo sistema;

- Ordenação: dividir ou agrupar assuntos de interesse;

- Acesso físico: facilitar o acesso físico às informações.

- Redução de ruído: concentração da atenção dos usuários nas informações que são apropriadas a determinados interesses, excluindo informações irrelevantes e/ou adicionando informações relevantes, e se refere às capacidades de:

- Acesso intelectual: auxiliar usuários a estreitar o universo de informações em um grupo específico de informações potencialmente úteis; 
- Captura: ajuste de parâmetros de pesquisa para incluir informações relacionadas à pesquisa e, assim, expandir as opções de informação dos usuários;

- Precisão: auxiliar usuários a encontrar exatamente o que é necessário, provendo sinais ou classificações relacionadas às restrições da pesquisa;

- Seletividade: certificar-se que as informações incluídas são de interesse dos usuários.

- Qualidade: satisfação dos usuários com relação aos produtos e serviços de informação prestados e se refere às capacidades de:

○ Exatidão: transferir informações livre de erros;

- Compreensão: realizar a cobertura completa de um tópico ou assunto pesquisado;

- Atualização: manter as informações e a linguagem atualizada;

- Confiabilidade: transmitir confiança ao usuário no que se refere ao desempenho consistente dos serviços;

- Validação: checagem dos sinais obtidos mediante a sondagem de outras fontes de informação.

- Adaptação: habilidade dos serviços em responder de forma responsiva às necessidades e circunstâncias dos usuários no ambiente de trabalho, muitas vezes sendo necessária a intervenção humana para customizar os produtos, e se refere às seguintes capacidades:

- Profundidade: prover produtos ou serviços que se adequem a necessidades particulares dos usuários;

- Flexibilidade: promover uma variedade de maneiras para os usuários trabalhem interativamente com as informações;

- Simplicidade: apresentar informações, explicações, hipóteses ou métodos claros dentro dos limites de qualidade e validade;

- Motivação: aumentar a visibilidade através de atividades como seminários, edição de documentos, discursos e assim por diante. 
- Redução de Tempo: redução do tempo necessário para a prestação de um serviço ou a entrega de produtos de informação.

- Redução de Custo: redução do custo necessário para a prestação de um serviço ou a entrega de produtos de informação.

\subsection{Monitoramento Ambiental}

O monitoramento ambiental (environmental scanning) é um conceito antigo apresentado por Aguilar (1967) e corroborado por inúmeros autores (HAMBRICK,1982; LENZ; ENGLEDOW, 1986; GHOSHAL; WESTNEY, 1991; $\mathrm{CHOO}, 2001)$. Entretanto, este campo de pesquisa ainda é pouco desenvolvido na literatura e, segundo Lesca e Caron-Fasan (2008), pode ser considerado um sinônimo de IC.

O monitoramento ambiental é conceituado como o processo de aquisição e uso de informações sobre eventos do ambiente externo à organização, com o objetivo de evitar surpresas, identificar oportunidades e ameaças, obter vantagem competitiva e estabelecer melhores planos de curto e longo prazo. Assim, um dos motivos que leva uma organização a monitorar o ambiente externo é a redução das incertezas ambientais durante o processo decisório (AGUILAR, 1967; CHOO, 2001).

O trabalho de Lenz e Engledow (1986) se desenvolve com o objetivo de investigar a origem das transformações ambientais e, mais especificamente, como uma organização pode obter conhecimento sobre o ambiente. Para isto, apresentam-se cinco perspectivas de análise do ambiente, conforme descritos na Tabela 3.2. Além disso, o artigo inicia a discussão sobre como estas perspectivas podem afetar os processos de monitoramento ambiental. 
Tabela 3.2 - Modelos de ambiente de negócio

\begin{tabular}{|c|c|c|c|c|c|}
\hline MODELO & $\begin{array}{l}\text { Modelo de } \\
\text { estrutura da } \\
\text { indústria }\end{array}$ & $\begin{array}{l}\text { Modelo } \\
\text { cognitivo }\end{array}$ & $\begin{array}{l}\text { Modelo de } \\
\text { campos } \\
\text { organizacionais }\end{array}$ & $\begin{array}{l}\text { Modelo } \\
\text { ecológico de } \\
\text { dependência de } \\
\text { recursos }\end{array}$ & Modelo de era \\
\hline $\begin{array}{l}\text { Hipóteses } \\
\text { sobre o } \\
\text { ambiente }\end{array}$ & $\begin{array}{l}\text { O ambiente é } \\
\text { composto por } \\
\text { forças } \\
\text { competitivas }\end{array}$ & $\begin{array}{c}\text { Os fatores } \\
\text { ambientais e } \\
\text { suas relações } \\
\text { causais definem } \\
\text { uma estrutura } \\
\text { cognitiva do } \\
\text { ambiente }\end{array}$ & $\begin{array}{l}\text { O ambiente é } \\
\text { composto por } \\
\text { organizações } \\
\text { interdependentes } \\
\text { caracterizadas } \\
\text { por uma } \\
\text { hierarquia de } \\
\text { relevância } \\
\text { definida pela } \\
\text { organização foco }\end{array}$ & $\begin{array}{l}\text { O ambiente é um } \\
\text { sistema que se } \\
\text { caracteriza por } \\
\text { níveis de } \\
\text { hierarquia } \\
\text { relacionados a } \\
\text { certas dimensões } \\
\text { (sociais, naturais, } \\
\text { recursos, etc.) }\end{array}$ & $\begin{array}{c}\text { O ambiente é } \\
\text { diferenciado por } \\
\text { estruturas sociais } \\
\text { e institucionais, } \\
\text { relações, regras } \\
\text { e valores } \\
\text { definidos por } \\
\text { uma ideologia, } \\
\text { cultura, etc }\end{array}$ \\
\hline $\begin{array}{l}\text { Origem das } \\
\text { mudanças } \\
\text { ambientais }\end{array}$ & $\begin{array}{l}\text { As mudanças } \\
\text { são provocadas } \\
\text { pelo processo } \\
\text { evolucionário da } \\
\text { indústria }\end{array}$ & $\begin{array}{l}\text { As mudanças } \\
\text { refletem nas } \\
\text { revisões das } \\
\text { estruturas } \\
\text { cognitivas, } \\
\text { dando-lhes } \\
\text { novos } \\
\text { significados }\end{array}$ & $\begin{array}{c}\text { As mudanças } \\
\text { são originadas } \\
\text { no ambiente } \\
\text { geral e afetam os } \\
\text { fenômenos do } \\
\text { ambiente tarefa }\end{array}$ & $\begin{array}{l}\text { As mudanças } \\
\text { são contínuas, } \\
\text { potencialmente } \\
\text { previsíveis e } \\
\text { ocorrem de modo } \\
\text { autônomo em } \\
\text { cada nível }\end{array}$ & $\begin{array}{l}\text { Experiências } \\
\text { realizadas por } \\
\text { indivíduos e } \\
\text { organizações } \\
\text { provocam } \\
\text { distúrbios nas } \\
\text { estruturas, } \\
\text { ideologias, } \\
\text { culturas, etc }\end{array}$ \\
\hline $\begin{array}{l}\text { Como obter } \\
\text { conhecimento } \\
\text { sobre o } \\
\text { ambiente }\end{array}$ & $\begin{array}{l}\text { Desenvolver um } \\
\text { sistema formal } \\
\text { de análise dos } \\
\text { competidores } \\
\text { conectados ao } \\
\text { planejamento } \\
\text { estratégico }\end{array}$ & $\begin{array}{l}\text { Estimular a } \\
\text { aprendizagem } \\
\text { organizacional } \\
\text { através de um } \\
\text { processo de } \\
\text { decisão flexível }\end{array}$ & $\begin{array}{l}\text { Definir uma } \\
\text { estrutura } \\
\text { administrativa } \\
\text { consistente com } \\
\text { as contingências } \\
\text { ambientais e um } \\
\text { processo de } \\
\text { gestão dos } \\
\text { stakeholders }\end{array}$ & $\begin{array}{c}\text { Estimular a } \\
\text { aprendizagem } \\
\text { organizacional } \\
\text { nas unidades de } \\
\text { negócio }\end{array}$ & $\begin{array}{c}\text { Monitorar as } \\
\text { tendências mais } \\
\text { amplas }\end{array}$ \\
\hline
\end{tabular}

Fonte: Lenz e Engledow (1986)

Neste sentido, Choo (2001) argumenta que as abordagens de monitoramento ambiental são afetadas pela combinação das hipóteses da organização sobre o ambiente. Neste sentido, Aguilar (1967) alerta que para o programa de monitoramento ser eficaz e eficiente, ele deve evitar distorções entre o ambiente real e o ambiente percebido pela organização, conforme a Figura 3.1. 


\begin{tabular}{|c|l|l|}
\hline \multirow{2}{*}{$\begin{array}{c}\text { Ambiente } \\
\text { Real }\end{array}$} & \multicolumn{2}{|c|}{ Ambiente Percebido } \\
\cline { 2 - 3 } & Estável & Instável \\
\hline \multirow{5}{*}{ Estável } & $\begin{array}{l}\text { Hipótese: a organização reconhece que o } \\
\text { ambiente externo é estável } \\
\text { Tendência: sistema de monitoramento em } \\
\text { consonância com o ambiente } \\
\text { Resultado: a organização toma suas } \\
\text { decisões com conhecimento necessário e } \\
\text { suficiente }\end{array}$ & $\begin{array}{l}\text { Hipótese: a organização acredita que o } \\
\text { ambiente é mais instável do que se } \\
\text { verifica } \\
\text { Tendência: sistema de monitoramento } \\
\text { além do necessário para o monitoramento } \\
\text { ambiental } \\
\text { Resultado: a organização incorre em } \\
\text { custos elevados }\end{array}$ \\
\hline \multirow{5}{*}{ Instável } & $\begin{array}{l}\text { Hipótese: a organização acredita que o } \\
\text { ambiente é menos instável do que se } \\
\text { verifica } \\
\text { Tendência: sistema de monitoramento } \\
\text { aquém do necessário para o } \\
\text { monitoramento ambiental } \\
\text { Resultado: a organização incorre em } \\
\text { ameaças de mudanças ambientais } \\
\text { inesperadas }\end{array}$ & $\begin{array}{l}\text { Hipótese: A organização reconhece que o } \\
\text { ambiente externo é instável. } \\
\text { Tendência: o sistema de monitoramento } \\
\text { em consonância com o ambiente } \\
\text { Resultado: a organização toma suas } \\
\text { decisões com conhecimento necessário e } \\
\text { suficiente }\end{array}$ \\
\hline
\end{tabular}

Figura 3.1 - Hipóteses sobre o ambiente

Fonte: Adaptado de Aguilar (1967)

Considerando que a organização não incorra em erros de percepção sobre o ambiente, então ela pode adotar uma das abordagens de monitoramento ambiental. Entretanto, para decidir sobre a melhor estratégia, é necessário considerar a postura da empresa em relação à busca de informações e compreensão do ambiente. Enquanto a postura ativa indica que as atividades de monitoramento são executadas com esforço deliberado para se encontrar a informação, a postura passiva indica que a informação é recebida sem a interferência da organização no ambiente (CHOO, 2001; AGUILAR, 1967). Nesse sentido, Daft e Weick (1984) detalham a dicotomia entre a postura da organização, conforme a Figura 3.2.

\begin{tabular}{|c|c|}
\hline Postura Passiva & Postura Ativa \\
\hline $\begin{array}{c}\text { As organizações não têm um departamento } \\
\text { específico para descobrir ou manipular o } \\
\text { ambiente. }\end{array}$ & $\begin{array}{c}\text { As organizações alocam recursos para as } \\
\text { atividades de monitoramento, muitas vezes } \\
\text { destinando departamentos específicos. }\end{array}$ \\
$\begin{array}{c}\text { As organizações aceitam as informações } \\
\text { que o ambiente lhes oferece, procurando } \\
\text { estabelecer receptores. }\end{array}$ & $\begin{array}{c}\text { As organizações procuraram ativamente por } \\
\text { respostas e, em casos extremos, podem } \\
\text { enviar agentes ao campo. }\end{array}$ \\
$\begin{array}{c}\text { As organizações aceitam o ambiente como } \\
\text { dado e desenvolvem aversão a testes e } \\
\text { experimentações. }\end{array}$ & $\begin{array}{c}\text { As organizações podem quebrar regras na } \\
\text { tentativa de manipular fatores críticos no } \\
\text { ambiente. }\end{array}$ \\
\hline
\end{tabular}

Figura 3.2 - Comparação entre as posturas da organização 
Desta forma, combinando as hipóteses da organização sobre o ambiente com a postura da empresa, pode-se construir a Figura 3.3, a qual apresenta os modelos de monitoramento ambiental (AGUILAR, 1967; CHOO, 2001).

\begin{tabular}{|c|c|c|}
\hline \multirow{2}{*}{$\begin{array}{c}\text { Hipóteses sobre o } \\
\text { Ambiente }\end{array}$} & \multicolumn{2}{|c|}{ Postura da Empresa } \\
\cline { 2 - 3 } & Passiva & Ativa \\
\hline $\begin{array}{c}\text { Ambiente } \\
\text { Não-analisável }\end{array}$ & $\begin{array}{c}\text { VISÃO NÃO DIRECIONADA } \\
\text { (undirected viewing) }\end{array}$ & $\begin{array}{c}\text { PESQUISA INFORMAL } \\
\text { (enacting) }\end{array}$ \\
\hline $\begin{array}{c}\text { Ambiente } \\
\text { Analisável }\end{array}$ & $\begin{array}{c}\text { VISÃO CONDICIONADA } \\
\text { (conditioned viewing) }\end{array}$ & $\begin{array}{c}\text { PESQUISA FORMAL } \\
\text { (searching) }\end{array}$ \\
\hline
\end{tabular}

Figura 3.3 - Modelos de monitoramento ambiental

Fonte: Choo (2001); Aguilar (1967)

Cada abordagem possui um conjunto de características próprias que facilitam sua utilizam em programas específicos (AGUILAR, 1967):

- Visão Não Direcionada (VND): é utilizada quando não se conhece previamente o propósito do monitoramento e, portanto, expõe-se a diversos sinais de mercado provenientes de diferentes fontes, não havendo um padrão de coleta dos sinais. Desta forma, a capacidade de coleta do programa de IC está intimamente ligada à capacidade do coletor em distinguir uma informação relevante dentre os sinais capturados.

- Visão Condicionada (VC): é comum quando se está sob exposição direta a um tipo de informação proveniente de fontes específicas e pré-selecionadas. Entretanto, não há nenhum objetivo de coleta predefinido e a atividade geralmente está a cargo de um especialista capacitado a identificar uma informação relevante caso apareça.

- Procura Informal (PI): é utilizada quando se tem um objetivo claro de busca, mas não se sabe como obter a informação. Assim, a busca é feita de maneira desestruturada e várias alternativas de obtenção da informação são experimentadas.

- Procura Formal (PF): é a busca de forma deliberada e planejada por determinada informação sobre um ponto específico do ambiente externo. A procura pela informação é feita de acordo com procedimentos e metodologias preestabelecidas, cujo propósito é o de sistematicamente recuperar determinada informação relevante para suportar uma decisão específica. 
Choo (2001) discorre que esses quatro modelos de monitoramento ambiental podem ser avaliados em um continuum, conforme a Figura 3.4. Segundo o autor, quando se movimenta neste continuum, a necessidade de informação específica, aplicável e confiável se intensifica. Assim, se por um lado os modelos de visão permitem fazer uma varredura mais abrangente para capturar todos os possíveis sinais de mudança, por outro lado os modelos de pesquisa permitem um exame mais profundo e preciso destes sinais.

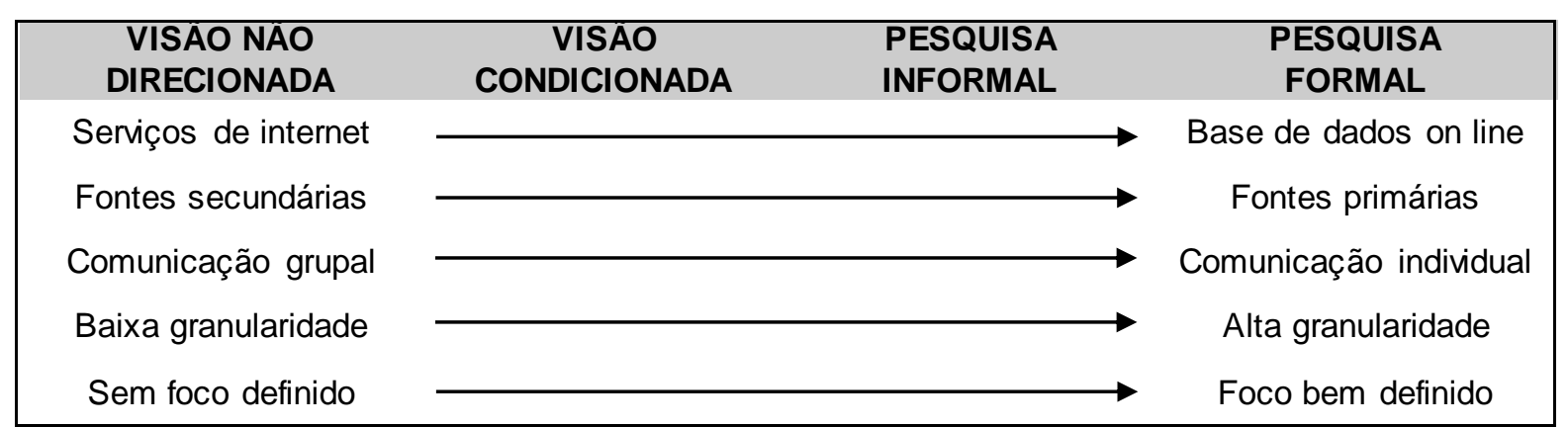

Figura 3.4 - Continuum dos modelos de monitoramento

Fonte: Choo (2001)

\subsection{Business Intelligence}

Na literatura selecionada, o conceito de business intelligence (BI), que muitas vezes se confunde com o conceito de IC, fica claramente relacionado a ferramentas de suporte à decisão. Heinrichs e Lim (2003) argumentam que a capacidade de BI de uma organização pode ser utilizada na infraestrutura de suporte à decisão para auxiliar os trabalhadores do conhecimento no desenvolvimento de estratégias.

Ao utilizar o termo trabalhadores do conhecimento, Heinrichs e Lim (2003) faz referência ao campo de pesquisa gestão do conhecimento, o que é comum na literatura. Cheng; Lu e Sheu (2009) destacam que pode ser criada sinergia através da integração dos processos de suporte à decisão e gestão do conhecimento devido à complementaridade das suas atividades. Por exemplo, as atividades de recuperação e armazenamento informações são funções centrais da gestão do conhecimento, mas também são pré-requisitos para o processo de decisão e dependem de uma infraestrutura organizacional capaz de capturar, filtrar, armazenar, organizar e disseminar dados.

Além destas atividades, Kohavi et al. (2004) ressaltam que BI é um conjunto de técnicas que podem ser utilizadas em diferentes processos: coleta, validação, 
processamento, compreensão, construção de modelos, exploração de dados, compartilhamento de conhecimento, elaboração de relatórios, e visualização. Nesse sentido, a literatura de $\mathrm{BI}$ apresenta diversas ferramentas que possibilitam 0 desenvolvimento destas atividades. Chung; Chen e Nunamaker Junior (2005) reforçam que as ferramentas de $\mathrm{BI}$ permitem que a organização compreenda o ambiente interno e externo através de um processo sistemático de aquisição, coleta, análise, interpretação e exploração de informações.

Contudo, para se construir uma visão geral das ferramentas de Bl e suas aplicações no contexto da IC, é importante relacionar tais ferramentas às etapas do ciclo de inteligência: planejamento, coleta, análise e disseminação. Considerando que estas etapas são compostas de diferentes atividades, conforme a Tabela 3.1, pode-se esperar que cada atividade possua ferramentas de BI específicas. Entretanto, esta expectativa se confirma parcialmente na literatura selecionada (KOHAVI et al., 2004).

Considerando a etapa de planejamento, não foram encontradas ferramentas de BI disponíveis para auxiliar as atividades de identificação de variáveis e de fontes de informação. Nesse sentido, Kohavi et al. (2004) apresentam uma série de desafios aos pesquisadores deste campo de pesquisa: Seria possível desenvolver ferramentas de $\mathrm{BI}$ capazes de facilitar a transformação dos questões chaves do negócio em variáveis a serem monitoradas? As ferramentas e os modelos de BI poderiam ser mais compreensíveis aos usuários? Seria possível automatizar a criação de modelos de BI?

Em contrapartida, foram identificadas três ferramentas de BI capazes de auxiliar atividades da etapa de coleta, conforme a Tabela 3.3. Enquanto a captura de dados dispõe de ferramentas como agentes inteligentes (XU; WANG, 2002), o armazenamento possui uma ferramenta já bastante robusta e desenvolvida: data warehouse (MARCH; HEVNER, 2007). Além disso, a literatura mostra diversos algoritmos para a atividade de catalogação (CHUNG et al., 2008), mas não apresenta nenhuma ferramenta para as atividades de validação e classificação. 
Tabela 3.3 - Ferramentas de BI relacionadas a coleta

\begin{tabular}{|l|l|l|}
\hline ATIVIDADE & FERRAMENTA & PUBLICAÇÃO \\
\hline Captura & Agentes inteligentes & Xu e Wang (2002) \\
\hline Validação & - & - \\
\hline Catalogação & Algoritmos & Chung et al. (2008) \\
\hline Classificação & - & - \\
\hline Armazenamento & Data Warehouse & March e Hevner (2007) \\
\hline \multicolumn{2}{|l}{} \\
\hline
\end{tabular}

Para a captura de dados, Xu e Wang (2002) argumentam que a captura de dados pode ser feita através de agentes inteligentes. Estes agentes possibilitam o transporte automático de dados capturados de algum site ou sistema de informações interno para softwares de inteligência. Para isso, os agentes inteligentes precisam ter as seguintes características: autonomia (devem funcionar sem a intervenção humana), co-operabilidade (devem funcionar em conjunto com outros agentes inteligentes e ferramentas de $\mathrm{Bl}$ ), reatividade (devem perceber as mudanças da rotina), pró-atividade (devem exibir as modificações da rotina, sugerindo mudanças) e mobilidade (devem funcionar não apenas nos computadores em que foram programados, mas em qualquer computador).

Em relação à atividade de catalogação, Chung et al. (2008) discutem diversos algoritmos que foram testados com o objetivo de automatizar essa atividade. Embora existam hoje diversas ferramentas disponíveis, a dificuldade frequente é a qualidade com que esta catalogação é realizada. Em outras palavras, existem algoritmos que conseguem organizar informações em categorias, mas a falta de precisão da estrutura lógica prejudica a recuperação posterior destas. Por este motivo, a aplicação destas ferramentas ainda não é muito difundida.

Já em relação à atividade de armazenamento, March e Hevner (2007) apresentam a ferramenta data warehouse (DW) como sendo um repositório de dados orientado a objeto, integrado e invariante ao tempo. De acordo com os autores, a arquitetura de DW é composta por quatro camadas que representam níveis de funcionalidade dentro da ferramenta, conforme mostra a Figura 3.5. 

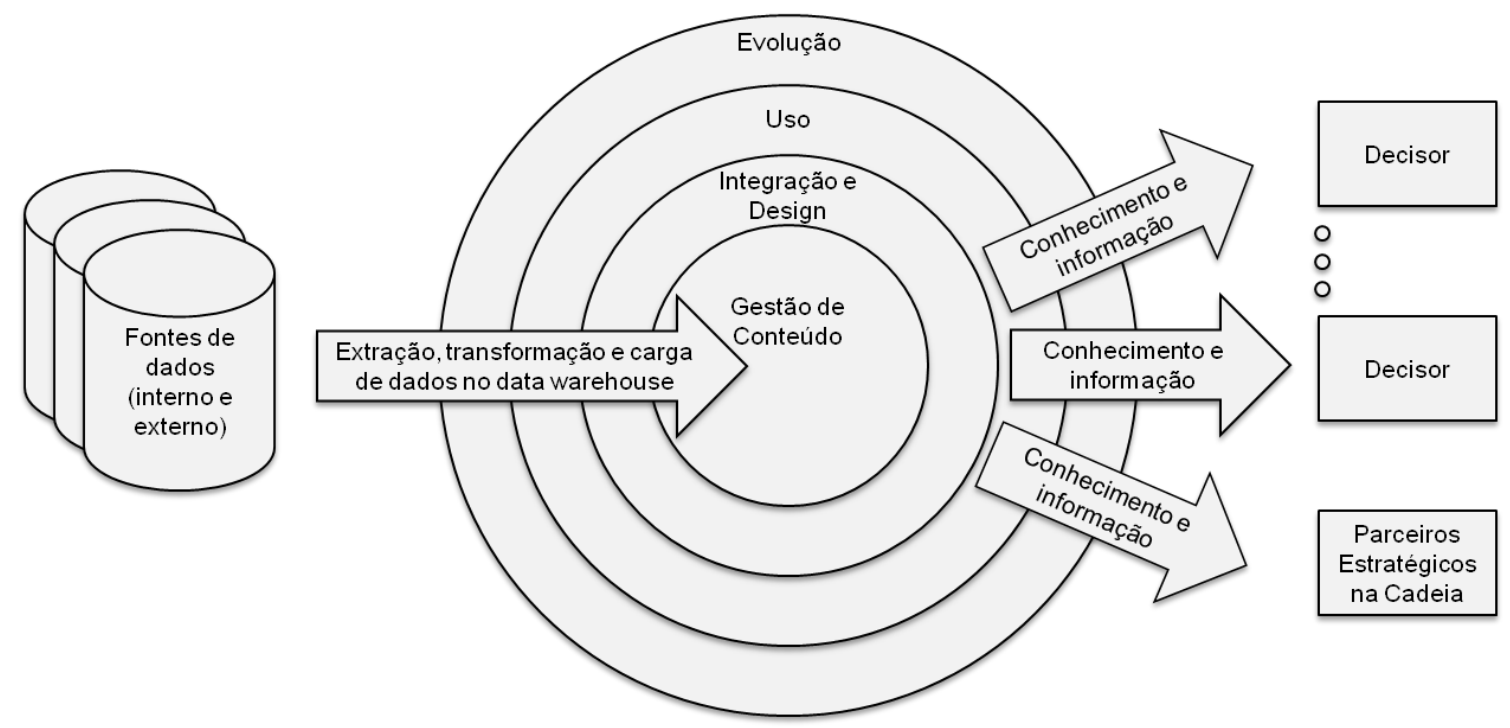

Figura 3.5 - Arquitetura de Data Warehouse

Fonte: March e Hevner (2007)

Entretanto, esta ferramenta deve ser acompanhada do processo chamado data warehousing. Este é o processo de desenvolvimento e gestão de práticas e métodos operacionais que definem como as informações são coletadas e integradas ao sistema. Além disso, neste processo são definidos os níveis de acesso dos usuários para que se faça o uso correto e para que se garanta a qualidade da administração das informações (MARCH; HEVNER, 2007).

Nesse sentido, o data warehousing já representa a relação da etapa de coleta com a etapa de análise, pois a camada de uso disponibiliza informação aos tomadores de decisão. Contudo, de acordo com os conceitos de IC, esta informação ainda precisa ser analisada. Nesse sentido, os dispositivos OLAP (on-line analitical process) e os modelos preditivos figuram como as principais ferramentas de $\mathrm{BI}$ no processo de análise, conforme resume a Tabela 3.4.

Tabela 3.4 - Ferramentas de BI relacionadas a análise

\begin{tabular}{lll}
\hline ATIVIDADE & FERRAMENTA & PUBLICAÇÃO \\
\hline Processamento & OLAP & McHugh; Roche e Bédard (2009) \\
Mineração & Data Mining & Shi et al. (2005); Saar-Tsechansky; Melville e Provost \\
& & $(2009)$ \\
Interpretação & - & - \\
\hline & & Fonte: elaborado pelo autor
\end{tabular}

De acordo com McHugh; Roche e Bérdard (2009), as tecnologias OLAP existem há bastante tempo e sua principal função é permitir a manipulação dos dados armazenados sem que haja a necessidade de um especialista. Em outras palavras, 
esses dispositivos facilitam o processamento de dados, uma atividade fundamental na etapa de análise.

Já na atividade de mineração de dados, Saar-Tsechansky; Melville e Provost (2009) afirmam que os modelos preditivos representam uma boa parcela das ferramentas. A partir de dados históricos, os modelos são capazes de prever o comportamento dos consumidores ou detectar riscos, como fraudes. Nesse sentido, Shi et al. (2005) discutem um modelo que representa o funcionamento das ferramentas de $\mathrm{BI}$ na etapa de análise, conforme a Figura 3.6.

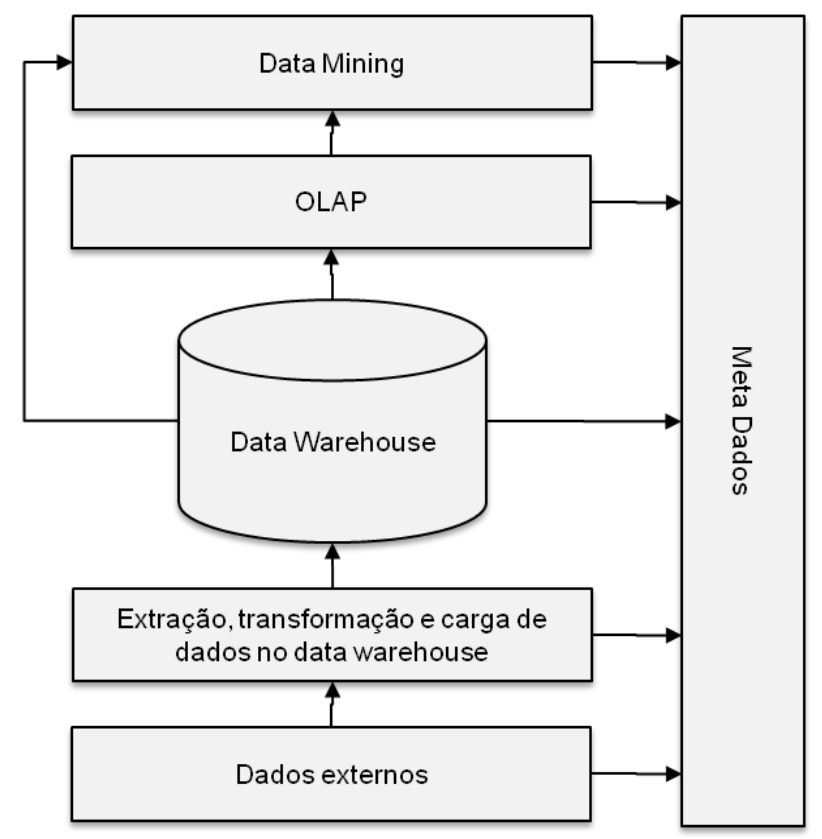

Figura 3.6 - Arquitetura de Data Mining

Fonte: Shi et al. (2005)

\subsection{Gestão do Conhecimento}

A gestão do conhecimento (knowedge management) é um campo de pesquisa que tem sido bastante explorado nos últimos anos por diferentes áreas da ciência. $O$ conceito central promove uma abordagem integrada de identificação, captura, recuperação, compartilhamento e evolução dos ativos de conhecimento da organização (ONG et al., 2005).

O programa de gestão do conhecimento sintetiza um processo de seleção de conhecimento acumulado com decisões passadas que podem ser recuperadas para utilização em tomadas de decisão presentes e futuras. Por este motivo, o sucesso de um programa de gestão do conhecimento depende das estratégias 
organizacionais, da infraestrutura de $\mathrm{Tl}$ e dos seus próprios processos (LIU; WANG; 2009). Entretanto, quando se trata do desenvolvimento de sistemas de suporte à decisão baseado em gestão do conhecimento, ainda não se conhece nenhuma ferramenta ou modelo eficiente (CHENG; LU; SHEU, 2009).

No que se refere à infraestrutura de TI da gestão do conhecimento, Erickson e Rothberg (2008) discutem que é necessário apenas o suporte às atividades de coleta, armazenamento e distribuição codificada do conhecimento. Entretanto, Tseng e Chou (2006) acreditam que a participação da TI é mais ampla e, para provar, desenvolveram um modelo geral do processo de gestão do conhecimento. No processo desenvolvido pelos autores, os documentos armazenados em diferentes fontes são transformados e carregados em uma base de documentos específica ao mesmo tempo em que são criados metadados que irão auxiliar os processos de recuperação do conhecimento. Para isso, os autores sugerem a utilização de técnicas de $\mathrm{Bl}$, como data warehouse e OLAP, como suporte aos processos de gestão do conhecimento, assim como Heinrichs e Lim (2003).

Já no que se refere aos processos, além das etapas de catalogação, armazenamento e recuperação do conhecimento apresentados por Tseng e Chou (2006), Erickson e Rothberg (2008) acrescentam atividades como aquisição, compartilhamento, identificação, classificação e mensuração dos ativos de conhecimento. Por sua vez, Raol et al. (2003) defendem atividades como filtragem, categorização, organização, interação e distribuição do conhecimento. A própria definição utilizada por Ong et al. (2005) também carrega atividades de identificação, captura, recuperação, compartilhamento e evolução do conhecimento. Resumindo, as atividades de gestão do conhecimento identificados na literatura são apresentadas na Tabela 3.5:

Tabela 3.5 - Atividades da Gestão do Conhecimento

\begin{tabular}{ll}
\hline ATIVIDADE & DESCRIÇÃO \\
\hline Captura / aquisição & Obtenção do conhecimento \\
Filtragem / validação & Validação do conhecimento obtido \\
Identificação / Classificação & Atribuição de valor no conhecimento \\
Categorização / catalogação & Alocação do conhecimento em categorias \\
Armazenamento & Custódia do conhecimento \\
Recuperação & Rastreabilidade do conhecimento armazenado \\
Compartilhamento & Distribuição do conhecimento \\
\hline
\end{tabular}




\subsection{Estratégia}

O conceito de estratégia tem sido estudado desde a década de 60 , quando iniciou a escola clássica. Esta escola considera a estratégia como um produto resultante do processo de formulação estratégica. Nesta perspectiva, a estratégia deveria ser bem definida e estruturada, oriunda de múltiplos processos analíticos em diferentes níveis como resposta às alterações do ambiente competitivo (PORTER, 1980).

Apesar de ao longo das últimas décadas o conceito de estratégia ter evoluído, a perspectiva clássica ainda é muito presente devido seu caráter analítico, o que permite aos tomadores de decisão uma melhor compreensão da competição através de técnicas como análise SWOT, por exemplo (POWELL; BRADFORD, 2000).

Erickson e Rothberg (2009) discutem que o conhecimento pode ser utilizado como vantagem competitiva para a organização através de bons processos de identificação e gestão dos ativos de conhecimento. Este contexto permite considerar que a IC é uma importante ferramenta para a estratégia (POWELL; BRADFORD, 2000), pois seu objetivo é promover inteligência aplicável, isto é, informações contextualizadas, analisadas e sintetizadas (SAAYMAN et al., 2008).

Admitindo que a IC seja um processo, Kahener (1996) aponta diversas vantagens da sua utilização para as organizações, como antecipar as mudanças no mercado e as ações dos competidores bem como promover a aprendizagem sobre novas tecnologias, produtos, processos, legislações, entre outros, com o objetivo de suportar decisões estratégicas, por exemplo entrar em um novo mercado. Por este motivo, Sayyman et al. (2008) destaca que a IC deve ter parte no processo de formulação estratégica e suas ações devem estar alinhadas com a estratégia organizacional.

A importância da IC para o processo de formulação estratégica é explicita no modelo da Figura 3.7, apresentado por Mortara et al. (2009). Por um lado, a formulação estratégia deve promover os inputs do processo de IC à medida que apresenta as necessidades de inteligência da organização. Por outro lado, a IC deve fornecer subsídios para que os tomadores de decisão possam refinar suas necessidades até que se obtenha a inteligência necessária para a tomada de decisão e, consequentemente, a ação. 


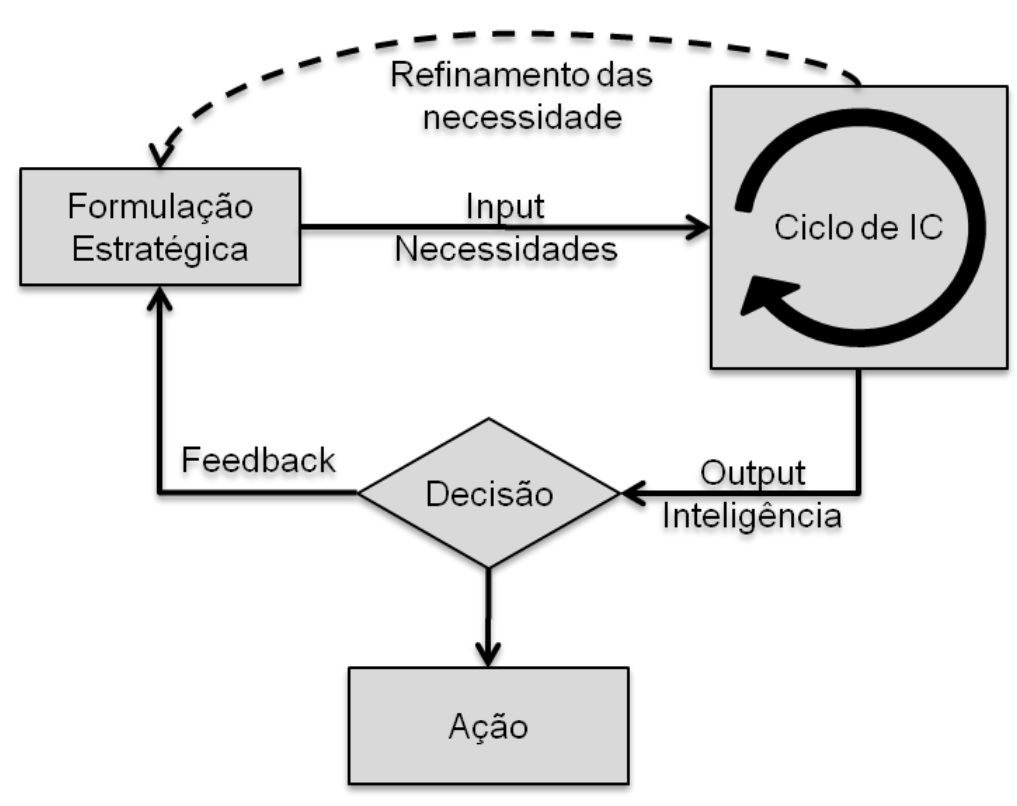

Figura 3.7 - Processo de inteligência

Fonte: adaptado de Mortara et al. (2009)

O modelo de Mortara et al. (2009) torna explícita a interação entre a estratégia e a inteligência competitiva, construindo uma relação de cliente-fornecedor. O processo de formulação estratégica é responsável por definir as necessidades de inteligência e, portanto, as diretrizes das atividades. Neste sentido, o modelo permite refinar a proposição utilizada para a construção da Figura 2.9. Ao invés de desenvolver estratégias competitivas, a IC é demandada por um processo de formulação estratégico, o qual deve ocorrer paralelamente.

Neste sentido, Hambrick (1982) argumenta que é necessário existir um alinhamento entre a estratégia de negócio e a estratégia de inteligência competitiva. De acordo com o autor, a IC não deve ser utilizada apenas para obter uma nova competência, mas sim para potencializar as competências da organização, através do conhecimento das suas capacidades de agir.

\subsection{Decisão}

A análise do campo de pesquisa decisão (decision making) é provavelmente o campo de pesquisa menos evoluído dentro da literatura de IC. Em geral, as publicações recentes abordam o relacionamento entre os processos de tomada de decisão e de inteligência competitiva (MORTARA et al., 2009; DISHMAN; CALOF, 2008; KAHENER, 1996), conforme o modelo da Figura 3.8. 


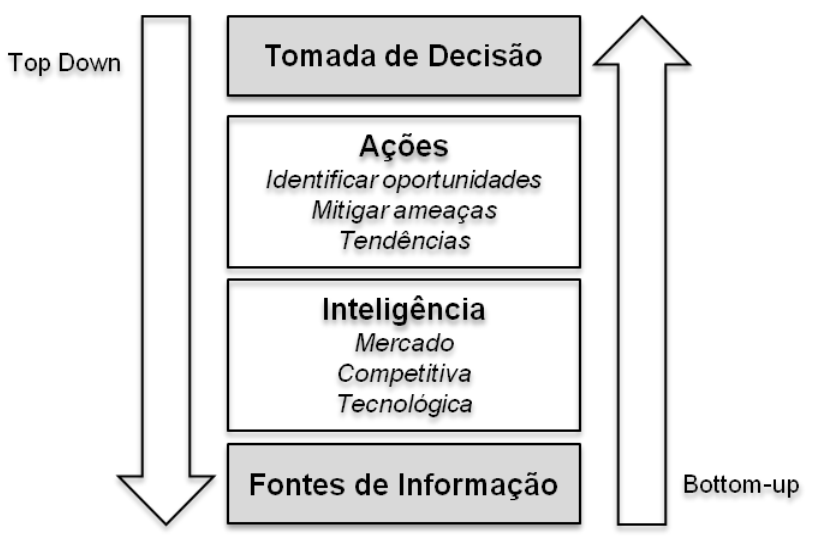

Figura 3.8 - Framework de inteligência

Fonte: adaptado de Mortara et al. (2009)

Mortara et al. (2009) tornam explícita a interface entre IC e decisão e, considerando o modelo da Figura 3.7, coloca a decisão e a estratégia em um mesmo nível de interação com a IC, isto é, de cliente-fornecedor: a IC deve promover subsídios ao processo de decisão, através da entrega de inteligência. Neste sentido, pode-se admitir que decisão e estratégia caminhem em conjunto, ou seja, um processo de decisão estratégia.

Ghoshal e Westney (1991) reforçam a hipótese de que a IC deve dar subsídios ao processo de decisão estratégica, mas Prescott e Smith (1987) apontam limitações para o uso da IC como suporte a tomada de decisões pontuais. Esta discussão suscita o debate sobre o posicionamento organizacional da unidade de IC dentro da organização (LENZ; ENGLEDOW, 1986).

Porter (1980) sugere a criação de uma unidade administrativa especializada no monitoramento ambiental que atue de modo independente das demais funções organizacionais. Kahener (1996) simplifica a discussão colocando que a IC deve estar o mais próximo dos tomadores de decisão, mas disponível a todos os na organização. Contudo, vigora ainda a hipótese de que a IC deve estar integrada ao planejamento estratégico (LENZ; ENGLEDOW, 1986). 


\section{METODOLOGIA}

Conforme discutido até este momento, as seções anteriores deste trabalho permitiram identificar os campos de pesquisa relevantes à IC bem como um modelo preliminar sobre como eles se relacionam através de proposições extraídas da literatura. Entretanto, para atender o objetivo deste trabalho e construir a visão holística sobre a IC, é importante questionar a validade destas percepções conceituais através de pesquisa empírica. Nesse sentido, a estratégia metodológica adotada para cumprir com este objetivo foi o estudo de casos múltiplos confirmatórios.

De acordo com Yin (1994), o estudo de caso é um dos métodos de pesquisa mais utilizados na engenharia de produção e, particularmente, no desenvolvimento de novas teorias. Primeiro, porque não se tem a pretensão de que o trabalho tenha uma representatividade estatística nem tampouco a mensuração de frequências estatísticas. Segundo, porque é um método de pesquisa que proporciona a generalização analítica dos fenômenos sociais. Nesse sentido, pode-se considerar que o objetivo do estudo de caso é o estudo em profundidade de um fenômeno social complexo.

Em relação à representatividade estatística, Voss; Tsikriktsis e Frohlich (2002) destacam que um estudo de caso é a descrição de acontecimentos ou situações reais, enquanto um estudo estatístico envolve abstrações destas mesmas situações. Assim, o estudo de caso pode ser definido como a história de um fenômeno passado ou presente, extraída a partir de múltiplas fontes de evidência.

Já em relação à generalização analítica dos fenômenos sociais, Eisenhardt (1989) argumenta que o estudo de caso é uma estratégia de pesquisa que se preocupa com a compreensão do contexto dinâmico destes fenômenos. Nesse sentido, mesmo que o estudo de caso seja considerado uma representação simples das situações reais, ele pode envolver múltiplos casos e numerosos níveis de análise. Por isso, os autores sustentam que há possibilidades de geração de teorias a partir deste método.

Desta forma, Yin (1994) apresenta as suas principais características:

- Permite ao pesquisador estabelecer uma análise "generalizante" e não "particularizante" de um determinado fenômeno social; 
- É apropriado para questões de pesquisa do tipo "como" ou "por que";

- Não exige controle sobre os eventos comportamentais;

- Tem foco nos acontecimentos contemporâneos;

- Estuda situações onde as fronteiras entre o fenômeno e seu contexto não são claras; e

- Usa múltiplas fontes de informação.

Em resumo, o estudo de caso apresenta vantagens em sua utilização. Primeiro, possibilita estudar um fenômeno em seu contexto natural para adquirir conhecimento relevante, por meio da observação da realidade, e propor uma nova teoria. Segundo, viabiliza responder questões com uma compreensão relativamente ampla da natureza e complexidade do fenômeno. Terceiro, pode ser utilizado para diferentes propósitos de pesquisa, como exploração, construção de teoria, teste de teoria ou extensão e refinamento de teoria. Por isso, apesar de se aproximar mais de uma pesquisa qualitativa, é bastante difundido na Engenharia de Produção (MIGUEL, 2007; NAKANO; FLEURY, 1996; WESTBROOK, 1995).

\subsection{Modelo de Estudo de Caso}

Segundo Yin (1994), a aplicação do método de estudo de caso deve estar preocupada com a confiabilidade e a validade dos dados durante a coleta e a análise. Por isso, é importante definir alguns conceitos relacionados:

- Validade de construtos: é a extensão do estabelecimento de medidas operacionais corretas para os conceitos que serão estudados;

- Validade interna: é a extensão do estabelecimento de relações de causa e efeito;

- Validade externa: verifica se os achados de um estudo se aplicam a casos similares;

- Repetitividade: mede em que extensão um estudo pode ser reaplicado, com os mesmos resultados.

No modelo apresentado por Miguel (2007), o estudo de caso pode ser segmentado em seis macro-fases, sendo que a primeira compreende a definição de um referencial teórico. Para isso, é importante revisar a bibliografia especializada 
disponível a fim de compor as bases do trabalho bem como identificar as lacunas que o trabalho possa suprir e extrair os constructos, ou seja, conceitos a serem verificados sobre os elementos extraídos da literatura, dos quais se podem estabelecer proposições. Uma vez que as lacunas teóricas foram identificadas, torna-se valioso delinear o grau de evolução e expansão das fronteiras científicas.

A macro-fase seguinte da realização do estudo de caso se refere ao planejamento propriamente dito do caso. Dentro desta, inicialmente se deve selecionar uma ou mais unidades de análise ou casos para na sequência se determinar as melhores técnicas de coleta e análise de dados. Deve-se sempre privilegiar a utilização de múltiplas fontes de evidência, que pode incluir todas as outras abordagens mencionadas além de entrevistas e análise documental, de tal forma a atingir maior validade construtiva da pesquisa (EISENHARDT, 1989). Em seguida, é importante desenvolver um protocolo para a coleta dos dados, de tal forma a compor um conjunto de questões a serem usadas bem como de procedimentos e regras para sua condução.

$\mathrm{Na}$ sequência da macro-fase de planejamento, sucede o teste piloto. O objetivo desta fase é verificar tanto os procedimentos de aplicação com base no protocolo estabelecido anteriormente quanto à qualidade dos dados a serem coletados. Esta etapa serve, portanto, como retro-alimentação do processo de planejamento do estudo de caso.

A quarta fase se refere à coleta de dados propriamente dita, que envolve desde a constatação dos casos e registro dos dados até processar as informações adquiridas. Uma vez que esta fase se encerra, é necessário que os dados sejam analisados, constituindo a quinta macro-fase. O intuito é produzir uma espécie de narrativa geral do caso e apresentar somente as informações que possuam estrita relação com os objetivos e os constructos da pesquisa, ou seja, é comum ocorrer o processo de redução dos dados coletados. Durante a narrativa podem ser destacadas as principais informações do(s) caso(s) de modo a permitir a construção de um painel demonstrativo do conjunto total de dados para cada caso analisado, facilitando a visualização da rede causal das variáveis pesquisadas e a extração de conclusões.

Realizada a coleta e análise dos dados, a última macro-fase diz respeito à comparação entre os resultados apresentados e a teoria, na tentativa de verificar se 
o fenômeno objeto da pesquisa pode ser explicado pela teoria em contextos diversos. A precaução a ser tomada é evitar o ajuste da teoria aos resultados de sorte que estes se apresentem vinculados aos conhecimentos teóricos. Outra questão a ser desenvolvida nesta etapa se refere à confiabilidade da pesquisa, ou seja, a certificação de que as macro-fases anteriores podem ser reproduzidas e continuem apresentando os mesmos resultados (YIN, 1994).

\subsection{Critérios de Seleção dos Casos}

De acordo com o modelo proposto, o planejamento do estudo de caso se inicia com a seleção das empresas a serem analisadas. Desta forma, considerando que o objetivo deste trabalho é apresentar uma visão holística da IC, devem ser priorizadas aquelas que permitam uma análise abrangente do tema, ou seja, empresas com utilização intensiva de conhecimento estratégico.

Sob o ponto de vista desta seleção, isso permite direcionar a pesquisa para empresas que utilizam grandes quantidades de dados e informações na gestão dos seus negócios. Isto significa que, fundamentalmente, empresas com maior dependência de informação no desenvolvimento das suas atividades são melhores escolhas.

Neste sentido, optou-se por concentrar o estudo no mercado de crédito para pessoa física (varejo). Em primeiro lugar, porque o mercado de crédito utiliza a informação como insumo principal na definição das suas estratégias de negócio, além de ser muito dependente das condições do ambiente. Em segundo lugar, a escolha do varejo reforça o maior volume de dados utilizados nas análises, além de ser um nicho que potencializa as oportunidades e as ameaças. Estas conclusões estão baseadas nas análises a seguir.

\subsubsection{Mercado de Crédito}

O crédito é inegavelmente um mercado em expansão. Como mostra a Figura 4.1, a carteira de crédito total do Brasil superou os $\mathrm{R} \$ 700$ bilhões em 2009, o que representa um crescimento médio anual de 18,7\% desde 1999. Dentre os produtos de crédito, a carteira de crédito Pessoa Física (PF) se destacou, superando o crescimento médio anual de $22,7 \%$ no mesmo período e representa hoje, cerca de $45,0 \%$ da carteira de crédito total do Brasil, o que reforça o momento de expansão de crédito no país. 


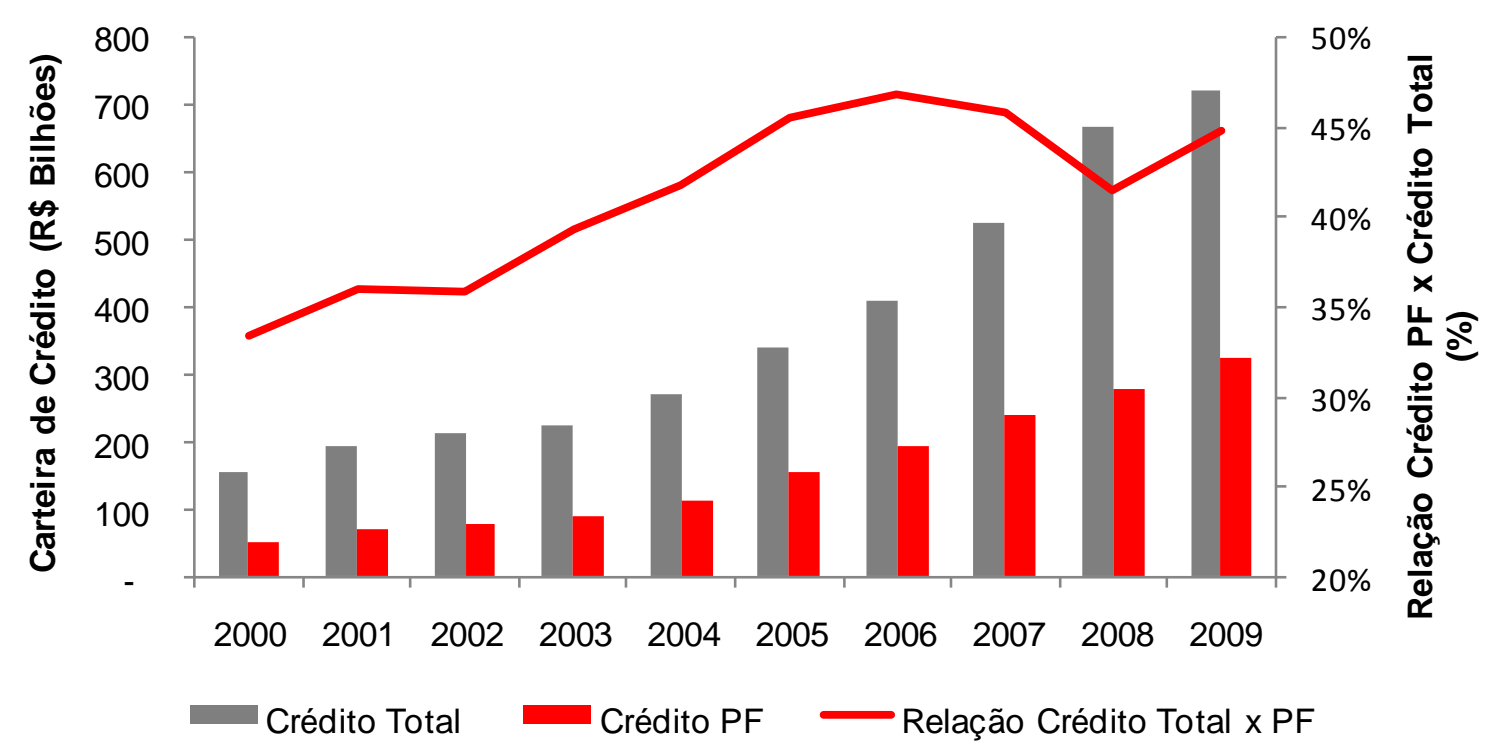

Figura 4.1 - Evolução do mercado de crédito para pessoa física

Fonte: Banco Central do Brasil (2010)

A Figura 4.1 mostra que a relação entre a carteira de crédito total e a carteira de crédito PF sempre cresceu, exceto em dois momentos. No biênio 2001-2002, durante a transição do governo federal, e no biênio 2007-2008, durante a crise de liquidez que se estabeleceu. Estas oscilações demonstram que o mercado de crédito, em especial para pessoa física, sofre grande impacto devido às condições do ambiente, o que reforça sua escolha para a análise deste projeto.

Em suma, esta análise preliminar reforça que as instituições financeiras devem monitorar o ambiente relacionado ao mercado de crédito para maximizarem suas oportunidades bem como minimizarem as ameaças. Isso já justificaria o estudo da IC neste mercado, mas existem ainda outras demandas de inteligência que este mercado ainda apresenta. Quais segmentos atuar, quais concorrentes monitorar, quais regiões focar e quais fornecedores selecionar são apenas algumas das muitas decisões que envolvem esta indústria. Neste sentido, definir quais segmentos serão analisados por este trabalho também representa uma decisão metodológica importante e, para isso, a Figura 4.2 apresenta este mercado. 


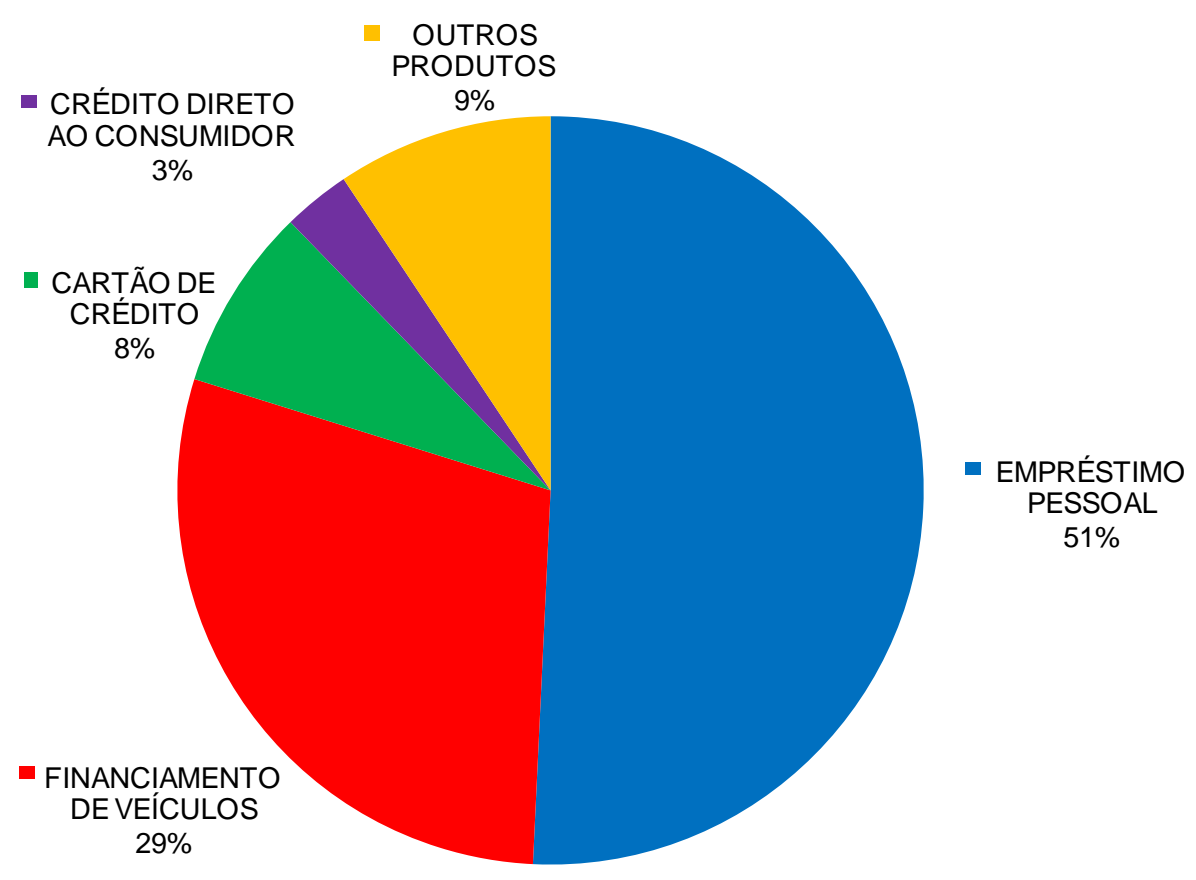

Figura 4.2 - Distribuição da carteira de crédito PF em dez/2009

Fonte: Banco Central do Brasil (2010)

A Figura 4.2 indica que mais de $90 \%$ do mercado de crédito de varejo está concentrado em quatro produtos principais: empréstimo pessoal, financiamento de veículos, cartão de crédito e crédito direto ao consumidor. Desta forma, optou-se por selecionar empresas em cada um destes segmentos, obedecendo à restrição de não pesquisar empresas com o mesmo produto core, visando maximizar a realização dos casos em diferentes ambientes e estratégias.

\subsection{Roteiro de Pesquisa}

Recuperando o objetivo da pesquisa, desenvolver uma visão holística sobre a IC, a coleta de dados deve priorizar a atenção sobre as atividades que possuem relação com os campos de pesquisa identificados anteriormente. Neste sentido, os estudos de caso são direcionados à compreensão das características do programa de IC e, sendo assim, são utilizados a estrutura e os conceitos desenvolvidos na revisão de literatura, resultando nos protocolos de pesquisa apresentados neste item. Assim, para cada um dos campos de pesquisa foi desenvolvido um protocolo, totalizando 
cinco: monitoramento ambiental (item 4.3.1), business intelligence (item 4.3.2), gestão do conhecimento (item 4.3.3), estratégia (item 4.3.4) e decisão (item 4.3.5).

O desdobramento do objetivo da pesquisa reflete nos objetivos destes protocolos: identificar a infraestrutura e os processos de IC. Além disso, a coleta de dados deve fornecer subsídios para que seja possível verificar como os campos de pesquisa se relacionam no contexto de um programa de IC. Com o objetivo de fornecer uma compreensão clara do método de pesquisa, é apresentada a construção das questões de pesquisa, e seus respectivos desdobramentos, com base nas hipóteses identificadas na literatura.

\subsubsection{Monitoramento Ambiental}

Conforme apresentado na revisão literatura, o monitoramento ambiental é o processo de aquisição e uso de informações sobre eventos do ambiente externo à organização (AGUILAR, 1967; CHOO, 2001). A literatura indica que seu objetivo é evitar surpresas estratégicas, isto é, identificar oportunidades e ameaças para obter vantagem competitiva. Desta forma, a proposição básica sobre este campo de pesquisa que se pretende checar com o estudo de caso é: a IC utiliza o monitoramento ambiental para coletar dados externos à organização. Considerando isso, a pergunta de pesquisa que direciona este protocolo é: como o monitoramento ambiental está inserido nos programas de IC. Para responder a esta questão, são desenvolvidas duas questões chaves:

- Baseado nos modelos de Lenz e Engledow (1986), como a organização enxerga o ambiente de negócios?

- Baseado no conceito de Aguilar (1967) e Choo (2001), a organização possui postura ativa na coleta de dados?

Como resultado da análise destas questões, pode-se admitir que um determinado modelo de monitoramento ambiental seja mais adequado para a empresa. Entretanto, para validar esta comparação, outra questão central foi incluída:

- Quais são os mecanismos utilizados pela organização para a coleta de dados externos? 


\subsubsection{Business Intelligence}

Conforme apresentado na revisão de literatura, o conceito de business intelligence (BI) está relacionado à infra-estrutura de TI. Heinrichs e Lim (2003) argumentam que a capacidade de $\mathrm{BI}$ de uma organização está relacionada à sua infraestrutura de suporte à decisão, de modo a auxiliar os trabalhadores do conhecimento no desenvolvimento de estratégias. Neste sentido, a proposição a ser investigada sobre este campo de pesquisa é: a IC utiliza as ferramentas de BI como infraestrutura de TI. Em outras palavras, o estudo de caso deve investigar como as ferramentas de BI são utilizadas nos programas de IC. Para isso, é importante responder a uma questão fundamental:

- Quais são as ferramentas de BI disponibilizadas pela organização?

\subsubsection{Gestão do Conhecimento}

Conforme descrito na revisão de literatura, a gestão do conhecimento pode ser apresentada como o processo de seleção de conhecimento acumulado com decisões passadas que podem ser recuperadas para utilização em tomadas de decisão presentes e futuras (LIU; WANG; 2009). Esta interpretação permite inferir que a gestão do conhecimento possua rotinas específicas no tratamento do conhecimento organizacional, desde sua aquisição até seu compartilhamento.

Nesse sentido, a proposição que se pretende verificar com o desenvolvimento dos casos é: a IC utiliza os processos de gestão do conhecimento nas suas rotinas. Diante desta afirmação, a questão central em relação a este campo de pesquisa é: como a IC utiliza os processos de gestão do conhecimento nos seus processos de gerenciamento de inteligência. Sendo assim, esta questão pode ser melhor explorada se for segmentada nas atividades de gestão do conhecimento:

- Quais são as atividades de gestão do conhecimento realizadas pela organização durante o processo de IC?

\subsubsection{Estratégia}

Conforme apresentado na revisão de literatura, a IC deve ter parte no processo de formulação estratégica e suas ações devem estar alinhadas com a estratégia organizacional (SAYMMAN et al., 2008). Desta forma, é possível supor que o processo de formulação estratégica seria responsável por definir as necessidades de inteligência. Portanto, no que se refere a este campo de pesquisa, a proposição a 
ser investigada é: a IC deve estar alinhada com a estratégia competitiva. Nesse sentido, a questão de pesquisa que direciona a elaboração deste protocolo é: como ocorre o alinhamento entre a IC e a estratégia competitiva. Para responder a esta questão, é necessário compreender duas situações:

- Qual é a estratégia competitiva da organização?

- Quais são as necessidades de inteligência demandadas pela estratégia competitiva?

\subsubsection{Decisão}

Conforme descrito na revisão de literatura, o campo de pesquisa relacionado à decisão não foi ainda muito explorado na literatura de IC, mas se admite que esta é uma interação baseada no conceito de cliente-fornecedor (MORTARA et al., 2009). Nesse sentido, na literatura vigora a hipótese de que a IC deve estar integrada ao planejamento estratégico (LENZ; ENGLEDOW, 1986). Desta forma, para a pesquisa deste campo é possível construir a seguinte proposição: a IC deve fornecer inteligência ao processo de planejamento estratégico. Nesse sentido, a questão central de pesquisa relacionada a este campo é: como o processo de decisão estratégica utiliza a inteligência gerada pelo programa de IC. Para isso, são levantadas duas questões:

- Como a IC está posicionada na organização?

- Como se definem as necessidades de IC?

Sumarizando, o roteiro de pesquisa está organizado para verificar cinco proposições sobre os programas de IC e, mais especificamente, sobre os campos de pesquisa que a envolvem. Esquematicamente, a Tabela 4.1 apresenta o roteiro de pesquisa. 
Tabela 4.1 - Estrutura do Roteiro de Pesquisa

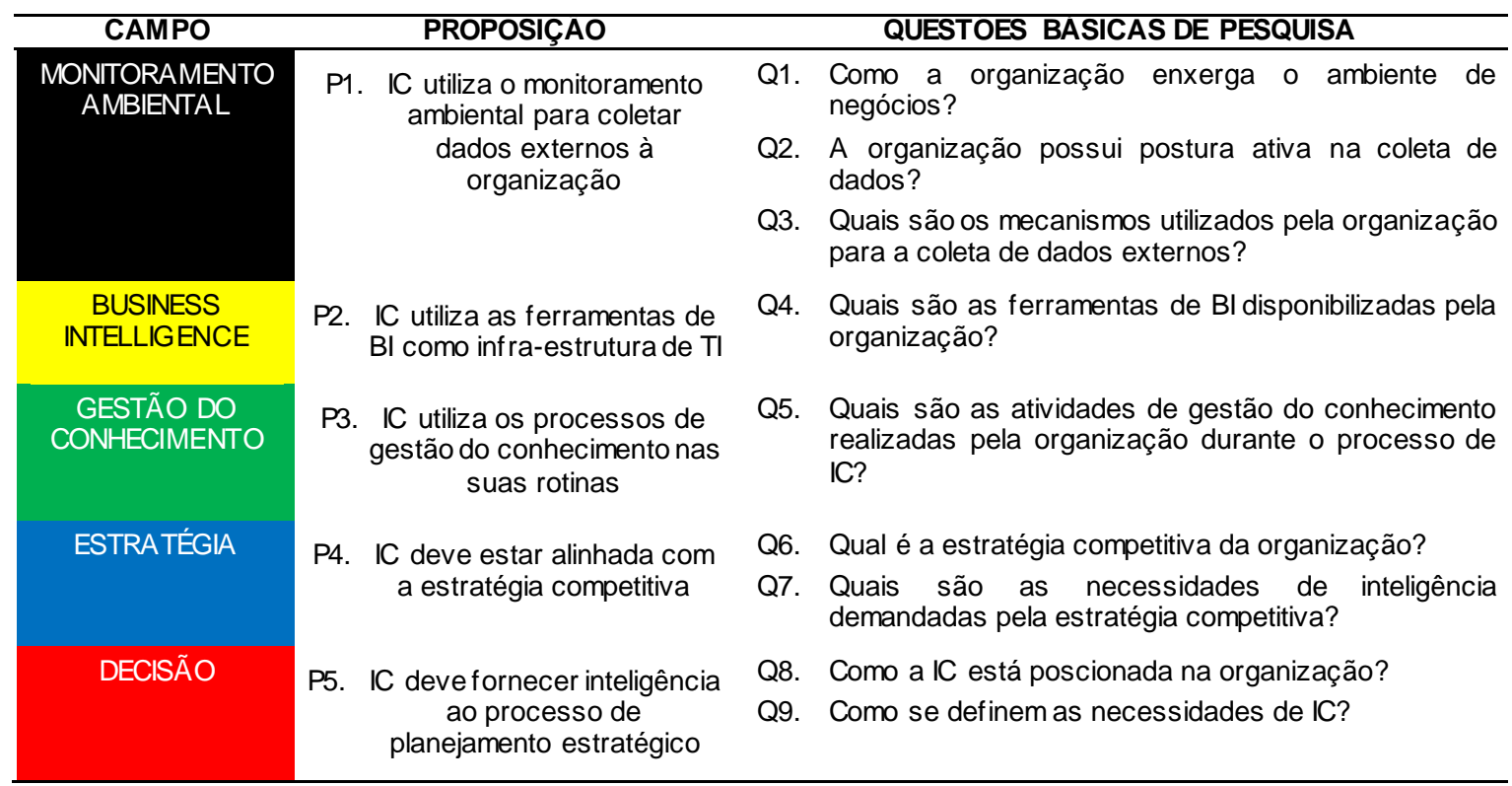

\subsection{Critérios de Coleta e Análise dos Dados}

A análise dos casos será realizada considerando os dados coletados através do roteiro de pesquisa construído a seguir e baseado nas questões já elaboradas. Para isso, são definidas as perguntas para cada campo de pesquisa bem como a estratégia de coleta e análise dos resultados de cada uma.

\subsubsection{Monitoramento Ambiental}

O objetivo do estudo de caso neste campo de pesquisa é compreender como o monitoramento ambiental pode ser utilizado pela IC, em especial na coleta de dados externos. Para isso, foram estruturadas 5 questões.

As questões 1 a 3 são destinadas a compreensão sobre como a organização enxerga o ambiente de negócios (referente à Q1 na Tabela 4.1). Considerando que existem cinco modelos identificados na literatura (LENZ; ENGLEDOW, 1986), foram desenvolvidas três perguntas de múltipla escolha. São elas:

1. Como a organização enxerga o ambiente de negócios?

a. O ambiente é composto por forças competitivas.

b. Os fatores ambientais e suas relações causais definem uma estrutura cognitiva do ambiente. 
c. O ambiente é composto por organizações interdependentes caracterizadas por uma hierarquia de relevância definida pela organização foco.

d. O ambiente é um sistema que se caracteriza por níveis de hierarquia relacionados a certas dimensões (sociais, naturais, recursos, etc.).

e. O ambiente é diferenciado por estruturas sociais e institucionais, relações, regras e valores definidos por uma ideologia, cultura, etc.

2. Como surgem as mudanças no ambiente de negócios?

a. As mudanças são provocadas pelo processo evolucionário da indústria.

b. As mudanças refletem nas revisões das estruturas cognitivas, dandoIhes novos significados.

c. As mudanças são originadas no ambiente geral e afetam os fenômenos do ambiente tarefa.

d. As mudanças são contínuas, potencialmente previsíveis e ocorrem de modo autônomo em cada nível.

e. Experiências realizadas por indivíduos e organizações provocam distúrbios nas estruturas, ideologias, culturas, etc.

3. Como é possível obter conhecimento sobre o ambiente de negócios?

a. Desenvolver um sistema formal de análise dos competidores conectados ao planejamento estratégico.

b. Estimular a aprendizagem organizacional através de um processo de decisão flexível.

c. Definir uma estrutura administrativa consistente com as contingências ambientais e um processo de gestão dos stakeholders.

d. Estimular a aprendizagem organizacional nas unidades de negócio.

e. Monitorar as tendências mais amplas.

As respostas obtidas deverão sinalizar o modelo que mais se adequa à visão de ambiente adotado pela organização. Elas serão analisadas da seguinte forma:

- Maioria de respostas A indica o modelo de estrutura da indústria 
- Maioria de respostas B indica o modelo cognitivo

- Maioria de respostas $\mathrm{C}$ indica o modelo de campos organizacionais

- Maioria de respostas $D$ indica o modelo ecológico de dependência de recursos

- Maioria de respostas E indica o modelo de era

Já a questão 4 é destinada a compreensão da postura da organização no processo de coleta de dados (referente à Q2 na Tabela 4.1). Considerando o conceito dicotômico apresentado por Choo (2001), a organização pode ser ativa ou passiva nesta atividade. Por isso, foram desenvolvidas três afirmações com respostas do tipo binária, verdadeiro ou falso. São elas:

4. Avalie as afirmações abaixo como VERDADEIRO ou FALSO.

a. A organização possui um departamento específico para monitorar, recriar e descobrir sinais de mudança no ambiente.

b. A organização procura validar as informações recebidas do ambiente, podendo até enviar alguém para uma pesquisa em campo.

c. A organização realizar testes no ambiente para testar inovações no negócio e decidir sobre sua viabilidade.

As respostas obtidas deverão sinalizar a postura da organização com relação à captura de dados externos. Elas serão analisadas da seguinte forma:

- Maioria de respostas VERDADEIRO indica a postura ativa

- Maioria de respostas FALSO indica a postura passiva

De posse dos resultados destes dois blocos de questão, pode-se identificar qual é o modelo de monitoramento ambiental mais apropriado ao perfil da organização. Entretanto, para validar se o monitoramento ambiental é a ferramenta utilizada pelas organizações na coleta de dados do ambiente externo, é necessário conhecer os principais mecanismos de coleta e verificar se eles estão alinhados com o modelo sugerido pela análise anterior. Por isso, a questão 5 é destinada a identificação dos mecanismos de captura de dados (referente à Q3 na Tabela 4.1). Considerando que são apresentados quatro modelos de monitoramento ambiental em um continuum 
(CHOO, 2001; AGUILAR, 1967), foram desenvolvidas cinco afirmações que devem ser avaliadas pelos entrevistados. São elas:

5. Com qual frequência a organização utiliza os mecanismos abaixo (utilize a escala: 1 = nunca e 5 =sempre).

a. A organização coleta dados através de bases de dados on line.

b. A organização coleta dados através de pesquisas de campo.

c. A organização coleta dados através de equipe de vendas.

d. A organização coleta dados com alto grau de detalhamento.

e. A organização coleta dados sobre assuntos pré-definidos.

As avaliações deverão ser realizadas com base na escala Likert para que os entrevistados respondam com graus variados de concordância a cada item que descreve o mecanismo de coleta de dados proposto, variando a avaliação entre 1 (nunca) a 5 (sempre). As respostas serão analisadas quantitativamente com base na média aritmética, de acordo com os resultados abaixo:

- Média aritmética entre 1 e 2 indica o modelo de visão não direcionada;

- Média aritmética entre 2 e 3 indica o modelo de visão condicionada;

- Média aritmética entre 3 e 4 indica o modelo de pesquisa informal; e

- Média aritmética entre 4 e 5 indica o modelo de pesquisa formal.

Após esta análise quantitativa, essas respostas serão analisadas qualitativamente e para indicar a sinergia entre os mecanismos adotados pela organização e o modelo de monitoramento ambiental. Desta forma, a análise individual dos casos permitirá verificar se os programas de IC realmente utilizam modelos de monitoramento ambiental nas suas rotinas ou se esta ferramenta não é contemplada.

\subsubsection{Business Intelligence}

O objetivo do estudo de caso relacionado a este campo de pesquisa é compreender como as ferramentas de BI são utilizadas pelos programas de IC. Para isso, a pergunta 6 procura identificar o grau de automatização das atividades do ciclo de IC (referente à Q4 na Tabela 4.1) apresentadas na Tabela 3.1. 
6. Qual é o grau de automatização das atividades? (utilize a seguinte escala: $0=$ não desenvolve esta atividade; 1 = atividade manual, realizada por um indivíduo e sem a utilização de nenhum software; 2 = atividade semiautomatizada, realizada por um indivíduo e com a utilização de software específico; 3 = atividade automatizada, realizada através de rotinas de um software)

a. Definição dos indicadores para monitoramento

b. Definição das fontes de informação para monitoramento

c. Captura de dados:

i. Estruturados internos - relatórios das áreas internas

ii. Não-estruturados internos - idéias, sugestões e opiniões das equipes

iii. Estruturados externos - relatórios e bases de dados on line

iv. Não-estruturados externos - notícias e publicações

d. Validação de dados capturados

e. Catalogação de dados capturados

f. Classificação de dados capturados

g. Armazenamento de dados coletados

h. Processamento de dados armazenados

i. Análise de dados armazenados

j. Interpretação de informações

k. Seleção de usuários da informação

I. Distribuição da informação

Desta forma, a análise individual dos casos permitirá identificar se a IC utiliza as ferramentas de $\mathrm{BI}$ como suporte às atividades se a média aritmética das respostas for superior a 2; caso contrário, esta proposição não é sustentada. Além disso, a análise cruzada dos casos permitirá identificar as atividades de IC que mais requerem o suporte das ferramentas de Bl, caso se aplique esta proposição. 


\subsubsection{Gestão do Conhecimento}

De modo análogo, o objetivo do estudo de caso relacionado à gestão do conhecimento é compreender qual é a sinergia entre as atividades relacionadas a este tema e à IC. Para isso, é necessário construir um paralelo entre as atividades do ciclo de inteligência (Tabela 3.1) e as atividades de gestão do conhecimento (Tabela 3.5). Esta comparação foi realizada com base na proximidade conceitual da descrição destas atividades e o resultado é apresentado na Tabela 4.2.

Tabela 4.2 - Diagnóstico referente à gestão do conhecimento

\begin{tabular}{|c|c|}
\hline CICLO DE INTELIGENCIA & ATIVIDADES DE GESTAO DO CONHECIMENTO \\
\hline Identificação de variáveis & \\
\hline Identificação de fontes & Captura / aquisição \\
\hline Captura & Filtragem / validação \\
\hline Validação & Categorização / catalogação \\
\hline Catalogação & Identificação / classificação \\
\hline Classificação & Armazenamento \\
\hline Armazenamento & Recuperação \\
\hline Processamento & \\
\hline Mineração & Compartilhamento \\
\hline Interpretação & pelo autor \\
\hline Seleção de destinatários & Fonte: elaborado \\
\hline Distribuição &
\end{tabular}

Admitindo este paralelo, pode-se considerar que algumas perguntas realizadas no campo de pesquisa anterior sejam úteis neste bloco. Mais especificamente, as respostas obtidas com a pergunta 6 já definem se essas atividades de gestão do conhecimento são utilizadas pelos programas de IC (referente à Q5 na Tabela 4.1). Portanto, não é necessário desenvolver perguntas adicionais a este tema.

Analogamente à análise anterior, a análise individual dos casos permitirá identificar se a IC realiza atividades de gestão do conhecimento se a média aritmética das respostas for superior a 1; caso contrário, esta proposição não é sustentada. Além disso, a análise cruzada dos casos permitirá identificar as atividades de gestão do conhecimento mais importantes para o desenvolvimento da IC.

\subsubsection{Estratégia}

O objetivo desta pesquisa, no que se refere ao campo de pesquisa em estratégia, é verificar se a IC deve possuir alinhamento com a estratégia competitiva da organização, através das definições de necessidade de inteligência. Neste sentido, foram desenvolvidas afirmações para serem avaliadas como VERDADEIRO ou 
FALSO, que visam confirmar a existência deste alinhamento nos programas de IC estudados. Em primeiro lugar, as perguntas 7 a 11 são destinadas a compreender a intensidade das forças competitivas da indústria, conceito que é detalhado Anexo I (referente à Q6 na Tabela 4.1).

7. Rivalidade dos Concorrentes

a. Os concorrentes são numerosos ou equilibrados

b. A indústria apresenta taxa de crescimento baixa

c. Os custos fixos associados ao mercado são elevados

d. Os produtos ofertados pelo mercado não possuem muito diferenciação

e. O aumento da capacidade produtiva da indústria requer investimentos elevados

f. Os concorrentes possuem estratégias competitivas muito divergentes

g. As barreiras de saída do mercado são elevadas

8. Poder de Barganha dos Fornecedores

a. O produto dos fornecedores é um insumo crítico

b. O grupo de fornecedores é constituído por poucas companhias e mais concentrado do que a indústria em análise

c. A indústria não é um cliente importante para o grupo de fornecedores

d. Os produtos dos fornecedores são diferenciados e não concorrem com produtos substitutos

e. Os fornecedores são uma ameaça concreta de integração vertical

9. Poder de Barganha dos Clientes

a. Os clientes estão concentrados ou adquirem produtos em grandes quantidades

b. As compras representam uma fração significativa de seus custos

c. Os produtos da indústria são padronizados e/ou não são importantes para a qualidade de produtos dos clientes

d. Os clientes têm total informação 
e. O grupo de clientes é uma ameaça concreta de integração para trás 10. Ameaça de Novos Entrantes

a. Existe a necessidade de economia de escala

b. O grau de dependência de patentes é elevado

c. O acesso à matéria-prima é difícil

d. Existem políticas de subsídio oficiais

e. A curva de aprendizado da indústria não é lenta

\section{Ameaça de Produtos Substitutos}

a. Existem outros produtos que desempenham a mesma função

As avaliações deverão ser realizadas com base na escala Likert, variando a resposta entre 1 (discordo totalmente) a 5 (concordo totalmente). As respostas serão analisadas quantitativamente com base na média aritmética, de acordo com os resultados abaixo:

- Média aritmética entre 1 e 2 indica que a intensidade da força competitiva é irrelevante na formulação estratégica;

- Média aritmética entre 2 e 3 indica que a intensidade da força competitiva é pouco relevante na formulação estratégica;

- Média aritmética entre 3 e 4 indica que a intensidade da força competitiva é muito relevante na formulação estratégica;

- Média aritmética entre 4 e 5 indica que a intensidade da força competitiva é fundamental na formulação estratégica;

Contudo, para avaliar o alinhamento entre a formulação estratégica e a IC, é necessário conhecer as principais necessidades de inteligência demandadas pela organização, ou seja, quais tipos de informações a organização espera que a IC forneça. Para isso, foram elaboradas cinco questões com respostas binárias, do tipo verdadeiro ou falso, sobre quais são as expectativas da organização com relação à IC (referente à Q7 na Tabela 4.1), ou seja:

12. A organização espera que a IC forneça informações relevantes sobre:

a. Concorrentes existentes 

b. Fornecedores
c. Clientes
d. Potenciais ingressantes
e. Produtos substitutos

As respostas obtidas serão comparadas conforme a Tabela 4.3. Através desta análise, pretende-se identificar se os programas de IC devem estar alinhados com a formulação estratégica através da definição de necessidades.

Tabela 4.3 - Diagnóstico referente à estratégia

\begin{tabular}{|l|c|c|}
\hline FORÇAS COMPETITIVAS & INTENSIDADE & NECESSIDADE \\
\hline Rivalidade entre concorrentes existentes & 7 & $12 \mathrm{a}$ \\
\hline Poder de barganha dos fornecedores & 8 & $12 \mathrm{~b}$ \\
\hline Poder de barganha dos clientes & 9 & $12 \mathrm{c}$ \\
\hline Ameaça de novos ingressantes & 10 & $12 \mathrm{~d}$ \\
\hline Ameaça de produtos substitutos & 11 & $12 \mathrm{e}$ \\
\hline
\end{tabular}

Fonte: elaborado pelo autor

A análise individual dessas questões é realizada mediante a confrontação da estratégia competitiva com as necessidades de inteligência de modo compreender como ocorre esta interação. Além disso, a análise conjunta dos casos fornecerá indícios sobre se o programa de IC precisa ser alinhado à estratégia adotada pela organização.

\subsubsection{Decisão}

Como apresentado na revisão de literatura, o campo de pesquisa decisão é o campo conceitualmente menos evoluído na teoria de IC. Em relação à este tópico, o objetivo do estudo de campo é compreender como os produtos e serviços oferecidos pela IC são utilizados pelas organizações em seu processo decisório. Para isso, foram elaboradas duas questão (referente à Q8 e $\quad$ Q9 na Tabela 4.1, respectivamente) de múltipla escolha:

13. Qual é o posicionamento hierárquico da equipe de IC na organização?

a. A IC é uma unidade administrativa independente.

b. A IC é uma unidade administrativa subordinada à área de negócio.

c. A IC é uma unidade administrativa subordinada à área de planejamento. 
d. A IC não é uma unidade administrativa.

14. Qual estrutura é responsável por definir as necessidades de inteligência?

a. A IC define suas necessidades baseada na sua própria percepção dos fatores críticos do negócio.

b. A área de negócio pré-define as necessidades de IC.

c. A área de planejamento pré-define as necessidades de IC.

d. A IC não possui necessidades pré-definidas. 


\section{RESULTADOS}

Esta seção tem por objetivo apresentar os resultados obtidos no desenvolvimento da pesquisa de campo. Para cada estudo de caso realizado será construído um item de apresentação e análise dos dados, com base no questionário. Assim, cada item será composto por:

- Monitoramento ambiental (questões 1 a 5);

- Business intelligence (questão 6);

- Gestão do conhecimento (questão 6);

- Alinhamento estratégico (questão 7 a 12); e

- Decisão (questões 13 e 14).

Entretanto, antes de exprimir os resultados dos casos, é importante avaliar o desempenho de cada segmento do mercado de crédito, em termos de participação no mercado e crescimento médio anual, para identificar os diferentes contextos estratégicos, conforme a Figura 5.1.

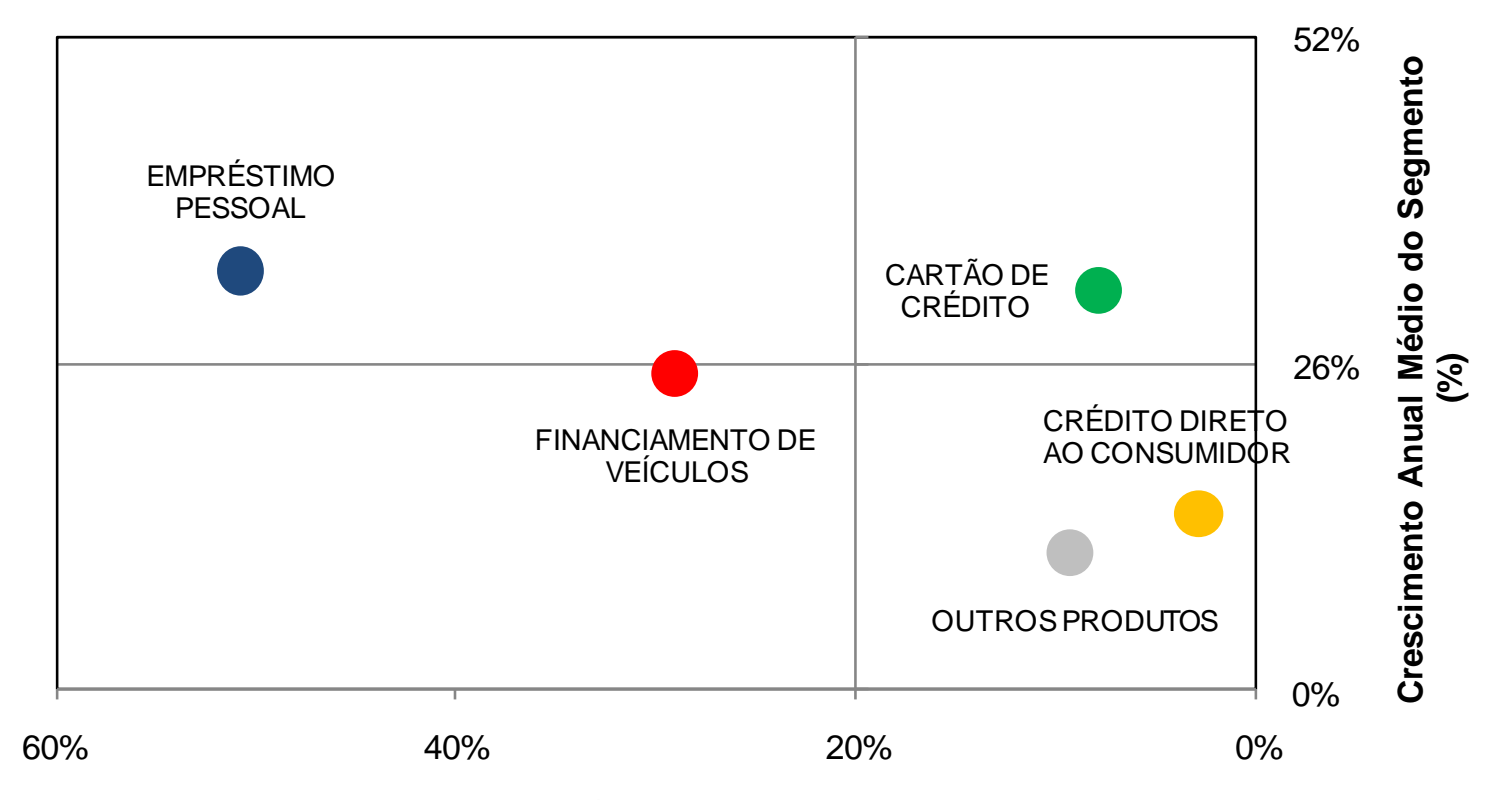

Participação no Mercado (\%)

Figura 5.1 - Análise do mercado de crédito PF

Fonte: elaborado pelo autor

Os resultados indicam que o empréstimo pessoal pode ser considerado o principal segmento do mercado de crédito, representando $50,8 \%$ da carteira de crédito total 
do varejo e registrando crescimento anual médio de 33,4\%. Além disso, observando a Figura 5.2, percebe-se que o mercado de empréstimo pessoal se desenvolveu muito nos últimos, superando o saldo de R\$ 160 bilhões em dezembro de 2009 . Desta forma, conclui-se que este segmento está em expansão.

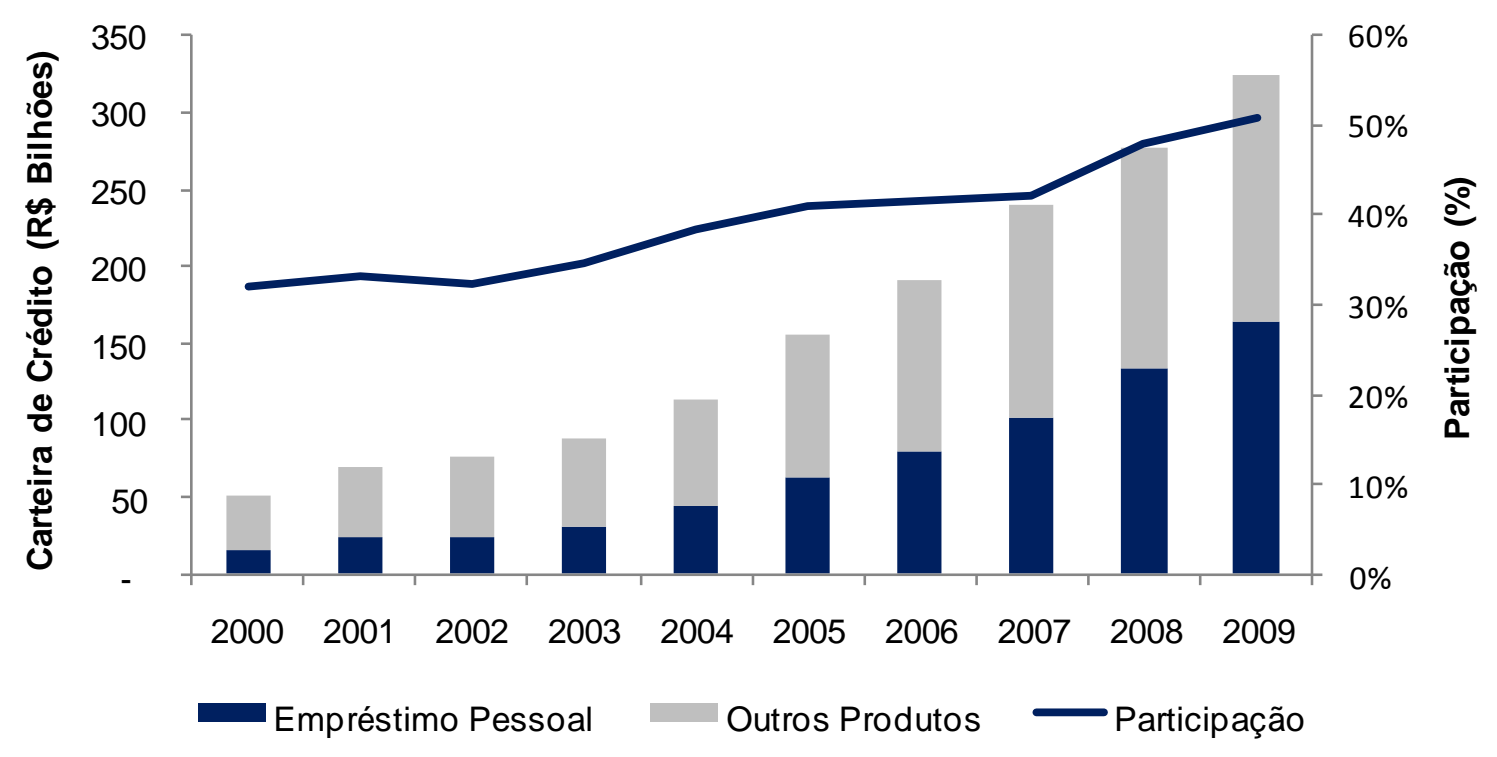

Figura 5.2 - Evolução do mercado de empréstimo pessoal

Fonte: Banco Central do Brasil (2010)

De modo análogo, pode-se considerar que o financiamento de veículos é o segundo principal segmento do mercado de crédito de varejo com $29,1 \%$ de participação no mercado. Entretanto, o crescimento médio anual deste segmento, que registra $25,3 \%$, está abaixo do resultado obtido pelo mercado. A Figura 5.3 mostra a evolução deste segmento na última década e, por um lado, reforça a estabilidade deste segmento, permitindo concluir que este segmento está estável. Por outro lado, concentrando a análise no biênio 2008/2009, nota-se que a redução de participação deste segmento no mercado coincide com o período da crise, o que permite inferir sobre a volatilidade deste segmento com relação ao ambiente externo. 


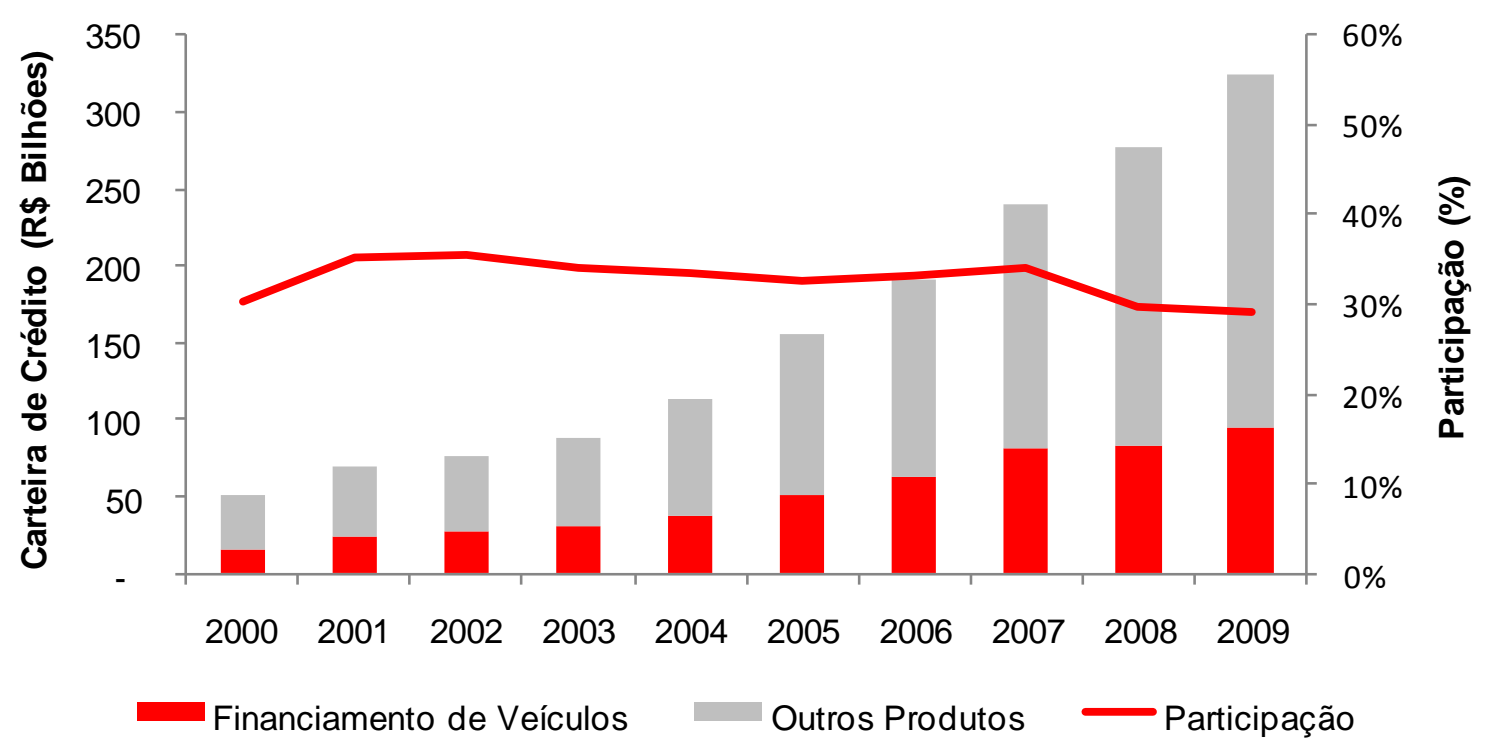

Figura 5.3 - Evolução do mercado de financiamento de veículos Fonte: Banco Central do Brasil (2010)

O terceiro segmento deste mercado, cartão de crédito, tem registrado crescimento médio anual de 31,9\%, mas sua participação no mercado de crédito ao varejo ainda é pequena, com 7,9\%. Pela análise da Figura 5.4, percebe-se que este segmento tem aumentado sua participação no mercado ano a ano, porém sem grandes oscilações. Desta forma, pode-se concluir que este é um segmento em expansão.

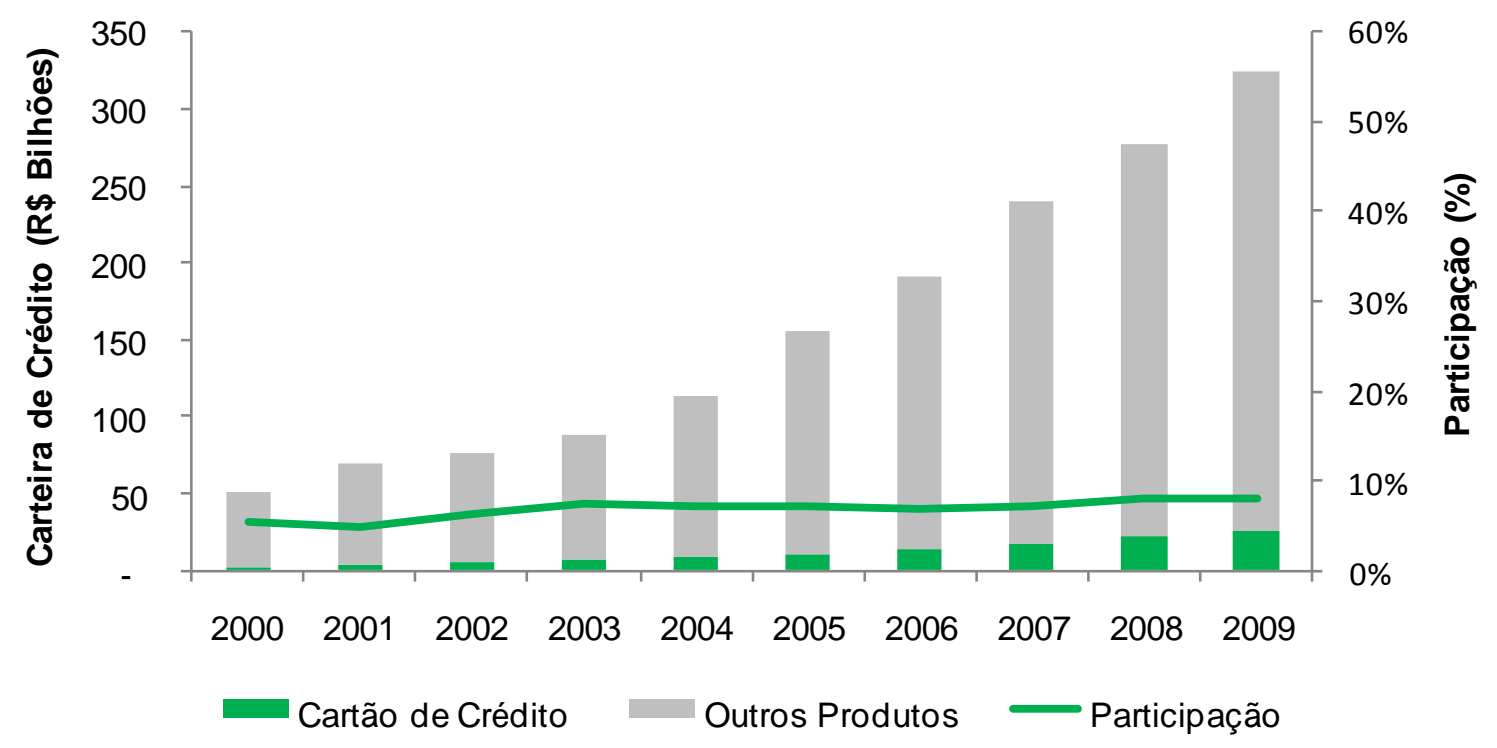

Figura 5.4 - Evolução do mercado de cartão de crédito

Fonte: Banco Central do Brasil (2010) 
Por fim, o quarto segmento do mercado de crédito de varejo é o crédito direto ao consumidor. A Figura 5.1 mostra que tanto a parcela quanto o crescimento deste segmento são baixos quando comparados ao mercado e, sob outra ótica, a Figura 5.5 mostra que sua participação está declinando a cada ano. Desta forma, conclui se que este é um mercado em retração.

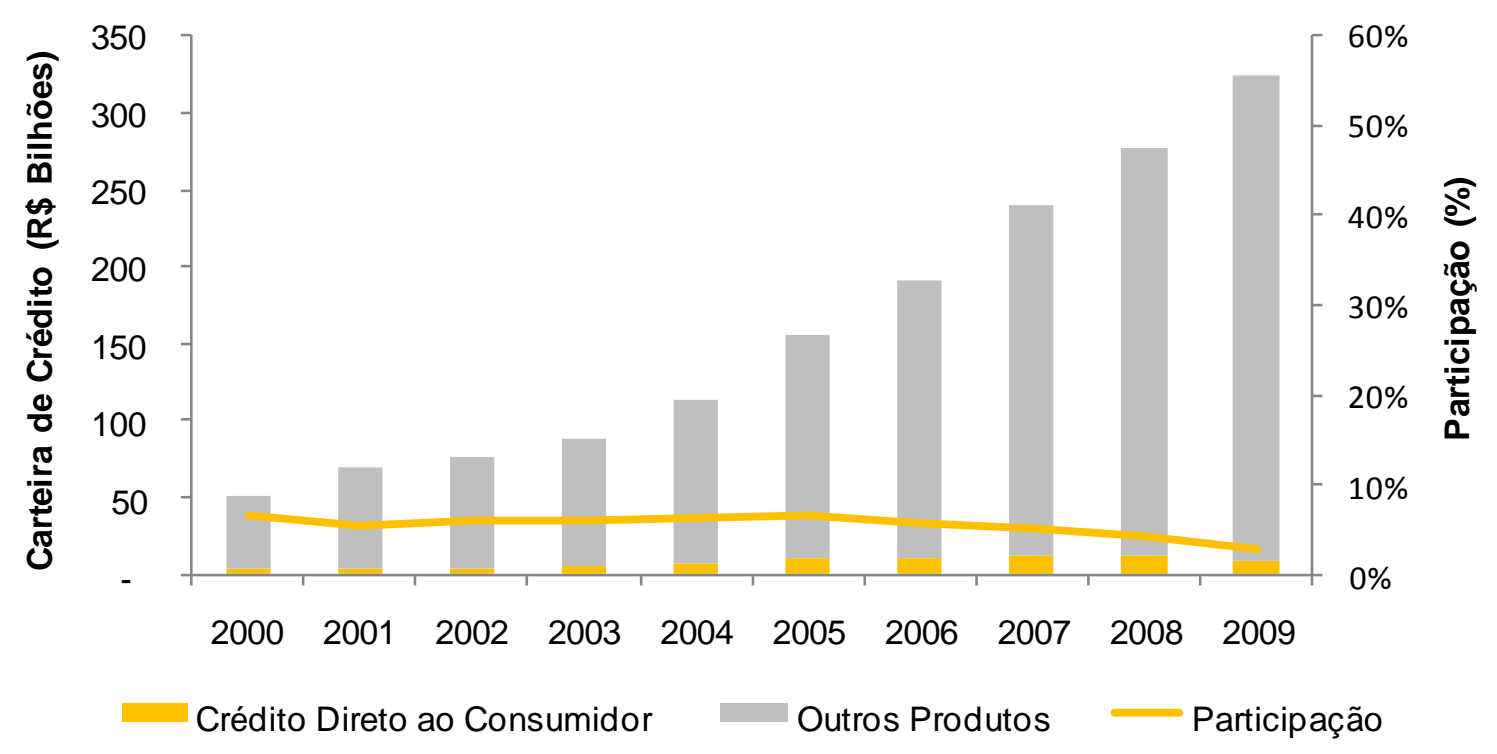

Figura 5.5 - Evolução do mercado de crédito direto ao consumidor

Fonte: Banco Central do Brasil (2010)

Realizada a análise preliminar dos principais segmentos que compõem o mercado de crédito de varejo, o próximo passo é discutir cada caso individualmente.

\subsection{Caso A - Empréstimo Pessoal}

O caso A se desenvolve em um banco médio que atua no segmento de empréstimo pessoal, cujo modelo de negócio está baseado em correspondentes. Estes são pessoas jurídicas cadastradas pela instituição junto ao Banco Central do Brasil para realizarem a prestação de alguns serviços. Para este caso, em particular, os correspondentes são empresas que possuem relacionamento não exclusivo para a distribuição de crédito pessoal. A Figura 5.6 ilustra o funcionamento da indústria em função de seus principais atores, considerando os resultados obtidos durante a entrevista. 


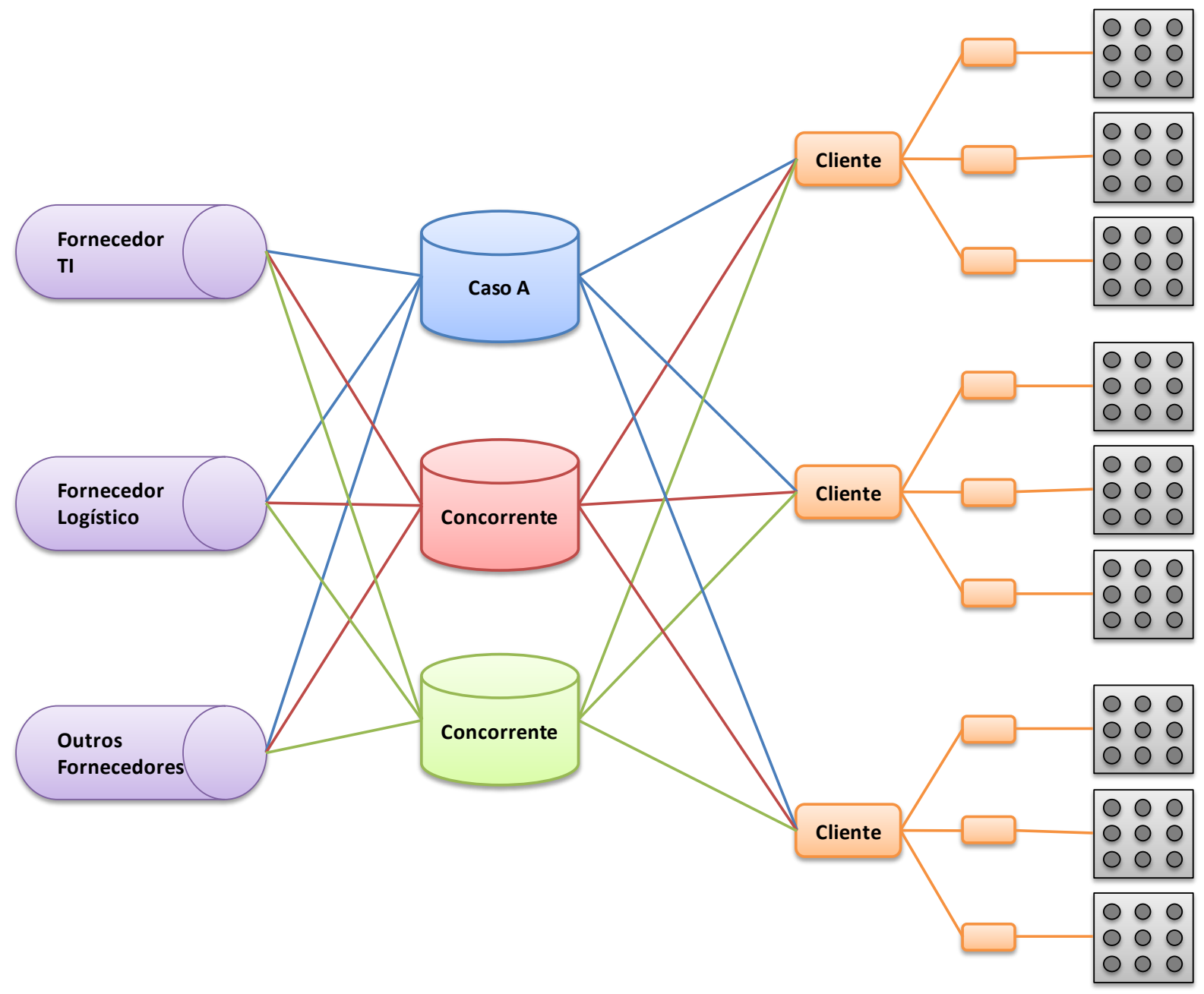

Figura 5.6 - Sistema de valor do caso A

Fonte: elaborado pelo autor

Em primeiro lugar, destaca-se que existem diversos players atuando fortemente neste segmento; cada um está representado por uma cor diferente. Entretanto, para construir sua operação, cada player opta pela contratação de fornecedores em certas atividades, destacando-se TI (sistemas operacionais) e logística (rede de coleta de documentação). Enquanto os sistemas de TI são fundamentais para agilizar os processos de venda, a estrutura logística é fundamental para garantir a formalização das operações e, com isso, minimizar riscos jurídicos do negócio. Além destas, os concorrentes devem dispor de outras atividades de suporte.

De acordo com as entrevistas, pode-se perceber que para cada atividade, as opções de fornecedores são restritas e não existem acordos de exclusividade na prestação dos serviços. Sendo assim, todos os players podem acessar os mesmos fornecedores, o que é representado na Figura 5.6 pelas linhas de diferentes cores que ligam os concorrentes aos fornecedores. 
Em segundo lugar, é importante entender quem são os clientes destes players e, para isso, será necessário explicar o canal de distribuição dos produtos. Quando um consumidor deseja adquirir um empréstimo pessoal, ele procura um agente financeiro em sua região que lhe apresenta as diversas opções de empréstimo pessoal. Após a decisão do consumidor, este agente oferece a operação para um determinado correspondente com que possui relacionamento, entregando-lhe toda a documentação necessária para iniciar a solicitação de empréstimo junto às instituições financeiras. Por isso, os correspondentes são os clientes.

Esclarecido o papel do cliente, é importante entender este relacionamento. Para o segmento de empréstimo pessoal, no qual se destaca o empréstimo consignado, não é prática comum a existência de contratos de exclusividade entre os players e os correspondentes. Em outras palavras, os clientes possuem o relacionamento com os consumidores e também atuam com diversos players em paralelo.

\subsubsection{Monitoramento Ambiental}

Em virtude da importância do ambiente para a IC, identificar o modelo de monitoramento ambiental é o ponto de partida para compreender o programa de IC da organização. Para isso, a Tabela 5.2 apresenta as respostas das questões 1 a 5 .

Tabela 5.1 - Dados do caso A: monitoramento ambiental

\begin{tabular}{|c|c|c|}
\hline & QUESTÃO & RESPOSTA \\
\hline 1 & Como a organização enxerga o ambiente de negócios? & $\mathrm{C}$ \\
\hline 2 & Como surgem as mudanças no ambiente de negócios? & C \\
\hline 3 & Como é possível obter conhecimento sobre o ambiente de negócios? & C \\
\hline $4 a$ & $\begin{array}{l}\text { A organização possui um departamento específico para monitorar, } \\
\text { recriar e descobrir sinais de mudança no ambiente. }\end{array}$ & $\mathrm{F}$ \\
\hline $4 b$ & $\begin{array}{l}\text { A organização procura validar as informações recebidas do } \\
\text { ambiente, podendo até enviar alguém para uma pesquisa em campo. }\end{array}$ & V \\
\hline $4 c$ & $\begin{array}{l}\text { A organização realizar testes no ambiente para testar inovações no } \\
\text { negócio e decidir sobre sua viabilidade. }\end{array}$ & $\mathrm{F}$ \\
\hline $5 a$ & A organização coleta dados através de bases de dados on line. & 1 \\
\hline $5 b$ & A organização coleta dados através de pesquisas de campo. & 2 \\
\hline $5 c$ & A organização coleta dados através de equipe de vendas. & 3 \\
\hline $5 d$ & A organização coleta dados com alto grau de detalhamento. & 1 \\
\hline $5 e$ & A organização coleta dados sobre assuntos pré-definidos. & 1 \\
\hline
\end{tabular}


Utilizando o critério definido na metodologia, pode-se perceber que as questões 1 a 3 possuem respostas predminantemente $\mathrm{C}$, o que indica que a organização enxerga o ambiente através do modelo de campos organizacionais. Por outro lado, para a questão 4, foram obtidas a maioria de respostas FALSO e, de acordo com os critérios adotados, pode-se considerar que a postura da organização é passiva.

Nesse sentido, de acordo com o modelo de Choo (2001), a literatura aponta que o modelo de monitoramento ambiental adequado a esta organização seria a visão não direcionada, pois o ambiente não é analisável e a postura é passiva. Esta percepção é confirmada pelo resultado da questão 5 , cuja a média aritimética das respostas obtidas foi 1,6. Desta forma, a Tabela 5.2 consolida a análise do monitoramento ambiental para este caso.

Tabela 5.2 - Análise do caso A: monitoramento ambiental

\begin{tabular}{clcl}
\hline QUESTÃO & CONSTRUCTO & RESPOSTA & CONCLUSÃO \\
\hline 1 a 3 & Modelo de ambiente & Maioria C & Campos organizacionais \\
4 & Postura da empresa & Maioria F & Passiva \\
5 & Modelo de monitoramento & Média 1,6 & Visão não direcionada \\
\hline
\end{tabular}

Fonte: elaborado pelo autor

\subsubsection{Business Intelligence e Gestão do Conhecimento}

Considerando que o critério de análise sobre business intelligence e gestão do conhecimento é baseado na média aritimética da questão 6, a Tabela 5.3 apresenta todas as respostas.

Tabela 5.3 - Dados do caso A: business intelligence e gestão do conhecimento

\begin{tabular}{llc}
\hline & \multicolumn{1}{c}{ QUESTAO } & RESPOSTA \\
\hline $6 \mathrm{a}$ & Definição dos indicadores para monitoramento & 1 \\
$6 \mathrm{~b}$ & Definição das fontes de informação para monitoramento & 1 \\
$6 \mathrm{c} . \mathrm{i}$ & Captura de dados: estruturados internos - relatórios das áreas internas & 3 \\
$6 \mathrm{c} . \mathrm{ii}$ & $\begin{array}{l}\text { Captura de dados: não-estruturados internos - idéias, sugestões e } \\
\text { opiniões das equipes }\end{array}$ & 1 \\
$6 \mathrm{c} . \mathrm{iii}$ & Captura de dados: estruturados externos - relatórios e bases de dados & 1 \\
$6 \mathrm{c} . \mathrm{iv}$ & Captura de dados: não-estruturados externos - notícias e publicações & 3 \\
$6 \mathrm{~d}$ & Validação de dados capturados \\
$6 \mathrm{e}$ & Catalogação de dados capturados & 1 \\
$6 f$ & Classificação de dados capturados & 0 \\
$6 \mathrm{~g}$ & Armazenamento de dados coletados & 0 \\
$6 \mathrm{~h}$ & Processamento de dados armazenados & 2 \\
$6 \mathrm{i}$ & Análise de dados armazenados & 2 \\
$6 \mathrm{j}$ & Interpretação de informações \\
$6 \mathrm{k}$ & Seleção de usuários da informação & 2 \\
$6 \mathrm{ll}$ & Distribuição da informação & 1 \\
\hline
\end{tabular}

Fonte: elaborado pelo autor 
O resultado obtido para o caso $A$ foi 1,5 . No que se refere à utilização de ferramentas de $\mathrm{BI}$ para dar suporte às atividades de IC, essa média indica que a IC ainda não utiliza amplamente as ferramentas de BI nesta empresa. Apontam-se algumas iniciativas, isto é, atividades cuja resposta é superior a 2 , das quais se destacam a captura de dados estruturados internos e dados não estruturados externos.

Já no que se refere ao desenvolvimento de atividades de gestão do conhecimento pela IC, a média obtida indica que existe grande sinergia, pois é superior a 1,0. Além disso, dentre todas as atividades listadas, somente a catalogação e a classificação dos dados capturados não são realizados.

\subsubsection{Alinhamento Estratégico}

De acordo com os resultados obtidos nas questões 7 a 11, os quais são apresentados na Tabela 5.4, pode-se construir a análise estrutural da indústria de empréstimo pessoal.

Com relação à rivalidade entre concorrentes existentes, foram obtidas 5 respostas do tipo VERDADEIRO, o que indica que esta é uma força competitiva relevante neste mercado. De acordo com as percepções do entrevistado, existem diversos concorrentes neste segmento e, em geral, são equilibrados devido às determinações impostas pelos órgãos reguladores, o que reflete em estratégias competitivas bastante semelhantes e produtos com pouca diferenciação. Além disso, os custos fixos da operação são elevados, em especial para o crédito consignado, o que envolve a necessidade de abertura e manutenção dos convênios com órgãos públicos bem como dos clientes. Nesse sentido, o investimento para a ampliação das operações envolve a necessidade de capital para alavancagem das operações bem como a disposição para a redução das margens operacionais visando oferecer maiores benefícios para os clientes. Entretanto, alguns fatores amenizam esta força, em especial a alta taxa de crescimento do mercado, como já mostrava Figura 5.2.

Já em relação ao poder de barganha dos fornecedores, nenhuma das respostas foi do tipo VERDADEIRO, ou seja, está não é uma força competitiva relevante para este mercado. Na maioria das situações, os fornecedores oferecem serviços agregados a operações do segmento, o qual representa uma significativa parcela da receita da maioria dos fornecedores. Além disso, eles não representam uma ameaça 
de integração vertical já que, em muitos casos, o serviço core oferecido nada tem relação com o produto da indústria.

Tabela 5.4 - Dados do caso A: estratégia

\begin{tabular}{|c|c|c|c|}
\hline $\begin{array}{c}\text { FORÇA } \\
\text { COMPETITIVA }\end{array}$ & & QUESTÃO & RESPOSTA \\
\hline \multirow{7}{*}{$\begin{array}{l}\text { Rivalidade entre } \\
\text { concorrentes } \\
\text { existentes }\end{array}$} & $7 a$ & Os concorrentes são numerosos ou equilibrados & $\bar{V}$ \\
\hline & $7 \mathrm{~b}$ & A indústria apresenta taxa de crescimento baixa & $\mathrm{F}$ \\
\hline & 7c & Os custos fixos associados ao mercado são elevados & V \\
\hline & $7 d$ & $\begin{array}{l}\text { Os produtos ofertados pelo mercado não possuem muito } \\
\text { diferenciação }\end{array}$ & V \\
\hline & $7 e$ & $\begin{array}{l}\text { O aumento da capacidade produtiva da indústria requer } \\
\text { investimentos elevados }\end{array}$ & V \\
\hline & $7 f$ & $\begin{array}{l}\text { Os concorrentes possuem estratégias competitivas muito } \\
\text { divergentes }\end{array}$ & $\mathrm{F}$ \\
\hline & $7 g$ & As barreiras de saída do mercado são elevadas & V \\
\hline \multirow{5}{*}{$\begin{array}{l}\text { Poder de barganha } \\
\text { dos fornecedores }\end{array}$} & $8 a$ & O produto dos fornecedores é um insumo crítico & $\mathrm{F}$ \\
\hline & $8 b$ & $\begin{array}{l}\text { O grupo de fornecedores é constituído por poucas companhias } \\
\text { e mais concentrado do que a indústria em análise }\end{array}$ & $\mathrm{F}$ \\
\hline & $8 \mathrm{c}$ & $\begin{array}{l}\text { A indústria não é um cliente importante para o grupo de } \\
\text { fornecedores }\end{array}$ & $F$ \\
\hline & $8 d$ & $\begin{array}{l}\text { Os produtos dos fornecedores são diferenciados e não } \\
\text { concorrem com produtos substitutos }\end{array}$ & $F$ \\
\hline & $8 e$ & $\begin{array}{l}\text { Os fornecedores são uma ameaça concreta de integração } \\
\text { vertical }\end{array}$ & $\mathrm{F}$ \\
\hline \multirow[t]{5}{*}{$\begin{array}{l}\text { Poder de barganha } \\
\text { dos clientes }\end{array}$} & $9 a$ & $\begin{array}{l}\text { Os clientes estão concentrados ou adquirem produtos em } \\
\text { grandes quantidades }\end{array}$ & V \\
\hline & $9 b$ & $\begin{array}{l}\text { As compras representam uma fração significativa de seus } \\
\text { custos }\end{array}$ & V \\
\hline & $9 c$ & $\begin{array}{l}\text { Os produtos da indústria são padronizados e/ou não são } \\
\text { importantes para a qualidade de produtos dos clientes }\end{array}$ & V \\
\hline & $9 d$ & Os clientes têm total informação & V \\
\hline & $9 e$ & $\begin{array}{l}\text { O grupo de clientes é uma ameaça concreta de integração } \\
\text { para trás }\end{array}$ & $\mathrm{F}$ \\
\hline \multirow{5}{*}{$\begin{array}{l}\text { Ameaça de novos } \\
\text { ingressantes }\end{array}$} & $10 a$ & Existe a necessidade de economia de escala & V \\
\hline & $10 \mathrm{~b}$ & O grau de dependência de patentes é elevado & $\mathrm{F}$ \\
\hline & $10 c$ & O acesso à matéria-prima é difícil & $\mathrm{F}$ \\
\hline & $10 d$ & Existem políticas de subsídio oficiais & $\mathrm{F}$ \\
\hline & $10 e$ & A curva de aprendizado da indústria não é lenta & $\mathrm{F}$ \\
\hline $\begin{array}{l}\text { Ameaça de } \\
\text { produtos substitutos }\end{array}$ & $11 \mathrm{a}$ & Existem outros produtos que desempenham a mesma função & $\mathrm{F}$ \\
\hline
\end{tabular}


Em terceiro lugar, com relação ao poder de barganha dos clientes, a obtenção de 4 repostas do tipo VERDADEIRO indica que está também é uma força competitiva de intensidade forte. Uma vez que se considera o correspondente como cliente, nota-se que eles adquirem grandes quantidades além do algto grau de maturidade e exigência de informações dos clientes. Contudo, talvez o ponto mais crítico no relacionamento com esses clientes seja que os produtos oferecidos pelo mercado não conseguem oferecer grandes diferenciações, em virtude da regulação, impulsionando a disputa por preço que acaba por transformar a comissão no maior custo da operação. Entretanto, um fator atenuante é a incapacidade destes clientes em realizar a integração para trás, devido às restrições regulatórias impostas às instituições financeiras.

Em quarto lugar, tratando da ameaça de novos ingressantes, registrou-se apenas uma resposta do tipo VERDADEIRO, isto é, esta não é uma força muito signficativa para o segmento. Isso porque não existe a dependência de patentes nem a política de subsídios oficiais além das particularidades dos convênios de crédito consignado refletir na dificuldade do acesso à matéria-prima bem como na complexidade dos seus mecanismos implicam na lentidão da curva de aprendizado.

Por fim, no que se refere à ameaça de produtos substitutos, pode-se considerar que está não é uma questão relevante. O principal motivo é que, em virtude do grande crescimento deste segmento e principalmente das regulações, o crédito pessoal consignado figura hoje como a alternativa de crédito mais atrativa para o consumidor, seja pela facilidade de acesso ao crédito, pelo prazo alongado ou mesmo pelas menores taxas de juros.

Sendo assim, a partir destas respostas, a Tabela 5.5 consolida a quantidade de respostas VERDADEIRO para avaliar a intensidade de cada força competitiva.

Tabela 5.5 - Intensidade das forças competitivas do caso A

\begin{tabular}{clcc}
\hline QUESTÃOO & FORÇA COMPETITIVA & $\begin{array}{c}\text { RESPOSTA } \\
\text { VERDADEIRO }\end{array}$ & $\begin{array}{c}\text { INTENSIDADE } \\
\text { DA FORÇA }\end{array}$ \\
\hline 7 & Rivalidade entre concorrentes existentes & $5 / 7$ & Forte \\
8 & Poder de barganha dos fornecedores & $0 / 5$ & Fraco \\
9 & Poder de barganha dos clientes & $4 / 5$ & Forte \\
10 & Ameaça de novos ingressantes & $1 / 5$ & Fraco \\
11 & Ameaça de produtos substitutos & $0 / 1$ & Fraco \\
\hline
\end{tabular}

Fonte: elaborado pelo autor 
Considerando esta análise, foi possível perceber como é a lógica competitiva da indústria. Entretanto, é importante também compreender como a organização está estruturada para entender o ambiente, em especial no que se refere às expectativas da organização com relação às demandas de inteligência. Para isso, como discutido no referencial teórico e na metodologia, a questão 12 avalia quais são essas necessidades em função das forças competitivas, conforme a Tabela 5.6.

Tabela 5.6 - Análise sobre alinhamento estratégico do caso A

\begin{tabular}{clcc}
\hline QUESTÃOO & FORÇA COMPETITIVA & $\begin{array}{c}\text { INTENSIDADE } \\
\text { DA FORÇA }\end{array}$ & RESPOSTA \\
\hline $12 \mathrm{a}$ & Rivalidade entre concorrentes existentes & Forte & $\mathrm{V}$ \\
$12 \mathrm{~b}$ & Poder de barganha dos fornecedores & Fraco & $\mathrm{F}$ \\
$12 \mathrm{c}$ & Poder de barganha dos clientes & Forte & $\mathrm{V}$ \\
$12 \mathrm{~d}$ & Ameaça de novos ingressantes & Fraco & $\mathrm{F}$ \\
$12 \mathrm{e}$ & Ameaça de produtos substitutos & Fraco & $\mathrm{F}$ \\
\hline
\end{tabular}

Fonte: elaborado pelo autor

A Tabela 5.6 resume os resultados obtidos e indica que há alinhamento entre a intensidade das forças competitivas e as expectativas da organização sobre as demandas de inteligência. Por um lado, repara-se que a rivalidade entre concorrentes existentes e o poder de barganha dos clientes são as forças mais relevantes nesta indústria e, neste caso, refletem as principais expectativas da organização. Por outro lado, o poder de barganha dos fornecedores, a ameaça de novos ingressantes e a ameaça de produtos substitutos não são forças relevantes para este segmento e também não são alvos do monitoramento. Assim, o alinhamento é evidente para este caso.

\subsubsection{Decisão}

Em relação à estrutura de decisão da IC para o Caso $A$, as respostas apresentadas na Tabela 5.7 mostram que ainda não há uma unidade administrativa organizada com a responsabilidade de desenvolver as atividades de IC (questão 13). Além disso, esta função se encontra diluída na organização e é entregue aos tomadores de decisão em diferentes formatos e, normalmente, sob demanda (questão 14).

Tabela 5.7 - Dados do caso A: decisão

\begin{tabular}{ccc}
\hline & QUESTÃO & RESPOSTA \\
\hline 13 & A IC não é uma unidade administrativa & D \\
14 & A IC não possui necessidades pré-definidas & D \\
\hline \multicolumn{3}{c}{ Fonte: elaborado pelo autor }
\end{tabular}




\subsection{Caso B - Financiamento de Veículos}

$O$ caso $B$ se desenvolve em uma financeira que atua no segmento de financiamento de veículos, cujo modelo de negócio está baseado em representantes exclusivos. A Figura 5.7 ilustra o funcionamento da indústria em função de seus principais atores.

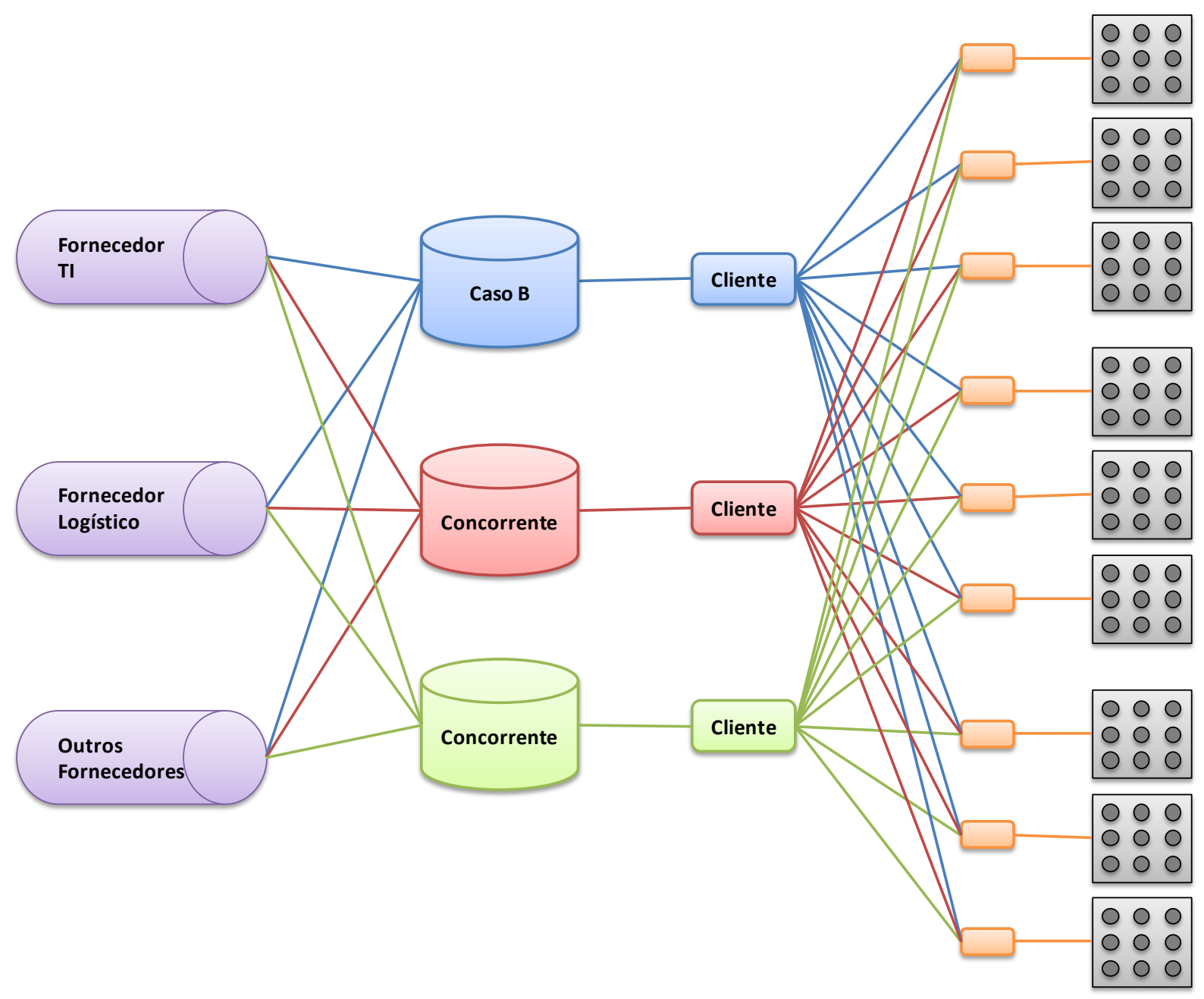

Figura 5.7 - Sistema de valor do caso B

Fonte: elaborado pelo autor

Em primeiro lugar, é importante destacar que o mercado de financiamento de veículos possui diferentes nichos e, mesmo havendo muitos players atuando neste mercado, o Caso $\mathrm{B}$ se desenvolve em um nicho no qual há um número menor de concorrentes - segmento de carros usados com mais de 10 anos da fabricação. Mesmo assim, visando criar um paralelo com o mercado de crédito pessoal, estes concorrentes são representados na figura por cores diferentes.

Em segundo lugar, analogamente ao Caso A, a construção da operação pode ser baseada na terceirização de certas atividades, com destaque para as atividades de 
TI e logística. De acordo com as entrevistas, as opções de fornecedores também são restritas e não existem acordos de exclusividade na prestação deste serviço, isto é, todos os players podem acessar os mesmos fornecedores.

A Figura 5.7 ilustra todo o sistema de valor do mercado. Quando um consumidor tem interesse no produto de financiamento, ele já fez a opção do veículo e, em geral, a decisão acontece nas revendas e concessionárias (em laranja). Isso demonstra que o produto desta indústria é um acessório e, de acordo com as entrevistas, a influência dos players sobre os consumidores é bastante restrita. Sendo assim, é possível inferir que a competição deste mercado acontece nas revendas e concessionárias. Contudo, a instituição não possui equipes próprias para atendimento às revendas, o que é realizado por correspondentes. Assim, analogamente ao caso $\mathrm{A}$, os corresondentes são os clientes da indústria.

\subsubsection{Monitoramento Ambiental}

Assim como para o caso A, o modelo de monitoramento ambiental é o ponto de partida para compreender o programa de IC da organização. Para isso, a Tabela 5.8 apresenta as respostas das questões 1 a 5 para o caso $B$.

Tabela 5.8 - Dados do caso B: monitoramento ambiental

\begin{tabular}{|c|c|c|}
\hline & QUESTÃO & RESPOSTA \\
\hline$\overline{1}$ & Como a organização enxerga o ambiente de negócios? & A \\
\hline 2 & Como surgem as mudanças no ambiente de negócios? & A \\
\hline 3 & Como é possível obter conhecimento sobre o ambiente de negócios? & A \\
\hline $4 a$ & $\begin{array}{l}\text { A organização possui um departamento específico para monitorar, } \\
\text { recriar e descobrir sinais de mudança no ambiente. }\end{array}$ & $\mathrm{F}$ \\
\hline $4 b$ & $\begin{array}{l}\text { A organização procura validar as informações recebidas do } \\
\text { ambiente, podendo até enviar alguém para uma pesquisa em campo. }\end{array}$ & $\mathrm{V}$ \\
\hline $4 c$ & $\begin{array}{l}\text { A organização realizar testes no ambiente para testar inovações no } \\
\text { negócio e decidir sobre sua viabilidade. }\end{array}$ & $\mathrm{V}$ \\
\hline $5 a$ & A organização coleta dados através de bases de dados on line. & 4 \\
\hline $5 b$ & A organização coleta dados através de pesquisas de campo. & 4 \\
\hline $5 c$ & A organização coleta dados através de equipe de vendas. & 5 \\
\hline $5 d$ & A organização coleta dados com alto grau de detalhamento. & 5 \\
\hline $5 e$ & A organização coleta dados sobre assuntos pré-definidos. & 5 \\
\hline
\end{tabular}


Utilizando o critério definido na metodologia, as respostas predominantes paras as questões 1 a 3 foram $A$, o indicando que o modelo de ambiente é de estrutura da indústria. Além disso, a questão 4 sinaizou a maioria de respostas VERDADEIRO, ou seja, pode-se considerar que a postura da organização é ativa. Desta forma, a literatura sugere que a pesquisa formal será o modelo de monitoramento ambiental indicado, pois o ambiente é analisável e a postura é ativa. Assim como no caso A, isso se confirmada com o resultado da questão 5 , cuja a média aritimética das respostas obtidas foi 4,6. Desta forma, a Tabela 5.9 consolida a análise do monitoramento ambiental para este caso.

Tabela 5.9 - Análise sobre o monitoramento ambiental do caso B

\begin{tabular}{clcl}
\hline QUESTAOO & CONSTRUCTO & RESPOSTA & CONCLUSAOO \\
\hline 1 a 3 & Modelo de ambiente & Maioria $A$ & Estrutura da indústria \\
4 & Postura da empresa & Maioria $V$ & Ativa \\
5 & Modelo de monitoramento & Média 4,6 & Pesquisa formal \\
\hline
\end{tabular}

Fonte: elaborado pelo autor

\subsubsection{Business Intelligence e Gestão do Conhecimento}

A Tabela 5.10 apresenta as respostas obtidas para a questão 6 .

Tabela 5.10 - Dados do caso B: business intelligence e gestão do conhecimento

\begin{tabular}{llc}
\hline & \multicolumn{1}{c}{ QUESTÃO } & RESPOSTA \\
\hline $6 \mathrm{a}$ & Definição dos indicadores para monitoramento & 1 \\
$6 \mathrm{~b}$ & Definição das fontes de informação para monitoramento & 1 \\
$6 \mathrm{c} . \mathrm{i}$ & Captura de dados: estruturados internos - relatórios das áreas internas & 3 \\
$6 \mathrm{c} . \mathrm{ii}$ & $\begin{array}{l}\text { Captura de dados: não-estruturados internos - idéias, sugestões e } \\
\text { opiniões das equipes }\end{array}$ & 1 \\
$6 \mathrm{c} . \mathrm{iii}$ & Captura de dados: estruturados externos - relatórios e bases de dados & 1 \\
6c.iv & on line & Captura de dados: não-estruturados externos - notícias e publicações \\
$6 \mathrm{~d}$ & Validação de dados capturados & 3 \\
$6 \mathrm{e}$ & Catalogação de dados capturados & 1 \\
$6 f$ & Classificação de dados capturados & 0 \\
$6 \mathrm{~g}$ & Armazenamento de dados coletados & 0 \\
$6 \mathrm{~h}$ & Processamento de dados armazenados & 2 \\
$6 \mathrm{i}$ & Análise de dados armazenados & 2 \\
$6 \mathrm{j}$ & Interpretação de informações & 2 \\
$6 \mathrm{k}$ & Seleção de usuários da informação & 1 \\
$6 \mathrm{l}$ & Distribuição da informação & 2 \\
\hline
\end{tabular}

Fonte: elaborado pelo autor

Para o caso B, a média obtida foi 1,5. Assim como no caso anterior, percebe-se que não é intensa a utilização de ferramentas de BI para dar suporte às atividades de IC. Entretanto, as atividades de captura de dados estruturados internos e dados não estruturados externos têm utlizado essas ferramentas. Com relação à gestão do conhecimento, o resultado superior a 1,0 sugere que a IC desenvolve essas atividades, exceto por catalogação e classificação dos dados. 


\subsubsection{Alinhamento Estratégico}

A Tabela 5.11 apresenta as respostas obtidas nas questões 7 a 11, visando construir a análise estrutural da indústria de financiamento de veículos.

Tabela 5.11 - Dados do caso B: estratégia

\begin{tabular}{|c|c|c|c|}
\hline $\begin{array}{c}\text { FORÇA } \\
\text { COMPETITIVA }\end{array}$ & & QUESTÃO & RESPOSTA \\
\hline \multirow{7}{*}{$\begin{array}{l}\text { Rivalidade entre } \\
\text { concorrentes } \\
\text { existentes }\end{array}$} & $7 a$ & Os concorrentes são numerosos ou equilibrados & $\mathrm{F}$ \\
\hline & $7 b$ & A indústria apresenta taxa de crescimento baixa & $\mathrm{F}$ \\
\hline & $7 c$ & Os custos fixos associados ao mercado são elevados & V \\
\hline & $7 d$ & $\begin{array}{l}\text { Os produtos ofertados pelo mercado não possuem muito } \\
\text { diferenciação }\end{array}$ & V \\
\hline & $7 e$ & $\begin{array}{l}\text { O aumento da capacidade produtiva da indústria requer } \\
\text { investimentos elevados }\end{array}$ & V \\
\hline & $7 f$ & $\begin{array}{l}\text { Os concorrentes possuem estratégias competitivas muito } \\
\text { divergentes }\end{array}$ & V \\
\hline & $7 g$ & As barreiras de saída do mercado são elevadas & V \\
\hline \multirow{5}{*}{$\begin{array}{l}\text { Poder de barganha } \\
\text { dos fornecedores }\end{array}$} & $8 a$ & O produto dos fornecedores é um insumo crítico & $\mathrm{F}$ \\
\hline & $8 b$ & $\begin{array}{l}\text { O grupo de fornecedores é constituído por poucas companhias } \\
\text { e mais concentrado do que a indústria em análise }\end{array}$ & $\mathrm{F}$ \\
\hline & $8 c$ & $\begin{array}{l}\text { A indústria não é um cliente importante para o grupo de } \\
\text { fornecedores }\end{array}$ & $\mathrm{F}$ \\
\hline & $8 d$ & $\begin{array}{l}\text { Os produtos dos fornecedores são diferenciados e não } \\
\text { concorrem com produtos substitutos }\end{array}$ & $F$ \\
\hline & $8 e$ & $\begin{array}{l}\text { Os fornecedores são uma ameaça concreta de integração } \\
\text { vertical }\end{array}$ & $\mathrm{F}$ \\
\hline \multirow[t]{5}{*}{$\begin{array}{l}\text { Poder de barganha } \\
\text { dos clientes }\end{array}$} & $9 a$ & $\begin{array}{l}\text { Os clientes estão concentrados ou adquirem produtos em } \\
\text { grandes quantidades }\end{array}$ & $F$ \\
\hline & $9 b$ & $\begin{array}{l}\text { As compras representam uma fração significativa de seus } \\
\text { custos }\end{array}$ & V \\
\hline & $9 c$ & $\begin{array}{l}\text { Os produtos da indústria são padronizados e/ou não são } \\
\text { importantes para a qualidade de produtos dos clientes }\end{array}$ & V \\
\hline & $9 d$ & Os clientes têm total informação & V \\
\hline & $9 e$ & $\begin{array}{l}\text { O grupo de clientes é uma ameaça concreta de integração } \\
\text { para trás }\end{array}$ & $\mathrm{F}$ \\
\hline \multirow{5}{*}{$\begin{array}{l}\text { Ameaça de novos } \\
\text { ingressantes }\end{array}$} & $10 \mathrm{a}$ & Existe a necessidade de economia de escala & V \\
\hline & $10 b$ & O grau de dependência de patentes é elevado & $\mathrm{F}$ \\
\hline & $10 \mathrm{c}$ & O acesso à matéria-prima é difícil & $\mathrm{F}$ \\
\hline & $10 d$ & Existem políticas de subsídio oficiais & $\mathrm{F}$ \\
\hline & $10 e$ & A curva de aprendizado da indústria não é lenta & V \\
\hline $\begin{array}{l}\text { Ameaça de } \\
\text { produtos substitutos }\end{array}$ & $11 \mathrm{a}$ & Existem outros produtos que desempenham a mesma função & V \\
\hline
\end{tabular}

Fonte: elaborado pelo autor 
No que se refere à rivalidade entre concorrentes existentes, 5 respostas foram do tipo VERDADEIRO, ou seja, é uma força competitiva relevante. Neste caso, fatores como os custos fixos associados à operação bem como a ausência de diferenciação dos produtos ofertados são fatores agravantes desta força. Além disso, a necessidade de investimento para o aumento da capacidade produtiva, notadamente um segmento de capital intensivo, bem como as elevadas barreiras de saída, devido aos prazos alongados de financiamento, corroboram com a intensidade desta força. Por outro lado, existem poucos concorrentes disputando nichos diferentes do mercado que, assim como mostra a Figura 5.3, tem crescido a taxas elevadas.

Em segundo lugar, tratando do poder de barganha dos fornecedores, não se obteve nenhuma resposta do tipo VERDADEIRO, indicando que esta força não é relevante para o mercado. Em geral, os fornecedores oferecem serviços de suporte à operação, sendo este mercado uma importante fração das suas receitas. Ainda, analogamente ao caso $A$, eles não representam uma ameaça de integração vertical já que, em muitos casos, o serviço core oferecido nada tem relação com o produto da indústria.

Em relação ao poder de barganha dos clientes, pode-se considerar que é uma força relevante, já que foram obtidos 3 repostas do tipo VERDADEIRO. Uma vez que se considera o correspondente como cliente, percebe-se que a operação é mais pulverizada, mas ainda sim eles representam uma fração sgnificativa dos custos da indústria. Além disso, os produtos oferecidos pela indústria são padronizados e os clientes possuem todas as informações, mas não se configuram como uma ameaça de integração vertical.

Em quarto lugar, foram apenas obtidas duas respostas do tipo VERDADEIRO para a ameaça de novos ingressantes, ou seja, não é considerada uma força significativa. Mesmo que exista a necessidade de economia de escala e a curva de aprendizado ser lenta, não existe a dependência de patentes nem a política de subsídios oficiais. Finalmente, entende-se que ameaça de produtos substitutos é uma questão relevante, pois existem outras opções de aquisição de veículos, como leasing ou consórcio.

Desta forma, a Tabela 5.12 consolida a quantidade de respostas do tipo VERDADEIRO para avaliar a intensidade de cada uma das forças competitivas. 
Tabela 5.12 - Intensidade das forças competitivas do caso B

\begin{tabular}{clcc}
\hline QUESTÃOO & FORÇA COMPETITIVA & $\begin{array}{c}\text { RESPOSTA } \\
\text { VERDADEIRO }\end{array}$ & $\begin{array}{c}\text { INTENSIDADE } \\
\text { DA FORÇA }\end{array}$ \\
\hline 7 & Rivalidade entre concorrentes existentes & $5 / 7$ & Forte \\
8 & Poder de barganha dos fornecedores & $0 / 5$ & Fraco \\
9 & Poder de barganha dos clientes & $3 / 5$ & Forte \\
10 & Ameaça de novos ingressantes & $2 / 5$ & Fraco \\
11 & Ameaça de produtos substitutos & $1 / 1$ & Forte \\
\hline \multicolumn{4}{c}{ Fonte: elaborado pelo autor }
\end{tabular}

A partir desta tabela, é possível estabelecer a lógica competitiva da indústria, contudo é importante aprofundar a análise sobre as expectativas da organização. Assim, a questão 12 avalia quais são essas necessidades em função das forças competitivas, conforme a Tabela 5.13.

Tabela 5.13 - Análise sobre alinhamento estratégico do caso B

\begin{tabular}{clcc}
\hline QUESTÃOO & FORÇA COMPETITIVA & $\begin{array}{c}\text { INTENSIDADE } \\
\text { DA FORÇA }\end{array}$ & RESPOSTA \\
\hline $12 \mathrm{a}$ & Rivalidade entre concorrentes existentes & Forte & $\mathrm{V}$ \\
$12 \mathrm{~b}$ & Poder de barganha dos fornecedores & Fraco & $\mathrm{F}$ \\
$12 \mathrm{c}$ & Poder de barganha dos clientes & Forte & $\mathrm{V}$ \\
$12 \mathrm{~d}$ & Ameaça de novos ingressantes & Fraco & $\mathrm{V}$ \\
$12 \mathrm{e}$ & Ameaça de produtos substitutos & Forte & $\mathrm{F}$ \\
\hline
\end{tabular}

Fonte: elaborado pelo autor

A análise da Tabela 5.13 mostra que a intensidade das forças competitivas e as expectativas da organização sobre as demandas de inteligência possuem um bom grau de alinhamento. De um lado, são monitoradas informações sobre concorrentes e clientes, os quais são forças relevantes da indústria; por outro lado, não se espera inteligência sobre fornecedores, os quais não interferem na competitividade da organização. Contudo, a organização despende esforços no monitoramento de novos ingressantes mesmo esta não sendo uma força relevante, mas não se preocupa com produtos substitutos que diretamente inteferem na competição.

\subsubsection{Decisão}

A Tabela 5.14 mostra que a IC ainda é uma unidade administrativa subordinada à área de negócio e, portanto, existem necessidades de IC pré-definidas pela área de negócio.

Tabela 5.14 - Dados do caso B: decisão

\begin{tabular}{llc}
\hline & \multicolumn{1}{c}{ QUESTÃO } & RESPOSTA \\
\hline 13 & $\begin{array}{l}\text { Qual é o posicionamento hierárquico da equipe } \\
\text { de IC na organização? }\end{array}$ & $\mathrm{B}$ \\
$14 \quad \begin{array}{l}\text { Qual estrutura é responsável por definir as } \\
\text { necessidades de inteligência? }\end{array}$ & $\mathrm{B}$ \\
\hline
\end{tabular}


Fonte: elaborado pelo autor

\subsection{Caso C - Cartão de Crédito}

O caso $C$ se desenvolve em uma administradora de cartões que atua no segmento de cartões private label, sendo o modelo de negócio baseado em parceiros comerciais exclusivos. A Figura 5.8 ilustra o funcionamento da indústria em função de seus principais atores, considerando os resultados obtidos durante a entrevista.

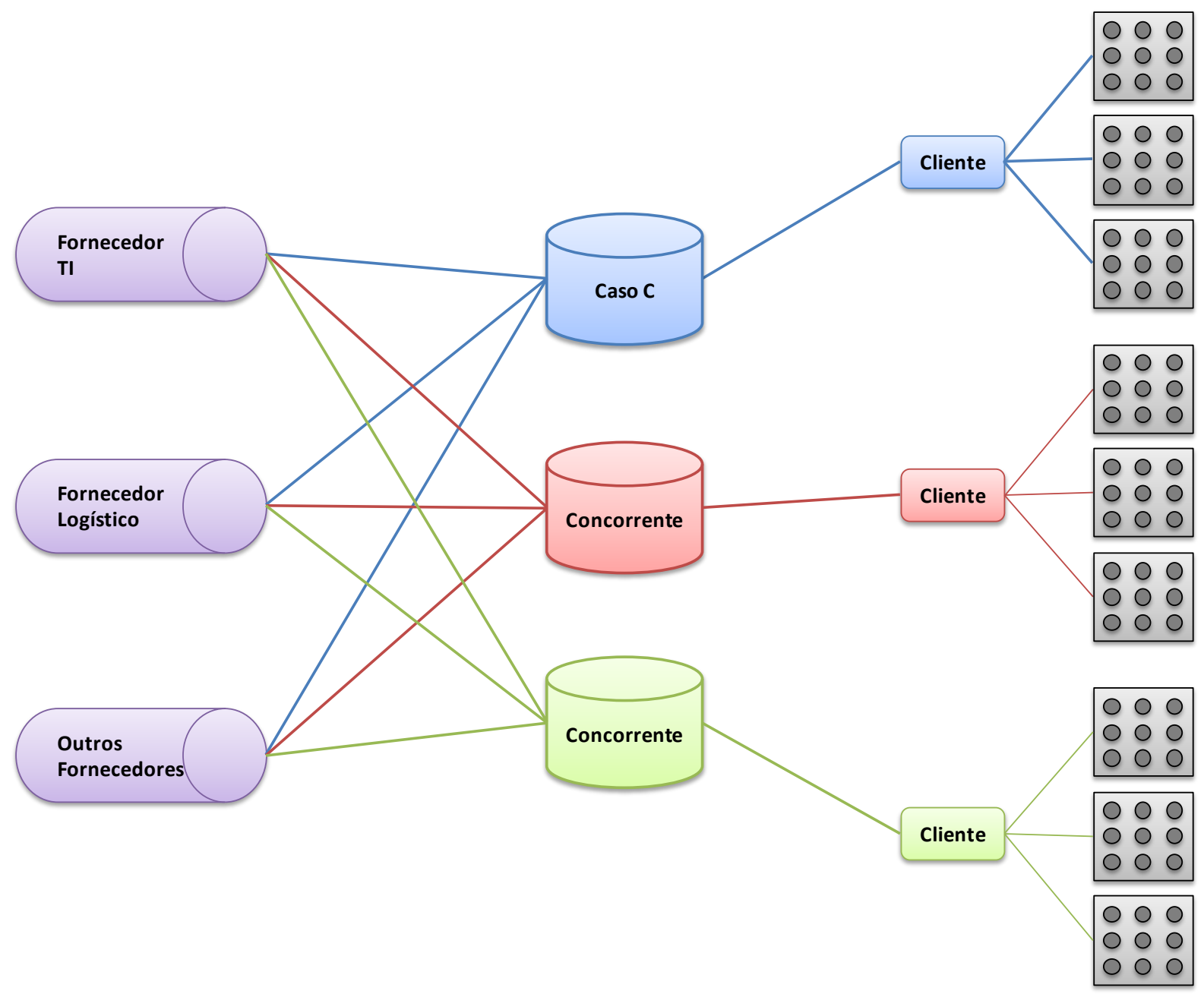

Figura 5.8 - Sistema de valor do caso C

Fonte: elaborado pelo autor

Em primeiro lugar, é importante destacar que o mercado de cartões possui dois nichos distintos de operação: bandeirados e private label. Os cartões bandeirados são aqueles emitidos por instituições financeiras e utilizam a rede de pagamentos das empresas chamadas "bandeiras", isto é, empresas especializadas em manter o relacionamento com estabelecimentos nela cadastrados para a aceitação dos 
cartões. Já os cartões private label são aqueles ligados a estabelecimentos e, por isso, permitem utilização somente na rede de distribuição destes.

Neste mercado, não há muitos players atuando, devido à necessidade de economia de escala, contudo os concorrentes são bastante equilibrados. Por isso, visando criar um paralelo com os demais casos estudados, estes concorrentes são representados na Tabela 5.8 por cores diferentes.

Em segundo lugar, no que se refere aos fornecedores, merecem destaque as atividades de TI (sistemas operacionais) e logística (rede de coleta de documentação). De acordo com as entrevistas, as opções de fornecedores também são restritas e não existem acordos de exclusividade na prestação deste serviço. Entretanto, a relevância dos fornecedores de TI para este caso é maior, uma vez que os custos fixos associados ao processamento requerem que os fornecedores sajam tão grandes ou até maiores do que os players. Mesmo assim, todos os players podem acessar os mesmos fornecedores, o que é representado na Figura 5.8 pelas linhas de diferentes cores que ligam os concorrentes aos fornecedores.

Além disso, foi possível ilustrar todo o sistema de valor do mercado. Quando um consumidor tem interesse no produto de cartão, principalmente private label, normalmente ele é um cliente fiel de um determinado estabelecimento, o qual possui clientes suficientes para atender a necessidade de escala da operação. Sendo assim, o estabelecimento é o principal direcionador da decisão do consumidor e, portanto, a empresa deve atender às suas necessidades, ou seja, o cliente da indústria são os estabelecimentos. Neste caso, como cada estabelecimento opera em caráter de exclusividade com um determinado concorrente, na ilustração eles são representados pela mesma cor.

\subsubsection{Monitoramento Ambiental}

Assim como para os casos anteriores, o modelo de monitoramento ambiental inicia a análise do programa de IC. Para isso, a Tabela 5.15 apresenta as respostas das questões 1 a 5 para o caso $\mathrm{C}$. 
Tabela 5.15 - Dados do caso C: monitoramento ambiental

\begin{tabular}{|c|c|c|}
\hline & QUESTÃO & RESPOSTA \\
\hline$\overline{1}$ & Como a organização enxerga o ambiente de negócios? & $\bar{C}$ \\
\hline 2 & Como surgem as mudanças no ambiente de negócios? & A \\
\hline 3 & Como é possível obter conhecimento sobre o ambiente de negócios? & $E$ \\
\hline $4 a$ & $\begin{array}{l}\text { A organização possui um departamento específico para monitorar, } \\
\text { recriar e descobrir sinais de mudança no ambiente. }\end{array}$ & $\mathrm{F}$ \\
\hline $4 b$ & $\begin{array}{l}\text { A organização procura validar as informações recebidas do } \\
\text { ambiente, podendo até enviar alguém para uma pesquisa em campo. }\end{array}$ & $\mathrm{F}$ \\
\hline $4 c$ & $\begin{array}{l}\text { A organização realizar testes no ambiente para testar inovações no } \\
\text { negócio e decidir sobre sua viabilidade. }\end{array}$ & V \\
\hline $5 a$ & A organização coleta dados através de bases de dados on line. & 3 \\
\hline $5 b$ & A organização coleta dados através de pesquisas de campo. & 1 \\
\hline $5 c$ & A organização coleta dados através de equipe de vendas. & 3 \\
\hline $5 d$ & A organização coleta dados com alto grau de detalhamento. & 5 \\
\hline $5 e$ & A organização coleta dados sobre assuntos pré-definidos. & 5 \\
\hline
\end{tabular}

Para este caso, foi obtida apenas 1 reposta VERDADEIRO para a questão 4, ou seja, a postura da organização é passiva. Contudo, não houve superioridade para nenhuma das respostas nas questões 1 a 3 , o que torna inconclusiva a análise sobre o modelo de ambiente utilizado. Por este motivo, não é possível comparar o resultado da questão 5 , pesquisa informal, com a literatura.

A Tabela 5.16 consolida as respostas obtidas com as questões 1 a 5 e suas conclusões.

Tabela 5.16 - Análise sobre o monitoramento ambiental do caso $C$

\begin{tabular}{clcl}
\hline QUESTÃOO & CONSTRUCTO & RESPOSTA & CONCLUSÃO \\
\hline 1 a 3 & Modelo de ambiente & Sem maioria & Inconclusivo \\
4 & Postura da empresa & Maioria F & Passiva \\
5 & Modelo de monitoramento & Média 3,4 & Pesquisa informal \\
\hline
\end{tabular}

Fonte: elaborado pelo autor 


\subsubsection{Business Intelligence e Gestão do Conhecimento}

Conforme já apresentado anteriormente, o critério de análise sobre business intelligence e gestão do conhecimento é baseado na média aritimética da questão 6 , cujas respostas são apresentadas na Tabela 5.17.

Tabela 5.17 - Dados do caso C: business intelligence e gestão do conhecimento

\begin{tabular}{llc}
\hline & \multicolumn{1}{c}{ QUESTÃO } & RESPOSTA \\
\hline $6 \mathrm{a}$ & Definição dos indicadores para monitoramento & 1 \\
$6 \mathrm{~b}$ & Definição das fontes de informação para monitoramento & 1 \\
$6 \mathrm{c.i}$ & Captura de dados: estruturados internos - relatórios das áreas internas & 3 \\
$6 \mathrm{c} . \mathrm{ii}$ & $\begin{array}{l}\text { Captura de dados: não-estruturados internos - idéias, sugestões e } \\
\text { opiniões das equipes }\end{array}$ & 1 \\
$6 \mathrm{c} . \mathrm{iii}$ & Captura de dados: estruturados externos - relatórios e bases de dados & 1 \\
$6 \mathrm{c} . \mathrm{iv}$ & On line & \\
$6 \mathrm{~d}$ & Vaptura de dados: não-estruturados externos - notícias e publicações & 1 \\
$6 \mathrm{e}$ & Catalogação de dados capturados & 1 \\
$6 \mathrm{ff}$ & Classificação de dados capturados & 0 \\
$6 \mathrm{~g}$ & Armazenamento de dados coletados & 0 \\
$6 \mathrm{~h}$ & Processamento de dados armazenados & 2 \\
$6 \mathrm{i}$ & Análise de dados armazenados & 2 \\
$6 \mathrm{j}$ & Interpretação de informações \\
$6 \mathrm{k}$ & Seleção de usuários da informação & 2 \\
$6 \mathrm{l}$ & Distribuição da informação & 1 \\
\hline
\end{tabular}

Fonte: elaborado pelo autor

Por um lado, a média de 1,3 obtida para o caso $C$ mostra que ainda não se utilizam amplamente as ferramentas de $\mathrm{Bl}$ como suporte às atividades de $\mathrm{IC}$, mas nota-se que a captura de dados estruturados internos já as utiliza. Por outro lado, essa média indica que há forte sinergia entre IC e gestão do conhecimento, destacando que somente a catalogação e a classificação dos dados capturados não são realizadas.

\subsubsection{Alinhamento Estratégico}

Assim como nos demais casos, a Tabela 5.18 mostra os resultados obtidos nas questões 7 a 11. Para este caso, a rivalidade entre concorrentes existentes não é indicada como uma força relevante, pois foram obtidas apenas 3 respostas do tipo VERDADEIRO. De acordo com as entrevistas, existem poucos concorrentes neste segmento, o qual cresce a taxas elevadas. Além disso, cada concorrente possui uma configuração de produtos diferenciada, oferencendo diferentes serviços, mas sempre mantendo uma mesma estratégia com relação ao produto core. Por outro lado, os custos fixos elevados e a necessidade de grandes investimentos para o 
aumento da capacidade produtiva, bem como as elevadas barreiras de saída do mercado, são fatores que tendem a acirrar a rivalidade dos concorrentes neste segmento.

Tabela 5.18 - Dados do caso C: estratégia

\begin{tabular}{|c|c|c|c|}
\hline $\begin{array}{c}\text { FORÇA } \\
\text { COMPETITIVA }\end{array}$ & & QUESTÃO & RESPOSTA \\
\hline \multirow{7}{*}{$\begin{array}{l}\text { Rivalidade entre } \\
\text { concorrentes } \\
\text { existentes }\end{array}$} & $7 a$ & Os concorrentes são numerosos ou equilibrados & $\mathrm{F}$ \\
\hline & $7 b$ & A indústria apresenta taxa de crescimento baixa & $\mathrm{F}$ \\
\hline & 7c & Os custos fixos associados ao mercado são elevados & $\mathrm{V}$ \\
\hline & $7 d$ & $\begin{array}{l}\text { Os produtos ofertados pelo mercado não possuem muito } \\
\text { diferenciação }\end{array}$ & $\mathrm{F}$ \\
\hline & $7 e$ & $\begin{array}{l}\text { O aumento da capacidade produtiva da indústria requer } \\
\text { investimentos elevados }\end{array}$ & $\mathrm{V}$ \\
\hline & $7 f$ & $\begin{array}{l}\text { Os concorrentes possuem estratégias competitivas muito } \\
\text { divergentes }\end{array}$ & $\mathrm{F}$ \\
\hline & $7 \mathrm{~g}$ & As barreiras de saída do mercado são elevadas & $\mathrm{V}$ \\
\hline \multirow{5}{*}{$\begin{array}{l}\text { Poder de barganha } \\
\text { dos fornecedores }\end{array}$} & $8 a$ & O produto dos fornecedores é um insumo crítico & V \\
\hline & $8 b$ & $\begin{array}{l}\text { O grupo de fornecedores é constituído por poucas companhias } \\
\text { e mais concentrado do que a indústria em análise }\end{array}$ & $\mathrm{v}$ \\
\hline & $8 c$ & $\begin{array}{l}\text { A indústria não é um cliente importante para o grupo de } \\
\text { fornecedores }\end{array}$ & $\mathrm{F}$ \\
\hline & $8 d$ & $\begin{array}{l}\text { Os produtos dos fornecedores são diferenciados e não } \\
\text { concorrem com produtos substitutos }\end{array}$ & V \\
\hline & $8 e$ & $\begin{array}{l}\text { Os fornecedores são uma ameaça concreta de integração } \\
\text { vertical }\end{array}$ & $\mathrm{V}$ \\
\hline \multirow[t]{5}{*}{$\begin{array}{l}\text { Poder de barganha } \\
\text { dos clientes }\end{array}$} & $9 a$ & $\begin{array}{l}\text { Os clientes estão concentrados ou adquirem produtos em } \\
\text { grandes quantidades }\end{array}$ & $\mathrm{F}$ \\
\hline & $9 b$ & $\begin{array}{l}\text { As compras representam uma fração significativa de seus } \\
\text { custos }\end{array}$ & $\mathrm{V}$ \\
\hline & $9 c$ & $\begin{array}{l}\text { Os produtos da indústria são padronizados e/ou não são } \\
\text { importantes para a qualidade de produtos dos clientes }\end{array}$ & $\mathrm{V}$ \\
\hline & $9 d$ & Os clientes têm total informação & $\mathrm{V}$ \\
\hline & $9 e$ & $\begin{array}{l}\text { O grupo de clientes é uma ameaça concreta de integração } \\
\text { para trás }\end{array}$ & $\mathrm{F}$ \\
\hline \multirow{5}{*}{$\begin{array}{l}\text { Ameaça de novos } \\
\text { ingressantes }\end{array}$} & $10 \mathrm{a}$ & Existe a necessidade de economia de escala & $\mathrm{V}$ \\
\hline & $10 b$ & O grau de dependência de patentes é elevado & $\mathrm{F}$ \\
\hline & $10 \mathrm{c}$ & O acesso à matéria-prima é difícil & $\mathrm{F}$ \\
\hline & $10 d$ & Existem políticas de subsídio oficiais & $\mathrm{F}$ \\
\hline & $10 \mathrm{e}$ & A curva de aprendizado da indústria não é lenta & $\mathrm{F}$ \\
\hline $\begin{array}{l}\text { Ameaça de } \\
\text { produtos substitutos }\end{array}$ & $11 \mathrm{a}$ & Existem outros produtos que desempenham a mesma função & V \\
\hline
\end{tabular}


Fonte: elaborado pelo autor

Em relação ao poder de barganha dos fornecedores, diferentemente dos casos já apresentados, pode-se considerar uma força competitiva significativa, pois foram obtidas 3 respostas do tipo VERDADEIRO. Dentre os fatores que intensificam essa força, destaca-se a dependência de sistemas e capilaridade dos fornecedores notavelmente as bandeiras e as processadoras. Nesse sentido, considera-se que ambos os fornecedores são mais concentrados do que os players deste mercado e, de forma geral, representam uma ameaça concreta de integração vertical.

Em terceiro lugar, com relação ao poder de barganha dos clientes, a obtenção de 3 repostas do tipo VERDADEIRO indica que está também é uma força competitiva de intensidade forte. Sobretudo no segmento de private label, foco estratégico desta instituição, a distribuição dos produtos depende de parceiras estabelecidas com os clientes, os quais possuem o relacionamento com o consumidor final. Nesse sentido, o produto da indústria tem impacto direto na qualidade e na imagem do cliente e, por isso, eles possuem informação total sobre as operações. Entretanto, dado os altos investimentos iniciais e a curva de aprendizado lenta, eles não representam uma ameaça concreta de integração.

A mesma lógica pode ser aplicada a baixa ameaça de novos ingressantes no mercado. Além disso, não existem políticas de subsídios oficiais e existe baixo grau de patentes envolvido.

Por fim, sabe-se que à ameaça de produtos substitutos é uma força significativa. Em destaque o produto da indústria oferece uma mudança de cultura no processo de concessão de crédito e do meio de pagamento. Contudo, mesmo com o crescimento elevado, os produtos substitutos ainda representam uma ameaça significativa.

Em suma, a Tabela 5.19 resumo a análise estrutural da indústria, apresentando a quantidade de respostas do tipo VERDADEIRO para avaliar a intensidade de cada uma das forças competitivas.

Tabela 5.19 - Intensidade das forças competitivas do caso $\mathrm{C}$

\begin{tabular}{clcc}
\hline QUESTÃO & FORÇA COMPETITIVA & $\begin{array}{c}\text { RESPOSTA } \\
\text { VERDADEIRO }\end{array}$ & $\begin{array}{c}\text { INTENSIDADE } \\
\text { DA FORÇA }\end{array}$ \\
\hline 7 & Rivalidade entre concorrentes existentes & $3 / 7$ & Fraco \\
8 & Poder de barganha dos fornecedores & $4 / 5$ & Forte \\
9 & Poder de barganha dos clientes & $3 / 5$ & Forte \\
10 & Ameaça de novos ingressantes & $1 / 5$ & Fraco \\
11 & Ameaça de produtos substitutos & $1 / 1$ & Forte \\
\hline
\end{tabular}


Fonte: elaborado pelo autor

Conhecida a lógica competitiva, devem-se compreender as expectativas da organização sobre as demandas de inteligência, conforme a questão 12. Para isso, a Tabela 5.6 centraliza a análise.

Tabela 5.20 - Análise sobre alinhamento estratégico do caso C

\begin{tabular}{clcc}
\hline QUESTÃOO & FORÇA COMPETITIVA & $\begin{array}{c}\text { INTENSIDADE } \\
\text { DA FORÇA }\end{array}$ & RESPOSTA \\
\hline $12 \mathrm{a}$ & Rivalidade entre concorrentes existentes & Fraco & $\mathrm{V}$ \\
$12 \mathrm{~b}$ & Poder de barganha dos fornecedores & Forte & $\mathrm{F}$ \\
$12 \mathrm{c}$ & Poder de barganha dos clientes & Forte & $\mathrm{F}$ \\
$12 \mathrm{~d}$ & Ameaça de novos ingressantes & Fraco & $\mathrm{F}$ \\
$12 \mathrm{e}$ & Ameaça de produtos substitutos & Forte & $\mathrm{F}$ \\
\hline
\end{tabular}

Fonte: elaborado pelo autor

Observando a Tabela 5.20, conclui-se que não há alinhamento entre a intensidade das forças competitivas e as expectativas da organização sobre as demandas de inteligência. A organização espera informações relevantes sobre os concorrentes, mas esta não é a força mais intensa deste segmento. Por outro lado, as demandas de inteligência sobre os fornecedores, os clientes e os produtos subtitutos não figuram como prioridades da organização.

\subsubsection{Decisão}

Em relação à estrutura de decisão da IC, a Tabela 5.21 indica que ainda não há uma unidade administrativa organizada com a responsabilidade de desenvolver as atividades de IC. Além disso, esta função se encontra diluída na organização e é entregue aos tomadores de decisão em diferentes formatos e, normalmente, sob demanda.

Tabela 5.21 - Dados do caso C: decisão

\begin{tabular}{ccc}
\hline & QUESTÃO & RESPOSTA \\
\hline 13 & A IC não é uma unidade administrativa & D \\
14 & A IC não possui necessidades pré-definidas & D \\
\hline \multicolumn{3}{c}{ Fonte: elaborado pelo autor }
\end{tabular}

\subsection{Caso D - Crédito Direto ao Consumidor}

O caso $D$ se desenvolve em uma financeira que atua no segmento de crédito direto ao consumidor (CDC), sendo o modelo de negócio baseado em parceiros comercais 
não exclusivos. A Figura 5.9 ilustra o funcionamento da indústria em função de seus principais atores, considerando os resultados obtidos durante a entrevista.

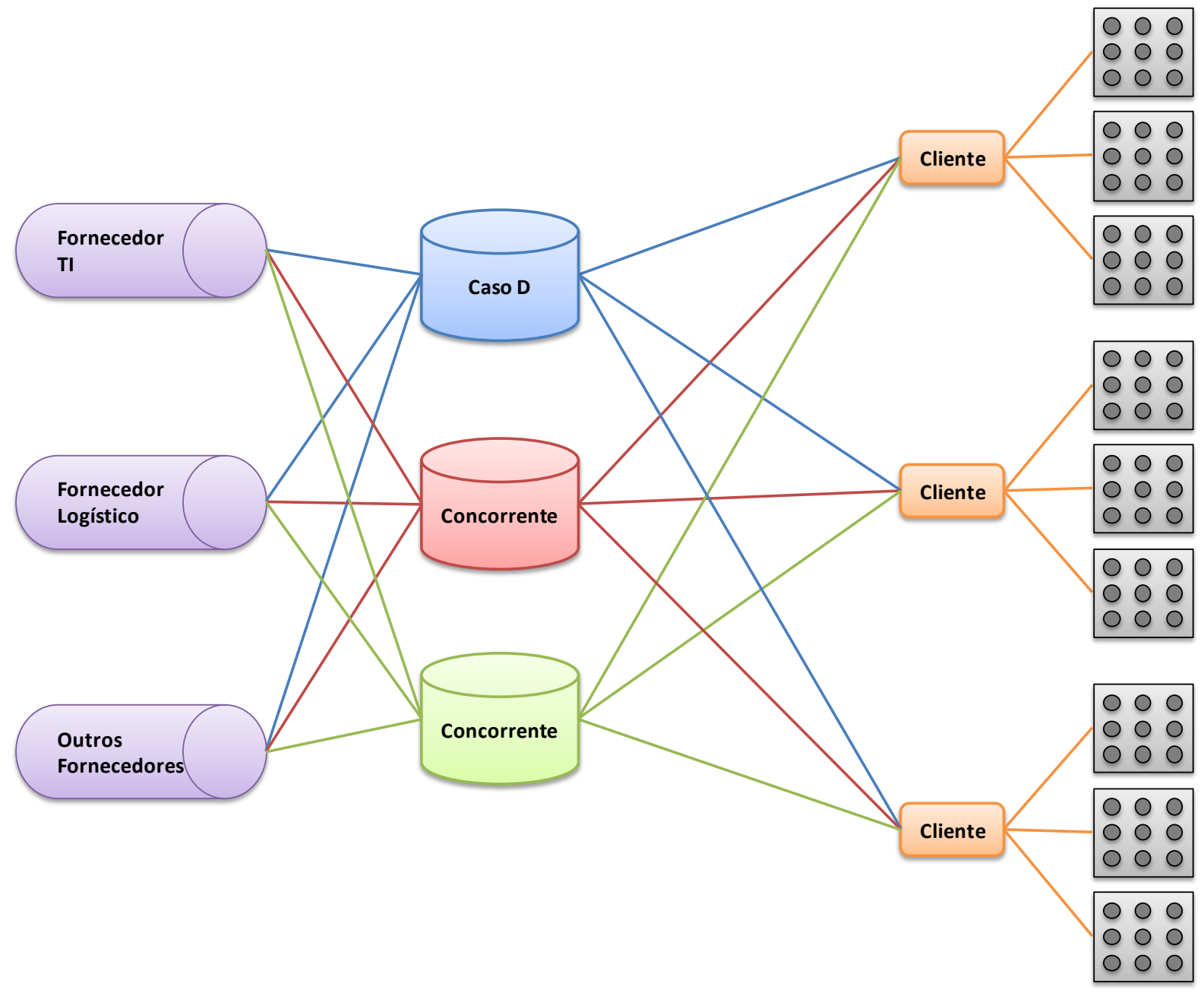

Figura 5.9 - Sistema de valor do caso $D$

Fonte: elaborado pelo autor

Em primeiro lugar, destaca-se que existem diversos players atuando fortemente no segmento de crédito direto ao consumidor, o que é representado na ilustração por diferentes cores. Além disso, analogamente aos casos anteriores, cada player pode optar pela contratação de fornecedores ou pelo desenvolvimento interno das atividades relacionadas à operação. Pelos mesmos motivos anteriormente citados, destacam-se as atividades de $\mathrm{TI}$ (sistemas operacionais) e logística (rede de coleta de documentação).

A Figura 5.9 ilustra todo o sistema de valor do mercado. Quando um consumidor tem interesse no produto de CDC, ele já fez a opção do bem que pretende adquirir e, em geral, a decisão acontece nas lojas (em laranja). Isso demonstra que o produto 
desta indústria é um acessório e, de acordo com as entrevistas, a influência direta dos players sobre os consumidores é restrita. Sendo assim, é possível inferir que a competição deste mercado acontece nas lojas, pois são elas que fazem a opção pelo melhor concorrente, indicando que elas são os clientes da indústria.

\subsubsection{Monitoramento Ambiental}

Os resultados obtidos para a análise sobre o monitoramento ambiental do caso D é apresentado na Tabela 5.22.

Tabela 5.22 - Dados do caso D: monitoramento ambiental

\begin{tabular}{|c|c|c|}
\hline & QUESTÃO & RESPOSTA \\
\hline$\overline{1}$ & Como a organização enxerga o ambiente de negócios? & $\bar{A}$ \\
\hline 2 & Como surgem as mudanças no ambiente de negócios? & A \\
\hline 3 & Como é possível obter conhecimento sobre o ambiente de negócios? & A \\
\hline $4 a$ & $\begin{array}{l}\text { A organização possui um departamento específico para monitorar, } \\
\text { recriar e descobrir sinais de mudança no ambiente. }\end{array}$ & $\mathrm{F}$ \\
\hline $4 b$ & $\begin{array}{l}\text { A organização procura validar as informações recebidas do } \\
\text { ambiente, podendo até enviar alguém para uma pesquisa em campo. }\end{array}$ & V \\
\hline $4 c$ & $\begin{array}{l}\text { A organização realizar testes no ambiente para testar inovações no } \\
\text { negócio e decidir sobre sua viabilidade. }\end{array}$ & V \\
\hline $5 a$ & A organização coleta dados através de bases de dados on line. & 4 \\
\hline $5 b$ & A organização coleta dados através de pesquisas de campo. & 3 \\
\hline $5 c$ & A organização coleta dados através de equipe de vendas. & 5 \\
\hline $5 d$ & A organização coleta dados com alto grau de detalhamento. & 5 \\
\hline $5 e$ & A organização coleta dados sobre assuntos pré-definidos. & 5 \\
\hline
\end{tabular}

Fonte: elaborado pelo autor

De acordo com os resultados, percebe-se que as questões 1 a 3 possuem respostas predominantemente $A$, o que indica que a organização enxerga o ambiente através do modelo de estrutura da indústruia. Além disso, a questão 4, mostrou a maioria de de respostas VERDADEIRO, indicando que a postura da organização é ativa.

De acordo com a literatura, o modelo adequado seria a pesquisa formal, o que é confirmado pela questão 5 , cuja a média aritimética das respostas obtidas foi 4,4. Desta forma, a Tabela 5.23 consolida a análise do monitoramento ambiental.

Tabela 5.23 - Análise sobre o monitoramento ambiental do caso $D$

\begin{tabular}{clcl}
\hline QUESTÃO & CONSTRUCTO & RESPOSTA & CONCLUSÃO \\
\hline 1 a 3 & Modelo de ambiente & Maioria $A$ & Estrutura da indústria \\
4 & Postura da empresa & Maioria V & Ativa \\
5 & Modelo de monitoramento & Média 4,4 & Pesquisa formal \\
\hline
\end{tabular}


Fonte: elaborado pelo autor

\subsubsection{Business Intelligence e Gestão do Conhecimento}

A Tabela 5.24 apresenta as respostas para a questão 6 , a qual permite a análise sobre business intelligence e gestão do conhecimento.

Tabela 5.24 - Dados do caso D: business intelligence e gestão do conhecimento

\begin{tabular}{llc}
\hline & \multicolumn{1}{c}{ QUESTAO } & RESPOSTA \\
\hline $6 \mathrm{a}$ & Definição dos indicadores para monitoramento & 1 \\
$6 \mathrm{~b}$ & Definição das fontes de informação para monitoramento & 1 \\
$6 \mathrm{c.i}$ & Captura de dados: estruturados internos - relatórios das áreas internas & 3 \\
$6 \mathrm{c} . \mathrm{ii}$ & $\begin{array}{l}\text { Captura de dados: não-estruturados internos - idéias, sugestões e } \\
\text { opiniões das equipes }\end{array}$ & 1 \\
$6 \mathrm{c} . \mathrm{iii}$ & Captura de dados: estruturados externos - relatórios e bases de dados & 1 \\
$6 \mathrm{c} . \mathrm{iv}$ & Captura de dados: não-estruturados externos - notícias e publicações & 2 \\
$6 \mathrm{~d}$ & Validação de dados capturados & 1 \\
$6 \mathrm{e}$ & Catalogação de dados capturados & 0 \\
$6 f$ & Classificação de dados capturados & 0 \\
$6 \mathrm{~g}$ & Armazenamento de dados coletados & 2 \\
$6 \mathrm{~h}$ & Processamento de dados armazenados & 2 \\
$6 \mathrm{i}$ & Análise de dados armazenados & 2 \\
$6 \mathrm{j}$ & Interpretação de informações & 1 \\
$6 \mathrm{k}$ & Seleção de usuários da informação & 2 \\
$6 \mathrm{l}$ & Distribuição da informação & 2 \\
\hline
\end{tabular}
Fonte: elaborado pelo autor

A média de 1,4 obtida para este caso indica que ainda é pequena a utilização de ferramentas de $\mathrm{BI}$ como suporte às atividades de IC. Assim como no caso anterior, apenas a captura de dados estruturados internos as utiliza. Em contra partida, no que se refere ao desenvolvimento de atividades de gestão do conhecimento, o resultado indica forte sinergia com a IC.

\subsubsection{Alinhamento Estratégico}

Assim como nos demais casos, a Tabela 5.25 mostra os resultados obtidos nas questões 7 a 11. Para este caso, a rivalidade entre concorrentes existentes figura como uma das forças relevantes, obtendo 5 respostas do tipo VERDADEIRO. Sabese que existem diversos players disputando este mercado que tem crescido a baixas taxas. Além disso, os produtos ofertados não possuem grande diferenciação. Destaca-se, ainda, que os custos fixos associados à operação de CDC são elevados, sobretudo quanto a sistemas e estruturas de suporte operacional, assim como os investimentos necessários para o aumento da capacidade produtiva. 
Tabela 5.25 - Dados do caso D: estratégia

\begin{tabular}{|c|c|c|c|}
\hline $\begin{array}{c}\text { FORÇA } \\
\text { COMPETITIVA }\end{array}$ & & QUESTÃO & RESPOSTA \\
\hline \multirow{7}{*}{$\begin{array}{l}\text { Rivalidade entre } \\
\text { concorrentes } \\
\text { existentes }\end{array}$} & $7 a$ & Os concorrentes são numerosos ou equilibrados & $\mathrm{V}$ \\
\hline & $7 \mathrm{~b}$ & A indústria apresenta taxa de crescimento baixa & $\mathrm{V}$ \\
\hline & 7c & Os custos fixos associados ao mercado são elevados & $\mathrm{V}$ \\
\hline & $7 d$ & $\begin{array}{l}\text { Os produtos ofertados pelo mercado não possuem muito } \\
\text { diferenciação }\end{array}$ & V \\
\hline & $7 e$ & $\begin{array}{l}\text { O aumento da capacidade produtiva da indústria requer } \\
\text { investimentos elevados }\end{array}$ & V \\
\hline & $7 f$ & $\begin{array}{l}\text { Os concorrentes possuem estratégias competitivas muito } \\
\text { divergentes }\end{array}$ & $\mathrm{F}$ \\
\hline & $7 g$ & As barreiras de saída do mercado são elevadas & $\mathrm{F}$ \\
\hline \multirow{5}{*}{$\begin{array}{l}\text { Poder de barganha } \\
\text { dos fornecedores }\end{array}$} & $8 a$ & O produto dos fornecedores é um insumo crítico & $\mathrm{F}$ \\
\hline & $8 b$ & $\begin{array}{l}\text { O grupo de fornecedores é constituído por poucas companhias } \\
\text { e mais concentrado do que a indústria em análise }\end{array}$ & $\mathrm{F}$ \\
\hline & $8 c$ & $\begin{array}{l}\text { A indústria não é um cliente importante para o grupo de } \\
\text { fornecedores }\end{array}$ & $F$ \\
\hline & $8 d$ & $\begin{array}{l}\text { Os produtos dos fornecedores são diferenciados e não } \\
\text { concorrem com produtos substitutos }\end{array}$ & $\mathrm{F}$ \\
\hline & $8 e$ & $\begin{array}{l}\text { Os fornecedores são uma ameaça concreta de integração } \\
\text { vertical }\end{array}$ & $F$ \\
\hline \multirow[t]{5}{*}{$\begin{array}{l}\text { Poder de barganha } \\
\text { dos clientes }\end{array}$} & $9 a$ & $\begin{array}{l}\text { Os clientes estão concentrados ou adquirem produtos em } \\
\text { grandes quantidades }\end{array}$ & $\mathrm{F}$ \\
\hline & $9 b$ & $\begin{array}{l}\text { As compras representam uma fração significativa de seus } \\
\text { custos }\end{array}$ & $\mathrm{V}$ \\
\hline & $9 c$ & $\begin{array}{l}\text { Os produtos da indústria são padronizados e/ou não são } \\
\text { importantes para a qualidade de produtos dos clientes }\end{array}$ & $\mathrm{V}$ \\
\hline & $9 d$ & Os clientes têm total informação & $\mathrm{F}$ \\
\hline & $9 e$ & $\begin{array}{l}\text { O grupo de clientes é uma ameaça concreta de integração } \\
\text { para trás }\end{array}$ & $\mathrm{F}$ \\
\hline \multirow{5}{*}{$\begin{array}{l}\text { Ameaça de novos } \\
\text { ingressantes }\end{array}$} & $10 \mathrm{a}$ & Existe a necessidade de economia de escala & $\mathrm{V}$ \\
\hline & $10 b$ & O grau de dependência de patentes é elevado & $\mathrm{F}$ \\
\hline & $10 c$ & O acesso à matéria-prima é difícil & $\mathrm{F}$ \\
\hline & $10 d$ & Existem políticas de subsídio oficiais & $\mathrm{F}$ \\
\hline & $10 \mathrm{e}$ & A curva de aprendizado da indústria não é lenta & $\mathrm{V}$ \\
\hline $\begin{array}{l}\text { Ameaça de } \\
\text { produtos substitutos }\end{array}$ & $11 \mathrm{a}$ & Existem outros produtos que desempenham a mesma função & V \\
\hline
\end{tabular}

Fonte: elaborado pelo autor

Em segundo lugar, em relação ao poder de barganha dos fornecedores, nenhuma das respostas foi do tipo VERDADEIRO, ou seja, está não é uma força competitiva 
relevante para este mercado. Assim como nos casos A e B, os fornecedores em geral oferecem serviços agregados às operações do segmento, representando uma significativa parcela da receita da maioria deles. Também neste caso, eles não representam uma ameaça de integração vertical já que o serviço core oferecido nada tem relação com o produto da indústria.

No que se refere ao poder de barganha dos clientes, a obtenção de apenas 3 repostas do tipo VERDADEIRO indica que está não é uma força competitiva de intensidade forte. De modo geral, os produtos da indústria são padronizados e as compras representam uma parcela significativa dos clientes. Entretanto, a pulverização dos clientes e a ausência de conhecimento e capital necessário à integração vertical reduzem a intensidade desta força, assim como dificulta a obtenção da totalidade das informações.

Em quarto lugar, no que se refere à ameaça de novos ingressantes, registraram-se apenas 2 respostas do tipo VERDADEIRO, ou seja, não pode ser considerada uma força signficativa. Pelas entrevistas, percebe-se que a dependência de economia de escala é elevada e o aprendizado é rápido, mas não existe a dependência de patentes nem a política de subsídios oficiais.

Por fim, em relação à ameaça de produtos substitutos, considera-se está uma força relevante para o segmento. Nesse sentido, destaca-se que a evolução tecnológica tem fomentado estes produtos substitutos, sobretudo com o desenvolvimento do mecanismo de cartão.

Em resumo, a Tabela 5.26 sintetiza a análise da intensidade das forças competitivas da indústria.

Tabela 5.26 - Intensidade das forças competitivas do caso D

\begin{tabular}{clcc}
\hline QUESTÃOO & FORÇA COMPETITIVA & $\begin{array}{c}\text { RESPOSTA } \\
\text { VERDADEIRO }\end{array}$ & $\begin{array}{c}\text { INTENSIDADE } \\
\text { DA FORÇA }\end{array}$ \\
\hline 7 & Rivalidade entre concorrentes existentes & $5 / 7$ & Forte \\
8 & Poder de barganha dos fornecedores & $0 / 5$ & Fraco \\
9 & Poder de barganha dos clientes & $2 / 5$ & Fraco \\
10 & Ameaça de novos ingressantes & $2 / 5$ & Fraco \\
11 & Ameaça de produtos substitutos & $1 / 1$ & Forte \\
\hline
\end{tabular}

Fonte: elaborado pelo autor

A Tabela 5.26 apresenta a lógica competitiva da indústria e permite a avaliação do alinhamento estratégico entre esta lógica e as expectativas sobre a IC, com base na questão 12, conforme mostra a Tabela 5.27. 
Tabela 5.27 - Análise sobre alinhamento estratégico do caso D

\begin{tabular}{clcc}
\hline QUESTÃOO & FORÇA COMPETITIVA & $\begin{array}{c}\text { INTENSIDADE } \\
\text { DA FORÇA }\end{array}$ & RESPOSTA \\
\hline $12 \mathrm{a}$ & Rivalidade entre concorrentes existentes & Forte & $\mathrm{V}$ \\
$12 \mathrm{~b}$ & Poder de barganha dos fornecedores & Fraco & $\mathrm{F}$ \\
$12 \mathrm{c}$ & Poder de barganha dos clientes & Fraco & $\mathrm{F}$ \\
$12 \mathrm{~d}$ & Ameaça de novos ingressantes & Fraco & $\mathrm{F}$ \\
$12 \mathrm{e}$ & Ameaça de produtos substitutos & Forte & $\mathrm{V}$ \\
\hline \multicolumn{4}{c}{ Fonte: elaborado pelo autor }
\end{tabular}

Fonte: elaborado pelo autor

De acordo com os resultados apresentados na tabela, percebe-se que há alinhamento entre a intensidade das forças competitivas e as expectativas da organização sobre as demandas de inteligência. A instituição tem expectativa de receber inteligência sobre os concorrentes e os produtos substitutos, as forças consideradas relevantes para o segmento. Além disso, não se esperam informações sobre as demais forças que não são significativas.

\subsubsection{Decisão}

Em relação à estrutura de decisão da IC para o Caso D, percebe-se que a unidade administrativa com a responsabilidade de IC está alocada à área de planejamento. Neste sentido, existem necessidades de IC pré-definidas pela área de planejamento, mesmo que algumas atividades sejam realizadas sob demanda.

Tabela 5.28 - Dados do caso D: decisão

\begin{tabular}{llc}
\hline & QUESTÃO & RESPOSTA \\
\hline 13 & A IC não é uma unidade administrativa & C \\
14 & A IC não possui necessidades pré-definidas & C \\
\hline
\end{tabular}

Fonte: elaborado pelo autor

\subsection{Considerações Finais}

Os resultados obtidos com o desenvolvimento dos estudos de caso permitem inferências para que se realize uma avaliação inicial sobre a aplicabilidade dos programas de IC. Por um lado, destaca-se que não se obteve consenso sobre o funcionamento de uma estrutura de IC em quase nenhum dos itens abordados. Por outro, constatou-se que o nível de estruturação dos programas de IC são bastante diferentes em cada um dos segmentos analisados.

No que se refere ao funcionamento dos programas de IC, o consenso não foi obtido. Com relação ao monitoramento ambiental, por exemplo, houve uma grande 
dispersão entre as organizações, principalmente sobre o modelo de ambiente idealizado pelos tomadores de decisão. Há indícios de que o modelo de estrutura da indústria favoreça as atividades de IC, mas seria necessário aprofundar a análise para que se pudesse concluir algo sobre este tópico. Contudo, ressalta-se que todas as organizações demonstram preocupação com a compreensão do ambiente competitivo.

Nesse sentido, pode-se considerar que a compreensão integral do ambiente é uma tarefa utópica. Os resultados apontam que as organizações priorizam determinados aspectos externos que, em geral, estão alinhados com a estrutura da indústria. Entretanto, não existe uma preocupação formal com os métodos de alinhamento estratégico da IC com o negócio.

Em contra partida, a análise dos resultados deixa claro que os programas de IC desenvolvidos pelas organizações possuem níveis de desempenho e responsabilidade diferentes, mas não permite a comparação entre eles. O principal motivo que impossibilita esta comparação é a ausência de um modelo padrão que seja ideal ao programas de IC, capaz de mensurar e estabelecer níveis de exigência aos programas em seus diferentes aspectos. Portanto, estas reflexões iniciais reforçam a necessidade de uma visão holística da IC. 


\section{DISCUSSÃO}

Conforme os resultados apresentados, a pesquisa de campo possibilitou validar as proposições destacadas durante a construção do referencial teórico. Portanto, a discussão sobre os resultados visa à construção de um modelo holístico de IC, o último objetivo específico deste trabalho.

\subsection{A Interação da Organização com o Ambiente Competitivo}

Para se construir o modelo holístico de IC, é útil destacar o modelo conceitual que serve de base ao desenvolvimento. O principal objetivo deste será alinhar as estruturas e os constructos no que se refere à interação entre a organização e o ambiente competitivo. Para isso, o ponto de partida deste trabalho é compreender o que o constructo "ambiente competitivo" representa à IC.

\subsubsection{O Ambiente Competitivo}

Recuperando o trabalho de Lenz e Engledow (1986), o ambiente de negócios pode ser explicado de diferentes formas, principalmente no que se refere à origem das mudanças ambientais e como se obter conhecimento em cada uma destas interpretações. Para efeito deste trabalho, o conceito de ambiente de negócios proposto pelos autores foi definido como o constructo Ambiente Competitivo. Neste sentido, a análise dos resultados obtidos com as questões 1 a 3 indicam o modelo de Ambiente Competitivo que está mais adequado às necessidades da IC, conforme mostra a Tabela 6.1.

Tabela 6.1 - Análise sobre o monitoramento ambiental

\begin{tabular}{|c|c|c|c|c|c|}
\hline CASOS & $\mathbf{A}$ & B & $\mathbf{C}$ & $\mathbf{D}$ & TOTAL \\
\hline Modelo de estrutura da indústria & & $\checkmark$ & & $\sqrt{ }$ & 2 \\
\hline Modelo cognitivo & & & & & $\overline{0}$ \\
\hline Modelo de campos organizacionais & $\checkmark$ & & & & 1 \\
\hline Modelo ecológico de dependência de recursos & & & & & 0 \\
\hline Modelo de era & & & & & 0 \\
\hline
\end{tabular}

Fonte: elaborado pelo autor

Os resultados indicam que, dentre os casos analisados, o modelo de estrutura da indústria é o mais utilizado. Mesmo que o objetivo da pesquisa não seja identificar o modelo de ambiente mais adequado à $\mathrm{IC}$, esses resultados ressaltam esta questão: quais são as vantagens e as desvantagens da utilização de cada um dos modelos para o desenvolvimento das atividades de IC? 
Obviamente, não se pretende responder precisamente a esta questão. Entretanto, cruzando os resultados destas questões com os resultados da questão 4, pode-se inferir que o modelo de estrutura da indústria permite uma compreensão melhor do ambiente e favorece o desenvolvimento de atividades de IC com uma postura mais ativa e focada nas necessidades da organização.

Considerando todos os argumentos apresentados, fica nítida a necessidade de uma discussão mais profunda sobre os modelos de ambiente que podem ser utilizados pela IC, o que pode ser tema de futuros trabalhos. Contudo, concentrando esforços no objetivo desta pesquisa, é importante concluir que, independente do modelo de Ambiente Competitivo adotado, este é um constructo fundamental, pois a IC deve ser capaz de compreender quais e como as mudanças ocorrem neste ambiente e como é possível extrair seu conhecimento.

\subsubsection{A Organização}

O conceito de organização é utilizado em várias áreas de conhecimento e conota diferentes definições em cada uma delas, dependendo do que se pretende observar. Do ponto de vista deste trabalho, a organização precisa ser compreendida como uma entidade que interage com o ambiente competitivo no que se refere a processos de competição entre empresas. Por isso, para efeito deste desenvolvimento, as organizações precisam ser compreendidas como entidades que tomam decisões para atuarem no Ambiente Competitivo de modo a obterem vantagem no processo de competição.

Decorrem desta interpretação duas constatações fundamentais para a elaboração do modelo de interação entre organização e ambiente. Por um lado, as organizações tomam decisões; por outro, elas atuam para obter vantagem competitiva. Sendo assim, para efeito desta construção, a organização pode ser traduzida em dois componentes organizacionais: Tomadores de Decisão e Estratégia Competitiva, os quais definem outros dois constructos do modelo.

- Tomadores de Decisão: representa o grupo de gestores responsável pela decisão estratégica, independente do modelo de decisão organizacional

- Estratégia Competitiva: representa o conjunto de decisões deliberadas pelos Tomadores de Decisão para obter vantagens no Ambiente Competitivo 
Partindo destes conceitos, é possível admitir que exista um constructo que relacione os Tomadores de Decisão à Estratégia Competitiva. Observando a definição do constructo Estratégia Competitiva, percebe-se que esta decorre de um processo no qual os Tomadores de Decisão são os protagonistas. Nesse sentido, quando se recupera o trabalho de Mortara et al. (2009), nota-se que já se apontava para um processo de decisão estratégica que fosse capaz de nivelar o relacionamento da IC com os campos de pesquisa decisão e estratégia.

Em suma, para efeito deste trabalho, conclui-se que a organização pode ser representada pela descrição: Os Tomadores de Decisão desenvolvem a Estratégia Competitiva pela qual a organização atua no Ambiente Competitivo através do Processo de Decisão Estratégica.

\subsubsection{Os Processos Estratégicos}

Considerando o que já foi discutido, a organização desenvolve a Estratégia Competitiva para atuar no Ambiente Competitivo, mas não se definiram ainda os mecanismos pelos quais a organização desenvolve esta Estratégia Competitiva nem como esta atua sobre o Ambiente Competitivo. Ou seja, devem existir mecanismos que ainda precisam ser compreendidos para a compreensão desta interação.

Por um lado, refletindo sobre os mecanismos utilizados pelas organizações para desenvolvimento de estratégia, deve-se considerar que a organização coleta sinais do Ambiente Competitivo para realizar diversas análises e reflexões internas, visando desenvolver a Estratégia Competitiva mais adequada à sua realidade. Este processo é denominado Formulação Estratégica.

Por outro lado, não basta a organização desenvolver a Estratégia Competitiva se não conseguir efetivamente executar seu plano e, assim, obter as vantagens esperadas. Não se pretende discutir a eficácia da execução de estratégias, mas sim constatar que é através do processo de Implementação Estratégica que as organizações efetivamente interferem no Ambiente Competitivo.

Com base na definição dos constructos apresentados anteriormente, é possível estruturar um modelo da interação entre a organização e o Ambiente Competitivo, como apresentado na Figura 6.1. 


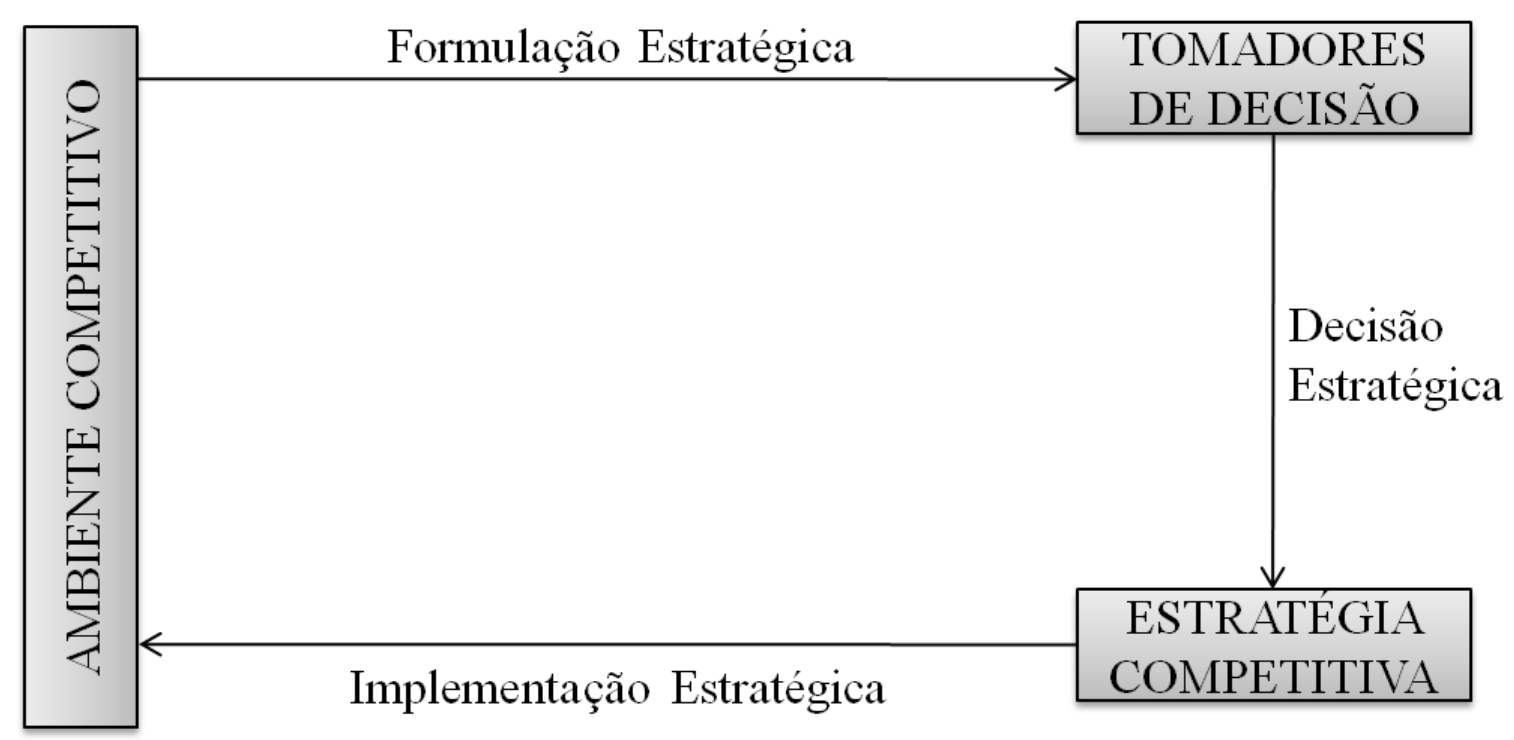

Figura 6.1 - Interação da organização com o ambiente competitivo

Fonte: elaborado pelo autor

\subsection{A Visão Holística de IC}

Considerando que é "a inteligência competitiva é o processo que investiga o ambiente onde a empresa está inserida, com o propósito de descobrir oportunidades e reduzir os riscos" (VALENTIM et al., 2003) e admitindo que a representação da Figura 6.1 seja a interação da organização com o Ambiente Competitivo, surge uma questão: como a IC pode ser inserida neste modelo para favorecer a empresa?

Em outras palavras, para que seja possível desenvolver o modelo que se propõe, é necessário introduzir a função IC na representação da Figura 6.1 de modo a tornar explícitas as implicações da implantação de um programa de IC para a organização e o papel desta função.

\subsubsection{Função Inteligência Competitiva}

De acordo com as constatações da literatura e dos resultados obtidos com a pesquisa de campo, a função IC ainda não está plenamente estabelecida nas organizações. A análise das questões 13 e 14 mostra que em nenhum dos casos foi encontrada uma estrutura administrativa dedicada a essa função. Portanto, para que seja possível desenvolver a visão holística, é imprescindível conceituar a função IC. Para isso, é importante considerar a ambiguidade do conceito de inteligência: posse e criação de conhecimento (JOURDAN; REINER; MARSHALL, 2008). Se por um lado a IC é a função organizacional responsável pelo domínio do conhecimento 
sobre o Ambiente Competitivo, por outro faz parte de suas atribuições a manutenção e a atualização destes conhecimentos.

Esta proposição é reforçada pelas reflexões sobre os resultados da questão 6, em especial no que se refere às atividades de gestão do conhecimento. Ficou constatado que, em todos os casos, essas atividades de criação e manutenção dos conhecimentos organizacionais são relevantes para o bom funcionamento dos processos de IC. Neste sentido, a IC deveria ser uma função organizacional que possua e desenvolva conhecimentos sobre a competição.

Sendo assim, pode-se considerar que a decisão estratégica recebe os benefícios gerados pela IC, independentemente deste benefício ser um conhecimento que a organização já possui ou um novo conhecimento a ser construído. Entretanto, para que a IC contribua com a organização através desta função dupla, é necessário que se desenvolvam processos de IC capazes de atender às necessidades do processo de decisão estratégica.

Observando a Figura 3.7, percebe-se que essas necessidades podem ser de dois tipos distintos: necessidades do processo decisório ou necessidades da formulação estratégica.

- Entende-se por necessidades da formulação estratégica todo e qualquer conhecimento referente à competição. Em outras palavras, estas necessidades se referem ao conteúdo da inteligência solicitada pelo processo de formulação estratégica e, como mostram os resultados obtidos, ela deve estar alinhada com a estratégia competitiva da empresa. Estas necessidades refletem a função de criação de conhecimento.

- Entende-se por necessidades do processo decisório toda a distribuição deste conhecimento obtido. Neste sentido, essas necessidades estão mais relacionadas à entrega do conhecimento necessário aos usuários corretos no momento adequado. Estas necessidades refletem a função de posse de conhecimento.

Desta forma, pode-se perceber que a IC possui relacionamento direto tanto com a estratégia competitiva, que defini as necessidades da formulação estratégica, quanto com os tomadores de decisão, que definem as necessidades do processo decisório. 
Mortara et al. (2009), através do modelo da Figura 3.7, já apontava para a solução que pode ser incluída na representação da Figura 6.1, como mostra a Figura 6.2.

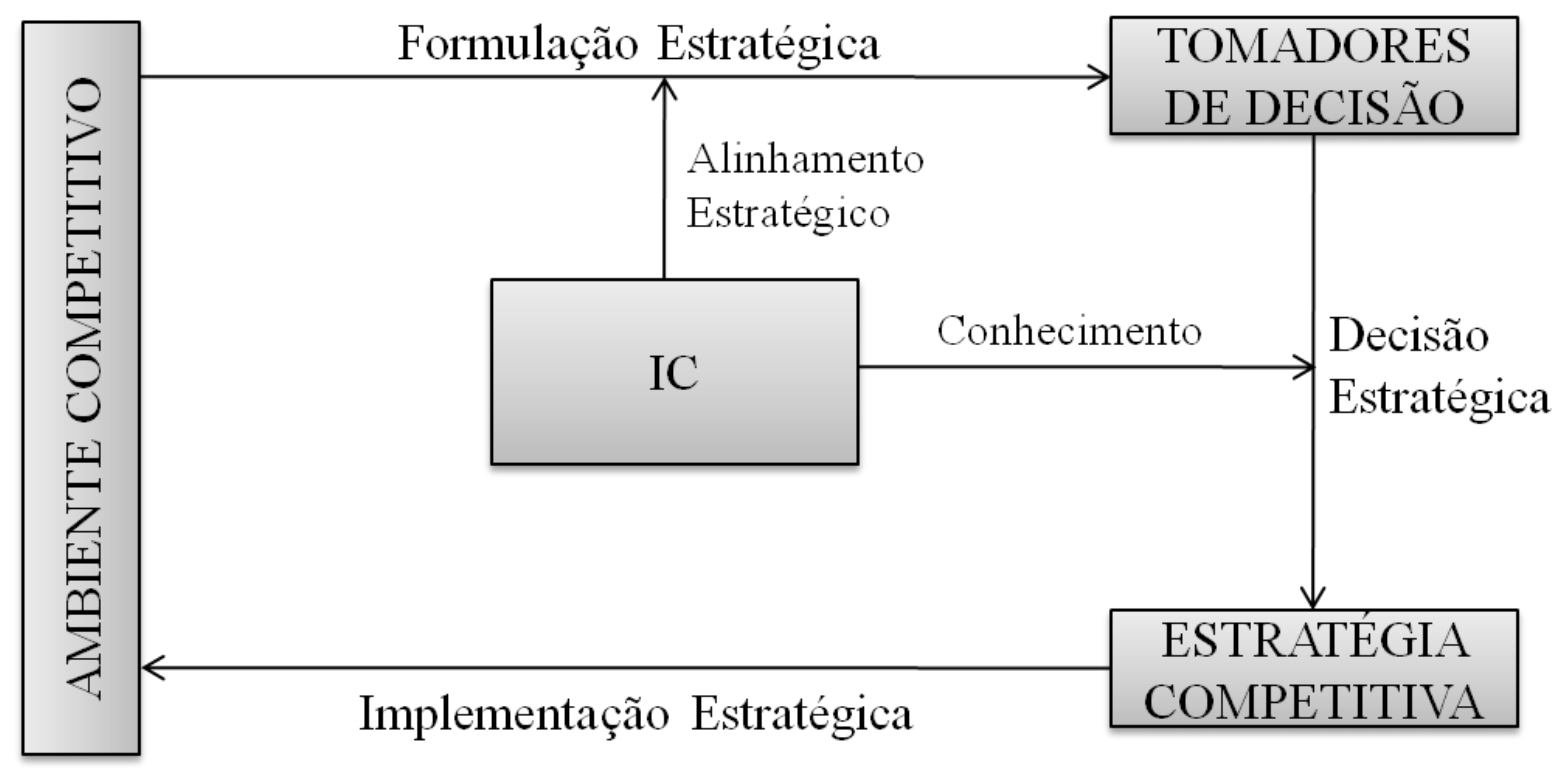

Figura 6.2 - Papel da IC no processo de decisão estratégica

Fonte: elaborado pelo autor

Para que a função IC seja capaz de atender a essas necessidades da formulação estratégica é necessário desenvolver um processo organizacional. Este processo é, em última instância, um conjunto de atividades que representam o ciclo de inteligência: coleta sinais de mercado no ambiente competitivo, análise destes sinais para a criação de conhecimento e disseminação do conhecimento obtido a um determinado grupo de decisão.

Considerando a solução proposta e promovendo uma comparação com o conceito de ciclo de inteligência, pode-se admitir que a estratégia e a decisão sejam diretamente relacionadas às etapas de planejamento e disseminação. Desta forma, pode-se inferir que as necessidades da formulação estratégica são os direcionadores da função IC e, portanto, estão diretamente relacionadas ao seu planejamento. De modo análogo, é possível assumir que as necessidades do processo decisório são supridas pela disseminação do conhecimento obtido pelo ciclo de IC.

\subsubsection{Gestão do Conhecimento}

$\mathrm{Na}$ análise da solução proposta, destaca-se a palavra "conhecimento". A questão que se pode supor é como a função IC entrega este "conhecimento" aos Tomadores 
de Decisão. Os resultados da questão 6 indicam que esta atividade está relacionada às atividades de gestão do conhecimento, o que é verificado em todos os casos. Portanto, pode-se supor que a função IC deve dispor deste mecanismo para estruturar toda sua solução de disseminação, ou seja, pode-se introduzir o constructo Gestão do Conhecimento. Evidentemente, a teoria de Gestão do Conhecimento é muito mais ampla do que o escopo deste trabalho, mas esta abordagem permite compreender em linhas gerais como estão relacionados estes campos de pesquisa. É importante, contudo, que se desenvolvem pesquisas com foco na compreensão ampla e irrestrita do relacionamento entre a função IC e a gestão do conhecimento.

\subsubsection{Alinhamento Estratégico}

Outro ponto de destaque no modelo da Figura 6.2 é o conceito de "alinhamento estratégico". As respostas das questões 7 a 12 mostram que a função IC está normalmente relacionadas às forças competitivas mais relevantes da indústria, refletindo que o alinhamento estratégico entre IC e negócio é significante.

Sendo assim, decorre que a IC deve estar completamente alinhada com as necessidades da Formulação Estratégica, como mostra a Figura 6.2, sobretudo na entrega dos resultados da etapa de análise. Contudo, este alinhamento se inicia antes, durante a fase de planejamento da IC, a qual deve estar alinhada ao processo que define os reais impactos e os controles da implantação da Estratégia Competitiva, ou seja, o processo de Implementação Estratégica.

Além disso, os resultados da questão 14 demonstram que, particularmente nos casos estudados, as organizações valorizam o alinhamento entre o negócio e a função IC, o que reforça a necessidade de promover o Alinhamento Estratégico.

\subsubsection{Monitoramento Ambiental}

Entretanto, esta solução ainda não parece demonstrar a real participação da função IC, pois ela precisa acessar o Ambiente Competitivo de forma programada na coleta de informações relevantes sobre a competição de modo a atender às necessidades da formulação estratégica. Por este motivo, pode-se promover a alteração na solução, inserindo um canal alternativo de comunicação do Ambiente Competitivo com a organização, através do Monitoramento Ambiental. 
Analisando os resultados obtidos nas questões 1 a 5 , fica evidente que as organizações desenvolvem a atividade de monitoramento ambiental de diferentes formas. Não é objetivo deste trabalho a compreensão sobre qual a abordagem de monitoramento ambiental $(\mathrm{CHOO}, 2001)$ mais se adequa à realização da função IC, nem entender as vantagens e as desvantagens de cada um. Ao invés disto, basta constatar que esta é uma atividade relevante para o desenvolvimento do modelo holístico da IC.

A utilização do Monitoramento Ambiental no programa de IC é relacionada à etapa de coleta de dados. A priori, não é razoável admitir que existam dois processos de coleta de informações do ambiente: Monitoramento Ambiental e Formulação Estratégica. Contudo, deve-se considerar que o Monitoramento Ambiental é o processo especializado na coleta de informações do Ambiente Competitivo enquanto o objetivo da formulação estratégica é utilizar conhecimentos sobre este mesmo ambiente para desenvolver a Estratégia Competitiva. Neste sentido, é possível admitir que o Monitoramento Ambiental forneça informações à Formulação Estratégica.

Entretanto, considerando que o Monitoramento Ambiental está diretamente relacionado à etapa de Coleta do ciclo de inteligência, pode-se supor que exista uma etapa intermediária entre esta Coleta e a Formulação Estratégica. Nesse sentido, a etapa de Análise atenderia a estas restrições o que indica que a Formulação Estratégica utiliza o conhecimento gerado pela função IC para desenvolver a Estratégia Competitiva.

\subsubsection{Business Intelligence}

Para finalizar a construção do modelo e considerando a abordagem desenvolvida até então, é possível se questionar onde estão as ferramentas de BI. Os resultados obtidos com os estudos de caso (questão 6) mostram que mesmo que as atividades de IC estejam em crescimento e sejam desenvolvidas pelas organizações, as ferramentas de BI ainda não estam sendo utilizadas de modo amplo.

Desta forma, pode-se inferir que estes dois campos de pesquisa não são intrinsecamente relacionados, isto é, não fazem parte do mesmo plano. Na realidade, é possível considerar que as ferramentas de $\mathrm{Bl}$ são utilizadas como suporte tecnológico à função IC. Nesse sentido, o campo de pesquisa BI não 
compõe a estrutura de processos para a construção do modelo holístico sobre a IC que é foco deste trabalho.

Em suma, a proposta de visão holística da IC resultado deste trabalho é apresentada na Figura 6.3.

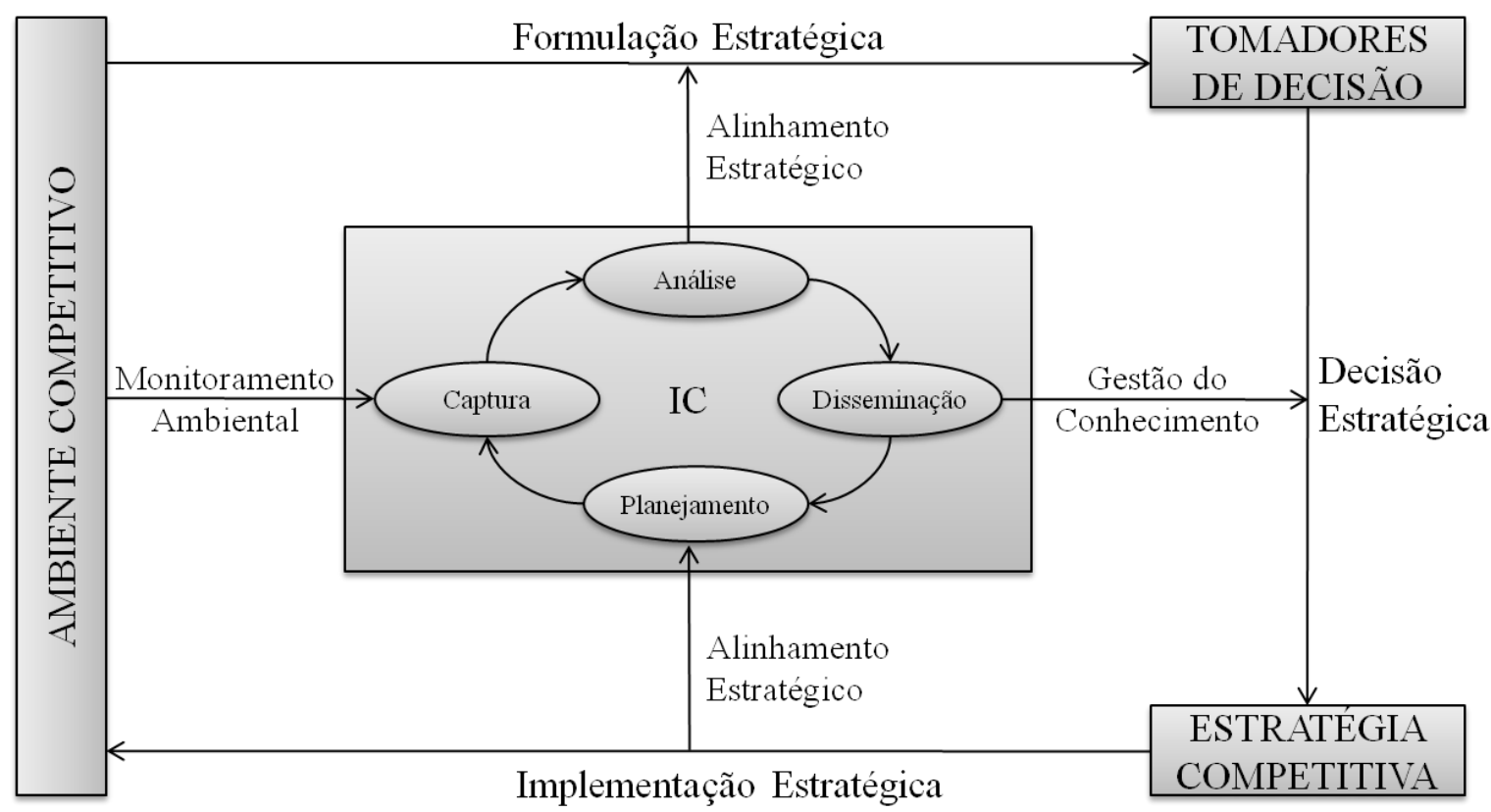

Figura 6.3 - Visão holística de IC 


\section{CONCLUSÃO}

É anuência geral que ao longo dos últimos anos, as pesquisas e as publicações sobre IC se intensificaram. Contudo, a análise quantitativa realizada por este trabalho constatou que ainda não há consenso sobre os rumos do desenvolvimento desta teoria. Este resultado destaca a importância das pesquisas continuarem a aprofundar o conhecimento teórico para que se possa efetivamente estruturar conceitos sólidos envolvendo a IC.

Como apontado por Saayman et al. (2008), a literatura recente sobre o tema já demandava a necessidade de uma visão holística capaz de integrar as partes da IC em um todo. Através do resgate de importates elementos desta literatura, conforme apresentados nesta pesquisa, foi possível suprir parte desta lacuna conceitual, principalmente no que se refere a partir da identificação e do confonto dos principais autores, obras e abordagens teóricas envolvendo o tema.

Devido às limitações téoricas da própria literatura, não se pretende que o modelo de IC desenvolvido seja aceito de modo único e irrestrito. Entretanto, é esperado que este trabalho possa incentivar a realização de outras pesquisas que visem o seu desenvolvimento teórico-conceitual sólido e consistente. Para este caso, ressalta-se que os resultados encontrados nesta dissertação se preocuparam em agir de maneira ativa para organizar e direcionar a construção do conhecimento sobre a IC que ainda não estavam explícitos.

Em primeiro lugar, foram identificados os principais campos de pesquisa em IC bem como suas principais referências bibliográficas através de um método científico quantitativo. Os resultados obtidos por esta pesquisa corroboram com os resultados da pesquisa realizada por Jourdan; Reiner e Marshall (2008), além de apresentar outras abordagens sobre o tema.

Em seguida, a revisão de literatura pode esclarecer alguns conceitos que até então estavam obscuros do ponto de vista conceitual. Neste aspecto, uma das principais contribuições teóricas da pesquisa foi caracterizar a distinção conceitual dos termos de inteligência competitiva e business intelligence. Na prática, esta simples constatação permite delimitar e delinear o escopo dos trabalhos acadêmicos e profissionais no que se refere à IC. Outra importante contribuição que se enquadra no campo conceitual é a adequação do conceito de monitoramento ambiental para a IC. Este trabalho mostrou que o monitoramento ambiental é tratado como um 
processo de inteligência, mais especificamente, o processo que se preocupa com a coleta dos dados externos à organização. As implicações práticas desta conclusão permitem enfatizar a sinergia entre os campos de pesquisa, o que ainda pode ser melhor explorado em pesquisas futuras.

Por fim, a organização dos campos de pesquisa em um modelo capaz de fornecer uma visão holística da IC talvez seja a mais importante das contribuições deste trabalho. Entender a IC como um processo analítico de interação da orgaização com o ambiente permite compreender de modo abrangente seus benefícios. A introdução do conceito de função IC como mecanismo catalisador dos processos estratégicos e a sincronização das etapas do ciclo de inteligência com esses processos consolidam a visão holística sobre o tema que, até este momento, estava difusa. De modo resumido, a função IC representa todas as atividades necessárias ao bom funcionamento dos programas.

Considerando, portanto, todos os resultados apresentados e todas as lacunas conceituais que haviam sido identificadas, conclui-se que este trabalho materializa uma fase de consolidação da teoria de IC. Esta etapa representa somente um avanço na construção do conhecimento, mas evidentemente este trabalho possui limitações, sobretudo sobre sua aplicabilidade.

Os estudos de casos realizados nesta foram importantes instrumentos confirmatórios de proposições identificadas na literatura. Por outro lado, eles não foram elaborados para explorar a complexidade da IC em sua utilização pelas organizações. Neste sentido, essa limitação propicia novas pesquisas de cunho mais fenomenológico.

Além disso, a própria constituição do modelo incita outras questões necessárias e relevantes à evolução conceitual do tema, as quais podem ser exploradas em trabalhos futuros para a construção de uma teoria de IC. Uma alternativa seria a identificação do modelo de Ambiente Competitivo que está mais adequado ao desenvolvimento das atividades da função IC ou mesmo como cada um dos cinco modelos identificados na literatura podem ser adotados de modo complementar. Essa pesquisa seria de fundamental importância para o desenvolvimento de modelos matemáticos e computacionais que permitam a criação de ferramentas de BI capazes de realizar simulações estratégicas, por exemplo.

Outra questão de grande valia à teoria de IC seria a construção de um modelo prescritivo que oriente a promoção do Alinhamento Estratégico da função IC ao 
negócio. Está claro que este alinhamento é importante para o bom desempenho das atividades em um programa de IC, mas como ele pode ser implementado de modo simples e objetivo em um contexto organizacional. Mais do que isso, este modelo poderia ser complementado com a identificação de indicadores de eficácia e eficiência para que se possa mensurar o desempenho dos programas.

Nesse sentido, outra questão emerge: como é possível comparar o desempenho de diferentes programas de IC? Um instante de reflexão sobre os resultados obtidos nos estudos de caso permite concluir que não é possível comparar o desempenho dos programas em cada um dos quatro casos estudados. Sendo assim, fica explícita a necessidade de um modelo de maturidade em IC, capaz de descrever e orientar a evolução das iniciativas práticas.

Em suma, todas essas oportunidades de pesquisa remetem ao modo como a IC pode ser melhor compreendida e aplicada. A preocupação com a estruturação conceitual sólida não se restringe somente aos bons costumes da academia, mas ao modo como a IC pode contribuir com a competitivade das organizações. 


\section{BIBLIOGRAFIA}

\subsection{Referências Bibliográficas}

ABBOTT, R. Integration and structuring for enhanced knowledge management. Drulnformation Journal, v. 38, n. 2, p.187-196, 2004.

ABELSON, P. Mechanisms for evaluating scientific information and the role of peer review. Journal of the American Society for Information Science, v. 41, n.3, p. 216-22, 1990.

ADOMAVICIUS, G.; BOCKSTEDT, J. C-TREND: Temporal cluster graphs for identifying and visualizing trends in multiattribute transactional data. IEEE Transactions on Knowledge and Data Engineering, v.20, n.6, p. 721-735, 2008.

AGUILAR, F. J. Scanning the business environment. New York: Macmillan Co. 1967. 239p.

ANSOFF, H. I. Managing strategic surprise by response to weak signals. California Management Review, v. 18 n. 2, p. 21-33, 1975.

ARAÚJO, C.A. Bibliometria: evolução histórica e questões atuais. Em Quetão, Porto Alegre, v.12, n.1, p.11-32, 2006.

ARAYA, S.; SILVA, M.; WEBER, R. A methodology for web usage mining and its application to target group identification. Fuzzy Sets and Systems, v.148, n.1, p.139-152, 2004.

BAARS, H.; KEMPER, H.G. Management support with structured and unstructured data: anintegrated business intelligence framework. Information Systems Management, v. 25, n.2, p.132-148, 2008.

BENCZUR, D. Environmental scanning: how developed is information acquisition in Western European companies? Information Research an International Electronic Journal, v.11, n.1, 2005.

BERLER, A.; PAVLOPOULOS, S.; KOUTSOURIS, D. Using key performance indicators as knowledge-management tools at a regional health-care authority level. IEEE Transactions On Information Technology In Biomedicine, v.9, n.2, p.184- 
192, 2005.

BERTO, R.; NAKANO, D.R. A produção científica nos anais do encontro nacional de engenharia de produção: um levantamento dos métodos e tipos de pesquisa. Produção, São Paulo, v. 9, n. 2, p. 65-76, 2000.

BHATTACHARYA, S.; BASU, P.K. Mapping a research area at the micro level using co-word analysis. Scientometrics, v.43, n.3, p.359-372, 1998.

BHATTI, R.; GAO, D.F.; LI, W.S. Enabling policy-based access control in BI applications. Data \& Knowledge Engineering, v.66, n.2, p.199-222, 2008.

BLACK, T. R. Evaluating social science research: an introduction. 2 nd ed. London: Sage Publications Ltd. 1993. 196p.

BONTIS, N.; DRAGONETTI, N.; JACOBSEN, K. AND ROOS, G. The knowledge toolbox: a review of the tools available to measure and manage intangible resources. European Management Journal, v. 17, n. 4, p. 391-402, 1999.

BRAGA, Gilda Maria. Relações bibliométricas entre a frente de pesquisa e revisões de literatura: estudo aplicado à ciência da informação. 1972. Dissertação (Mestrado) - Curso de Pós-Graduação em Ciência da Informação, Instituto Brasileiro de Biblioteconomia Rio de Janeiro, Rio de Janeiro, 1972.

BROCKHOFF, K. Competitor technology intelligence in German companies. Industrial Marketing Management, v. 20, n. 2, p. 91-98, 1991.

BUTKOVICH, N.J. Reshelving study of review literature in the physical science. Library Resources, v. 40, n. 2, p. 139-144, 1996.

BUTTERFIELD, K.D.; TREVINO, L.K.; WEAVER, G.R. Moral awareness in business organizations: Influences of issue-related and social context factors. Human Relations, v.53, n.7, p.981-1018, 2000.

CABRAL NETTO, O. V. Inteligência competitiva: sistema aplicado ao mercado de crédito. 2007. Trabalho final. - Escola Politécnica, Universidade de São Paulo, São Paulo, 2007.

CANONGIA, C.; ANTUNES, A.; PEREIRA, M.D.F. Technological foresight the use of 
biotechnology in the development of new drugs against breast cancer. Technovation, v. 24, n. 4, p. 299-309, 2004.

CARDOSO, R. L.; MENDONÇA NETO, O. R.; RICCIO, E. L.; SAKATA, M.C.G. Pesquisa científica em contabilidade entre 1990 e 2003. Revista de Administração de Empresas, Rio de Janeiro, v. 43, n.1, p. 91-103, 2005.

CARVALHO, M. M.; LAURINDO, F. J. B. Estratégias para competitividade. São Paulo: Futura, 2003. 254p.

CHAMONI, P; GLUCHOWSKI, P. Integration trends in business intelligence systems: an empirical study based on the business intelligence maturity model. Wirtschaftsinformatik, v.46, n.2, p.119-128, 2004.

CHEN, H.C.; CHAU, M.; ZENG, D. CI Spider: a tool for competitive intelligence on the Web. Decision Support Systems, v.34, n.1, p.1-17, 2002.

CHEN, Y.; CHONG, P. P; TONG, M. Y. The Simon-Yule approach to bibliometric modeling. Information Processing \& Management, v. 30, n. 4, p. 535-56, 1994.

$\mathrm{CHOO}, \mathrm{C} . \mathrm{W}$. Information management for the intelligent organization: the art of scanning the environment. 3nd ed. New Jersey: Medford, 2001. 325p.

CHRISTENSEN, E.W.; BAILEY, J.R. Task performance using the library and Internet to acquire business intelligence. Internet Research-Electronic Networking Applications and Policy, v.8, n.4, p.290-302, 1998.

CHUNG, K. H.; COX, R. A. K.; PAK, H. S. Patterns of research output in the accounting literature: a study of the bibliometric distributions. Abacus, v. 28, n. 2, p. 168-185, 1992.

CHUNG, W.Y.; CHEN, H.C.; REID, E. Business stakeholder analyzer: an experiment of classifying stakeholders on the web. Journal of the American Society for Information Science and Technology, v.60, n.1, p. 59-74, 2009.

CHUNG, W.Y.; BONILLAS, A.; LAI, G.P.; ET AL. Supporting non-English Web searching: An experiment on the Spanish business and the Arabic medical intelligence portals. Decision Support Systems, v.42, n.3, p.1697-1714, 2006. 
CHUNG, W.; CHEN, H.; NUNAMAKER, J.F. A visual framework for knowledge discovery on the Web: An empirical study of business intelligence exploration. Journal of Management Information Systems, v.21, n.4, p. 57-84, 2005.

CHUNG, W.Y.; LAI, G.; BONILLAS, A.; ET AL. Organizing domain-specific information on the Web: An experiment on the Spanish business Web directory. International Journal of Human-Computer Studies, v.66, n.2, p. 51-66, 2008.

CLELAND, D.I.; KING, W.R. Competitive business intelligence systems. Business Horizons, v.18, n.6, p.19-28, 1975.

COLLINS, J.; HUSSEY, R. Pesquisa em Administração. 2 ed. Porto Alegre: Bookman, 2005. 349p.

COMAI, A.; TENA, J.; VERGARA, J. Technology watch software for patents: an evaluation from the user's perspective. Profesional de la Informacion, v.15, n.6, p.452-458, 2006.

COUTINHO, E. As armadilhas da lei de Bradford. Revista Biblioteconomia. Brasilia, v.16, n.2, p.217-225, 1988.

CRABLE, E.; BRODZINSKI, J.; FROLICK, M. The intelligent new business electronic application and automated underwriting solution at the Western-Southern Life Insurance Company. Information Systems Management, v. 25, n.2, p. 155-158, 2008.

CRONIN, B; OVERFELT, K; FOUCHEREAUX, K; et al. The internet and competitive intelligence: a survey of current practice. International Journal of Information Management, v.14, n.3, p. 204-222, 1994.

CUYERS, L.; DUMONT, M.; VIVIERS, W.; ET AL. Export intensity and the competitive intelligence of exporting companies: Evidence from South Africa. South African Journal of Economic and Management Sciences, v.11, n.1, p. 85-97, 2008.

DAFT, R.; WEICK K. Toward a model of organizations as interpretation systems. Academy of Management Review, v.9, n.2, p. 284-295, 1984.

DAFT, R. L.; SORMUNEN, J.; PARKS, D. Chief executive scanning, environmental characteristics, and company performance: an empirical study. Strategic 
Management Journal, v. 9, n. 2, p.123-139, 1988.

DEGEUS, A. P. Planning as learning. Harvard Business Review, v.66, n.2, p. 7074, 1988.

DISHMAN, P.L.; CALOF, J.L. Competitive intelligence: a multiphasic precedent to marketing strategy. European Journal of Marketing, v.42, n. 7-8, p. 766-785, 2008.

DISHMAN, P.; PEARSON, T. Assessing intelligence as learning within an industrial marketing group: a pilot study. Industrial Marketing Management, v. 32, n. 7, p. 615-620, 2003.

DOU, H.; DOU, J.M. Innovation management technology: experimental approach for small firms in a deprived environment. International Journal of Information Management, v.19, n.5, p.401-412, 1999.

DOU, H; HASSANALY, P; QUONIAM, L; et al. Technology watch and competitive intelligence - a new challenge in education information. Education for information, v.11, n.3, p.35-45, 1993.

DOUGLAS, S.; AGARWAL, D.; ALONSO, T.; ET AL. Mining customer care dialous for "daily news". IEEE Transactions on Speech and Audio Processing, v.13, n.5, p.652-660, 2005.

DU PLESSIS, T.; DU TOIT, A.S.A. Knowledge management and legal practice. International Journal of Information Management, v.26, n.5, p.360-371, 2006.

DU TOIT, A.S.A. Competitive intelligence in the knowledge economy: what is in it for South African manufacturing enterprises? International Journal of Information Management, v.23, n. 2, p. 111-120, 2003.

EISENHARDT, K. M. Building theories from case study research. The Academy of Management Review, v. 14, n. 4, p. 532-550, 1989.

ERICKSON, G.S.; ROTHBERG, H.N. Intellectual capital in business-to-business markets. Industrial Marketing Management, v.38, n.2, p.159-165, 2009. 
FAYYAD, U. M. Data mining and knowledge discovery: making sense out of data. IEEE Expert: Intelligent Systems and Their Applications, v.11, n.5, p.20-25, 1996.

FILIPPINI, R. Operations management research: some reflections on evolution, models and empirical studies in OM. International Journal of Operations and Production Management, v. 17, n. 7, p. 655-670, 1997.

FAN, WG; GORDON, MD; PATHAK, P. Genetic programming-based discovery of ranking functions for effective Web search. Journal of Management Information Systems, v.21, n.4, p.37-56, 2005.

FORESTI, N. Estudo da contribuição das revistas brasileiras de biblioteconomia e ciência da informação enquanto fonte de referência para a pesquisa. 1989. Dissertação (Mestrado). Departamento de Biblioteconomia da Universidade de Brasilia, Universidade de Brasilia, Brasilia, 1989.

FULD, L. M. The new competitor intelligence: the complete resource for finding, analyzing, and using information about your competitors. New York: John Wiley \& Sons, 1995. 512p.

GARFIELD, E. Citation indexing: its theory and application in science, technology and humanities. New York: Wiley, 1979. 274p.

GARVEY, W. D. Communication: the essence of science: facilitating information among librarians, scientists, engineers and students. Oxford: Pergamon, 1979. 332p.

GARVIN, D. A. Building a Learning Organization. Harvard Business Review, v.71, n.4, p. 78-91, July-Aug, 1993.

GHOSHAL, S.; KIM, S. K. Building effective Intelligence Systems for competitive advantage. Sloan Management Review, v. 28, n.1, p. 49-58, 1986.

GHOSHAL, S.; WESTNEY, D. E. Organizing competitor analysis systems. Strategic Management Journal, v.12, n.1, p. 17-31, 1991.

GIBBONS, P.T.; PRESCOTT, J.E. Parallel competitive intelligence processes in organizations. International Journal of Technology Management, v.11, n.1-2, p.162-178, 1996.

GILAD, B. The role of organized competitive intelligence in corporate-strategy. 
Columbia Journal of World Business, v.24, n.4, p.29-35, 1989.

GREGG, D.G.; WALCZAK, S. Exploiting the information Web. IEEE Transactions on Systems Man And Cybernetics Part C-Applications And Reviews, v.37, n.1, p.109-125, 2007.

GUNTER, K. A comparison of two case studies illustrating the use of a collaborative information system to support competitive advantage. International Journal of Technology Management, v.18, n.5-8, p.549-561 1999.

HAMBRICK, D. C. Environmental scanning and organizational strategy. Strategic Management Journal, v. 13, n. 2, p. 44-49, 1982.

HANNON, J.M. Leveraging HRM to enrich competitive intelligence. Human Resource Management, v.36, n.4, p.409-422, 1997.

HART, M.; PORTER, G. The impact of cognitive and other factors on the perceived usefulness of OLAP. Journal of Computer Information Systems, v.45, n.1, p.47$56,2004$.

HEINRICHS, J.H.; LIM, J.S. Integrating web-based data mining tools with business models for knowledge management. Decision Support Systems, v.35, n.1, p.103112, 2003.

HUBER, G.P. Organizational learning: The contributing processes and the literatures. Organization Science, v.2, n.1, p.88-115, 1990.

IFAN, H.K.; DOU, J.B.; MANULLANG, S.; ET AL. Developing competitive technical intelligence in Indonesia. Technovation, v.24, n.12, p. 995-999, 2004.

INSTTUTO BRASILEIRO DE INTELIGÊNCIA DE MERCADO. Panorama de aplicação de inteligência de Mercado no Brasil: cenário 2008. 2009. Disponível em: $<$ http://www.febracorporg.br> . Acesso em: 04 jun. 2009.

JOURDAN, Z.; RAINER, R.K.; MARSHALL, T.E. Business intelligence: an analysis of the literature. Information Systems Management, v.25, n.2, p.121-131, 2008.

JUNQUA, G.; ABRIAK, N.E.; GREGOIRE, P.; et al. Methodology of management of dredging operations II. Applications Environmental Technology, v.27, n. 4, p. 431- 
446, 2006.

KAHANER, L. Competitive intelligence: how to gather, analyse, and use information to move your business to the top. New York: Touchstone Book, 1996. $300 p$.

KERLINGER, F. Foundations of behavioural research. New York: Holt, Rienhart and Winston, 1974. 667p.

KIMBALL, R. 1996. The data warehouse toolkit: practical techniques for building dimensional data warehouse. New York: John Wiley \& Sons, 1996. 374p.

LEAL, R. P. C; OlIVEIRA, J.; SOLURI, A. F. Perfil da pesquisa em finanças no Brasil. Revista de Administração de Empresas, Rio de Janeiro, v. 43, n. 1, p. 91 103, 2003.

LEE, J.; PODLASECK, M.; SCHONBERG, E.; ET AL. Visualization and analysis of clickstream data of online stores for understanding Web merchandising. Data Mining and Knowledge Discovery, v.5, n.1-2, p.59-84, 2001.

LENZ, R.T.; ENGLEDOW, J.L. Environment analysis: the applicability of current theory. Strategic Management Journal. v.7, n.4, p. 329-346, 1986.

LESCA, N.; CARON-FASAN, M.L. Strategic scanning project failure and abandonment factors: lessons learned. European Journal of Information Systems, v.17, n.4, p. 371-386, 2008.

LÉVY, P. As tecnologias da inteligência: o futuro do pensamento na era da informática. Rio de Janeiro: Editora 34, 2004. 203p.

LEWIS, M. W. Iterative Triangulation: a theory development process using existing case studies. Journal of Operations Management, v. 16, n.4, p. 455-469, 1998.

LEYDESDORFF, L. Theories of citations? Scientometrics, v.43, n.1, p.5-25, 1998.

LI, S.T.; SHUE, L.Y.; LEE, S.F. Business intelligence approach to supporting strategy-making of ISP service management. Expert Systems with Applications, v.35, n.3, p.739-754, 2008. 
LICHTENTHALER, E. Third generation management of technology intelligence processes. R\&D Management, v. 33, n.3, p. 361-375, 2003.

LICHTENTHALER, E. Technology intelligence processes in leading European and North American multinationals. R\&D Management, v. 34, n. 2, p. 121-135, 2004.

LICHTENTHALER, E. The choice of technology intelligence methods in multinationals: towards a contingency approach. International Journal of Technology Management, v. 32, n. 3-4, p. 388-407, 2005.

LIN, Y.H.; TSAI, K.M.; SHIANG, W.J.; ET AL. Research on using ANP to establish a performance assessment model for business intelligence systems. Expert Systems with Applications, v.36, n.2, p. 4135-4146, 2009.

LIU, Y.; WANG, H. A comparative study on e-learning technologies and products: from the east to the west. Systems Research and Behavioral Science, v.26, n.2, p.191-209, 2009.

LUNGU, I.; VELICANU, M.; BARA, A.; ET AL. Practices for designing and improving data extraction in a virtual data warehouses project. International Journal of Computers Communications \& Control, v.3, p.369-374, 2008.

MACIAS-CHAPULA, Cesar. O papel da informetria e da cienciometria e sua perspectiva nacional e internacional. Ciência da Informação, Brasilia, v. 27, n. 2, p. 134-140, 1998.

MARCH, S.T.; HEVNER, A.R. Integrated decision support systems: A data warehousing perspective. Decision Support Systems, v.43, n.3, p. 1031-1043, 2007.

MARIN, J.; POULTER, A. Dissemination of competitive intelligence. Journal of Information Science, v. 30, n. 2, p.165-180, 2004.

MARTIN, B.R. The use of multiple indicators in the assessment of basic research. Scientometrics, v.36, n.3, p.343-362, 1996.

MATHEUS, R. F.; PARREIRAS, F. S. Inteligência empresarial versus business intelligence: abordagens complementares para o apoio à tomada de decisão no Brasil. São Paulo: Sociedade Brasileira de Gestão do Conhecimento, 2004. 
MCHUGH, R.; ROCHE, S.; BEDARD, Y. Towards a SOLAP-based public participation GIS. Journal of Environmental Management, v.90, n.6, p.2041-2054, 2009.

MEADOWS, A. J. A comunicação científica. Brasilia: Briquet de Lemos Livros, 1999. 268p.

MIGUEL, P. A. C. Case research in production engineering: structure and recommendations for its conduction. Produção, São Paulo, v.17, n. 1, p.216-229, 2007.

MONTGOMERY D. Toward strategic intelligence systems. Journal of Marketing, v.3, n.4, p. 41-52, 1979.

MORGAN, S.; SMIRCICH, L. The case for qualitative research. Academy of Management, v.5, n. 4, p.491-500, 1980.

MORTARA, L.; KERR, C.I.V; PHAAL, R.; ET AL. Technology Intelligence practice in UK technology-based companies. International Journal of Technology Management, v.48, n.1, p.115-135, 2009.

MURESAN, M. The corporate memory: a challenge for the metallurgy. Metalurgia International, v.13, n. 2, p.33-38, 2008.

NAKANO, D.; FLEURY, A. Métodos de pesquisa em engenharia de produção. In: ENCONTRO NACIONAL DE ENGENHARIA DE PRODUÇÃO, 16., PIRACICABA: UNIMEP/ABEPRO. Anais...Piracicaba: ENEGEP, 1996. CD- ROM.

NIE, G.L.; ZHANG, L.L.; LIU, Y.; ET AL. Decision analysis of data mining project based on Bayesian risk. Expert Systems with Applications, v.36 n.3, p. 45894594, 2009.

NONAKA, I.; TAKEUCHI, H. The knowledge creating company: how Japanese companies create the dynamics of innovation. New York: Oxford University Press, 1995. 284p.

NORONHA, D.P.; FERREIRA, S.M.S.P. Revisões da literatura. In: CAMPELLO, B.S.; CENDÓN, B.V.; KREMER, J.M. Fontes de informação para pesquisadores e profissionais. Belo Horizonte: Editora UFMG, p. 191-198, 2000. 
ONG, T.H.; CHEN, H.C.; SUNG, W.K.; ET AL. Newsmap: a knowledge map for online news. Decision Support Systems, v.39, n.4, p.583-597, 2005.

PAWAR, B.S.; SHARDA, R. Obtaining business intelligence on the Internet. Long Range Planning, v.30, n.1, p.110-121, 1997.

PEDHAZUR, E.J.; SCHMELKIN, L.P. Measurement, design and analysis: an Integrated Approach. New Jersey: Lawrence Erlbaum Associates Inc, 1991. 819p.

PERSIDIS, A. Competitive information gathering and analysis in biotechnology. Expert Opinion on Therapeutic Patents, v.9, n.10, p.1333-1337, 1999.

PORTER, M. E. Competitive strategy: techniques for analyzing industries and competitors. New York: Free Press, 1980. 397p.

Competitive advantage: creating and sustaining competitive performance. New York: Free Press, 1985. 557p.

. The five competitive forces that shape strategy. Harvard Business Review, v. 86, n.1, p.78-93, 2008.

POWELL, J.H.; BRADFORD, J.P. Targeting intelligence gathering in a dynamic competitive environment. International Journal of Information Management, v.20, n.3, p.181-195, 2000.

PRESCOTT, J.; SMTH, D.C. A project-based approach to competitive analysis. Strategic Management Journal, v.8, n.5, p. 411-423, 1987.

PRINZIE, A.; VAN DEN POEL, D. Investigating purchasing-sequence patterns for financial services using Markov, MTD and MTDg models. European Journal of Operational Research, v.170, n.3, p.710-734, 2006.

RAISIG, M.L. Mathematical evaluation of the scientific serial. Science, v.131, n.3411, p.1417-1419, 1960.

RAOL, J.M.; KOONG, K.S.; LIU, L.C.; et al. An identification and classification of enterprise portal functions and features. Industrial Management \& Data Systems, v.103, n.8-9, p. 693-702, 2003. 
RATIU-SUCIU, C. Mathematical interdependences in managerial decision-making for business development. Economic Computation and Economic Cybernetics Studies and Research, v.43, n.1, p. 147-163, 2009.

REGER, G. Technology Foresight in Companies: an Indicator to a Network and Process Perspective. Technology \& Strategic Management, v. 13, n. 4, p.533-553, 2001.

RIP, A.; COURTIAL, J.P. Co-words maps of biotechnology: an example of cognitive scientometrics. Scientometrics, v.6, n.6, p.381-400, 1984.

ROSSEAU, R. Indicadores bibliométricos e econométricos para a avaliação de instituições científicas. Ciência da Informação, Brasilia, v. 27, n. 2, p. 149-158, 1998.

ROUIBAH, K.; OULD-ALI, S. Puzzle: a concept and prototype for linking business intelligence to business strategy. Journal of Strategic Information Systems, v.11, n.2, p.133-152, 2002.

ROUSSINOV, D.; CHAU, M. Combining information seeking services into a meta supply chain of facts. Journal of the Association for Information Systems, v.9, n.3-4, p.175-199, 2008.

SAAR-TSECHANSKY, M.; MELVILLE, P.; PROVOST, F. Active Feature-Value Acquisition. Management Science, v.55, n.4, p.664-684, 2009.

SALMERON, J.L. Supporting decision makers with fuzzy cognitive maps. ResearchTechnology Management, v. 53, n.3, p.53-59, 2009.

SAYERS. M.; JOICE, J.; BAWDEN, D. Retrieval of biomedical reviews: a comparative evaluation of online databases for reviews of drug therapy. Journal of Information Science, v. 16, n.4, p. 321-325, 1990.

SAAYMAN, A.; PIENAAR, J.; PELSMACKER, P.; VIVIERS, W.; CUYVERS, L.; MULLER, M.L.; JEGERS, M. Competitive intelligence: construct exploration, validation and equivalence. Aslib Proceedings: New Information Perspectives, v.60, n.4, p.383-411, 2008.

SHILDT, H.A. Sitkis: software for bibliometric data management and analysis, Helsinki Institute os Strategy and International Business, 2002. 
SCHULTZE, U.; BOLAND, R.J. Knowledge management technology and the reproduction of knowledge work practices. Journal of Strategic Information Systems, v.9, n.2-3, p.193-212, 2000.

SHI, Z.Z; HUANG, Y.P.; HE, Q.; ET AL. MSMiner - a developing platform for OLAP. Decision Support Systems, v.42, n.4, p.2016-2028, 2007.

SHI, Y; PENG, Y; KOU, G; ET AL. Classifying credit card accounts for business intelligence and decision making: A multiple-criteria quadratic programming approach. International Journal of Information Technology \& Decision Making, v.4, n.4, p.581-599, 2005.

SINKULA, J. M. Market Information Processing and Organizational Learning. Journal of Marketing, v.58, n.1, p.35-45, 1994.

SLATER, S. F.; NARVER, J. C. Does competitive environment moderate the market orientation performance relationship? Journal of Marketing, v. 58. n.1, p.46-55, 1994.

SMTH, R. Modeling R\&D investments. Research-Technology Management, v. 49, n.6, p. 16-22, 2006.

SPINAK, Ernesto. Indicadores cienciométricos. Ciência da Informação, Brasilia, v. 27, n. 2, p. 141-148, 1998.

STERN, C.W.; STALK, J.R.G. Estratégia em Perspectiva: the Boston Consulting Group. Rio de Janeiro: Campus, 2002. 448p.

TARAPANOFF, K.; GREGOLIN, J. A. Inteligência organizacional e competitiva. Brasília: UnB, 2001. 344p.

TARGINO, M.G.; GARCIA, J.C.R. Ciência brasileira na base de dados do Institute for Scienctific Information (ISI). Ciência da Informação, Brasília, v.29, n.1, p.103-117, 2000.

TEO, T.S.H.; CHOO, W.Y. Assessing the impact of using the Internet for competitive intelligence. Information \& Management, v.39, n.1, p.67-83, 2001. 
TERRA, J. C. Gestão do conhecimento: o grande desafio empresarial. São Paulo: Negócio Editora, 2001. 283p.

TSENG, F.S.C.; CHOU, A.Y.H. The concept of document warehousing for multidimensional modeling of textual-based business intelligence. Decision Support Systems, v.42, n.2, p. 727-744, 2006.

TYSON, K. The complete guide to competitive intelligence: gathering, analyzing and using competitive intelligence. Lisle: Kirk Tyson International Ltd, 1998.

VALENTIM, M.; CERVANTES, B.M.N.; CARVALHO, E.L.; GARCIA, H.D.; LENZI, L.A.F.; CATARINO, M.E.; TOMAÉL, M.I. O processo de inteligência competitiva em organizações. DataGramaZero, Rio de Janeiro, v.4, n.3, p.1-23, 2003. Disponível em: <http://www.datagramazero.org.br>. Acesso em: 05 jun. 2008.

VAN DEN POEL, D.; BUCKINX, W. Predicting online-purchasing behaviour. European Journal of Operational Research, v.66, n.2, p.557-575, 2005.

VAN RAAN, A.F.J. Scientometrics: state-of-the-art. Scientometrics, v.38, n.1, p.205218, 1997.

VANTI, N. A. Da bibliometria à webometria: uma exploração conceitual dos mecanismos utilizados para medir o registro da informação e a difusão do conhecimento. Ciência da Informação, Brasília, v. 31, n. 2, p. 152-162, 2002.

VINKLER, P. Relations of relative scientometric impact indicators: the relative publications strategy índex. Scientometrics, v.40, n.1, p.163-169, 1997.

VINKLER, P. Composite scientometric indicators for evaluating publication of research institutes. Scientometrics, v.68, n.3, p. 629-642, 2006.

VOSS, C.; TSIKRIIKTSIS, N.; FROHLICH, M. Case research in operations management. International Journal of Operations \& Production Management, v. 22, n. 2, p. 195-219, 2002.

WACKER, J. G. A Definition of theory: research guidelines for different theorybuilding research methods in operations management. Journal of Operations Management, v. 16, n.4, p. 361-385, 1998. 
WACKER, J. G. A theory of formal conceptual definition: developing theory-building measurement instruments. Journal of Operations Management, v. 22, n.6, p. 629650, 2004.

WALLE, A.H. Corporate configurations and competitive intelligence: understanding organizations at a distance. Competitive Intelligence Review, v. 10, n. 4, p 55-64, 1999.

WALLMARK, J.T., SEDIG, K.G. Quality of research measured by citation method and by peer review: a comparison. IEEE Transactions on Engineering Management, $\mathrm{V}$. 33, n.4, p. 218-22, 1986.

WANG, H.; WANG, S.H. A knowledge management approach to data mining process for business intelligence. Industrial Management \& Data Systems, v.108, n.5-6, p. 622-634, 2008.

WESTBROOK, R.K., Action Research: a new paradigm for research in production and operations management. International Journal of Operations and Production Management, Vol. 15 no. 12, pp. 6-20, 1995.

WINTER, R.; GERICKE, A. Teradata University Network - A teaching support portal for business intelligence, data warehousing and database. Wirtschaftsinformatik, v.48, n.4, p.276-281, 2006.

WINTER, R.; GERICKE, A.; BUCHER, T. Using teradata university network (TUN), a free internet resource for teaching and learning. Educational Technology \& Society, v.11, n.4, p.113-127, 2008.

WIXOM, B.H.; WATSON, H.J.; REYNOLDS, A.M.; ET AL. Continental airlines continues to soar with business intelligence. Information Systems Management, v.25, n.2, p.102-112, 2008.

WHETTEN, D. A. What constitutes a theoretical contribution? Academy of Management Review, v. 14, n. 4, p. 490-495, 1989.

XU, D.M.; WANG, H.Q. Multi-agent collaboration for B2B workflow monitoring. Knowledge-Based Systems, v.15, n.8, p.485-491, 2002.

XU, X.F.; ZHANG, L.; LI, Y.; ET AL. Digital enterprise management in China: current status and future development. International Journal of Production Research, 
v.43, n.12, p.2593-2601, 2005.

YEUNG, D.S.; NG, W.W.Y.; CHAN, A.P.F.; ET AL. A multiple intelligent agent system for credit risk prediction via an optimization of localized generalization error with diversity. Journal of Systems Science and Systems Engineering, v.16, n.2, p.166180, 2007.

Yin, R. K. Case Study Research: design and methods. Sage Publications: Thousand Oaks, 1994.171p.

YUAN, S.T.; HUANG, M.Z. A study on time series pattern extraction and processing for competitive intelligence support. Expert Systems with Applications, v.21, n.1, p.37-51, 2001.

ZANGOUEINEZHAD, A.; MOSHABAKI, A. The role of structural capital on competitive intelligence. Industrial Management \& Data Systems, v.109, n.2, p.262-280, 2009. 


\subsection{Bibliografia Consultada}

ADOMAVICIUS, G.; BOCKSTEDT, J. C-TREND: Temporal cluster graphs for identifying and visualizing trends in multiattribute transactional data. IEEE Transactions on Knowledge and Data Engineering, v.20, n.6, p. 721-735, 2008.

AGARWAL, D. Detecting anomalies in cross-classified streams: a Bayesian approach. Knowledge And Information Systems, v.11, n.1, p. 29-44, 2007.

AKYUZ, G.A.; REHAN, M. Requirements for forming an 'e-supply chain'. International Journal of Production Research, v.47, n.12, p.3265-3287, 2009.

ALBAGLI, A.; DAWSON, P.; HASNAIN, S. Competitive science and technology intelligence. International Journal of Technology Management, v.12, n.3, p.320328, 1996.

ASHTON, W.B.; KINZEY, B.R.; GUNN, M.E. A structured approach for monitoring science and technology developments. International Journal of Technology Management, v.6, n.1/2, p.91-111, 1991.

AZVINE, B.; CUI, Z.; MAJEED, B.; ET AL. Operational risk management with realtime business intelligence. Bt Technology Journal, v.25, n.1, p. 154-167, 2007.

AZVINE, B.; CUI, Z.; NAUCK, D.D. Towards real-time business intelligence. Bt Technology Journal, v.23, n.3, p. 214-225, 2005.

BABBAR, S.; RAI, A. Competitive intelligence for international-business. Long Range Planning, v.26, n.3, p.103-113, 1993.

BACK, T. Adaptive business intelligence based on evolution strategies: some application examples of self-adaptive software. Information Sciences, v.148, n.1-4, p.113-121, 2002.

BATNI, R.P.; HECK, J.F. An analytics engine architecture for service provider deployments. Bell Labs Technical Journal, v.13, n.3, p.129-141, 2008.

BECKER, J.; KNACKSTEDT, R.; POPPELBUSS, J. Developing Maturity Models for IT Management. Wirtschaftsinformatik, v.1, n.3, p.213-222, 2009. 
BERNHARDT, D.C. I want it fast, factual, actionable: tailoring competitive intelligence to executives needs. Long Range Planning, v.27, n.1, p.12-24, 1994.

BERNIER, E.; GOSSELIN, P.; BADARD, T.; BÉDARD, Y. Easier surveillance of climate-related health vulnerabilities through a Web-based spatial OLAP application. International Journal of Health Geographics, v.8, n.18, p.8-18, 2009.

BERS, J.A.; DISMUKES, J.R.; MILLER, L.K.; ET AL. Accelerated radical innovation: Theory and application. Technological Forecasting and Social Change, v. 76, n.1, p. 165-177, 2009.

BERZAL, F.; CUBERO, J.C.; JIMENEZ, A. The design and use of the TMiner component-based data mining framework. Expert Systems with Applications, v.36, n.4, p. 7882-7887, 2009.

BEVANDA, V.; PAVLETIC, M. Business intelligence portal using concept maps. Ekonomska Istrazivanja-Economic Research, v.20, n.1, p.100-108, 2007.

BEXON, M.; STEPHENS, D.; PRITCHETT, C. Competitive intelligence: a career opportunity for the information professional in industry. Journal of Librarianship and Information Science, v.34, n.4, p.187-196, 2002.

BOSE, R. Competitive intelligence process and tools for intelligence analysis. Industrial Management \& Data Systems, v.108, n. 3-4, p. 510-528, 2008.

BOSE, R. Advanced analytics: opportunities and challenges. Industrial Management \& Data Systems, v.109, p.155-172, 2009.

BREITZMAN, A.; THOMAS, P. Using patent citation analysis to target/value M\&A candidates. Research-Technology Management, v.45, n.5, p.28-36, 2002.

BROWN, E. Analyze this. Forbes, v.169, n.8, p.96-98, 2002.

BUHLER, B.; ROSENOGGER, J. Business intelligence - theory and practice Progress through knowledge. Nfd Information-Wissenschaft Und Praxis, v.53, n.8, p.486-489, 2002.

CARLTON, S.A. Industrial espionage: reality of the information age. ResearchTechnology Management, v.35, n.6, p.18-24, 1992. 
CEVALLOS, F.; WANG, X.B. Data Archiving and Mining System for Transit Service Improvements. Transportation Research Record, n.2063, p. 43-51, 2008.

CHANG, E.; HUSSAIN, F.K.; DILLON, T. Reputation ontology for reputation systems.OTM Workshops, v.3762, p.957-966, 2005.

CHEN, H.C.; MARTINEZ, J.; NG, D.T.; SCHATZ, B.R. A concept spaceapproach to addressing the vocabulary problem in scientificinformation retrieval: an experiment on the worm communitysystem. Journal of the American Society for Information Science, v.48, n.1, p.17-31, 1997.

CHOO, W.C. Environmental scanning as information seeking and organizational learning. Information Research, v.7, n.1, 2001.

CHAU, M; SHIU, B; CHAN, I; ET AL. Redips: Backlink search and analysis on the Web for business intelligence analysis. Journal of the American Society for Information Science and Technology, v.58, n.3, p.351-365, 2007.

CHUNG, W.; CHEN, H.; NUNAMAKER, J.F. A visual framework for knowledge discovery on the web: an empirical study on business intelligence exploration. Journal of Management Information Systems, v.21, n.4, p.57-84, 2005.

CHUNG, W.Y.; ZHANG, Y.W.; HUANG, Z.; ET AL. Internet searching and browsing in a multilingual world: An experiment on the Chinese Business Intelligence Portal (CBizPort). Journal of the American Society for Information Science and Technology, v.55, n.9, p.818-831, 2004.

CLEGG, $H$. Keeping up with the news: Web clipping and media analysis for competitive intelligence. Online, v. 29, n.3, p.16-21, 2005.

CODY, WF; KREULEN, JT; KRISHNA, V; ET AL. The integration of business intelligence and knowledge management. IBM Systems Journal, v.41, n.4, p.697713, 2002.

COMBS, R.; MOORHEAD, J. Competitive intelligence: finding the clues online. Database, v.13, n.5, p. 15-18, 1990.

CORCORAN, M. Bring business intelligence to wireless computing. Communications News, v.38, n. 5, p.28-29, 2001. 
COSTEA, C. Application of Tuncay's language teacher model to business-customer relations. International Journal of Modern Physics, v.19, n.2, p. 267-270, 2008.

CRABLE, E.; BRODZINSKI, J.; FROLICK, M. The intelligent new business electronic application and automated underwriting solution at the Western-Southern Life Insurance Company. Information Systems Management, v. 25, n.2, p. 155-158, 2008.

CRONIN, B; OVERFELT, K; FOUCHEREAUX, K.; MANZVANZVIKE, T.; CHA, M. Y.S. The internet and competitive intelligence: a survey of current practice. International Journal of Information Management, v.14, n.3, p.204-222, 1994.

CUYERS, L.; DUMONT, M.; VIVIERS, W.; DE PELSMACKER, P.; MULLER, M.L.; JEGERS, M.; SAAYMAN, A. Export intensity and the competitive intelligence of exporting companies: Evidence from South Africa. South African Journal of Economic and Management Sciences, v.11, n.1, p. 85-97, 2008.

DAVENPORT, E.; CRONIN, B. Competitive intelligence and social advantage. Library Trends, v.43, n.2, p.239-252, 1994.

DELBAERE, M.; FERREIRA, R. Addressing the data aspects of compliance with industry models. IBM Systems Journal, v.46, n.2, p.319-334, 2007.

DEVILLERS, R.; BEDARD, Y.; JEANSOULIN, R.; ET AL. Towards spatial data quality information analysis tools for experts assessing the fitness for use of spatial data. International Journal of Geographical Information Science, v.21, n.3, p.261-282, 2007.

DOU, H.; DOU, J.M. Innovation management technology: experimental approach for small firms in a deprived environment. International Journal of Information Management, v.19, n.5, p.401-412, 1999.

DOU, H; HASSANALY, P; QUONIAM, L; et al. Technology watch and competitive intelligence - a new challenge in education information. Education for information, v.11, n.3, p.35-45, 1993.

DOUGLAS, S.; AGARWAL, D.; ALONSO, T.; ET AL. Mining customer care dialous for "daily news". IEEE Transactions on Speech and Audio Processing, v.13, n.5, p.652-660, 2005. 
EKLUND, T. Financial benchmarking using the self-organizing map: a tool for visual benchmarking. Ekonomiska Samfundets Tidskrift, v.58, n.3, 2005.

ELALFI, A.E.; HAQUE, R.; ELALAMI, M.E. Extracting rules from trained neural network using GA for managing e-business. Applied Soft Computing, v.4, n.1, p.6577, 2004.

EWUSIMENSAH, K. Developing a competitive intelligence system for it. Long Range Planning, v. 22, n.5, p. 121-127, 1989.

FERNANDEZ, E.; MONTES, J.M.; PEREZ-BUSTAMANTE, G.O.; ET AL. Competitive strategy in technological knowledge imitation. International Journal of Technology Management, v.18, n.5-8, p.535-548, 1999.

FLEISHER, C.S.; WRIGHT, S.; ALLARD, H.T. The role of insight teams in integrating diverse marketing information management techniques. European Journal of Marketing, v.42, n.7-8 p. 836-851, 2008,

FONG, J.; SHIU, H.; CHEUNG, D. A relational-XML data warehouse for data aggregation with SQL and XQuery. Software-Practice \& Experience, v.38, n.11, p.1183-1213, 2008.

FRANCIS, D.B.; SAWKA, K.A.; HERRING, J.P. Competitors: Who to watch, what to watch, who to ignore, and how to tell the difference. Competitive Intelligence Review, v.6, n.3, p.41-46, 1995.

FURNHAM, A. Gender and personality differences in self- and other ratings of business intelligence. British Journal of Management, v.16, n.2, p. 91-103, 2005.

GAO, S.J.; XU, D.M. Conceptual modeling and development of an intelligent agentassisted decision support system for anti-money laundering. Expert Systems with Applications, v.36, n.2, p.1493-1504, 2009.

GEORGY, U. Competitive intelligence in the internet. Nfd InformationWissenschaft Und Praxis, v.52, n. 4, p.197-200, 2001.

GESSNER, G.; SCOTT, R.A. Using Business Intelligence Tools to Help Manage Costs and Effectiveness of Business-to-Business Inside-Sales Programs. Information Systems Management, v.26, n.2, p.199-208, 2009. 
GESSNER, G.H.; VOLONINO, L. Quick response improves returns on business intelligence investments. Information Systems Management, v.22, n.3, p.66-74, 2005.

GILAD, B.; GILAD, T. A systems-approach to business intelligence. Business Horizons, v.28, n.5, p.65-70, 1985.

GILAD, B.; GORDON, G.; SUDIT, E. Identifying gaps and blinds in competitive intelligence. Long Term Planning, v.26, n.6, p.107-113, 1993.

$\mathrm{GOH}, \mathrm{B} . \mathrm{H}$. Creating intelligent enterprises in the Singapore construction industry to support a knowledge economy. Building and Environment, v.41 n.3, p.367-379, 2006.

GOTIA, S.; SAENZ-DE-LACUESTA, S.; BILBAO, M. Business information systems in companies. Profesional de la Informacion, v.17, n.5, p. 540-545, 2008.

GORDON, S; TARAFDAR, M; COOK, R.; MAKSIMOSKI, R.; ROGOWITZ, B. Improving the front end of innovation with information technology. ResearchTechnology Management, v.51, n.3, p. 50-58, 2008.

GOREA, D. Dynamically integrating knowledge in applications an online scoring engine architecture. Advances in Electrical and Computer Engineering, v.8, n.1, p.44-49, 2008.

GOTTSCHALK, P. Expert systems at stage IV of the knowledge management technology stage model: The case of police investigations. Expert Systems with Applications, v.31, n.3, p. 617-628, 2006.

GRABOWSKI, D. Building an effective competitive intelligence system. Journal of Business and Industrial Marketing, v.2, p. 39-44, 1987.

Graham, C. Gartner clients consider business intelligence to be a major priority. Gartner Group, 2005.

GRANEBRING, A.; REVAY, P. Service-oriented architecture is a driver for daily decision support. Kybernetes, v.36, n. 5-6, p. 622-635, 2007. 
GREENE, H.F. Competitive intelligence and the information-center. Special Libraries, v.79, n.4, p. 285-295, 1988.

GREGG, D.G.; WALCZAK, S. Adaptive web information extraction - The Amorphic system works to extract Web information for use in business intelligence applications.Communications of The Acm, v.49, n.5, p.78, 2006.

GULLEDGE, T.; CHAVUSHOLU, T. Automating the construction of supply chain key performance indicators. Industrial Management \& Data Systems, v.108, n.5-6, p.750-774, 2008.

GUPTA, R.K. Data mining business intelligence for competitive advantage. Electronics Information \& Planning, v.29, n.1, p.27-42, 2001.

HALLAQ, J.H.; STEINHORST, K. Business intelligence methods: how ethical. Journal of Business Ethics, v.13, n.10, p.787-794, 1994.

HEALEY, R.G.; DELVE, J. Integrating GIS and data warehousing in a Web environment: A case study of the US 1880 Census. International Journal of Geographical Information Science, v.21, n.6, p. 603-624, 2007.

HEFTMAN, G. Crystal/oscillator markets look to wireless growth. Microwaves \& Rf, v.38, n.11, 1999.

HEINRICHS, J.H.; LIM, J.S. Model for organizational knowledge creation and strategic use of information. Journal of The American Society for Information Science and Technology, v. 56, n.6, p. 620-629, 2005.

HENNEL, M. Focusing the business intelligence microscope. Chemical Engineering, v.109, ,n.6, 2002.

HEPPES, D.; DU TOIT, A. Level of maturity of the competitive intelligence function case study of a retail bank in South Africa. Aslib Proceedings, v.61, n.1, p.48-66, 2009.

HIRSCH, J.E. An index to quantify an individual's scientific research output, Proceedings of the National Academy of Sciences of the United States of America, v.102, n.46, p.16569-16572, 2005.

HOHHOF, B. Developing information-systems for competitive intelligence support. Library Trends, v.43, n.2, p.226-238, 1994. 
HOLT, P.J.; LIGHT, J. Process intelligence: Using Internet technology to improve effective drug trial throughput. Drug Information Journal, v.35, n.3, p.767-779, 2001.

HOSANAGAR, K.; KRISHNAN, R.; CHUANG, J.; CHOUDAHARY, V. Pricing and resource allocation in caching services with multiple levels of quality of service. Management Science, v.51, n.12, p.1844-1859, 2005.

HRANAC, R.; PETTY, K. Dashboards for transportation operations: detector health case study. Transportation Research Record, n.1993, p.36-42, 2007.

HSIEH, K.L. Conceptual modeling and development of an intelligent agent-assisted decision support system for anti-money laundering. Expert Systems with Applications, v.36, n.2, p.2864-2872, 2009.

JERMOL, M.; LAVRAC, N.; URBANCIC, T. Managing business intelligence in a virtual enterprise: A case study and knowledge management lessons learned. Journal of Intelligent \& Fuzzy Systems, v.14, n.3, p.121-136, 2003.

JIANG, H.F.; GAO, D.F.; LI, W.S. Improving parallelism of federated query processing. Data \& Knowledge Engineering, v.64, n.3, p. 511-533, 2008.

JI, J.Z.; LIU, C.N.; SHA, Z.Q.; ZHONG, N. Personalized recommendation based on a multilevel customer model. International Journal of Pattern Recognition and Artificial Intelligence, v.19, n.7, p.895-916, 2005.

KASSLER, H.S. Competitive intelligence on the web: finding true net worth. Econtent, v.22, n.4, p.16-24,1999.

KASSLER, H.S. Mining the Internet for competitive intelligence: How to track and sift for golden nuggets. Online, v.21, n.5, p.34-45, 1997.

$\mathrm{KHO}$, N.D. Smart search: business intelligence and search converge. Econtent, v.30, n. 9, p.50, 2007.

KOHAVI, R.; MASON, L.; PAREKH, R.; ZHENG, Z. Lessons and challenges from mining retail e-commerce data. Machine Learning, v.57, n.1-2, p. 83-113, 2004. 
KOKUBO, A. Japanese competitive intelligence for research-and-development. Research-Technology Management, v.35, n. 1, p. 33-34,1992. . Competitive intelligence. IEEE Spectrum, v.30, n.8, p.44-46, 1993.

KOMNINOS, N. Regional intelligence: distributed localised information systems for innovation and development. International Journal of Technology Management, v.28, n.3-6, p.483-506, 2004.

KRAUSE, J. Business intelligence. Aba Journal, v.92, p. 61, 2006.

KRISHNA, P.R.; DE, S.K. A fuzzy approach to build an intelligent data warehouse. Journal of Intelligent \& Fuzzy Systems, v.11, n.1-2, p. 23-32. 2001.

KRUPA, K.W. Chaos theory and model for business intelligence organizations. Actual Problems of Economics, v.90, p.267-272, 2008.

KUCHINSKAS, S. News flash: business intelligence no longer an oxymoron. Econtent, v.26, n.10, p.24-28, 2003.

KURGAN, L.A.; CIOS, K.J.; DICK, S. Highly scalable and robust rule learner: Performance evaluation and comparison. IEEE Transactions on Systems Man and Cybernetics Part B-Cybernetics, v.36, n.1, p. 32-53, 2006.

LAROSA, S.M. 1st look - investext - the business intelligence database. Online, v.9, n.5, p.41-45, 1985.

LEE, C.F.; CHANGCHIEN, S.W.; WANG, W.T.; ET AL. A data mining approach to database compression. Information Systems Frontiers, v.8, n.3, p.147-161, 2006.

LEE, C.K.M.; LAU, H.C.W.; HO, G.T.S.; ET AL. Design and development of agentbased procurement system to enhance business intelligence. Expert Systems with Applications, v.36, n.1, p. 877-884, 2009.

LEE, J.H.; PARK, S.C. Intelligent profitable customers segmentation system based on business intelligence tools. Expert Systems with Applications, v. 29, n.1, p.145$152,2005$.

LEGER, A.; HEINECKE, J.; NIXON, L.J.B.; ET AL. The semantic web from an industry perspective. Lecture Notes in Computer Science, v.4126, p.232-268, 
2006.

LEMOS, A.D; PORTO, A.C. Technological forecasting techniques and competitive intelligence: tools for improving the innovation process. Industrial Management \& Data Systems, v.98, n.7-8, 1998.

LI, C.H. ERP packages: What's next? Information Systems Management, v.16, n.3, p.31-35, 1999.

LONNQVIST, A.; PIRTTIMAKI, V. The measurement of business intelligence. Information Systems Management, v.23, n.1, p.32-40, 2006.

LUHN, H.P. A business intelligence system. IBM Journal of Research and Development, v.2, n.4, p.314-319, 1958.

MARFLEET, J; KELLY, C. Leading the field: the role of the information professional in the next century. Electronic Library, v.17, n.6, p.359-364, 1999.

MARSHALL, B.; MCDONALD, D.; CHEN, H.C.; CHUNG, W. EEBizPort: Collecting and analyzing business intelligence information. Journal of the American Society for Information Science and Technology, v.55, n.10, p.873-891, 2004.

MARTIN, J.S. Building an information resource center for competitive intelligence. Online Review, v.16, n. 6, p. 379-389, 1992.

MARTINEZLAGE, J.F.; POZA, M.; SOLA, J.; SOLER, C.L.; MONTALVO, C.G.; DOMINGO, R.; PUCHE, A.; RAMÓN, F.H.; AZORÍN, P.; LASSO, R. The child with a cephalocele: Etiology, neuroimaging, and outcome. Child Nervous System, v.12, n.9, p.540-550, 1996.

MCCROHAN, K.F. Competitive intelligence: Preparing for the information war. Long Range Planning, v.31, n.4, p.586-593, 1998.

MEIER, M.C. Competitive intelligence. Wirtschaftsinformatik, v.46, n.5, p. 405-407, 2004.

MENKES, J. Hiring for smarts. Harvard Business Review, v.83, n.11, p.100, 2005. 
MICHAELI, R.; SIMON, L. An illustration of Bayes' theorem and its use as a decisionmaking aid for competitive intelligence and marketing analysts. European Journal of Marketing, v.42, n. 7-8, p. 804-813, 2008.

MICHALEWICZ, Z; MICHALEWICZ, M. Machine intelligence, adaptive business intelligence, and natural intelligence. IEEE Computational Intelligence Magazine, v. 3, n.1, p. 54-63, 2008.

MILLER, J.P. Information science and competitive intelligence: Possible collaborators? Bulletin of the American Society for Information Science, v.23, n.1, p.11-12, 1996.

MILLER, J.P. Educational-programs for intelligence professionals. Library Trends, v.43, n.2, p.253-270,1994.

MILLER, M.B. The business trip: Maritime networks in the twentieth century. Business History Review, v.77, n.1, p.1-32, 2003.

MILLER, R. Get smart with business intelligence software. Econtent, v.26, n. 11, p.24-29, 2003.

MONOD, E. Internet and enterprise performance: a study of the industrial organization of 104 SMEs in Loire-Atlantique (France). Annales des Telecommunications-Annals of Telecommunications, v.58, n.1-2, p.99-128, 2003.

MONTGOMERY, D.B.; MOORE, M.C.; URBANY, J.E. Reasoning about competitive reactions: Evidence from executives. Marketing Science, v. 24 n.1, p. 138-149, 2005.

MOORE, T. Market potential high for fuel cells. Epri Journal, v.22, n.3, p.6-17, 1997.

MULLEN, A.; BLUNCK, M.; KALBFLEISCH, E.; ROHBECK, H.G. Using pharmaceutical development product databases for competitive intelligence. Online, v.27, n.3, p. 44-49, 2003.

NANAVATI, A.A.; SINGH, R.; CHAKRABORTY, D.; DASGUPTA, K.; MUKHERJEA, S.; DAS, G.; GURUMURTHY, S.; JOSHI, A. Analyzing the structure and evolution of massive telecom graphs. IEEE Transactions on Knowledge and Data Engineering, v.20, n.5, p. 703-718, 2008. 
NENORTAITE, J.; BUTLERIS, R. Improving business rules management through the application of adaptive business intelligence technique. Information Technology and Control, v.38, n.1, p.21-28, 2009.

NELSON, R.R.; TODD, P.A.; WIXOM, B.H. Antecedents of information and system quality: An empirical examination within the context of data warehousing. Journal of Management Information Systems, v.21, n.4, p.199-235, 2005.

O'CONNELL, B. Bringing business intelligence to the masses. Econtent, v.27, n.10, p.28-32, 2004.

ODER, N. The competitive intelligence opportunity. Library Journal, v.126, n. 4, p.42-44, 2001.

OJALA, M.; LAURSEN, J.V. Head-to-head for competitive intelligence. Online, v.22, n.6, p. 62-63, 1998.

PARRISH, A.; VRBSKY, S.; DIXON, B.; NI, W. Optimizing disk storage to support statistical analysis operations. Decision Support Systems, v.38, n.4, p.621-628, 2005.

PEARCE, F.T. Business intelligence systems: need, development, and integration. Industrial Marketing Management, v.5, n.2-3, p.115-138, 1976.

PETRUSHCHAK, T.I.; MYKHALENYCH, S.I.; ZHYVKO, V.V. competitor intelligence in information environment. Actual Problems of Economics, v.88, p.163-171, 2008.

PIKAS, C.K. Blog searching for competitive intelligence, brand image, and reputation management. Online, v. 29, n. 4, p.16-21, 2005.

PIRTTILA, A. Organising competitive intelligence activities in a corporate organisation. Aslib Proceedings, v.50, n.4, p.79-84, 1998.

POWER, D.J. Understanding data-driven decision support systems. Information Systems Management, v.25, n. 2, p. 149-154, 2008.

QIU, T.J. Scanning for competitive intelligence: a managerial perspective. European Journal of Marketing, v.42, n.7-8, p. 814-835, 2008.

QIU, L.; LI, Y.J.; WU, X.T. Protecting business intelligence and customer privacy 
while outsourcing data mining tasks. Knowledge and Information Systems, v.17, n.1, p.99-120, 2008.

QIN, J.L.; ZHOU, Y.L.; CHAU, M.; CHEN, H. Multilingual web retrieval: An experiment in English-Chinese business intelligence. Journal of The American Society for Information Science And Technology, v.57, n.5, p. 671-683, 2006.

RANTZAU, R.; SHAPIRO, L.D.; MTSCHANG, B.; ET AL. Algorithms and applications for universal quantification in relational databases. Information Systems, v.28, n.1-2, p.3-32, 2003.

REISCH, M.S. Competitive intelligence. Chemical \& Engineering News, v. 85, n.6, p. 12-15, 2007.

RENNOLLS, K.; AL-SHAWABKEH, A. Formal structures for data mining, knowledge discovery and communication in a knowledge management environment. Intelligent Data Analysis, v.12, n.2, p.147-163, 2008.

RIVEST, S.; BEDARD, Y.; PROULX, M.J.; NADEAU, M.; HUBERT, F.; PASTOR, J. SOLAP technology: Merging business intelligence with geospatial technology for interactive spatio-temporal exploration and analysis of data. ISPRS Journal of Photogrammetry and Remote Sensing, v.60, n., p.17-33, 2005.

SALLES, M. Decision making in SMEs and information requirements for competitive intelligence. Production Planning \& Control, v.17, n.3, p. 229-237, 2006.

SCHALEY, T. Business intelligence unit: clear and present logic. Food Technology, v.48, n.9, p.34, 1994.

SCHLOSSER, J. Looking for intelligence in ice cream. Fortune, v.147, n.5, 2003.

SCHONBERG, E.; COFINO, T.; HOCH, R.; PODLASECK, M.; SPRARAGEN, S.L. Measuring success: E-business intelligence is a complex, yet vital, element to building a strong customer base. Communications of the Acm, v.43, n.8, p.53-57, 2000.

SCHULTZ, N.O.; COLLINS, A.B.; MCCULLOCH, M. The ethics of business intelligence. Journal of Business Ethics, v.13, n.4, p.305-314, 1994. 
SCHULTZE, U. A confessional account of an ethnography about knowledge work. MIS QUARTERLY, v.24, n.1, p.3-41, 2000.

SCHWALM, S.; BANGE, C. Application types and potentials of XML in businessintelligence-systems. Wirtschaftsinformatik, v.46, n.1, p.5-14, 2004.

SHETH, A.; ALEMAN-MEZA, B.; ARPINAR, I.B.; HALASCHEK, C.; RAMAKRISHNAN.; BERTRAM, C.; WARKE, Y.; AVANT, D.; ARPINAR, F.S.; ANYANWU, K.; KOCHUT, K. Semantic association identification and knowledge discovery for national security applications. Journal of Database Management, v.16, n.1, p.33-53, 2005.

SHETTY, Y.K. Aiming high: competitive benchmarking for superior performance. Long Range Planning, v.26, n.1, p. 39-44, 1993.

SMIRNOV, A; SHILOV, N; LEVASHOVA, T.; SHEREMETOV, L.; CONTRERAS, M. Ontology-driven intelligent service for configuration support in networked organizations. Knowledge and Information Systems, v.12, n.2, p.229-253, 2007.

SMTH, R.W. Going beyond competitive intelligence. Adhesives Age, v.45, n.3, p.39-39, 2002.

SNOW, B. Competitive intelligence in the health device industry. Online, v.13 n.4, p. 107-114, 1989.

SRINIVASAN, P.; MENCZER, F.; PANT, G. A general evaluation framework for topical crawlers. Information Retrieval, v. 8, n. 3, p. 417-447, 2005.

STEPHAN, J.; MURMANN, J.P.; BOEKER, W.; GOODSTEIN, J. Bringing managers into theories of multimarket competition: CEOs and the determinants of market entry. Organization Science, v.14, n.4, p. 403-421, 2003.

SUGUMARAN, V.; BOSE, R. Data analysis and mining environment: a distributed intelligent agent technology application. Industrial Management \& Data Systems, v.99, n.1-2, p.71-80, 1999.

SVOBODA, O. The special-library as a competitive intelligence center. Electronic Library, v.9, n. 4-5, p. 239-243, 1991. 
SYMEONIDIS, A.L.; ATHANASIADIS, I.N.; MTKKAS, P.A. A retraining methodology for enhancing agent intelligence. Knowledge-Based Systems, v.20, n.4, p.388-396. 2007.

TAN, A.H.; ONG, H.L.; PAN, H.; NG, J.; LI, Q.Towards personalised web intelligence. Knowledge and Information Systems, v.6, n. 5, p. 595-616, 2004.

TAN, B.; FOO, S.; HUI, S.C. Web information monitoring for competitive intelligence. Cybernetics and Systems, v.33, n.3, p.225-251, 2002.

TAN, P.N.; KUMAR, V. Discovery of web robot sessions based on their navigational patterns. Data Mining and Knowledge Discovery, v.6, n.1, p.9-35, 2002.

TANEV, S.; BALLETTI, T. Competitive intelligence information and innovation in small Canadian firms. European Journal of Marketing, v.42, n.7-8, p. 786-803, 2008.

TELL, B.V. Towards intelligent management of information resources - a case for special-libraries or the national intelligence. LIBRI, v.42, n.1, p. 20-34, 1992.

TIGGEMANN, R.F.; DWORACZYK, D.A.; SABEL, H. Project portfolio management: A powerful strategic weapon in pharmaceutical drug development. Drug Information Journal, v.32, n.3, p.813-824, 1998.

TORRISI, N.M.; OLIVEIRA, J.F.G. Remote control of CNC machines using the CyberOPC communication system over public networks. International Journal of Advanced Manufacturing Technology, v.39, n.5-6, p. 570-577, 2008.

TRASENSTER, M. New ways of delivering information. Electronic Library, v.15, n.5, p.395-397, 1997.

TRIM, P.R.J.; LEE, Y.I. A strategic marketing intelligence and multi-organizational resilience framework. European Journal of Marketing, v.42 n.7-8, p. 731-745, 2008.

TSENG, F.S.C. Design of a multi-dimensional query expression for document warehouses. Information Sciences, v.174, n.1-2, p. 55-79, 2005.

TSENG, G.; DRENTH, H.; MORRIS, A. The selection of online databases for UK company. Journal of Librarianship and Information Science, v.27, n.3, p.159-170, 
1995.

VAN DER WALT, M.S. A classification scheme for the organization of electronic documents in small, medium and micro enterprises (SMMEs). Knowledge Organization, v.31, n.1, p.26-38, 2004.

VARMA-O'BRIEN, S.; BROWN, F.K.; LEBEAU, A.; BROWN, R.D. Changing paradigms in drug discovery: Scientific Business Intelligence (TM) and workflow solutions. Current Computer-Aided Drug Design, v.4, n.1, p.13-22, 2008.

VAUGHAN, L.; YOU, J. Content assisted web co-link analysis for competitive intelligence. Scientometrics, v.77, n.3, p. 433-444, 2008.

VAZQUEZ, L. Ferroatlantica R\&D the technology watch. Profesional de la Informacion, v.15, n. 6, p. 420-425, 2006.

VEDDER, R.G.; GUYNES, C.S. CAPPEL, J.J. CIOs' perspectives on competitive intelligence. Information Systems Management, v.19, n.4, p.49-55, 2002.

VEDDER, R.G.; GUYNES, C.S. A study of competitive intelligence practices in organizations. Journal of Computer Information Systems, v.41, n.2, p.36-39, 2000.

VEDDER, R.G.; VANECEK, M.T.; GUYNES, C.S.; CAPPEL, J.J. CEO and CIO perspectives on competitive intelligence. Communications of the Acm, v.42, n.8, p.108-116, 1999.

VELARDI, P.; CUCCHIARELLI, A.; PETIT, M. A taxonomy learning method and its application to characterize a scientific Web community. IEEE Transactions On Knowledge And Data Engineering, v.19, n.2, p. 180-191, 2007.

VINE, D. I.Gathering business intelligence. Internet World, v.8, n.3, p.48-51, 1997.

WAGERS, R. Online sources of competitive intelligence. Database, v.9, n.3, p. 2838,1986

WAIFE, R,S. Transitioning clinical data management from the 1980s to the 2010s: Strategies for corporate decision making. Drug Information Journal, v.35, n.3, p.713-719, 2001. 
WAKIO, K.; YOSHIBAYASHI, T.; AKABOSHI, N. Early detection of changes using event sequence extractor. Fujitsu Scientific \& Technical Journal, v.40, n.1, p.54$60,2004$.

WANG, X.S.; NAYDA, L.; DETTINGER, R. Infrastructure for a clinical-decisionintelligence system. IBM Systems Journal, v.46, n.1, p.151-169, 2007.

WALKER, T.D. The literature of competitive intelligence. Library Trends, v.43, n.2, p.271-284, 1994.

WARR, T.; Patents in competitive intelligence. Chemistry \& Industry, n.15, p.617, 1995.

WATSON, H.J.; WIXOM, B.H.; HOFFER, J.; ANDERSON-LEHMAN, J.R.; REYNOLDS, A.M. . Real-time business intelligence: Best practices at Continental Airlines. Information Systems Management, v.23, n.1, p.7-18, 2006.

WATTS, R.J.; PORTER, A.L. Innovation forecasting. Technological Forecasting and Social Change, v.56, n.1, p.25-47, 1997.

WEIGANG, L.; YAMASHITA, Y.; KOENDJBIHARIE, M.W.; JUCÁ, R.C.M.; MACIVER, A. The development and implementation of the operation system and data bank for the intelligent transportation system - Sitcuo. Journal of Advanced Transportation, v.38, n.2, p.163-186, 2004.

WEIR, J. A Web/business intelligence solution. Information Systems Management, v.17, n.1, p.41-46, 2000.

WERNER, E.; DEGOUL, P. Technological awareness and competitive intelligence: a new profession for the firm. Recherché, v.25, n.269, p. 1068-1077, 1994.

WESTERVELT, R. Gaining an edge: competitive intelligence takes off. Chemical Week, v.158, n.25, p.29-31, 1996.

ZHAN, J.M.; LOH, H.T.; LIU, Y. Gather customer concerns from online product reviews: a text summarization approach. Expert Systems with Applications, v.36, n.2, p.2107-2115, 2009. 
ZINKHAN, GM; GELB, BD. Competitive intelligence practices of industrial marketers. Industrial Marketing Management, v.14, n. 4, p. 269-275,1985. 


\section{APÊNDICE I - ANÁLISE ESTRUTURAL DA INDÚSTRIA}

A análise estrutura da indústria (PORTER, 1985) é uma ferramenta de diagnóstico estratégico para avaliar o contexto do mercado através de cinco forças competitivas, apresentadas na Figura I.1, que determinam seu potencial de lucratividade. Desta forma, uma empresa deve ser buscar a uma "posição na qual a empresa seja capaz de melhor se defender contra estas forças ou de influenciá-las em seu favor" (PORTER, 1999, p. 28).

A estrutura industrial tem uma forte influência na determinação das regras competitivas do jogo, assim como das estratégias potencialmente disponíveis para empresa. Forças externas à indústria são significativas principalmente em sentido relativo; uma vez que as forças externas em geral afetam todas as empresas na indústria, o ponto básico encontra-se nas diferentes habilidades das empresas em lidar com elas. (PORTER, 2004, p. 3)

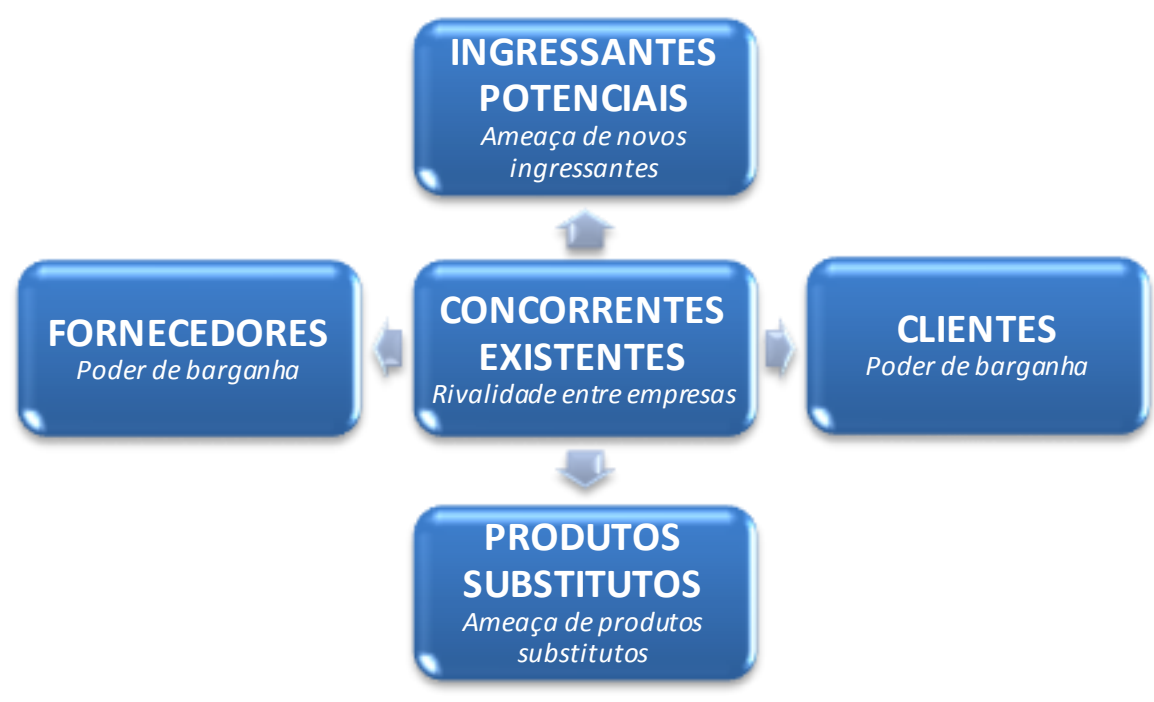

Figura I.1 - Análise estrutural da indústria

Eventualmente, o conhecimento dessas forças é tão evidente que não basta apenas conhecer somente a força, mas também as suas fontes. O conhecimento destas fontes deve ser o principal esforço para a compreensão desta análise (PORTER, 2008). A decomposição dessas forças, que serviu de base para a elaboração do protocolo de pesquisa do bloco de questões sobre o contexto de mercado, em suas fontes é apresentada na Tabela I.1 (CARVALHO;LAURINDO, 2003).

"Elas realçam os pontos fortes e os pontos fracos mais importantes da empresa, inspiram o seu posicionamento no setor, iluminam as áreas em que as mudanças estratégicas talvez proporcionem o maior retorno e identificam os pontos em que as tendências setoriais são mais significativas, em termos de oportunidades ou ameaças". (CARVALHO; LAURINDO, 2003, p. 28) 
Tabela I.1 - Decomposição das forças competitivas

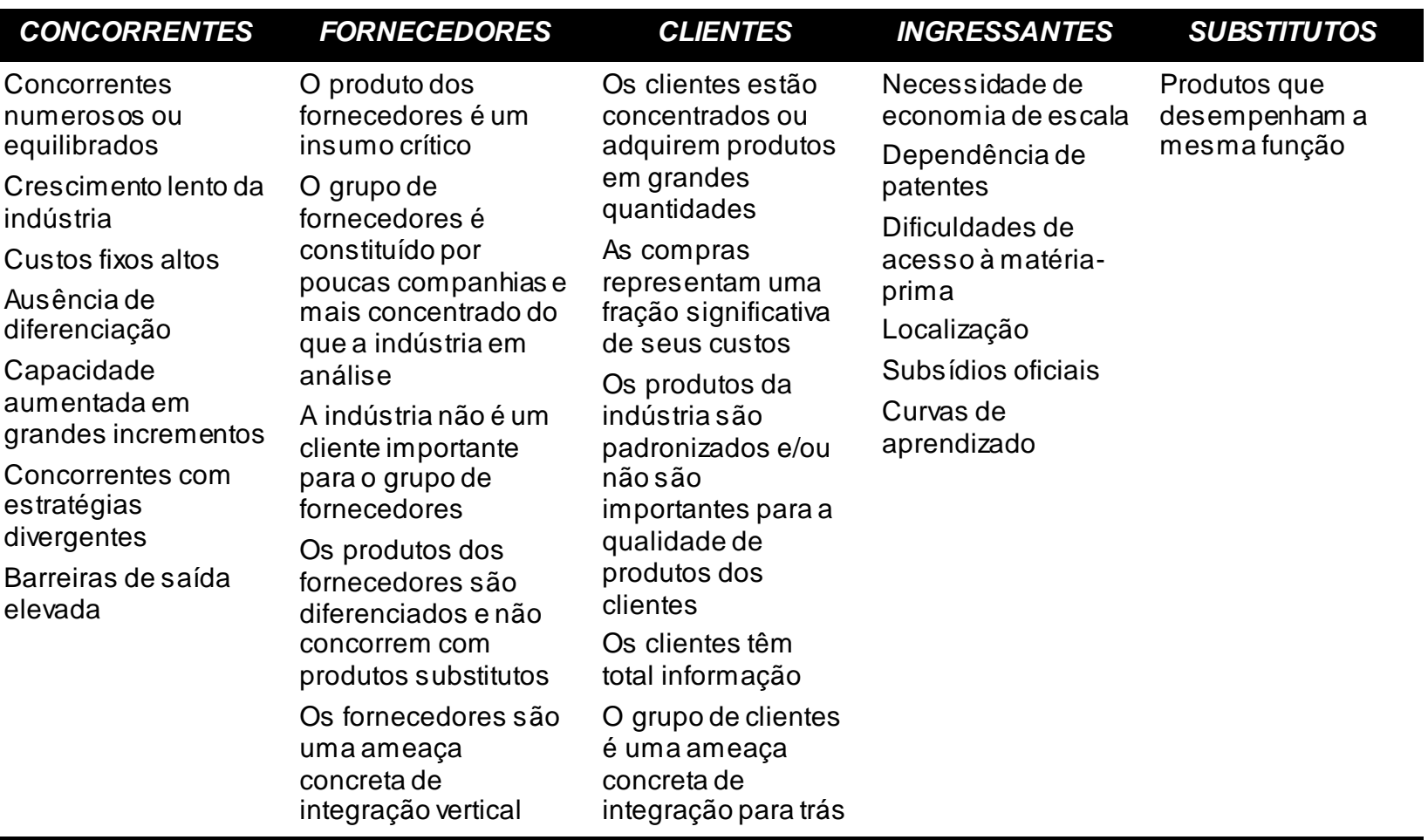

Fonte: Carvalho e Laurindo (2003)

Esta análise avalia, na horizontal, a competição por lucratividade ao longo da cadeia produtiva enquanto estuda a relação entre os diversos concorrentes no sentido vertical. Assim, a intensidade das forças e a paridade competitiva são alteradas de acordo com as movimentações estratégicas dos concorrentes devido ao caráter dinâmico da competição (PORTER, 1980; CARVALHO;LAURINDO, 2003; STERN; STALK JUNIOR, 2002). 